\title{
The role of the skeletal muscle in the early onset of the metabolic syndrome : a nutrigenomics approach
}

Citation for published version (APA):

de Wilde, J. (2010). The role of the skeletal muscle in the early onset of the metabolic syndrome: a nutrigenomics approach. [Doctoral Thesis, Maastricht University]. Universitaire Pers Maastricht. https://doi.org/10.26481/dis.20101217jw

Document status and date:

Published: 01/01/2010

DOI:

10.26481/dis.20101217jw

Document Version:

Publisher's PDF, also known as Version of record

\section{Please check the document version of this publication:}

- A submitted manuscript is the version of the article upon submission and before peer-review. There can be important differences between the submitted version and the official published version of record. People interested in the research are advised to contact the author for the final version of the publication, or visit the DOI to the publisher's website.

- The final author version and the galley proof are versions of the publication after peer review.

- The final published version features the final layout of the paper including the volume, issue and page numbers.

Link to publication

\footnotetext{
General rights rights.

- You may freely distribute the URL identifying the publication in the public portal. please follow below link for the End User Agreement:

www.umlib.nl/taverne-license

Take down policy

If you believe that this document breaches copyright please contact us at:

repository@maastrichtuniversity.nl

providing details and we will investigate your claim.
}

Copyright and moral rights for the publications made accessible in the public portal are retained by the authors and/or other copyright owners and it is a condition of accessing publications that users recognise and abide by the legal requirements associated with these

- Users may download and print one copy of any publication from the public portal for the purpose of private study or research.

- You may not further distribute the material or use it for any profit-making activity or commercial gain

If the publication is distributed under the terms of Article $25 \mathrm{fa}$ of the Dutch Copyright Act, indicated by the "Taverne" license above, 
The role of the skeletal muscle in early-stage metabolic syndrome

\author{
A nutrigenomics approach
}




\title{
Rution
}

The study presented in this thesis was performed within NUTRIM School for Nutrition, Toxicology and Metabolism which participates in the Graduate School VLAG (Food Technology, Agrobiotechnology, Nutrition and Health Sciences), accredited by the Royal Netherlands Academy of Arts and Sciences.

\author{
Cover design: Thierry van Eijsden (thierryvaneijsden@gmail.com) \\ Lay-out: Janneke de Wilde \\ Printed by: Datawyse / Universitaire Pers Maastricht
}

(C) Copyright Janneke de Wilde, Maastricht 2010

Universitaire Pers Maastricht

ISBN 9789052789828

All rights reserved to the author with the exception of those chapters published by the journals refered to. No part of this publication may be reproduced, stored in a retrieval system, or transmitted, in any form or by any means, with out the prior permission in writing from the author or the copyright owning journal. 


\title{
The role of the skeletal muscle in early-stage metabolic syndrome
}

\author{
A nutrigenomics approach
}

\author{
PROEFSCHRIFT \\ ter verkrijging van de graad van doctor \\ aan de Universiteit Maastricht, \\ op gezag van de Rector Magnificus, \\ Prof. dr. G.P.M.F. Mols, \\ volgens het besluit van het College van Decanen, \\ in het openbaar te verdedigen \\ op vrijdag 17 december 2010 om 12.00 uur \\ door
}

Janneke de Wilde

geboren op 18 juni 1983,

te Oostburg

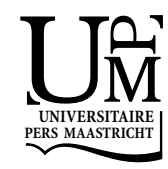




\section{Promotor}

Prof. dr. Edwin C.M. Mariman

\section{Copromotor}

Dr. Egbert Smit

\section{Beoordelingscommissie}

Prof. dr. ir. Ronald P. Mensink (voorzitter)

Dr. ir. Chris Evelo

Prof. dr. Jan F.C. Glatz

Prof. dr. ir. Jaap Keijer (Wageningen University)

Prof. dr. Patrick A.J. Schrauwen

Financial support of Top Institute Food and Nutrition for publication of this thesis is gratefully acknowledged.

Additional support granted by Danone Research - Centre For Specialised Nutrition is gratefully appreciated. 


\section{CONTENTS}

Chapter 1 Introduction

Chapter 2 Short-term high fat-feeding results in morphological and metabolic adaptations in the skeletal muscle of $\mathrm{C} 57 \mathrm{BL} / 6 \mathrm{~J}$ mice

Chapter 3 An 8-week high fat diet induces obesity and insulin resistance 53 with small changes in the muscle transcriptome of C57BL/6J mice

Chapter 4 High fat diet-induced changes in mouse muscle mitochondrial 75 phospholipid composition and function are unrelated to insulin resistance

Chapter 5 Adipophilin protein expression in muscle: a possible protective role against insulin resistance

Chapter 6 The embryonic genes Dkk3, Hoxd8, Hoxd9 and Tbx1 identify muscle types in a diet-independent and fiber type-unrelated way

Chapter 7 General Discussion

Summary

Samenvatting

Supplemental data

Dankwoord

Publications

Curriculum Vitae 

CHAPTER 1

General introduction 


\section{The metabolic syndrome}

The metabolic syndrome (MetS) is a cluster of metabolic abnormalities that increases the risk for cardiovascular diseases (CVD) and type 2 diabetes mellitus (T2DM). The MetS is also known as the Insulin Resistance Syndrome, Syndrome $\mathrm{X}$ or The Deadly Quartet and is characterized by obesity, insulin resistance, dyslipidaemia, endothelial dysfunction, a pro-inflammatory state and a pro-thrombotic state (Figure 1.1) (1-4). In Western societies the prevalence of the MetS in the adult population is estimated around $20 \%$ and it is expected to increase in the near future (5). Also the prevalence of the MetS in children and adolescents is rapidly increasing (6). With the elevated risk for both CVD and T2DM it is clear that these increases will have major economic and societal consequences.

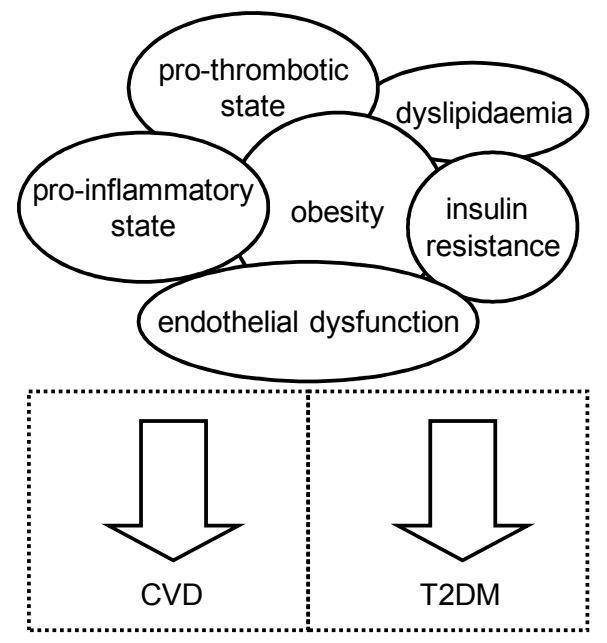

Figure 1.1 The metabolic syndrome is characterized by obesity, insulin resistance, endothelial dysfunction, pro-inflammatory state, dyslipidaemia and pro-thrombotic state and gives an increased risk for T2DM and CVD. T2DM, type 2 diabetes mellitus; CVD, cardiovascular diseases.

\section{Definitions of the metabolic syndrome}

During the past decade numerous clinical definitions have been proposed to diagnose patients with the MetS (Table 1.1). The World Health Organization (WHO) was the first that formulated a definition. Following the publication of the WHO definition in 1999, the European Group for the Study of Insulin Resistance (EGIR) developed a modified version of the WHO definition. The EGIR definition was easier to use as it relied on fasting insulin levels instead of the euglycemic clamp to measure insulin resistance. In 2001, the Adult Treatment Panel III (ATPIII) of the National Cholesterol Education Program (NCEP) published a definition which was designed to facilitate diagnosis in clinical practice. The NCEP states that the MetS can be diagnosed when a person has three out of the five components which are obesity, an increased fasting glucose level, hypertension, increased plasma triglycerides and 
decreased HDL cholesterol. In 2005, the International Diabetes Federation (IDF) proposed a definition that was designed to facilitate the comparison of research across countries and populations. Substantial differences exist between the four definitions. Firstly, WHO and EGIR include measurements of insulin resistance, whereas NCEP and IDF do not. Secondly, both WHO and EGIR consider insulin resistance as the essential risk factor in the diagnosis of the MetS, whereas NCEP treats all risk factors with equal importance. In contrast, the IDF gives the highest priority to abdominal obesity. Thirdly, according to the WHO and EGIR definition decreased HDL cholesterol and/or increased triglycerides is one of the four risk factors, whereas the NCEP and IDF consider these two disturbances in the plasma lipid profile as independent risk factors for the MetS. Finally, only the WHO definition has included microalbuminuria. Although the four definitions have substantial differences, all recognize the MetS as a multiplex risk factor for the development of CVD and T2DM $(2,3)$.

Table 1.1 Risk factors for the metabolic syndrome according to different definitions

\begin{tabular}{lllll}
\hline & WHO & EGIR & NCEP ATPIII & IDF \\
& $(1999)$ & $(1999)$ & $(2001)$ & $(2005)$ \\
\hline Insulin resistance & ++ & ++ & - & - \\
& Two of the & Two of the fol- & At least 3 of the & \\
& following & lowing & following & ++ \\
Abdominal obesity & + & + & + & Two of the \\
& & & & following \\
Increased fasting & - & + & + & + \\
glucose & & & & + \\
Increased TG & + & + & + & + \\
and/or decreased & & & + & + \\
HDL cholesterol & & + & - & - \\
Hypertension & + & - & + & + \\
Microalbuminuria & + & & + & + \\
\hline
\end{tabular}

WHO, World Health Organization; EGIR, European Group for the Study of Insulin resistance; NCEP ATPIII, National Cholesterol Education Program, Adult Treatment Panel III; IDF, International Diabetes Federation; TG, triglycerides. ++, + and - represent obligatory; possible characteristic and no part of definition, respectively. (Adapted from Alberti, Diabetic Medicine, 2006). 


\section{Risk factors for the metabolic syndrome}

A strong association between obesity, which is assessed by body mass index (BMI), and T2DM as well as CVD has been described (7-9). However, remarkable heterogeneity among individuals with similar BMI values is observed. Especially overweight or obese individuals with an increase in abdominal fat, which is assessed by waist circumference, are at higher risk for T2DM and CVD (4). Insulin resistance is manifested by decreased insulin-stimulated glucose transport and metabolism in adipose tissue and the skeletal muscle, while the liver shows an impaired suppression of the glucose production (10). The key features of atherogenic dyslipidaemia found in patients with the MetS are raised levels of plasma triacylglycerols (TAG) and low levels of plasma HDL cholesterol. Also other lipoprotein abnormalities are found such as increased levels of plasma $\operatorname{LDL}$ cholesterol $(4,11)$. In patients with the MetS endothelial dysfunction is recognized as hypertension and is strongly associated with obesity and commonly occurs in insulin-resistant persons $(2,11)$. A proinflammatory state is commonly present in patients with the MetS and is recognized by elevated levels of plasma C-reactive protein. Also other pro-inflammatory cytokines such as interleukin 6 and tumor necrosis factor are increased in the MetS (12). In patients with the MetS a pro-thrombotic state is characterized by increased plasma levels of plasminogen activator inhibitor 1 (PAI-1) and fibrinogen. Plasma fibrinogen increases in response to high levels of plasma cytokines suggesting an association between a pro-inflammatory state and a pro-thrombotic state (4).

\section{Pathogenesis of the metabolic syndrome}

The pathogenesis of the MetS and each of its risk factors is complex and still not fully elucidated. Although abdominal obesity and insulin resistance are considered as the potential causative factors (2), it is difficult to distinguish between causes and consequences. Obesity contributes to hypertension, high serum cholesterol, low HDL cholesterol and insulin resistance and is associated with an increased CVD risk (4). When adipose tissue expands, plasma levels of fatty acids (FA) and TAG will gradually become elevated which leads to an increased flux of FA and TAG into the liver and skeletal muscle. Eventually this will result in impaired insulin sensitivity in these tissues (12). The association between obesity and the MetS is not only related to the degree of obesity, but also to the pattern of upper-body fat distribution (13). An excess of visceral fat is strongly associated with perturbations in lipid metabolism, glucose metabolism and inflammatory processes (14) which are all components of the MetS.

As insulin resistance is present in the majority of patients with the MetS, it is considered by most as the central characteristic of the MetS (12). However, identifying a unique role for insulin resistance is complicated, because it is closely linked to obesity (4). Nevertheless, insulin resistance is strongly associated with atherogenic dysli- 
pidaemia and a pro-inflammatory state, whereas associations with hypertension and the pro-thrombotic state are less tight (2). Furthermore, factors like genetics, physical inactivity and aging are also implicated in the development of the MetS (4). Altogether, the pathogenesis of the MetS is very complex with risk factors that cannot be dissociated from each other (15).

\section{Treatment of the metabolic syndrome}

The primary goal of treatment of the MetS is to reduce the risk for CVD and T2DM. Even in patients with established T2DM, intensive treatment of the MetS will diminish the higher risk for CVD. As the MetS is strongly associated with obesity, weight reduction is an obvious target. As such, primary treatment for the MetS should be the promotion of a healthy lifestyle including increased physical activity, a reduced energy intake and an increased consumption of fruits and vegetables. Weight loss will result in decreased plasma TAG, increased plasma HDL cholesterol, lower blood pressure and improved insulin sensitivity and thus improving all risk markers of the MetS (16). For patients at a high risk for CVD drug therapy may be necessary. As the pathogenesis of the MetS is still not fully elucidated, specific pharmaceutical therapies are not yet available. Therefore it is necessary to treat each risk factor of the MetS individually. For example, insulin resistance can be treated with insulin sensitizers such as thiazolidinediones and hypertensive patients with the MetS can use anti-hypersensitive drugs $(2,4,12)$.

\section{The role of the skeletal muscle in the metabolic syndrome}

Although many risk factors characterize the MetS, insulin resistance is considered as the major risk factor contributing to the pathogenesis of this disorder (12). As skeletal muscle is the predominant site of insulin-stimulated glucose uptake and metabolism, it might play an important role in the pathogenesis of the MetS.

\section{Structure of the skeletal muscle}

The skeletal muscle is surrounded by connective tissue named the epimysium. Every skeletal muscle is composed of numerous muscle fibers which are grouped together in fascicles that are covered by a layer of fibrous connective tissue called perimysium. Each muscle fiber contains several hundreds to thousands of myofibrils which have a striated appearance. The myofibrils are the contractile elements of the skeletal muscle (Figure 1.2) $(17,18)$. 


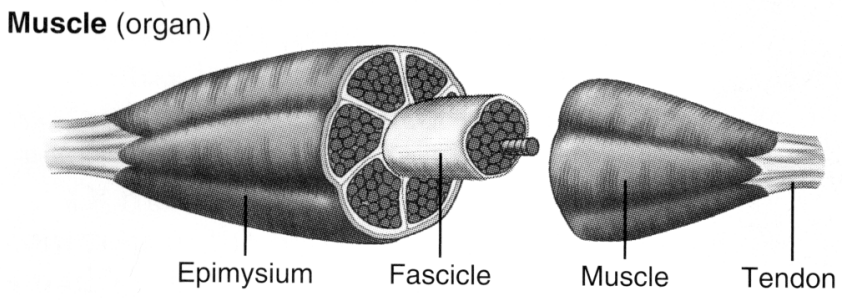

Fascicle (a portion of the muscle)

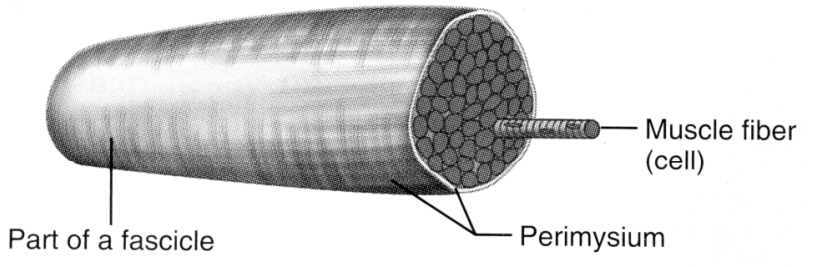

Muscle fiber (cell)

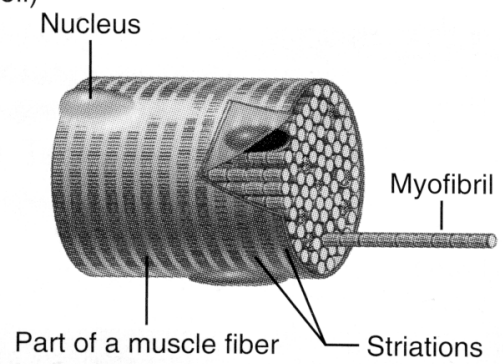

Figure 1.2 Structure of the skeletal muscle. The skeletal muscle is surrounded by connective tissue named the epimysium. Every skeletal muscle is composed of numerous muscle fibers which are grouped together in fascicles that are covered by a layer of fibrous connective tissue called perimysium. Each muscle fiber contains several hundreds to thousands of myofibrils which have a striated appearance. (Adapted from Marieb, Muscle and Muscle tissue in Human Anatomy and Physiology, 2001).

Each myofibril is composed of two smaller structures named the thick and the thin filaments. The thick filaments consist of the protein myosin which is composed of two heavy chains, two regulatory light chains and two alkali light chains. The heavy chains form the tail of the protein and the regulatory light chains and the alkali light chains form the head of the myosin protein (Figure 1.3A). The myosin proteins are bundled together with the tails forming the central part of the thick filament and the heads are facing outward (Figure 1.3B). The heads of the myosin proteins contains an ATP binding site and ATPase enzymes that convert ATP into ADP to generate energy for muscle contraction. The thin filament contains a strand of actin twisted into a helix. Each strand of actin is made up of $\mathrm{G}$ actin subunits containing an active site that forms cross bridges with myosin during contraction. Two tropomyosin molecules are wrapped spirally around the actin helix. Attached along the 
site of the tropomyosin molecules are other protein molecules called troponin. This is a complex of three loosely bound protein subunits named troponin I, troponin $\mathrm{T}$ and troponin $\mathrm{C}$, each of which plays a specific role in controlling muscle contraction (Figure 1.3C) $(17,18)$.

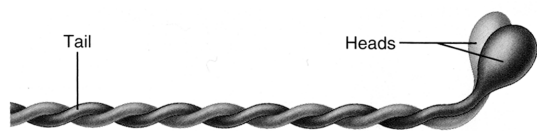

(a) Myosin molecule

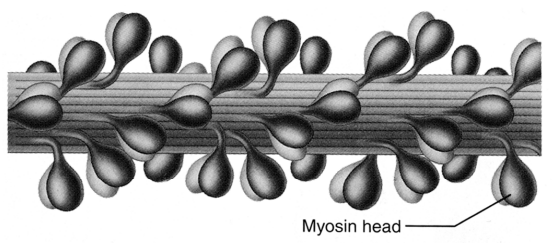

(b) Portion of a thick filament

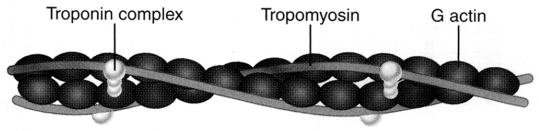

(c) Portion of a thin filament



(d) Longitudinal section of filaments

Figure 1.3 Composition of the myofibrils. (A) A myosin molecule consists of a tail and a head region. (B) Each thick filament consists of many myosin molecules. The tail of the myosin molecules forms the central part and the head of the myosin molecules is facing outwards. (C) The thin filament contains a helix-twisted strand of actin with two tropomyosin molecules wrapped around the helix. Troponin complexes are attached to the tropomyosin molecules. (D) Arrangement of the thick and thin filaments. (Adapted from Marieb, Muscle and Muscle tissue in Human Anatomy and Physiology, 2001).

\section{Muscle fiber typing}

Based on morphological, biochemical and physiological characteristics different fiber types can be distinguished. Currently, muscle fibers are typed using three different methods e.g. myosin ATPase staining, myosin heavy chain ( $\mathrm{MHC}$ ) isoform identification and biochemical identification of metabolic enzymes (19).

MHC isoforms are the main determinants of the functional properties of muscle fibers. Therefore, MHC isoform expression has been frequently used to type the different muscle fibers. According to the expression of $\mathrm{MHC}$ isoforms pure fiber types, which express one MHC isoform, and hybrid fiber types, which express two or more MHC isoforms, can be identified (20). In the rodent skeletal muscle four pure fiber types can be defined which are type I fibers containing $\mathrm{MHCl}$, type IIA fibers (MHClla), type IID fibers (MHCIId) and type IIB fibers (MHCllb). The slow type I fibers can sustain prolonged low power work, contain more mitochondria and exhibit higher rates of oxidative metabolism. The fast type IId and IIb fibers are adapted to brief and intense contractions, contain fewer mitochondria and they generate ener- 
gy mainly through glycolysis. The type Ila fibers exhibit an intermediate contractile function and are oxidoglycolytic $(21,22)$.

Based on the pre-dominant $\mathrm{MHC}$ isoform the following hybrid fiber types can be distinguished: type I/IIA, also named type IC ( $\mathrm{MHCl}>\mathrm{MHClla})$; type IIA/I, also named type IIC (MHClla>MHCl); type IIAD (MHClla>MHClld); type IIDA (MHClld>MHClla); type IIDB (MHCIId>MHCllb) and type IIBD (MHCllb>MHCIld). That these hybrid fiber types are found during steady state conditions suggests that the coexistence of different $\mathrm{MHC}$ isoforms is needed to match specific functional demands $(21,22)$.

Additionally, many other muscle proteins, e.g. myosin light chains, the three troponin subunits and tropomyosin, show a fiber type-specific expression pattern. This expression pattern can be graded with e.g. high expression levels in type I fibers and low expression levels in type IIB fibers. Another possible pattern is the so-called onor-off expression with e.g. expression in type II fibers, but not in type I fibers $(19,21$, 22).

\section{Fiber type transitions}

Muscle fibers are dynamic structures that can change their fiber type under various conditions such as altered innervation, exercise, mechanical loading or unloading, altered hormone levels and aging. In general, changes in $\mathrm{MHC}$ isoform expression follow a general scheme of sequential and reversible transitions from fast-to-slow or slow-to-fast: $\mathrm{MHCl} \leftrightarrow \mathrm{MHClla} \leftrightarrow \mathrm{MHClld} \leftrightarrow \mathrm{MHCllb}$ (20-22). Different signaling pathways have been identified that mediate these fiber type transitions. The calcineurin/NFAT-dependent transcriptinal pathway is implicated in the transition from a fast to a slow fiber type. Calcineurin is a $\mathrm{Ca}^{2+}$-dependent phosphatase which activates NFAT by dephosphorylation (23). The role of the calcineurin/NFAT pathway in the activation of slow fiber type genes has been demonstrated in both in vitro and in vivo experiments (24-27). In addition to the calcineurin/NFAT pathway, the CaMK/HDAC/MEF2 pathway has been implicated in the fast-to-slow fiber type transition. The transcription of the MEF2 gene is suppressed by histone deacetylase proteins (HDAC). This suppression is abolished when calmodulin dependent kinase (CaMK) is activated and phosphorylates HDAC. Alternatively, transcription of the MEF2 gene can be initiated via dephosphorylayion by calcineurin (23). Recently, it was demonstrated that peroxisome proliferator-activated receptor, gamma, coactivator 1 alpha (Ppargc1a) also plays a role in the fast-to-slow fiber type transitions. Ppargc1a is expressed in several tissues including the skeletal muscle and activates mitochondrial biogenesis and oxidative metabolism. When Ppargc1a is expressed at physiological levels in muscle normally rich in type II fibers, a fiber type conversion occurs resulting in muscle tissue containing more type I fibers and genes involved in mitochondrial oxidative metabolism are activated (28-30). It is still unclear which pathways are involved in activation of Ppargc1a, however, evidence is accumulating that both calcineurin and CaMK play important roles in the regulation of Ppargc1a 
(31). Finally, peroxisome proliferator-activator receptor delta (Ppard) has also been implicated in transition from a fast fiber type to a slow fiber type. Muscle-specific overexpression of Ppard resulted in the increase of the number of oxidative fibers and in higher expression levels of several markers of oxidative metabolism $(32,33)$. Interestingly, Ppargc1a is a possible co-activator of Ppard is (31). Altogether, numerous pathways are involved in mediating these fiber type transitions. Further characterization of transcription factors, co-activators and inhibitors is necessary to fully elucidate these pathways.

\section{Metabolic disturbances associated with insulin resistance}

In the skeletal muscle insulin promotes the uptake of glucose via the activation of the phosphatidylinositol 3-kinase (PI3K) pathway which is responsible for most of the metabolic actions of insulin. Upon activation of PI3K, Akt/PKB is activated by phosphorylation. Consequently, glucose transporter 4 is translocated to the cell membrane mediating the uptake of glucose (34). Furthermore, insulin stimulates the uptake of FA by facilitating the translocation of specific FA transporters such as CD36 to the cell membrane (35). In the skeletal muscle insulin resistance is manifested by a decreased ability of insulin to stimulate glucose uptake and metabolism (10), whereas the uptake of FA is increased (35). Numerous metabolic disturbances are associated with insulin resistance.

\section{Intramuscular lipid accumulation}

When energy intake exceeds energy expenditure the excess of energy is stored as TAG in adipose tissue. In obesity, adipose tissue is overloaded with TAG. When adipose tissue is not able to effectively store more lipids, FA and TAG are released into the circulation. This will lead to an increased flux of TAG and FA into non-adipose tissues such as the skeletal muscle. When the capacity to oxidize FA is not sufficient, lipids are stored in the skeletal muscle as TAG (36).

An excess accumulation of TAG in the skeletal muscle is associated with impaired insulin signaling (Figure 1.4) (37-40). Paradoxically, endurance training showed to improve insulin sensitivity together with increased levels of intramuscular TAG (41, 42). Therefore, it has been proposed that it are not TAG per se, but lipid intermediates such as long-chain fatty acyl CoAs, diacylglycerol and ceramides that may act as signaling molecules interrupting insulin signaling and glucose metabolism (43, 44). 


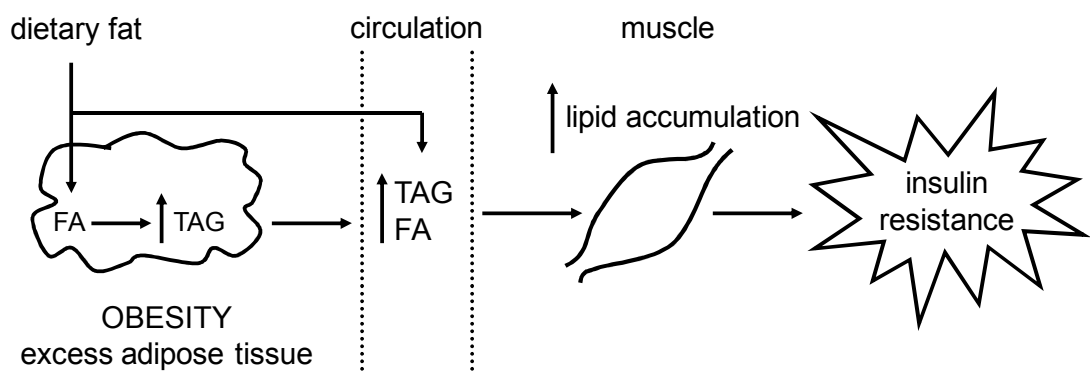

Figure 1.4 In obesity, adipose tissue is overloaded with TAG. When adipose tissue is not able to effectively store more lipids, FA and TAG are released into the circulation. This will lead to an increased flux of TAG and FA into the skeletal muscle. When the capacity to oxidize FA is not sufficient lipids are stored in the skeletal muscle as TAG and lipid intermediates. Accumulation of TAG and lipid intermediates is associated with insulin resistance. FA, fatty acids; TAG, triacylglycerol (adapted from Goossens, Physiology \& Behavior, 2008).

TAG are mainly stored as lipids droplets (LDs) surrounded by a phospholipid monolayer and coated with one or more proteins of the PAT family (Perilipin, Adipophilin (Adfp), TIP47, S3-12 and OXPAT) (45-47). The best-characterized member of the PAT family is perilipin which is exclusively expressed in adipocytes and steroidogenic cells (47). Perilipin is involved in the regulation of storage and lipolysis of TAG (4852). Adfp is expressed in almost all cell types including the skeletal muscle (53). Originally, Adfp was discovered as one of the earliest markers of adipocyte development. Recent in vitro studies have provided more insight in the functional role of Adfp. In various cell types it has been shown that Adfp stimulates the uptake of FA (54), increases the storage of TAG (55-57) and decreases the turnover rate of TAG (55). Also TIP47 is expressed in almost all cell types. The TIP47 protein has $43 \%$ sequence homology with Adfp and can replace Adfp as predominant protein on lipid droplets. S3-12 expression is detectable in white adipose tissue, heart and skeletal muscle and it has been hypothesized that S3-12 primarily serves to facilitate longerterm neutral lipid storage. Finally, OXPAT is found in tissues that have high rates of FA oxidation such as heart, brown adipose tissue, fasted liver and muscle types with predominantly slow fiber types. In contrast with S3-12, it has been proposed that OXPAT may facilitate lipid storage for short-term utilization through oxidative pathways $(46,47,53,58)$. Until now, not much is known about the regulation of these lipid droplet coating proteins in the skeletal muscle.

\section{Mitochondrial dysfunction}

Insulin resistance is characterized by a reduced capacity of the muscle to oxidize FA or an inability to switch between carbohydrates and FA as substrate for oxidation (59-61). One of the proposed underlying mechanisms is an impaired mitochondrial function. Indeed, impaired mitochondrial function is observed in the skeletal muscle of T2DM subjects $(62,63)$. Furthermore, decreased mitochondrial density as well as 
decreased expression of genes involved in mitochondrial respiration is often observed in skeletal muscle of T2DM patients (64-67). Interestingly, a reduced mitochondrial function is also observed in muscle tissue of so-called pre-diabetic subjects: insulin resistant offspring of T2DM subjects $(62,68)$.

It is unclear which factors are involved in impairing mitochondrial function. An increased supply of fat to the muscle has been suggested as a possible cause. Indeed, acute elevation of plasma FA by lipid infusion decreases the expression of mitochondrial genes in the skeletal muscle of healthy subjects (69). Also decreased expression levels of Ppargc1a and Ppargc1b, which are both important transcription factors for mitochondrial biogenesis, are reported after lipid infusion (70).

Rodents that are fed a high fat diet (HFD) are frequently used to study mitochondrial function in relation to insulin resistance. Several studies have found a lower mitochondrial respiration rate and decreased expression of mitochondrial respiration genes and proteins upon feeding a HFD $(71,72)$. However, numerous studies have shown that the skeletal muscle adapts to the HFD by increasing whole-body lipid oxidation, mitochondrial FA oxidation, mitochondrial respiration, activity of mitochondrial enzymes and markers for mitochondrial density (73-76). Moreover, increased TAG accumulation in the skeletal muscle of HFD-fed rats was found, whereas mitochondrial function was not negatively affected (77). Altogether, it is unclear whether mitochondrial dysfunction is a prerequisite for the development of insulin resistance.

\section{Adipokines}

In addition to its function as storage for excess of energy, adipose tissue functions as an endocrine organ that responds to metabolic signals by the secretion of soluble proteins, named adipokines. These adipokines have different systemic effects including modulating energy metabolism in the skeletal muscle. Enlargement of adipose tissue and especially visceral fat depots will lead to alterations in the secretion of these adipokines with detrimental effects on peripheral glucose and lipid metabolism $(78,79)$.

Two well-described adipokines are leptin and adiponectin (Adipoq). Leptin serves as a metabolic signal of energy sufficiency regulating energy homeostasis and is involved in the regulation of peripheral metabolic mechanisms in muscle, liver, pancreas and other tissues (79). Increased leptin levels are reported in both obese and insulin resistant subjects indicating a state of leptin resistance (80). Adipoq levels are decreased in obese and insulin resistant subjects. Increasing Adipoq levels have beneficial effects on insulin sensitivity and lipid metabolism indicating that Adipoq is a modulator of glucose and lipid metabolism in muscle (Figure 1.5). Altogether, alterations in the secretion of these adipokines are linked to the impairment of insulin-stimulated glucose metabolism $(78,79)$. 


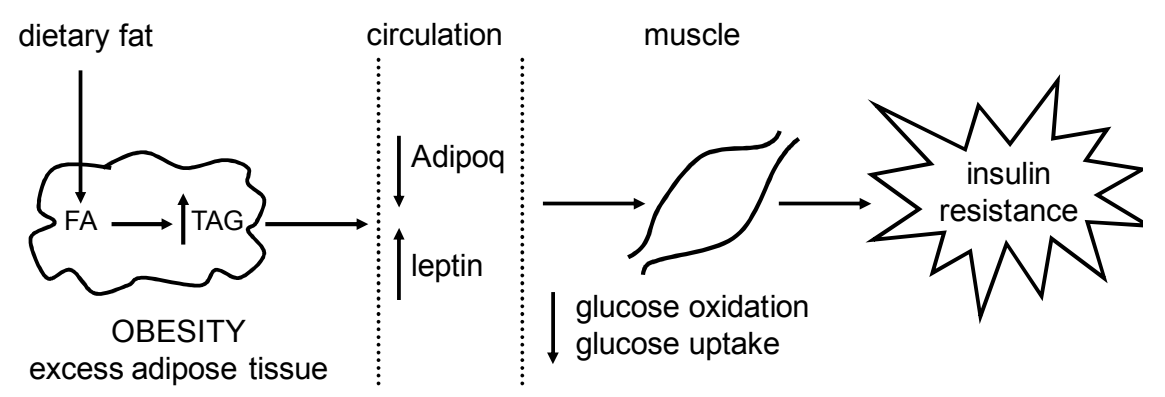

Figure 1.5 Increased accumulation of TAG in adipose tissue will lead to alteration in the secretion of the adipokines Adipoq and leptin. Decreased Adipoq levels and increased leptin levels will have detrimental effects on glucose metabolism. Adipoq, adiponectin; FA, fatty acids; TAG, triacylglycerol (adapted from Goossens, Physiology \& Behavior, 2008).

\section{Mitochondrial membrane phospholipids}

The FA composition of the skeletal muscle membrane phospholipids is associated with the development of insulin resistance (81). Increased levels of saturated FA are related to impaired insulin action, whereas polyunsaturated FA, especially $n-3$ polyunsaturated FA, protect against the development of obesity and insulin resistance (82-84). Interestingly, a link between the composition of the mitochondrial membrane and activity of mitochondrial enzymes has been described for various tissues. Aging increases the proportion of saturated FA in rat testis mitochondria together with decreased activity of the mitochondrial respiratory enzymes (85). In mouse brain mitochondria positive associations between the proportion cardiolipin and activity of the respiratory complexes has been observed (86). However, in rat heart tissue no major impact of a change of FA composition of the mitochondrial membrane on activity of mitochondrial respiratory enzymes was found (87). Whether changes in the FA composition of skeletal muscle mitochondrial membrane phospholipids affect insulin sensitivity requires further investigation.

\section{C57BL/6J mice}

It is difficult to study the early development of the MetS in humans. Therefore, inbred mouse and rat strains sensitive to development of diet-induced obesity and insulin resistance are used as models. A frequently used model is the C57BL/6J mouse strain, because a HFD induces the development of obesity, hyperglycemia, hyperinsulinemia and hypertension $(88,89)$. Also hyperleptinemia, increased plasma cholesterol levels, glucose intolerance and insulin resistance are observed in C57BL/6J mice fed a HFD (90). The development of these metabolic disturbances closely parallels the progression of the human MetS. As in human subjects the MetS 
in $\mathrm{C} 57 \mathrm{BL} / 6 \mathrm{~J}$ mice worsens with time and with increasing obesity (91). Both male and female $\mathrm{C} 57 \mathrm{BL} / 6 \mathrm{~J}$ mice develop characteristics of the MetS, however, the phenotypic characteristics are more pronounced in male than in female $\mathrm{C57BL} / 6 \mathrm{~J}$ mice $(90,92)$. Altogether, the $\mathrm{C} 57 \mathrm{BL} / 6 \mathrm{~J}$ strain is a very suitable model to study the underlying mechanisms of diet-induced obesity and insulin resistance, the two major characteristics of the MetS.

\section{Nutrigenomics}

Traditionally, nutritional research has focused on the epidemiological and physiological aspects of human health and disease. In the past decade, research emphasis gradually shifted to the more molecular and genetic effects of nutrition. Especially, the introduction of genomics has created new opportunities to increase our understanding of nutrition at the molecular level. Nutritional genomics (nutrigenomics) can be seen as a combination of molecular nutrition and genomics. By using nutrigenomics the effect of a specific nutrient or diet on gene expression patterns (transcriptome), on protein expression patterns including post-translation modifications (proteome), as well as on metabolite profiles (metabolome) can be studied. A major focus of nutrigenomics research is on the prevention of chronic diseases, such as CVD, cancer and the MetS, which are all related to an increased consumption of certain food components and nutrients. This goal is based on the idea that nutrition should focus on health and prevention of disease rather than on the pathophysiological aspects of disease which can be targeted by pharmacological therapies. To realize this goal, new biomarkers are needed that allow detection of nutritionally induced early changes in homeostatic control. Biomarker profiles can be determined on the transcriptome, proteome and metabolome level, which all have their own specific advantages as marker of body health status. Nutrigenomics-related research is focused on the pre-disease state and, therefore, it has to deal with small changes in the expression of genes, proteins and metabolites. As metabolomics and proteomics are technologies that are maturing, accuracy and sensitivity has still to be validated. A sensitive and well validated tool in nutrigenomics is transcriptomics $(93,94)$.

\section{Transcriptomics}

Transcriptomics is the genome-wide analysis of messenger RNA (mRNA) levels of genes in cells or tissues. Whereas the more conventional methods such as Northern blotting or RT-PCR measure the expression of one or a few genes, transcriptomics measures the expression of thousands of genes. Transcriptomics is performed by using the DNA microarray technology. A DNA microarray consists of a reproducible 
pattern of thousands of different DNA molecules attached to a glass slide. Fluorescently labeled cRNA, which is prepared from mRNA, is hybridized to complementary DNA molecules on the microarray. Signal intensities for each RNA molecule are measured by laser scanning and converted to a quantitative read-out of relative gene expression (Figure 1.6). Differences in gene expression between conditions are obtained by comparing microarrays of the same array type with each other (95).

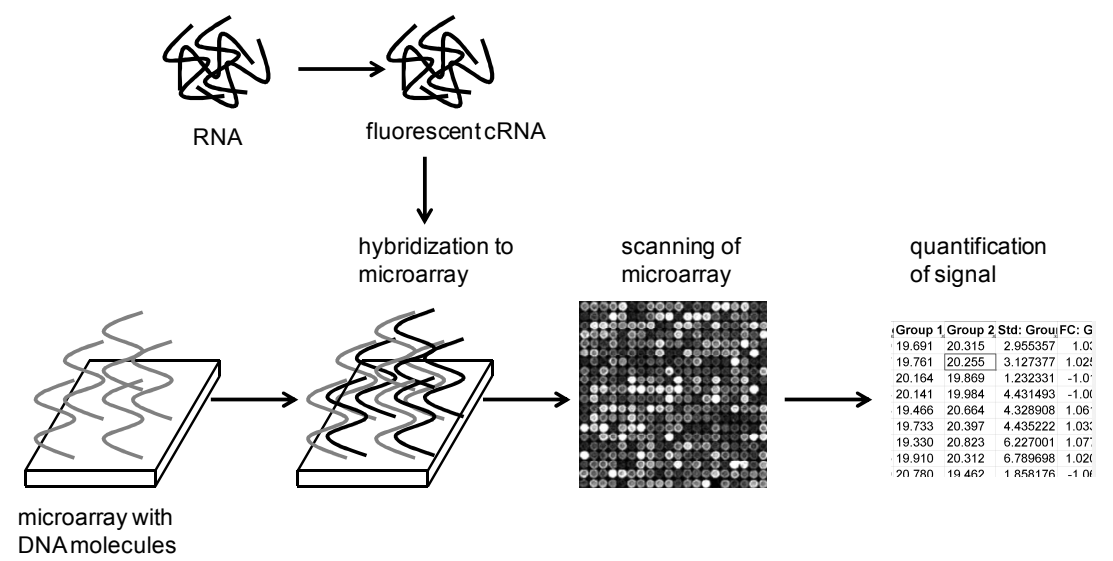

Figure 1.6 Schematic representation of the DNA microarray technology. RNA is isolated from cells and tissues and labeled with a fluorescent probe. This fluorescent cRNA is hybridized to complementary DNA molecules on the microarray. Signal intensities for each RNA molecule are measured by laser scanning and converted to a quantitative read-out of relative gene expression.

Different microarray platforms are described such as spotted microarrays, which can be produced in-house, or high-density oligonucleotide arrays, which are produced by photolithographic manufacturing processes and which are only commercially available (95). For the research described in this thesis high-density oligonucleotide arrays from Affymetrix, Inc. (Santa Clara, USA) were used. On these oligonucleotide arrays every gene is represented by a set of 20 probe pairs and every probe pair consists of a perfect match oligonucleotide and a mismatch oligonucleotide. These mismatch oligonucleotides are identical to their perfect match partners except for one single base. The advantage of this design is that the signal of the mismatch probe is used to correct the signal of the perfect match probe for crosshybridization and local background. In this way discrimination between real signals and those due to non-specific hybridization is allowed (96).

\section{From genes to processes}

One single microarray experiment produces a dataset consisting of a list with values representing the expression levels of thousands of genes. Therefore, an efficient and effective analysis strategy is necessary to extract the most significant informa- 
tion from this long list of genes. As not all genes from the genome are expressed in all tissues, these non-expressed genes have to be removed from the dataset. Usually, this is achieved by removing all the genes that are expressed below a userdefined signal threshold.

Experimental conditions induce biological changes which will be represented by genes that are differentially expressed. Thus, to get more insight in these biological changes the differentially expressed genes have to be identified. Several approaches exist that are used to extract differentially expressed genes from the data set. The classical approach is by using the fold change as a threshold. Although this method is very useful, it has been increasingly criticized for the arbitrariness of the chosen threshold and the lack of an adequate statistical test. Furthermore, this approach also disregards the broader context of differentially expressed genes (97). This implies that genes showing large changes in expression are identified, whereas small and coordinated changes in the expression of a related set of genes are not. In response, gene class testing has become increasingly popular and widely accepted (97). Different applications to perform gene class testing are available nowadays. ErmineJ and gene set enrichment analysis (GSEA) were used for the research described in this thesis. ErmineJ classifies genes according Gene Ontology (GO) terms meaning that genes are grouped according to the biological process they are a participant in, the cellular component they are associated with or the molecular function that has been attributed to them (98). GSEA is focused on predefined gene sets which are groups of genes that share biological function, chromosomal location or regulation $(65,99)$. The advantage is that both methods compute a score based on all genes in a GO term or gene set and are unbiased, meaning that no arbitrary threshold in terms of fold change or significance is chosen.

Microarray experiments have to deal with a number of difficulties. For example, microarray experiments are relatively expensive and therefore a small number of replicates (usually 2-10) are used. As a consequence, traditional statistics such as a $t$ test are not very suitable. Researchers also have to deal with the problem of multiple testing, because the number of genes is very large $(>1.000)(100)$. Initially, robust statistics like the family-wise error rate (FWER) were introduced to handle multiple-testing in microarray experiments. However, applications using the FWER yielded no statistically significant results indicating that FWER is too conservative to correct for multiple testing in microarray experiments (97). Therefore, less conservative statistics e.g. moderate $t$ statistics implementing the empirical Bayes regularization (100) and the false discovery rate (101) have been adapted to microarray analysis. 


\section{Outline of the thesis}

The increasing prevalence of the MetS will have major economic and societal consequences. Therefore, there is an urgent need for more effective intervention and treatment strategies. As the underlying mechanisms of the early onset of the MetS are still unclear, more molecular-based research is required. This will lead to a better understanding which eventually can contribute to the development of better preventive nutritional strategies. The aim of the research described in this thesis was to characterize the role of the skeletal muscle in the early onset of the MetS. To this end, a nutrigenomics approach has been followed in which transcriptomics and lipid metabolomics were combined with measurements of physiological parameters in C57BL/6J mice fed a palm oil-based HFD.

Chapter 2 describes the effect of a 3-day HFD and 4-week HFD on the quadriceps muscle as studied by transcriptomics. Additionally, we examined the effect of the 4week HFD on the muscle lipid metabolome. Both the 3-day HFD and 4-week HFD induced positive metabolic and morphological adaptations in the quadriceps muscle. Additionally, an experiment in which C57BL/6J mice were fed an HFD for 8 weeks was performed. In Chapter 3 extensive characterization of physiological changes was combined with transcriptomics of the quadriceps muscle using a unique combination of two comparison strategies. We found that FA oxidation was the only regulated biological process by the 8-week HFD. To find out if the increased expression of these FA oxidative genes was reflected in changed mitochondrial function we performed mitochondrial respirometry in muscle of the hind limb of C57BL/6J mice fed an 8-week and 20-week HFD. Chapter 4 describes the effect of a mid-term (8-week) and long-term (20-week) HFD on skeletal muscle mitochondria. HFD-induced adaptations in the FA composition of mitochondrial phospholipids as well as mitochondrial respiration were found, especially in the long run. However, these adaptations could not prevent the deterioration of insulin sensitivity.

Molecular in vitro studies were performed to get more insights in the effect of palmitic acid, which is the most common FA in Western-style diets (102), on muscle cells. Therefore, the $\mathrm{C} 2 \mathrm{C} 12$ cell line, which is commonly used to study the mouse skeletal muscle in vitro, was chosen as a model and palmitic acid-induced changes were assessed by proteomics. By using two-dimensional gel electrophoresis we identified Adfp as the protein regulated strongest by exposure of cells to palmitic acid. Accordingly, the regulation of Adfp in muscle cells in relation to insulin sensitivity was studied. The results of these experiments are presented in chapter 5.

In chapter 6, we compared the gene expression profiles of two muscle types that are commonly used in studies exploring the effect of HFD interventions in mouse: the gastrocnemius and quadriceps muscles. Aim of this study was to identify novel genes which specify these different muscle types and to assess if these genes are 
affected by an HFD. Finally, in chapter $\mathbf{7}$ the major findings of all studies are discussed and implications for further research are presented.

\section{References}

1. Kahn R, Buse J, Ferrannini E, Stern M. The metabolic syndrome: time for a critical appraisal: joint statement from the American Diabetes Association and the European Association for the Study of Diabetes. Diabetes care. 2005 Sep;28(9):2289-304.

2. Alberti KG, Zimmet P, Shaw J. Metabolic syndrome--a new world-wide definition. A Consensus Statement from the International Diabetes Federation. Diabet Med. 2006 May;23(5):469-80.

3. Zimmet P, Magliano D, Matsuzawa Y, Alberti G, Shaw J. The metabolic syndrome: a global public health problem and a new definition. J Atheroscler Thromb. 2005;12(6):295-300.

4. Grundy SM, Brewer HB, Jr., Cleeman JI, Smith SC, Jr., Lenfant C. Definition of metabolic syndrome: Report of the National Heart, Lung, and Blood Institute/American Heart Association conference on scientific issues related to definition. Circulation. 2004 Jan 27;109(3):433-8.

5. Balkau B, Vernay M, Mhamdi L, Novak M, Arondel D, Vol S, et al. The incidence and persistence of the NCEP (National Cholesterol Education Program) metabolic syndrome. The French D.E.S.I.R. study. Diabetes Metab. 2003 Nov;29(5):526-32.

6. Weiss R, Dziura J, Burgert TS, Tamborlane WV, Taksali SE, Yeckel CW, et al. Obesity and the metabolic syndrome in children and adolescents. N Engl J Med. 2004 Jun 3;350(23):2362-74.

7. Lavie CJ, Milani RV, Ventura HO. Obesity and cardiovascular disease: risk factor, paradox, and impact of weight loss. J Am Coll Cardiol. 2009 May 26;53(21):1925-32.

8. Marinou K, Tousoulis D, Antonopoulos AS, Stefanadi E, Stefanadis C. Obesity and cardiovascular disease: From pathophysiology to risk stratification. Int J Cardiol. 2009 Apr 25.

9. Venables $M C$, Jeukendrup AE. Physical inactivity and obesity: links with insulin resistance and type 2 diabetes mellitus. Diabetes Metab Res Rev. 2009 Sep;25 Suppl 1:S18-23.

10. Kahn BB, Flier JS. Obesity and insulin resistance. The Journal of clinical investigation. 2000 Aug;106(4):473-81.

11. Huang PL. A comprehensive definition for metabolic syndrome. Dis Model Mech. 2009 May-Jun;2(56):231-7.

12. Eckel RH, Grundy SM, Zimmet PZ. The metabolic syndrome. Lancet. 2005 Apr 16-22;365(9468):141528.

13. Pi-Sunyer FX. The obesity epidemic: pathophysiology and consequences of obesity. Obesity research. 2002 Dec;10 Suppl 2:97S-104S.

14. Nawrocki AR, Scherer PE. The delicate balance between fat and muscle: adipokines in metabolic disease and musculoskeletal inflammation. Current opinion in pharmacology. 2004 Jun;4(3):281-9.

15. Aizawa Y, Kamimura N, Watanabe H, Aizawa Y, Makiyama Y, Usuda Y, et al. Cardiovascular risk factors are really linked in the metabolic syndrome: this phenomenon suggests clustering rather than coincidence. Int J Cardiol. 2006 May 10;109(2):213-8.

16. Grundy SM. A constellation of complications: the metabolic syndrome. Clin Cornerstone. 2005;7(23):36-45.

17. Marieb E. Human Anatomy and Physiology. 5 ed. San Francisco: Pearson Benjamin Cummings 2001.

18. Guyton A, Hall J. Textbook of Medical Physiology. 10 ed. Philadelphia: W.B. SAUNDERS COMPANY 2000.

19. Scott W, Stevens J, Binder-Macleod SA. Human skeletal muscle fiber type classifications. Physical therapy. 2001 Nov;81(11):1810-6.

20. Malisoux L, Francaux M, Theisen D. What do single-fiber studies tell us about exercise training? Medicine and science in sports and exercise. $2007 \mathrm{Jul} ; 39(7): 1051-60$. 
21. Pette D, Staron RS. Myosin isoforms, muscle fiber types, and transitions. Microscopy research and technique. 2000 Sep 15;50(6):500-9.

22. Pette D, Staron RS. Transitions of muscle fiber phenotypic profiles. Histochemistry and cell biology. 2001 May;115(5):359-72.

23. Liu Y, Shen T, Randall WR, Schneider MF. Signaling pathways in activity-dependent fiber type plasticity in adult skeletal muscle. J Muscle Res Cell Motil. 2005;26(1):13-21.

24. Chin ER, Olson EN, Richardson JA, Yang Q, Humphries C, Shelton JM, et al. A calcineurin-dependent transcriptional pathway controls skeletal muscle fiber type. Genes \& development. 1998 Aug 15;12(16):2499-509.

25. Naya FJ, Mercer B, Shelton J, Richardson JA, Williams RS, Olson EN. Stimulation of slow skeletal muscle fiber gene expression by calcineurin in vivo. The Journal of biological chemistry. 2000 Feb $18 ; 275(7): 4545-8$.

26. Talmadge RJ, Otis JS, Rittler MR, Garcia ND, Spencer SR, Lees SJ, et al. Calcineurin activation influences muscle phenotype in a muscle-specific fashion. BMC cell biology. 2004 Jul 28;5:28.

27. Kubis HP, Hanke N, Scheibe RJ, Meissner JD, Gros G. Ca2+ transients activate calcineurin/NFATc1 and initiate fast-to-slow transformation in a primary skeletal muscle culture. Am J Physiol Cell Physiol. 2003 Jul;285(1):C56-63.

28. Lin J, Wu H, Tarr PT, Zhang CY, Wu Z, Boss O, et al. Transcriptional co-activator PGC-1 alpha drives the formation of slow-twitch muscle fibres. Nature. 2002 Aug 15;418(6899):797-801.

29. Mortensen $\mathrm{OH}$, Frandsen L, Schjerling P, Nishimura E, Grunnet N. PGC-1alpha and PGC-1beta have both similar and distinct effects on myofiber switching toward an oxidative phenotype. Am J Physiol Endocrinol Metab. 2006 Oct;291(4):E807-16.

30. Liang H, Balas B, Tantiwong P, Dube J, Goodpaster BH, O'Doherty RM, et al. Whole body overexpression of PGC-1alpha has opposite effects on hepatic and muscle insulin sensitivity. Am J Physiol Endocrinol Metab. 2009 Apr;296(4):E945-54.

31. Liang H, Ward WF. PGC-1alpha: a key regulator of energy metabolism. Advances in physiology education. 2006 Dec;30(4):145-51.

32. Luquet S, Lopez-Soriano J, Holst D, Fredenrich A, Melki J, Rassoulzadegan M, et al. Peroxisome proliferator-activated receptor delta controls muscle development and oxidative capability. Faseb J. 2003 Dec;17(15):2299-301.

33. Wang YX, Zhang CL, Yu RT, Cho HK, Nelson MC, Bayuga-Ocampo CR, et al. Regulation of muscle fiber type and running endurance by PPARdelta. PLoS biology. 2004 Oct;2(10):e294.

34. Taniguchi CM, Emanuelli B, Kahn CR. Critical nodes in signalling pathways: insights into insulin action. Nature reviews. 2006 Feb;7(2):85-96.

35. Glatz JF, Luiken JJ, Bonen A. Membrane fatty acid transporters as regulators of lipid metabolism: implications for metabolic disease. Physiological reviews. 2010 Jan;90(1):367-417.

36. Goossens $\mathrm{GH}$. The role of adipose tissue dysfunction in the pathogenesis of obesity-related insulin resistance. Physiology \& behavior. 2008 May 23;94(2):206-18.

37. Jacob S, Machann J, Rett K, Brechtel K, Volk A, Renn W, et al. Association of increased intramyocellular lipid content with insulin resistance in lean nondiabetic offspring of type 2 diabetic subjects. Diabetes. 1999 May;48(5):1113-9.

38. Krssak M, Falk Petersen K, Dresner A, DiPietro L, Vogel SM, Rothman DL, et al. Intramyocellular lipid concentrations are correlated with insulin sensitivity in humans: a $1 \mathrm{H}$ NMR spectroscopy study. Diabetologia. 1999 Jan;42(1):113-6.

39. Pan DA, Lillioja S, Kriketos AD, Milner MR, Baur LA, Bogardus C, et al. Skeletal muscle triglyceride levels are inversely related to insulin action. Diabetes. 1997 Jun;46(6):983-8.

40. Sinha R, Dufour S, Petersen KF, LeBon V, Enoksson S, Ma YZ, et al. Assessment of skeletal muscle triglyceride content by (1) $\mathrm{H}$ nuclear magnetic resonance spectroscopy in lean and obese adolescents: relationships to insulin sensitivity, total body fat, and central adiposity. Diabetes. 2002 Apr;51(4):1022-7. 
41. Goodpaster BH, He J, Watkins S, Kelley DE. Skeletal muscle lipid content and insulin resistance: evidence for a paradox in endurance-trained athletes. The Journal of clinical endocrinology and metabolism. 2001 Dec;86(12):5755-61.

42. Phillips SM, Green HJ, Tarnopolsky MA, Heigenhauser GJ, Grant SM. Progressive effect of endurance training on metabolic adaptations in working skeletal muscle. The American journal of physiology. 1996 Feb;270(2 Pt 1):E265-72.

43. Petersen KF, Shulman GI. Etiology of insulin resistance. The American journal of medicine. 2006 May;119(5 Suppl 1):S10-6.

44. Hegarty BD, Furler SM, Ye J, Cooney GJ, Kraegen EW. The role of intramuscular lipid in insulin resistance. Acta physiologica Scandinavica. 2003 Aug;178(4):373-83.

45. Brasaemle DL. Thematic review series: adipocyte biology. The perilipin family of structural lipid droplet proteins: stabilization of lipid droplets and control of lipolysis. Journal of lipid research. 2007 Dec;48(12):2547-59.

46. Ducharme NA, Bickel PE. Lipid droplets in lipogenesis and lipolysis. Endocrinology. 2008 Mar;149(3):942-9.

47. Martin S, Parton RG. Lipid droplets: a unified view of a dynamic organelle. Nature reviews. 2006 May; $7(5): 373-8$.

48. Brasaemle DL, Rubin B, Harten IA, Gruia-Gray J, Kimmel AR, Londos C. Perilipin A increases triacylglycerol storage by decreasing the rate of triacylglycerol hydrolysis. The Journal of biological chemistry. 2000 Dec 8;275(49):38486-93.

49. Mottagui-Tabar S, Ryden M, Lofgren P, Faulds G, Hoffstedt J, Brookes AJ, et al. Evidence for an important role of perilipin in the regulation of human adipocyte lipolysis. Diabetologia. 2003 Jun;46(6):789-97.

50. Miyoshi H, Souza SC, Zhang HH, Strissel KJ, Christoffolete MA, Kovsan J, et al. Perilipin promotes hormone-sensitive lipase-mediated adipocyte lipolysis via phosphorylation-dependent and independent mechanisms. The Journal of biological chemistry. 2006 Jun 9;281(23):15837-44.

51. Tansey JT, Sztalryd C, Gruia-Gray J, Roush DL, Zee JV, Gavrilova O, et al. Perilipin ablation results in a lean mouse with aberrant adipocyte lipolysis, enhanced leptin production, and resistance to dietinduced obesity. Proceedings of the National Academy of Sciences of the United States of America. 2001 May 22;98(11):6494-9.

52. Sztalryd C, Xu G, Dorward H, Tansey JT, Contreras JA, Kimmel AR, et al. Perilipin A is essential for the translocation of hormone-sensitive lipase during lipolytic activation. The Journal of cell biology. 2003 Jun 23;161(6):1093-103.

53. Murphy DJ. The biogenesis and functions of lipid bodies in animals, plants and microorganisms. Progress in lipid research. 2001 Sep;40(5):325-438.

54. Gao J, Serrero G. Adipose differentiation related protein (ADRP) expressed in transfected COS-7 cells selectively stimulates long chain fatty acid uptake. The Journal of biological chemistry. 1999 Jun 11;274(24):16825-30.

55. Listenberger LL, Ostermeyer-Fay AG, Goldberg EB, Brown WJ, Brown DA. Adipocyte differentiationrelated protein reduces the lipid droplet association of adipose triglyceride lipase and slows triacylglycerol turnover. Journal of lipid research. 2007 Dec;48(12):2751-61.

56. Imamura M, Inoguchi T, Ikuyama S, Taniguchi S, Kobayashi K, Nakashima N, et al. ADRP stimulates lipid accumulation and lipid droplet formation in murine fibroblasts. Am J Physiol Endocrinol Metab. 2002 Oct;283(4):E775-83.

57. Larigauderie G, Furman C, Jaye M, Lasselin C, Copin C, Fruchart JC, et al. Adipophilin enhances lipid accumulation and prevents lipid efflux from THP-1 macrophages: potential role in atherogenesis. Arteriosclerosis, thrombosis, and vascular biology. 2004 Mar;24(3):504-10.

58. Bickel PE, Tansey JT, Welte MA. PAT proteins, an ancient family of lipid droplet proteins that regulate cellular lipid stores. Biochimica et biophysica acta. 2009 Jun;1791(6):419-40.

59. Blaak EE. Basic disturbances in skeletal muscle fatty acid metabolism in obesity and type 2 diabetes mellitus. The Proceedings of the Nutrition Society. 2004 May;63(2):323-30. 
60. Corpeleijn E, Saris WH, Blaak EE. Metabolic flexibility in the development of insulin resistance and type 2 diabetes: effects of lifestyle. Obes Rev. 2009 Mar;10(2):178-93.

61. Stump CS, Henriksen EJ, Wei Y, Sowers JR. The metabolic syndrome: role of skeletal muscle metabolism. Annals of medicine. 2006;38(6):389-402.

62. Phielix E, Schrauwen-Hinderling VB, Mensink M, Lenaers E, Meex R, Hoeks J, et al. Lower intrinsic ADP-stimulated mitochondrial respiration underlies in vivo mitochondrial dysfunction in muscle of male type 2 diabetic patients. Diabetes. 2008 Nov;57(11):2943-9.

63. Schrauwen-Hinderling VB, Kooi ME, Hesselink MK, Jeneson JA, Backes WH, van Echteld CJ, et al. Impaired in vivo mitochondrial function but similar intramyocellular lipid content in patients with type 2 diabetes mellitus and BMI-matched control subjects. Diabetologia. 2007 Jan;50(1):113-20.

64. Boushel R, Gnaiger E, Schjerling P, Skovbro M, Kraunsoe R, Dela F. Patients with type 2 diabetes have normal mitochondrial function in skeletal muscle. Diabetologia. 2007 Apr;50(4):790-6.

65. Mootha VK, Lindgren CM, Eriksson KF, Subramanian A, Sihag S, Lehar J, et al. PGC-1alpha-responsive genes involved in oxidative phosphorylation are coordinately downregulated in human diabetes. Nat Genet. 2003 Jul;34(3):267-73.

66. Kelley DE, He J, Menshikova EV, Ritov VB. Dysfunction of mitochondria in human skeletal muscle in type 2 diabetes. Diabetes. 2002 Oct;51(10):2944-50.

67. Patti ME, Butte AJ, Crunkhorn S, Cusi K, Berria R, Kashyap S, et al. Coordinated reduction of genes of oxidative metabolism in humans with insulin resistance and diabetes: Potential role of PGC1 and NRF1. Proceedings of the National Academy of Sciences of the United States of America. 2003 Jul 8;100(14):8466-71.

68. Petersen KF, Dufour S, Befroy D, Garcia R, Shulman GI. Impaired mitochondrial activity in the insulinresistant offspring of patients with type 2 diabetes. N Engl J Med. 2004 Feb 12;350(7):664-71.

69. Richardson DK, Kashyap S, Bajaj M, Cusi K, Mandarino SJ, Finlayson J, et al. Lipid infusion decreases the expression of nuclear encoded mitochondrial genes and increases the expression of extracellular matrix genes in human skeletal muscle. The Journal of biological chemistry. 2005 Mar 18;280(11):10290-7.

70. Hoeks J, Hesselink MK, Russell AP, Mensink M, Saris WH, Mensink RP, et al. Peroxisome proliferatoractivated receptor-gamma coactivator-1 and insulin resistance: acute effect of fatty acids. Diabetologia. 2006 Oct;49(10):2419-26.

71. Lionetti L, Mollica MP, Crescenzo R, D'Andrea E, Ferraro M, Bianco F, et al. Skeletal muscle subsarcolemmal mitochondrial dysfunction in high-fat fed rats exhibiting impaired glucose homeostasis. International journal of obesity (2005). 2007 Oct;31(10):1596-604.

72. Sparks LM, Xie H, Koza RA, Mynatt R, Hulver MW, Bray GA, et al. A high-fat diet coordinately downregulates genes required for mitochondrial oxidative phosphorylation in skeletal muscle. Diabetes. 2005 Jul;54(7):1926-33.

73. Hancock CR, Han DH, Chen M, Terada S, Yasuda T, Wright DC, et al. High-fat diets cause insulin resistance despite an increase in muscle mitochondria. Proceedings of the National Academy of Sciences of the United States of America. 2008 Jun 3;105(22):7815-20.

74. Iossa S, Mollica MP, Lionetti L, Crescenzo R, Botta M, Liverini G. Skeletal muscle oxidative capacity in rats fed high-fat diet. Int J Obes Relat Metab Disord. 2002 Jan;26(1):65-72.

75. Turner N, Bruce CR, Beale SM, Hoehn KL, So T, Rolph MS, et al. Excess lipid availability increases mitochondrial fatty acid oxidative capacity in muscle: evidence against a role for reduced fatty acid oxidation in lipid-induced insulin resistance in rodents. Diabetes. 2007 Aug;56(8):2085-92.

76. de Wilde J, Mohren R, van den Berg S, Boekschoten M, Dijk KW, de Groot P, et al. Short-term high fat-feeding results in morphological and metabolic adaptations in the skeletal muscle of C57BL/6J mice. Physiol Genomics. 2008 Feb 19;32(3):360-9.

77. Hoeks J, Briede JJ, de Vogel J, Schaart G, Nabben M, Moonen-Kornips E, et al. Mitochondrial function, content and ROS production in rat skeletal muscle: Effect of high-fat feeding. FEBS letters. 2008 Feb 20;582(4):510-6. 
78. Trujillo ME, Scherer PE. Adipose tissue-derived factors: impact on health and disease. Endocrine reviews. $2006 \mathrm{Dec} ; 27(7): 762-78$.

79. Kershaw EE, Flier JS. Adipose tissue as an endocrine organ. The Journal of clinical endocrinology and metabolism. 2004 Jun;89(6):2548-56.

80. Flier JS. Obesity wars: molecular progress confronts an expanding epidemic. Cell. 2004 Jan 23;116(2):337-50.

81. Hulbert AJ, Turner N, Storlien LH, Else PL. Dietary fats and membrane function: implications for metabolism and disease. Biol Rev Camb Philos Soc. 2005 Feb;80(1):155-69.

82. Vessby $B$, Tengblad S, Lithell $H$. Insulin sensitivity is related to the fatty acid composition of serum lipids and skeletal muscle phospholipids in 70-year-old men. Diabetologia. 1994 Oct;37(10):1044-50.

83. Pan DA, Lillioja S, Milner MR, Kriketos AD, Baur LA, Bogardus C, et al. Skeletal muscle membrane lipid composition is related to adiposity and insulin action. The Journal of clinical investigation. 1995 Dec;96(6):2802-8.

84. Haugaard SB, Madsbad S, Hoy CE, Vaag A. Dietary intervention increases n-3 long-chain polyunsaturated fatty acids in skeletal muscle membrane phospholipids of obese subjects. Implications for insulin sensitivity. Clin Endocrinol (Oxf). 2006 Feb;64(2):169-78.

85. Vazquez-Memije ME, Cardenas-Mendez MJ, Tolosa A, Hafidi ME. Respiratory chain complexes and membrane fatty acids composition in rat testis mitochondria throughout development and ageing. Exp Gerontol. 2005 Jun;40(6):482-90.

86. Kiebish MA, Han X, Cheng $\mathrm{H}$, Lunceford A, Clarke CF, Moon $\mathrm{H}$, et al. Lipidomic analysis and electron transport chain activities in C57BL/6J mouse brain mitochondria. J Neurochem. 2008 Jul;106(1):299312.

87. Lemieux H, Blier PU, Tardif JC. Does membrane fatty acid composition modulate mitochondrial functions and their thermal sensitivities? Comp Biochem Physiol A Mol Integr Physiol. 2008 Jan;149(1):20-9.

88. Surwit RS, Kuhn CM, Cochrane C, McCubbin JA, Feinglos MN. Diet-induced type II diabetes in C57BL/6J mice. Diabetes. 1988 Sep;37(9):1163-7.

89. RossmeisI M, Rim JS, Koza RA, Kozak LP. Variation in type 2 diabetes--related traits in mouse strains susceptible to diet-induced obesity. Diabetes. 2003 Aug;52(8):1958-66.

90. Gallou-Kabani C, Vige A, Gross MS, Rabes JP, Boileau C, Larue-Achagiotis C, et al. C57BL/6J and A/J mice fed a high-fat diet delineate components of metabolic syndrome. Obesity (Silver Spring, Md. 2007 Aug;15(8):1996-2005.

91. Collins S, Martin TL, Surwit RS, Robidoux J. Genetic vulnerability to diet-induced obesity in the C57BL/6J mouse: physiological and molecular characteristics. Physiology \& behavior. 2004 Apr;81(2):243-8.

92. Reed DR, Bachmanov AA, Tordoff MG. Forty mouse strain survey of body composition. Physiology \& behavior. 2007 Aug 15;91(5):593-600.

93. Afman L, Muller M. Nutrigenomics: from molecular nutrition to prevention of disease. J Am Diet Assoc. 2006 Apr;106(4):569-76.

94. Muller M, Kersten S. Nutrigenomics: goals and strategies. Nat Rev Genet. 2003 Apr;4(4):315-22.

95. Harrington CA, Rosenow C, Retief J. Monitoring gene expression using DNA microarrays. Curr Opin Microbiol. 2000 Jun;3(3):285-91.

96. Lipshutz RJ, Fodor SP, Gingeras TR, Lockhart DJ. High density synthetic oligonucleotide arrays. Nat Genet. 1999 Jan;21(1 Suppl):20-4.

97. Allison DB, Cui X, Page GP, Sabripour M. Microarray data analysis: from disarray to consolidation and consensus. Nat Rev Genet. 2006 Jan;7(1):55-65.

98. Lee HK, Braynen W, Keshav K, Pavlidis P. ErmineJ: tool for functional analysis of gene expression data sets. BMC Bioinformatics. 2005;6:269. 
99. Subramanian A, Tamayo P, Mootha VK, Mukherjee S, Ebert BL, Gillette MA, et al. Gene set enrichment analysis: a knowledge-based approach for interpreting genome-wide expression profiles. Proceedings of the National Academy of Sciences of the United States of America. 2005 Oct 25;102(43):15545-50.

100.Gottardo R, Pannucci JA, Kuske CR, Brettin T. Statistical analysis of microarray data: a Bayesian approach. Biostatistics. 2003 Oct;4(4):597-620.

101.Storey JD, Tibshirani R. Statistical significance for genomewide studies. Proceedings of the National Academy of Sciences of the United States of America. 2003 Aug 5;100(16):9440-5.

102. Kien CL. Dietary interventions for metabolic syndrome: role of modifying dietary fats. Curr Diab Rep. 2009 Feb;9(1):43-50. 


\section{CHAPTER 2 \\ Short-term high fat-feeding results in morphological and metabolic adaptations in the skeletal muscle of C57BL/6J mice}

Janneke de Wilde, Ronny Mohren, Sjoerd A.A. van den Berg, Mark V. Boekschoten, Ko Willems Van Dijk, Philip de Groot, Michael Müller, Edwin C.M. Mariman and Egbert Smit

Physiological Genomics. 2008; 32(3): 360-369. 


\begin{abstract}
The prevalence of the metabolic syndrome (MetS) is rapidly increasing all over the world. Consequently, there is an urgent need for more effective intervention strategies. Both animal and human studies indicate that lipid oversupply to skeletal muscle can result in insulin resistance which is one of the characteristics of the MetS. C57BL/6J mice were fed a low fat palm oil diet (10 kcal\%) or a high fat palm oil diet (45 kcal\%; HFD) for 3 or 28 days. By combining transcriptomics with protein and lipid analyses we aimed to better understand the molecular events underlying the early onset of the MS. A short-term HFD intervention led to altered expression levels of genes involved in a variety of biological processes including morphogenesis, energy metabolism, lipogenesis and immune function. Protein analysis showed increased levels of the myosin heavy chain, slow fiber type protein and the complexes I, II, III, IV and V of the oxidative phosphorylation. Furthermore, we observed that the main mitochondrial membrane phospholipids, phosphatidylcholine and phosphatidylethanolamine, contained more saturated fatty acids. Altogether, these results point to a morphological as well as a metabolic adaptation by promoting a more oxidative fiber type. We hypothesize that after this early positive adaptation, a continued transcriptional down-regulation of genes involved in oxidative phosphorylation will result in decreased oxidative capacity at a later stage. Together with increased saturation of phospholipids of the mitochondrial membrane this can result in decreased mitochondrial function which is a hallmark observed in insulin resistance and type 2 diabetes.
\end{abstract}




\section{Introduction}

The metabolic syndrome (MetS) is defined as a cluster of metabolic abnormalities including glucose intolerance (i.e. impaired glucose tolerance, type 2 diabetes mellitus or impaired fasting glycaemia), abdominal obesity, dyslipidaemia and hypertension that are associated with insulin resistance (1-7). All these abnormalities are linked with an increased risk for developing cardiovascular diseases (CVD) $(1,3,5)$. Weight reduction is a way to manage the MetS, because it improves all risk factors associated with the MetS (5). Nevertheless, the prevalence of the MetS is rapidly increasing all over the world. So, there is an urgent need for more effective intervention strategies $(4,5)$.

Skeletal muscle is an important tissue for insulin-stimulated glucose metabolism (710). The switch to a high fat diet (HFD) will result in elevated levels of plasma triglycerides resulting in increased fluxes of fatty acids (FA) into muscle tissue (11). A healthy skeletal muscle is characterized by the ability to switch easily between glucose and fat oxidation in response to these homeostatic signals and will promote the oxidation of FA as source for energy. This is known as metabolic flexibility (12, 13). The transcriptional co-activator, peroxisome-proliferator-activated receptor- $\gamma$ co-activator $1 \alpha(P G C 1 \alpha)$, has been implicated in the regulation of energy metabolism. PGC1 $\alpha$ induces mitochondrial biogenesis and increases expression of enzymes acting in FA oxidation, the tricarboxylic acid cycle and oxidative phosphorylation (14, 15). PGC1 $\alpha$ is expressed preferentially in muscle tissue enriched in type I fibers which contain a high concentration of mitochondria and use oxidative metabolism as energy source. It has been observed that muscle tissue of mice over-expressing $P G C 1 \alpha$ are greatly enriched in type I fibers showing increased expression of genes involved in mitochondrial oxidative metabolism (e.g. the cox 2 and cox4 genes) and muscle contraction (e.g. the Tnni1 gene) $(16,17)$.

Another way in which skeletal muscle function can be affected is by lipid metabolites directly. Prolonged increased fluxes of FA into muscle tissue can result in the accumulation of FA as long chain acyl CoAs (LC-COAs), diacylglycerol (DAG) and triacylglycerol. There is evidence that LC-CoAs, DAG or the lipid derivative ceramide interfere with the insulin signaling pathway (18-22). A strong relationship between impaired insulin-stimulated glucose metabolism and increased intramuscular lipid pools has been frequently described $(8,9,18,21,23-25)$. Also a relation between insulin resistance and the fatty acid composition of skeletal muscle membrane phospholipids has been demonstrated in both humans and animals. It was observed that the greater the percentage of poly-unsaturated FA in membrane phospholipids the better the insulin action (26-28).

We investigated the short-term effects of a HF palm oil diet on the mouse skeletal muscle. By performing genome-wide analysis of HFD-responsive genes combined with protein and lipid analysis we aimed for a better understandig of molecular 
events underlying the early onset of the MetS. Eventually, this can contribute to the development of more effective nutritional intervention strategies.

\section{Methods}

\section{Animals and study protocol}

Male C57BI/6J mice were obtained from Charles River (Maastricht, The Netherlands) at 7 weeks of age. The mice were fed a standard growth diet (RM3(E)DU, Special Diet Services, Witham, England) for 2 weeks prior to switching to the low fat (LF) run-in diet for three weeks. Following the run-in period mice were randomly assigned to the LF diet or the high fat (HF) diet. The diets contained $10 \mathrm{kcal} \%$ fat or $45 \mathrm{kcal} \%$ fat in the form of palm oil (based on D12450B and D12451; Research Diet Services, Wijk bij Duurstede, the Netherlands). After 3 and 28 days mice were sacrificed ( $n=6$ per group). Quadriceps muscles were dissected and snap-frozen in liquid nitrogen. Animal experiments were approved by the animal experimentation committee of Leiden University.

\section{Measurements of fasting plasma glucose and fasting insulin levels}

Fasting plasma glucose and insulin levels were measured using the glucose hexokinase assay (Roche Molecular Chemicals, Basel Switzerland) and by ELISA (Mercodia, Uppsala, Sweden), respectively.

\section{Affymetrix microarray analysis}

Mouse total RNA was isolated from the quadriceps muscle with Trizol reagent (Invitrogen, Breda, the Netherlands) and purified with the RNeasy Mini Kit (Qiagen, Venlo, the Netherlands). Contaminating genomic DNA was removed with the RNase-free DNase set (Qiagen, Venlo, the Netherlands). RNA quantity was measured with the ND-1000 spectrophotometer (Isogen Life Science B.V., IJsselstein, the Netherlands) and RNA integrity was checked on an Agilent 2100 BioAnalyzer (Agilent Technologies, Amsterdam, The Netherlands) using nanochips according to the manufacturer's instructions. Affymetrix GeneChip ${ }^{\circledR}$ Mouse Genome 4302.0 arrays were used to determine the mouse quadriceps muscle transcriptome during LF diet and HF diet intervention. Individual microarrays were performed for each sample. Ten micrograms of RNA were used for one cycle cRNA synthesis (Affymetrix Inc., Santa Clara, USA). Hybridization, washing and scanning of Affymetrix Mouse Genome 4302.0 arrays was done according to standard Affymetrix protocols. Array images were processed using packages from the Bioconductor project (29). Probe 
sets were redefined according to Dai et al. (30). In this method probes are annotated using up to date databases and assigned to unique gene identifiers, in this case Entrez ID's, instead of the 'classic' GeneChip probe sets. This results in a less ambiguous and more accurate annotation. Arrays were normalized using quantile normalization, and expression estimates were calculated using GC-RMA, implementing the empirical Bayes estimate for non-specific binding (31). Differentially expressed probe sets were identified using linear models, applying moderated tstatistics that implement empirical Bayes regularization of standard errors (32). Comparison was between the LF mice and the HF mice. Probe sets that satisfied the criterion of a $p$ value $<0.05$ and fold-change $>1.3$ were considered to be significantly regulated.

To relate changes in gene expression to functional changes two complementary methods were used. The first method is based on overrepresentation of Gene Ontology (GO) terms, which uses a gene score resampling (GSR) method (33). Full resampling was run with 200,000 iterations. Only classes with a false discovery rate (FDR) $<0.001$ and with minimal 8 and maximal 125 genes were taken into account. The second method, gene set enrichment analysis (GSEA), is focused on predefined gene sets, that is, groups of genes that share biological function, chromosomal location or regulation (34). The 'functional catalogue' constructed by Subramanian et al. was modified to contain only 505 well-defined murine, biochemical, metabolic and signal pathways compiled from the following publicly available, curated databases: BioCarta (BioCarta. BioCarta, 2005, p. http://www.biocarta.com.), GenMAPP (35), Kyoto Encyclopedia of Genes and Genomes (KEGG) (36), Sigma-Aldrich pathways (Sigma-Aldrich. Sigma-Aldrich Metabolic and Cell Signaling pathways, 2005.) and Signal Transduction Knowledge Environment (STKE; Signal Transduction Knowledge Environment. In: http://stke.sciencemag.org/.2005.). The analysis was run using 1000 permutations per gene set. Gene sets with a FDR $<0.05$ were considered as significantly regulated. The advantage is that both methods are unbiased and a score is computed based on all genes in a GO term or gene set. Array data have been submitted to the Gene Expression Omnibus, accession number GSE8524.

\section{Real Time quantitative PCR}

To validate microarray-detected changes real time quantitative PCR (qPCR) was performed using individual cDNA samples. RNA $(1 \mu \mathrm{g})$ was reverse transcribed using the iScript cDNA synthesis kit (Biorad, Veenendaal, the Netherlands). Primers were designed across exon boundaries when possible using Beacon Designer5 (Biorad). The qPCR reactions were performed in a volume of $25 \mu$ l containing $12.5 \mathrm{ng}$ cDNA, 1x IQ SYBR Green Supermix (Biorad) and $400 \mathrm{nM}$ of gene-specific forward and reverse primers (Biolegio, Nijmegen, the Netherlands). cDNA was amplified using a 2step program ( 40 cycles of 10 seconds (sec) at $95^{\circ} \mathrm{C}$ and $45 \mathrm{sec}$ at $60^{\circ} \mathrm{C}$ ) with a MyiQ 
system (Biorad). Specificity of amplification was verified by melt curve analysis and evaluation of efficiency of PCR amplification. Gene expression levels were determined using qBase analysis software (37) using a $\Delta$-Ct relative quantification model with PCR efficiency correction and multiple reference gene normalization. The geometric mean of three internal control genes, the Canx, Hprt1, and Arbp genes, was calculated using Genorm (38) and used as a normalization factor in the qBase analysis software (37).

\section{Protein analysis by Western blotting}

Individual mouse muscle samples were crushed under liquid nitrogen and homogenized in lysis buffer containing $10 \%(w / v)$ SDS, 5 mM DTT, 20 mM Tris Base and proteinase inhibitor cocktail tablets (Roche Molecular Chemicals, Basel, Switzerland). After centrifugation protein samples at $14,000 \mathrm{~g}$ for $20 \mathrm{~min}$ at $10{ }^{\circ} \mathrm{C}$, supernatant was aliquoted and stored at $-80^{\circ} \mathrm{C}$. Protein concentration was measured with a BCA protein assay kit (Pierce, Etten-Leur, the Netherlands). Total protein was separated by SDS-PAGE on $4 \%$ to $15 \%$ Criterion gels (Biorad) at 150 Volt (V) and transferred to a polyvinylidene fluoride (PVDF) membrane (Biorad) for $90 \mathrm{~min}$ at $100 \mathrm{~V}$. Blocking and antibody $(\mathrm{Ab})$ incubation steps of the membrane were performed in TBST (10 mM Tris-HCl, $100 \mathrm{mM} \mathrm{NaCl}, 0.1 \%$ Tween-20, pH 7.6) supplemented with 5 $\%$ non-fat dry milk (Biorad, Veenendaal, the Netherlands). Membranes were incubated overnight with anti-mouse polyclonal Pgc1 $\alpha$ Ab (1:1000; Chemicon, Amsterdam, the Netherlands), anti-mouse polyclonal Fas Ab (1:350; Abcam, Cambridge, United Kingdom), anti-mouse monoclonal Srebp1 Ab (1:200; Santa Cruz Biotechnology, Heidelberg, Germany), anti-mouse polyclonal Scd1 Ab (1:200; Santa Cruz Biotechnology), anti-mouse monoclonal OXPHOS Ab cocktail directed to the ND6 subunit of complex I, the $30 \mathrm{kDa}$ Ip subunit of complex II, the $47 \mathrm{kDa}$ core protein 2 of complex III, subunit IV of complex IV and the $\alpha$ subunit of F1F10 ATP synthase (complex V) (1:2,000; Mitosciences, Eugene, USA) or anti-mouse monoclonal myosin (skeletal, slow) Ab (1:10,000 Sigma, Zwijndrecht, the Netherlands) at $4{ }^{\circ} \mathrm{C}$. After washing with TBST, membranes were incubated with a HRP-conjugated secondary Ab (Dako, Glostrup, Denmark). Signals were detected by ECL using Pierce reagents and CL-Xpose clear blue X-ray film (Perbio Science, Etten-Leur, the Netherlands). Gel images were obtained with a GS-800 calibrated densitometer and analyzed with Quantity One (Biorad, Veenendaal, the Netherlands). Since the Gapdh protein was stably expressed under the dietary conditions we applied, we have used the Gapdh signal to calculate the relative protein abundance. 


\section{Lipid metabolome analysis}

The composition of lipids in the quadriceps muscle of mice fed an LF or an HF diet for 28 days ( $n=3$ per group) was determined by high-throughput methods developed by Lipomics (San Diego, United States). Briefly, lipids from the quadriceps muscle $(20-40 \mathrm{mg}$ ) were extracted with chloroform : methanol $(2: 1, \mathrm{v} / \mathrm{v})$ in the presence of authentic internal standards by the method of Folch et al. (39). Individual lipid classes within the extract were separated by preparative thin-layer chromatography. Subsequently, FA methyl esters were separated and quantified as described previously Watkins et al. (40).

\section{Statistical analyses}

Unless otherwise indicated, all analyses were performed with SPSS for Windows, version 13.0. Means were compared per time point with an independent samples ttest and a $p$-value $<0.05$ was considered statistically significant.

\section{Results}

\section{Physiological effects of the high fat diet}

After 3 days or 28 days of diet intervention, neither total body weight nor the weight gain for the HFD group was significantly different from that of the LFD group (data not shown). However, plasma glucose levels were significantly increased after 3 days and 28 days of a HFD. Also the plasma insulin levels were already significantly increased after 3 days of HFD and were still higher at 28 days of diet intervention (Figure 2.1). The increase in glucose and insulin levels at 3 days was also observed in other experiments and may be induced by the change in diet. 



Figure 2.1 fasting blood glucose and insulin levels after a LF or a HF diet for 3 or 28 days. Values are means \pm S.E.M. of the LF mice and the HF mice $(n=5$ or $n=6),{ }^{*}$ and ${ }^{* *}$ indicate significant differences between LFD and HFD with $p<0.05$ and $p<0.01$, respectively. A indicates a significant difference between day 3 and day 28 with $p<0.05$. All obtained from independent samples t test. LFD, low fat diet; HFD, high fat diet

\section{High fat diet-induced changes in the skeletal muscle transcriptome}

Microarray analysis using Affymetrix whole genome mouse arrays revealed that the expression of numerous genes was significantly changed after 3 days and 28 days of a HFD intervention. When using the criteria of a fold change $>1.3$ and a $p$ value $<$ 0.05 , we found that the expression level of 1063 genes was significantly different between the 3 days LFD mice and the HFD mice. Of these 1063 genes, 445 genes were expressed at a lower level and 618 genes were expressed at a higher level in the HFD mce compared to the LFD mice. The expression level of 400 genes was increased and the expression level of 756 genes was decreased in the 28 days HFD mice compared to the LFD mice. The expression of 384 genes was altered to the same direction in both the 3 days HFD mice and the 28 days HFD mice (Figure 2.2). A complete list of regulated genes is available in supplement 1. qPCR analyses were performed for 16 genes validating the microarray results (supplement 2). Supplement 1 and 2 are available at the website of Physiological Genomics.

To gain insight into the biological processes affected by the HFD, a scoring-based resampling method was applied to identify significantly overrepresented GO classes (33). The top 25 of gene classes with respect to the concept Biological Process that changed most significantly are listed in Table 2.1. After 3 days of diet intervention, the top twenty-five of overrepresented GO classes consisted mainly of descriptors for morphogenesis like muscle contraction, cell differentiation and tissue development. Other overrepresented GO classes included descriptors for fatty acid catabolism and immune system. After 28 days of diet intervention, the top twenty-five of overrepresented GO classes were mainly descriptors of immune system, inflamma- 
tion and energy metabolism. A complete list of overrepresented GO classes is available in supplement 3 at the website of Physiological Genomics.

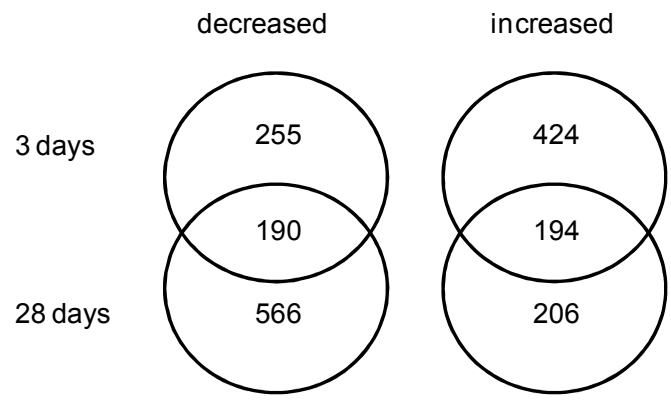

Figure 2.2 Venn diagrams of the number of genes with a decreased and increased expression after 3 days and 28 days of HF diet intervention, respectively. Genes that satisfied the criteria of fold change $>1.3$ and $p$ value $<0.05$ were considered significantly regulated.

Table 2.1 Top 25 of overrepresented Gene Ontology classes after 3 days and 28 days of HF-feeding

\begin{tabular}{|c|c|c|c|c|}
\hline GO ID & GO class & $\mathrm{N}$ & $\begin{array}{l}\text { Raw } \\
\text { Score }\end{array}$ & FDR \\
\hline \multicolumn{5}{|c|}{ Day 3} \\
\hline GO:0006937 & regulation of muscle contraction & 24 & 1.48 & $3.86 \mathrm{E}-04$ \\
\hline GO:0014033 & neural crest cell differentiation & 25 & 1.39 & $6.04 \mathrm{E}-10$ \\
\hline GO:0048762 & mesenchymal cell differentiation & 30 & 1.32 & 2.01E-04 \\
\hline GO:0014031 & mesenchymal cell development & 29 & 1.30 & 4.03E-04 \\
\hline GO:0006936 & muscle contraction & 63 & 1.27 & $2.42 \mathrm{E}-10$ \\
\hline GO:0009855 & determination of bilateral symmetry & 29 & 1.21 & 8.91E-04 \\
\hline GO:0008366 & axon ensheathment & 29 & 1.21 & $9.21 \mathrm{E}-04$ \\
\hline GO:0008064 & $\begin{array}{l}\text { regulation of actin polymerization and/or depoly- } \\
\text { merization }\end{array}$ & 38 & 1.20 & $3.94 \mathrm{E}-04$ \\
\hline GO:0030832 & regulation of actin filament length & 39 & 1.18 & $2.16 \mathrm{E}-04$ \\
\hline GO:0051258 & protein polymerization & 41 & 1.16 & 1.10E-10 \\
\hline GO:0043122 & regulation of I-kappaB kinase/NF-kappaB cascade & 50 & 1.13 & $1.51 \mathrm{E}-10$ \\
\hline GO:0008154 & actin polymerization and/or depolymerization & 48 & 1.12 & 1.95E-04 \\
\hline GO:0051128 & regulation of cell organization and biogenesis & 61 & 1.05 & $2.08 \mathrm{E}-04$ \\
\hline GO:0007179 & $\begin{array}{l}\text { transforming growth factor beta receptor signaling } \\
\text { pathway }\end{array}$ & 45 & 1.05 & 6.97E-04 \\
\hline GO:0043123 & $\begin{array}{l}\text { positive regulation of I-kappaB kinase/NF-kappaB } \\
\text { cascade }\end{array}$ & 46 & 1.05 & 8.63E-04 \\
\hline GO:0006818 & hydrogen transport & 66 & 1.04 & $5.25 \mathrm{E}-11$ \\
\hline GO:0006119 & oxidative phosphorylation & 49 & 1.03 & $2.32 \mathrm{E}-04$ \\
\hline GO:0051270 & regulation of cell motility & 63 & 1.01 & 7.55E-11 \\
\hline GO:0008360 & regulation of cell shape & 45 & 1.01 & 7.83E-04 \\
\hline GO:0015992 & proton transport & 60 & 1.00 & $1.78 \mathrm{E}-04$ \\
\hline GO:0007187 & $\begin{array}{l}\text { G-protein signaling, coupled to cyclic nucleotide } \\
\text { second messenger }\end{array}$ & 45 & 1.00 & 7.69E-04 \\
\hline GO:0030334 & regulation of cell migration & 56 & 0.99 & $1.83 \mathrm{E}-04$ \\
\hline GO:0040012 & regulation of locomotion & 66 & 0.99 & $1.73 \mathrm{E}-10$ \\
\hline GO:0051789 & response to protein stimulus & 58 & 0.99 & $2.42 \mathrm{E}-04$ \\
\hline GO:0031589 & cell-substrate adhesion & 66 & 0.98 & $1.21 \mathrm{E}-09$ \\
\hline
\end{tabular}


Table 2.1 Top 25 of overrepresented Gene Ontology classes after 3 days and 28 days of HF-feeding

\begin{tabular}{|c|c|c|c|c|}
\hline GO ID & GO class & $\mathrm{N}$ & $\begin{array}{l}\text { Raw } \\
\text { Score }\end{array}$ & FDR \\
\hline \multicolumn{5}{|c|}{ Day 28} \\
\hline GO:0050729 & positive regulation of inflammatory response & 11 & 3.10 & 3.90E-11 \\
\hline GO:0002474 & $\begin{array}{l}\text { antigen processing and presentation of peptide } \\
\text { antigen via MHC class I }\end{array}$ & 14 & 3.06 & $1.75 \mathrm{E}-11$ \\
\hline GO:0006957 & complement activation, alternative pathway & 10 & 2.77 & $3.78 \mathrm{E}-04$ \\
\hline GO:0048002 & $\begin{array}{l}\text { antigen processing and presentation of peptide } \\
\text { antigen }\end{array}$ & 28 & 2.71 & $9.29 \mathrm{E}-11$ \\
\hline GO:0002478 & $\begin{array}{l}\text { antigen processing and presentation of exogenous } \\
\text { peptide antigen }\end{array}$ & 17 & 2.60 & $2.42 \mathrm{E}-11$ \\
\hline GO:0002438 & acute inflammatory response to antigenic stimulus & 10 & 2.57 & 7.55E-04 \\
\hline GO:0002697 & regulation of immune effector process & 9 & 2.53 & $5.75 \mathrm{E}-04$ \\
\hline GO:0046460 & neutral lipid biosynthesis & 9 & 2.52 & $6.93 \mathrm{E}-04$ \\
\hline GO:0019886 & $\begin{array}{l}\text { antigen processing and presentation of exogenous } \\
\text { peptide antigen via MHC class II }\end{array}$ & 15 & 2.48 & $1.68 \mathrm{E}-11$ \\
\hline GO:0019884 & $\begin{array}{l}\text { antigen processing and presentation of exogenous } \\
\text { antigen }\end{array}$ & 22 & 2.29 & $2.63 \mathrm{E}-11$ \\
\hline GO:0050766 & positive regulation of phagocytosis & 14 & 2.27 & 1.17E-04 \\
\hline GO:0006635 & fatty acid beta-oxidation & 13 & 2.26 & $1.15 \mathrm{E}-04$ \\
\hline GO:0002822 & $\begin{array}{l}\text { regulation of adaptive immune response (sensu } \\
\text { Gnathostomata) }\end{array}$ & 11 & 2.25 & $4.85 \mathrm{E}-04$ \\
\hline GO:0006094 & gluconeogenesis & 18 & 2.17 & $6.50 \mathrm{E}-05$ \\
\hline GO:0050727 & regulation of inflammatory response & 24 & 2.14 & $1.55 \mathrm{E}-11$ \\
\hline GO:0006641 & triacylglycerol metabolism & 11 & 2.13 & $6.58 \mathrm{E}-04$ \\
\hline GO:0002541 & $\begin{array}{l}\text { activation of plasma proteins during acute inflamma- } \\
\text { tory response }\end{array}$ & 32 & 2.09 & 3.10E-11 \\
\hline GO:0019882 & antigen processing and presentation & 47 & 2.06 & $1.66 \mathrm{E}-11$ \\
\hline GO:0001523 & retinoid metabolism & 14 & 2.05 & 8.37E-04 \\
\hline GO:0006639 & acylglycerol metabolism & 16 & 2.03 & 4.54E-04 \\
\hline GO:0006637 & acyl-CoA metabolism & 13 & 2.01 & $4.51 \mathrm{E}-04$ \\
\hline GO:0006739 & NADP metabolism & 13 & 2.00 & 4.44E-04 \\
\hline GO:0046486 & glycerolipid metabolism & 17 & 1.98 & 7.55E-05 \\
\hline GO:0006090 & pyruvate metabolism & 23 & 1.97 & 2.47E-11 \\
\hline
\end{tabular}

A scoring-based resampling method was used to identify significantly overrepresented GO classes in the skeletal muscle of the 3 days $\mathrm{HF}$ mice and the 28 days HF mice, respectively. The analysis was performed using the tool ErmineJ (33). For the concept biological processes we selected 25 GO classes with a FDR $<0.001$ and with the highest raw score. For this analysis only classes containing 8 through 125 genes were taken into account. N, number of genes in GO class.

GSEA was used to focus on groups of genes that share biological function or regulation (34). This method allows the identification of up- or down-regulated processes making it a more refined method than GO-based analysis. However, due to overlap in the source databases several processes are represented multiple times. GSEA revealed that numerous gene sets were up-regulated after the 3-day HFD. Almost all increased gene sets were related to FA catabolism and muscle contraction. Only 4 gene sets were down-regulated and were related to protein degradation and 
amino acid metabolism. Twenty-eight days of the HFD intervention resulted in the up-regulation of 2 gene sets representing striated muscle contraction and mitochondrial fatty acid oxidation. The down-regulated gene sets corresponded to many diverse cellular processes such as carbohydrate catabolism, detoxification, immune function, lipogenesis and lipoprotein metabolism (Table 2.2).

Table 2.2 Changed gene sets after 3 days and 28 days of HF-feeding

\begin{tabular}{|c|c|c|c|c|c|c|c|c|}
\hline & \multicolumn{4}{|c|}{ Day 3} & \multicolumn{4}{|c|}{ Day 28} \\
\hline & $\mathrm{N}$ & ES & NES & FDR & $\mathrm{N}$ & ES & NES & FDR \\
\hline \multicolumn{9}{|c|}{ Up-regulated cellular processes } \\
\hline Striated muscle contraction ${ }^{1}$ & 41 & 0.73 & 2.57 & $<0.001$ & 41 & 0.72 & 2.43 & $<0.001$ \\
\hline Cell communication $^{2}$ & 91 & 0.57 & 2.30 & $<0.001$ & $\mathrm{nc}$ & & & \\
\hline $\begin{array}{l}\text { Mitochondrial fatty acid oxida- } \\
\text { tion }^{3}\end{array}$ & 29 & 0.71 & 2.26 & $<0.001$ & 29 & 0.69 & 2.16 & $<0.001$ \\
\hline Ecm receptor interaction ${ }^{2}$ & 81 & 0.57 & 2.24 & $<0.001$ & nc & & & \\
\hline Electron transport chain ${ }^{1}$ & 63 & 0.60 & 2.23 & $<0.001$ & $\mathrm{nc}$ & & & \\
\hline Oxidative phosphorylation ${ }^{2}$ & 97 & 0.56 & 2.22 & $<0.001$ & $\mathrm{nc}$ & & & \\
\hline $\begin{array}{l}\text { Mitochondrial fatty acid beta } \\
\text { oxidation }^{1}\end{array}$ & 15 & 0.76 & 2.10 & 0.001 & $\mathrm{nc}$ & & & \\
\hline Tissues blood and lymph ${ }^{1}$ & 31 & 0.63 & 2.08 & 0.002 & $\mathrm{nc}$ & & & \\
\hline Fatty acid beta oxidation ${ }^{1}$ & 34 & 0.60 & 1.95 & 0.008 & nc & & & \\
\hline Ribosome $^{2}$ & 21 & 0.65 & 1.93 & 0.008 & nc & & & \\
\hline Ribosomal proteins ${ }^{1}$ & 29 & 0.61 & 1.94 & 0.009 & $\mathrm{nc}$ & & & \\
\hline Focal adhesion $^{2}$ & 171 & 0.44 & 1.91 & 0.010 & nc & & & \\
\hline Fatty acid oxidation ${ }^{1}$ & 29 & 0.58 & 1.88 & 0.014 & nc & & & \\
\hline Smooth muscle contraction ${ }^{1}$ & 152 & 0.41 & 1.76 & 0.047 & $\mathrm{nc}$ & & & \\
\hline \multicolumn{9}{|c|}{ Down-regulated cellular processes } \\
\hline Proteasome $^{2}$ & 25 & -0.70 & -2.27 & $<0.001$ & 25 & -0.59 & -1.79 & 0.047 \\
\hline Aminoacyl-tRNA-biosynthesis $^{2}$ & 24 & -0.64 & -2.07 & 0.007 & $\mathrm{nc}$ & & & \\
\hline Amino acid metabolism ${ }^{1}$ & 46 & -0.55 & -2.01 & 0.010 & 46 & -0.64 & -2.2 & 0.001 \\
\hline Proteaome degradation $^{1}$ & 60 & -0.49 & -1.92 & 0.023 & nc & & & \\
\hline Lipogenesis $^{3}$ & nc & & & & 28 & -0.79 & -2.38 & $<0.001$ \\
\hline Adipogenesis $^{3}$ & nc & & & & 12 & -0.56 & -2.27 & $<0.001$ \\
\hline $\begin{array}{l}\text { Antigen processing and presen- } \\
\text { tation }^{2}\end{array}$ & $\mathrm{nc}$ & & & & 52 & -0.61 & -2.16 & 0.001 \\
\hline Pentose phosphate pathway ${ }^{2}$ & $\mathrm{nc}$ & & & & 25 & -0.71 & -2.13 & 0.002 \\
\hline Galactose metabolism ${ }^{2}$ & nc & & & & 32 & -0.65 & -2.03 & 0.005 \\
\hline Ppar signaling pathway ${ }^{2}$ & $\mathrm{nc}$ & & & & 64 & -0.57 & -2.04 & 0.005 \\
\hline Lipoprotein metabolism ${ }^{3}$ & $\mathrm{nc}$ & & & & 31 & -0.65 & -2.05 & 0.005 \\
\hline $\begin{array}{l}\text { Starch and sucrose metabo- } \\
\text { lism }^{2}\end{array}$ & nc & & & & 50 & -0.60 & -2.06 & 0.005 \\
\hline $\begin{array}{l}\text { Porphyrin and chlorophyll } \\
\text { metabolism }^{2}\end{array}$ & $\mathrm{nc}$ & & & & 22 & -0.66 & -1.93 & 0.015 \\
\hline $\begin{array}{l}\text { Complement and coagulation } \\
\text { pathways }^{1}\end{array}$ & $\mathrm{nc}$ & & & & 58 & -0.51 & -1.89 & 0.023 \\
\hline Fatty acid biosynthesis $^{1}$ & $\mathrm{nc}$ & & & & 23 & -0.64 & -1.87 & 0.026 \\
\hline
\end{tabular}


Table 2.2 Changed gene sets after 3 days and 28 days of HF-feeding

\begin{tabular}{|c|c|c|c|c|c|c|c|c|}
\hline & \multicolumn{4}{|c|}{ Day 3} & \multicolumn{4}{|c|}{ Day 28} \\
\hline & $\mathrm{N}$ & ES & NES & FDR & $\mathrm{N}$ & ES & NES & FDR \\
\hline \multicolumn{9}{|c|}{ Down-regulated cellular processes } \\
\hline Statin pathway ${ }^{1}$ & $\mathrm{nc}$ & & & & 20 & -0.67 & -1.87 & 0.029 \\
\hline Bisphenol A degradation ${ }^{2}$ & $\mathrm{nc}$ & & & & 16 & -0.67 & -1.86 & 0.029 \\
\hline $\begin{array}{l}\text { Metabolism of xenobiotics by } \\
\text { cytochrome } \mathrm{P} 450^{2}\end{array}$ & $\mathrm{nc}$ & & & & 50 & -0.53 & -1.85 & 0.030 \\
\hline Apoptosis $^{1}$ & $\mathrm{nc}$ & & & & 43 & -0.53 & -1.82 & 0.041 \\
\hline Glycan structures degradation $^{2}$ & $\mathrm{nc}$ & & & & 24 & -0.60 & -1.79 & 0.044 \\
\hline Nucleotide sugars degradaion ${ }^{2}$ & $\mathrm{nc}$ & & & & 16 & -0.67 & -1.78 & 0.045 \\
\hline Oxidative stress ${ }^{1}$ & $\mathrm{nc}$ & & & & 25 & -0.60 & -1.79 & 0.046 \\
\hline $\begin{array}{l}\text { Ascorbate and aldarate me- } \\
\text { tabolism }{ }^{2}\end{array}$ & $\mathrm{nc}$ & & & & 15 & -0.67 & -1.78 & 0.046 \\
\hline Insulin signaling pathway ${ }^{2}$ & $\mathrm{nc}$ & & & & 12 & -0.43 & -1.77 & 0.046 \\
\hline Type I diabetes mellitus ${ }^{2}$ & nc & & & & 38 & -0.54 & -1.77 & 0.047 \\
\hline Nitrogen metabolism ${ }^{2}$ & $\mathrm{nc}$ & & & & 21 & -0.61 & -1.76 & 0.048 \\
\hline Fatty acid biosynthesis $^{1}$ & $\mathrm{nc}$ & & & & 23 & -0.64 & -1.87 & 0.026 \\
\hline Statin pathway ${ }^{1}$ & $\mathrm{nc}$ & & & & 20 & -0.67 & -1.87 & 0.029 \\
\hline
\end{tabular}

Gene set enrichment analysis was applied to identify up-regulated and down-regulated processes after 3 days and 28 days of HF-feeding. The analyses were performed as described (30). Presented are regulated processes with a false discovery rate $(F D R)<0.05$. A FDR was calculated to adjust for multiple hypothesis testing. Sources of the gene sets: 1GenMAPP, 2KEGG, 3SKmanual. N, number of genes; ES, enrichment score for the gene set, that reflects the degree to which a gene set is overrepresented at the top or bottom of the ranked list; FDR, false discovery rate; nc, not changed; NES, normalized enrichment score, that is, the normalized ES to account for the size of the set

The outcome of the GSEA had numerous similarities to the outcome of the GObased analysis. Both methods resulted in the identification of descriptors for FA metabolism, and morphogenesis. However, the outcome of the GSEA also had some differences with the outcome of the GO-based analysis. For example, GSEA resulted in numerous down-regulated gene sets describing lipogenesis, whereas descriptors for this metabolic process were not present in the top twenty-five of overrepresented GO classes. This demonstrates that these methods should not be used separately but in a complementary way. The functional outcomes of the GO-based analysis and GSEA are summarized in Figure 2.3. 


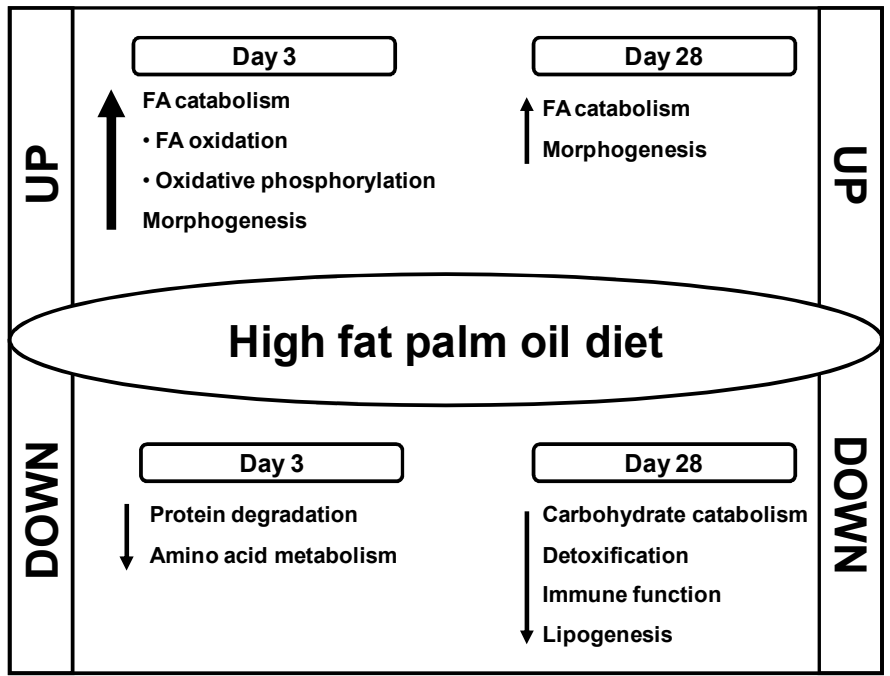

Figure 2.3 A HF palm oil diet altered expression of genes in various biological processes in mouse skeletal muscle. Summary of the functional implications of a HF palm oil diet as assessed by analyses of predefined gene sets based on Gene Ontology, biochemical, metabolic and signal pathways.

\section{Western blotting analysis revealed an adaptation to the HF diet}

Three of the outcomes of the transcriptome analyses were that the HFD suppressed lipogenesis and enhanced morphogenesis and FA catabolism, respectively. To look into this at the protein level, we analyzed the abundance of myosin heavy chain, slow fiber type protein (morphogenesis), Pgc1 $\alpha$ protein and subunits of the $5 \mathrm{com}$ plexes of the oxidative phosphorylation (OXPHOS; FA catabolism) and of the Srebp1, Scd1 and Fas proteins (lipogenesis) after 28 days of the HFD (Figure 2.4). Western blotting showed that the myosin heavy chain, slow fiber type protein content was increased by 5.1 -fold in the quadriceps muscle of the HFD mice confirming the increased gene expression of markers for type I fibers (Tnni1: 15.3-fold; Tnnc1: 12.6fold; Tnnt1: 12.3-fold; Myh7: 11.4-fold). Although we observed a 1.4-fold increased expression of the Ppargc1a gene, no differences were found in the Pgc1 $\alpha$ protein content. GSEA showed an up-regulation of the gene set describing mitochondrial fatty acid metabolism. Western blotting revealed that the protein abundance of 5 OXPHOS subunits was increased (complex I: 1.9 -fold $p=0.02$; complex II: 1.5 -fold $p$ $=0.05$; complex III: 2.6 -fold $p=0.03$; complex IV: 2.5 -fold $p=0.04$ and complex V: 1.4-fold $p=0.04$ ) in the HF mice compared to the LFD mice. The HFD did not influence the abundance of the Srebp1 protein confirming the unchanged Srebf gene expression. Also the processing of the Srebp1 protein as judged by the ratio between the $125 \mathrm{kDa}$ and the $68 \mathrm{kDa}$ bands was not changed by the HFD. The expression of the Scd1 gene was down-regulated with 16.0-fold. Despite the relatively high gene expression, the Scd1 protein could not be detected in the mouse quadriceps muscle (data not shown). After 28 days of an HFD a 5.6-fold decreased abundance of the Fas protein was detected, which is in line with the down-regulation of the expression of the Fasn gene (53.2-fold). 



Figure 2.4 Western blotting analyses of various proteins in quadriceps muscle. (A) Representative examples of Western blotting of equal amounts of total quadriceps muscle protein of the 28 day LF mouse $(n=5)$ and 28 day HF mouse $(n=4)$. Arrowheads indicate the quantified protein (B) Quantified protein expression levels are means + S.E.M of five (LF) or four (HF) biological replicates; \# indicates a tendency towards significance difference with $p<0.10$ and * indicate a significant difference with $p<0.05$ as obtained from independent samples t test. The Gapdh protein signal was used for normalization. LFD, low fat diet; HFD, high fat diet

\section{Changes in the quadriceps muscle lipid metabolome are lipid class-specific}

Because of the observed gene and protein changes we expected effects on lipid content and lipid composition in the skeletal muscle. Therefore, we performed a lipid metabolome analysis. The most abundant FA in the quadriceps muscle lipid metabolome were palmitic acid (16:0), stearic acid (18:0), palmitoleic acid (16:1n7), vaccenic acid (18:1n7), oleic acid (18:1n9), linoleic acid (18:2n6), arachidonic acid $(20: 4 n 6)$ and docosahexaenoic acid (22:6n3). Overall, the FA composition of the quadriceps muscle lipid metabolome was found to be comparable between the LF and the HF mice ( $n=3$ per group) (Figure 2.5). 




Figure 2.5 Fatty acid composition of the mouse muscle lipid metabolome. Fatty acids with an abundance $>2 \%$ were considered to be present. The most abundant fatty acids are mystric acid (14:0) palmitic acid (16:0), stearic acid (18:0), palmitoleic acid (16:1n7), vaccenic acid (18:1n7), oleic acid (18:1n9), linoleic acid (18:2n6), arachidonic acid (20:4n6) and docosahexaenoic acid (22:6n3). The fatty acid composition of the mouse muscle lipid metabolome was found to be comparable between mice fed the LF and the HF diet. Values are means + S.E.M of three biological replicates. LF, low fat diet; HF, high fat diet

Also no significant differences were observed on the total level of individual lipid classes (Table 2.3).

Table 2.3 Effect of a 28-days HF diet on total fatty acids per lipid class

\begin{tabular}{lcc}
\hline Total FA/lipid class & LFD & HFD \\
\hline Cholesterol ester & $673 \pm 156$ & $676 \pm 220$ \\
Diacylglycerol & $276 \pm 23$ & $260 \pm 29$ \\
Free fatty acid & $1034 \pm 196$ & $1015 \pm 133$ \\
Triacylglycerol & $2701 \pm 1227$ & $3895 \pm 388$ \\
Cardiolipin & $1225 \pm 112$ & $1108 \pm 110$ \\
Lysophosphatidylcholine & $401 \pm 28$ & $310 \pm 33$ \\
Phosphatidylcholine & $8915 \pm 632$ & $7483 \pm 351$ \\
Phosphatidylethanolamine & $5692 \pm 887$ & $4137 \pm 186$ \\
Phosphatidylserine & $963 \pm 37$ & $903 \pm 99$ \\
Free Cholesterol & $2383 \pm 470$ & $1865 \pm 99$ \\
\hline
\end{tabular}

Values are expressed as nmoles of total fatty acid per gram of muscle tissue and are means \pm S.E.M of three biological replicates. FA, fatty acid; LFD, low fat diet; HFD, high fat diet 
However, in the most predominant phospholipid class phosphatidylcholine (PC) increased saturated fatty acids (SFA) and decreased mono-unsaturated fatty acids (MUFA) were observed for the HF mice compared to the LF mice (Figure 2.6).

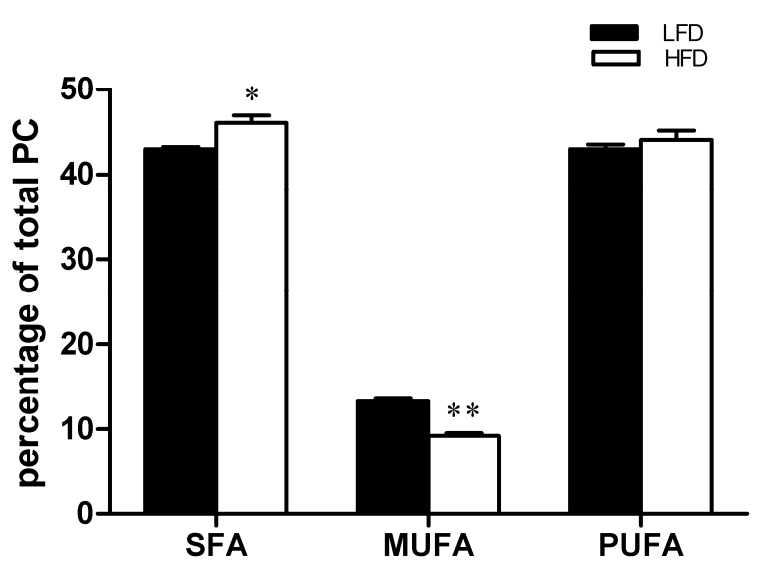

Figure 2.6 Relative percentages SFA, MUFA and PUFA in phosphatidylcholine. Values are means + S.E.M of three biological replicates, $*$ and $* *$ indicate a significant difference with $p<0.05$ and $p<$ 0.01 , respectively as obtained from independent samples $t$ test. LFD, low fat diet; HFD, high fat diet; MUFA, monounsaturated fatty acids; PUFA, poly-unsaturated fatty acids; SFA, saturated fatty acids

When looking in more detail, we found that 16:0 was significantly increased not only in PC, but also in the phosphatidylethanolamine (PE) lipid class. Furthermore, 18:0 was decreased in the lipid classes PC and lysophosphatidylcholine (LYPC). The MUFA 16:1n7 and 18:1n7 were decreased in LYPC, PE and PC, whereas 18:1n9 was decreased only in the phospholipid class PC (Table 2.4).

Table 2.4 Effect of 28-day HF diet on specific fatty acids per phospholipid class

\begin{tabular}{lllllll}
\hline & \multicolumn{2}{c}{ LYPC } & \multicolumn{2}{c}{ PC } & \multicolumn{2}{c}{ PE } \\
& \multicolumn{1}{c}{ LFD } & \multicolumn{1}{c}{ HFD } & \multicolumn{1}{c}{ LFD } & \multicolumn{1}{c}{ HFD } & \multicolumn{1}{c}{ LFD } & \multicolumn{1}{c}{ HFD } \\
\hline $16: 0$ & $37.6 \pm 2.2$ & $42.6 \pm 0.6$ & $36.9 \pm 0.5$ & $41.2 \pm 0.9^{*}$ & $9.3 \pm 0.5$ & $11.3 \pm 0.3^{*}$ \\
$18: 0$ & $20.5 \pm 0.6$ & $16.8 \pm 0.5^{*}$ & $5.1 \pm 0.3$ & $4.0 \pm 0.2^{*}$ & $23.3 \pm 1.7$ & $21.3 \pm 0.6$ \\
$16: 1 \mathrm{n} 7$ & $1.7 \pm 0.7$ & $1.0 \pm 0.18$ & $2.6 \pm 0.2$ & $1.3 \pm 0.2^{*}$ & $0.5 \pm 0.0$ & $0.3 \pm 0.0^{* *}$ \\
$18: 1 \mathrm{n} 7$ & $1.9 \pm 0.2$ & $1.3 \pm 0.1^{*}$ & $4.0 \pm 0.1$ & $2.4 \pm 0.3^{* *}$ & $0.9 \pm 0.1$ & $0.3 \pm 0.1^{*}$ \\
$18: 1 \mathrm{n} 9$ & $7.5 \pm 0.8$ & $8.0 \pm 0.4$ & $6.5 \pm 0.1$ & $5.3 \pm 0.1^{* *}$ & $4.2 \pm 0.6$ & $5.1 \pm 1.0$ \\
$18: 2 \mathrm{n} 6$ & $9.9 \pm 5.0$ & $4.7 \pm 0.3$ & $8.2 \pm 1.1$ & $6.4 \pm 1.1$ & $3.1 \pm 0.2$ & $2.7 \pm 0.2$ \\
$20: 4 n 6$ & $5.4 \pm 0.6$ & $5.2 \pm 0.3$ & $15.5 \pm 0.3$ & $15.4 \pm 9.9$ & $11.0 \pm 0.2$ & $10.3 \pm 0.3$ \\
\hline
\end{tabular}

Values are expressed as FA mole percent (moles of a FA as a percentage of total moles of fatty acid per lipid class) and are means \pm S.E.M. of three biological replicates, ${ }^{*}$ and ${ }^{* *}$ indicate significant differences with a $p<0.05$ and $p<0.01$, respectively as obtained from independent samples $t$ test. FA, fatty acids; LFD, low fat diet; HFD, high fat diet; LYPC, lysophosphatidylcholine; PC, phosphatidylcholine; PE, phosphatidylethanolamine 


\section{Discussion}

The increasing prevalence of the metabolic syndrome (MetS) in Western societies is caused by a combination of sedentary life-styles and an increased consumption of diets rich in SFA. Evidence from both animal and human studies indicates that lipid oversupply to skeletal muscle results in functional perturbations that eventually result in impaired insulin-stimulated glucose metabolism which is one of the characteristics of the MetS $(22,41,42)$. A better understanding of molecular mechanisms involved in the early onset of the MetS can contribute to the development of more effective intervention strategies. Therefore we set out to investigate the short-term effects of a HFD on the mouse muscle transcriptome by performing a genome-wide analysis of high fat diet-responsive genes combined with protein and lipid analyses. The short-term HFD resulted in a changed expression of genes involved in a variety of biological processes including morphogenesis, energy metabolism, lipogenesis, and immune function.

The skeletal muscle contains myofibers that differ in contractile function, mitochondrial content and metabolic properties. Slow-twitch (type I) fibers contain a high number of mitochondria and use oxidative metabolism as an energy source, whereas fast-twitch (type II) fibers generate energy mainly through glycolysis. The quadriceps muscle contains many type II fibers resulting in a low expression of the Tnni1 gene, which is a classical marker of type I fibers (16). The Short-term HFD resulted in enhanced expression of the Tnni1 gene and other markers for type I fibers, such as the Tnnt1, Tnnc1, Myl2 and Myh7 genes. In addition, the protein abundance of the myosin heavy chain, slow fiber type protein content was increased. Although the adult skeletal muscle is known to have the capacity to adapt to functional demands including exercise, innervation, mechanical loading and hormones by a conversion of fiber type $(43,44)$, the link between a HFD and fiber type conversion is yet unknown. Our findings indicate that the HFD induces rapid morphological adaptations in the skeletal muscle of adult mice by inducing a conversion to a more type I fiber phenotype via a transcriptional mechanism. This may result in a more oxidative character of the quadriceps muscle. Recently, it was shown that PGC1 $\alpha$ is a principal factor in regulating muscle fiber type determination $(16,17)$. Furthermore, both human and animal studies have associated type 2 diabetes and insulin resistance with reduced expression of the Ppargc1a gene and genes involved in OXPHOS in muscle tissue $(42,45,46)$. Although we showed that the short-term HFD increased expression of the Ppargc1a gene, the PGC1 $\alpha$ protein content was not changed. Despite this observation, protein analysis revealed a higher abundance of the OXPHOS complexes. This was also found on the mRNA level. Interestingly, the transcriptional up-regulation was much more pronounced on day 3 than on day 28. This observation indicates that over time OXPHOS gene expression tends to decrease while the protein levels are maintained. In view of recent studies $(42,45,46)$ 
we hypothesize that this trend will continue, gradually resulting in decreased protein levels which will result in a decreased oxidative capacity in the long run.

The HFD resulted in a suppression of lipogenic genes such as the Acaca, Acly, Elovl6, Fasn and Scd1 genes. This was supported by analysis of the FAS protein. A transcription factor involved in lipogenesis is sterol regulatory element binding protein 1 (Srebp1) (47-49). Srebp1 is strongly expressed in lipogenic tissues, such as adipose tissue and liver. Recent studies have shown that Srebp1 is also expressed in skeletal muscle $(50,51)$. Srebp1 is synthesized as an inactive precursor bound to the endoplasmatic reticulum (ER). Upon activation, the ER-bound Srebp1-precursor undergoes a cleavage followed by translocation to the nucleus $(47,48)$. Neither the abundance nor the processing of the Srebp1 protein showed diet-dependent differences. A diet-dependent effect on the nuclear translocation remains possible. Alternatively, down-regulation of lipogenic genes by other transcription factors can not be excluded.

Our study connects HF-feeding with the immune system of the skeletal muscle. Skeletal muscle cells can act as antigen presenting cells by expressing different major histocompatibility complex (MHC) molecules, thus making skeletal muscle cells active participants in the T-cell immune response $(52,53)$. It is known that fat can reduce several parameters of the immune system such as antigen presentation, resulting in suppression of immune function (54-57). Several studies have shown that activation of PPAR $\alpha$ results in reduction of the immune function (58-60). Since PPAR $\alpha$ was clearly activated in our study, as is evidenced by the consistent upregulation of a number of PPAR $\alpha$ target genes, we hypothesize that also in the skeletal muscle the fat-induced suppression of the immune system may be mediated by PPAR $\alpha$.

The major components of the mitochondrial membrane are phospholipids. Membranes permit the maintenance and regulation of ionic gradients, potential differences, and the passage of hormones, substrates, nutrients and intracellular signals, all of which are critical to normal cellular function $(7,26)$. As such, the fatty acyl composition and the degree of saturation of the membranes are of great importance for membrane fluidity and membrane permeability and thus for normal membrane function $(6,7,61)$. We observed that HF-feeding leads to a higher degree of saturation of phosphatidylcholine and phosphatidylethanolamine. Different studies have provided evidence linking obesity and insulin resistance to the FA composition of skeletal muscle membrane phospholipids $(26,27,62)$. We suggest that a more saturated phosphatidylcholine and a more saturated phosphatidylethanolamine, which are the main mitochondrial membrane phospholipids (63), will make the mitochondrial membrane more rigid and less responsive (21). This may gradually diminish the function of for example, the membrane bound OXPHOS subunits. In the long run, the disruption of the mitochondrial membrane may result in morphological aberrations like mitochondrial damage and reduced mitochondrial size, 
which has been observed in insulin resistance and type 2 diabetes patients $(46,64$, 65).

When looking for early molecular responses to the HF palm oil diet in the skeletal muscle of the mouse, we observed that short-term HF feeding resulted in a morphological adaptation by increasing genes and proteins which are markers for the more oxidative type I fibers. Simultaneously, our results point to a metabolic adaptation by increasing proteins involved in oxidative phosphorylation. We hypothesize that after early adaptation of the skeletal muscle a continued down-regulation of genes involved in oxidative phosphorylation will eventually result in decreased protein abundance and oxidative capacity. Together with increased saturation of mitochondrial membrane phospholipids this can result in a reduced mitochondrial function that has been observed in insulin resistance and type 2 diabetes. In conclusion, our results contribute to a better understanding of the molecular events underlying the early onset of the MS. This may benefit the development of more effective nutritional intervention strategies.

\section{Acknowledgements}

We would like to thank Mechteld Grootte Bromhaar and Shohreh Keshtkar Ghiasabadi for excellent technical assistance and Guido Hooiveld for helpful support with the Gene Ontology analysis and Gene set enrichment analysis. This study was funded by the Top Institute Food and Nutrition, with financial support by the Dutch government.

\section{References}

1. Carulli N. Metabolic syndrome--cardiovascular disease risk and more. Aliment Pharmacol Ther. 2005 Nov;22 Suppl 2:1-2.

2. Kahn R, Buse J, Ferrannini E, Stern M. The metabolic syndrome: time for a critical appraisal: joint statement from the American Diabetes Association and the European Association for the Study of Diabetes. Diabetes care. 2005 Sep;28(9):2289-304.

3. Grundy SM, Brewer HB, Jr., Cleeman JI, Smith SC, Jr., Lenfant C. Definition of metabolic syndrome: Report of the National Heart, Lung, and Blood Institute/American Heart Association conference on scientific issues related to definition. Circulation. 2004 Jan 27;109(3):433-8.

4. Zimmet P, Magliano D, Matsuzawa Y, Alberti G, Shaw J. The metabolic syndrome: a global public health problem and a new definition. J Atheroscler Thromb. 2005;12(6):295-300.

5. Eckel RH, Grundy SM, Zimmet PZ. The metabolic syndrome. Lancet. 2005 Apr 16-22;365(9468):141528.

6. Vessby B, Gustafsson IB, Tengblad S, Boberg M, Andersson A. Desaturation and elongation of Fatty acids and insulin action. Ann N Y Acad Sci. 2002 Jun;967:183-95.

7. Pan DA, Hulbert AJ, Storlien LH. Dietary fats, membrane phospholipids and obesity. The Journal of nutrition. 1994 Sep;124(9):1555-65. 
8. Pender C, Trentadue AR, Pories WJ, Dohm GL, Houmard JA, Youngren JF. Expression of genes regulating Malonyl-CoA in human skeletal muscle. J Cell Biochem. 2006 May 23.

9. Aas V, Rokling-Andersen M, Wensaas AJ, Thoresen GH, Kase ET, Rustan AC. Lipid metabolism in human skeletal muscle cells: effects of palmitate and chronic hyperglycaemia. Acta physiologica Scandinavica. 2005 Jan;183(1):31-41.

10. Koonen DP, Glatz JF, Bonen A, Luiken JJ. Long-chain fatty acid uptake and FAT/CD36 translocation in heart and skeletal muscle. Biochimica et biophysica acta. 2005 Oct 1;1736(3):163-80.

11. Rifai N, Merrill JR, Holly RG. Postprandial effect of a high fat meal on plasma lipid, lipoprotein cholesterol and apolipoprotein measurements. Ann Clin Biochem. 1990 Sep;27 ( Pt 5):489-93.

12. Cahova M, Vavrinkova H, Kazdova L. Glucose-fatty acid interaction in skeletal muscle and adipose tissue in insulin resistance. Physiological research / Academia Scientiarum Bohemoslovaca. 2007;56(1):1-15.

13. Randle PJ. Regulatory interactions between lipids and carbohydrates: the glucose fatty acid cycle after 35 years. Diabetes Metab Rev. 1998 Dec;14(4):263-83.

14. Knutti D, Kralli A. PGC-1, a versatile coactivator. Trends in endocrinology and metabolism: TEM. 2001 Oct;12(8):360-5.

15. Puigserver $\mathrm{P}$, Spiegelman BMP. Peroxisome proliferator-activated receptor-gamma coactivator 1 alpha (PGC-1 alpha): transcriptional coactivator and metabolic regulator. Endocrine reviews. 2003 Feb;24(1):78-90.

16. Lin J, Wu H, Tarr PT, Zhang CY, Wu Z, Boss O, et al. Transcriptional co-activator PGC-1 alpha drives the formation of slow-twitch muscle fibres. Nature. 2002 Aug 15;418(6899):797-801.

17. Puigserver $P$. Tissue-specific regulation of metabolic pathways through the transcriptional coactivator PGC1-alpha. International journal of obesity (2005). 2005 Mar;29 Suppl 1:S5-9.

18. Assimacopoulos-Jeannet $F$. Fat storage in pancreas and in insulin-sensitive tissues in pathogenesis of type 2 diabetes. Int J Obes Relat Metab Disord. 2004 Dec;28 Suppl 4:S53-7.

19. Ciapaite J, van Bezu J, van Eikenhorst G, Bakker SJ, Teerlink T, Diamant M, et al. Palmitate and oleate have distinct effects on the inflammatory phenotype of human endothelial cells. Biochimica et biophysica acta. $2007 \mathrm{Feb} ; 1771(2): 147-54$.

20. Gormsen LC, Jessen N, Gjedsted J, Gjedde S, Norrelund H, Lund S, et al. Dose-response effects of free fatty acids on glucose and lipid metabolism during somatostatin blockade of growth hormone and insulin in humans. The Journal of clinical endocrinology and metabolism. 2007 Mar 6.

21. Haag M, Dippenaar NG. Dietary fats, fatty acids and insulin resistance: short review of a multifaceted connection. Med Sci Monit. 2005 Dec;11(12):RA359-67.

22. Manco $M$, Calvani $M$, Mingrone $G$. Effects of dietary fatty acids on insulin sensitivity and secretion. Diabetes, obesity \& metabolism. 2004 Nov;6(6):402-13.

23. Gaster M, Rustan AC, Beck-Nielsen H. Differential utilization of saturated palmitate and unsaturated oleate: evidence from cultured myotubes. Diabetes. 2005 Mar;54(3):648-56.

24. Mingrone G, Rosa G, Greco AV, Manco M, Vega N, Nanni G, et al. Intramyocitic lipid accumulation and SREBP-1c expression are related to insulin resistance and cardiovascular risk in morbid obesity. Atherosclerosis. 2003 Sep;170(1):155-61.

25. Pinnamaneni SK, Southgate RJ, Febbraio MA, Watt MJ. Stearoyl CoA desaturase 1 is elevated in obesity but protects against fatty acid-induced skeletal muscle insulin resistance in vivo. Diabetologia. 2006;49:3027-37.

26. Pan DA, Lillioja S, Milner MR, Kriketos AD, Baur LA, Bogardus C, et al. Skeletal muscle membrane lipid composition is related to adiposity and insulin action. The Journal of clinical investigation. 1995 Dec;96(6):2802-8.

27. Vessby B, Tengblad S, Lithell $\mathrm{H}$. Insulin sensitivity is related to the fatty acid composition of serum lipids and skeletal muscle phospholipids in 70-year-old men. Diabetologia. 1994 Oct;37(10):1044-50.

28. Haugaard SB, Madsbad S, Hoy CE, Vaag A. Dietary intervention increases n-3 long-chain polyunsaturated fatty acids in skeletal muscle membrane phospholipids of obese subjects. Implications for insulin sensitivity. Clin Endocrinol (Oxf). 2006 Feb;64(2):169-78. 
29. Gentleman RC, Carey VJ, Bates DM, Bolstad B, Dettling M, Dudoit S, et al. Bioconductor: open software development for computational biology and bioinformatics. Genome biology. 2004;5(10):R80.

30. Dai M, Wang P, Boyd AD, Kostov G, Athey B, Jones EG, et al. Evolving gene/transcript definitions significantly alter the interpretation of GeneChip data. Nucleic Acids Res. 2005;33(20):e175.

31. Wu Z, Irizarry R, Gentleman R, Martinez-Murillo F, Spencer F. A model-based background adjustment for oligonucleotide expression arrays Journal of the American Statistical Association 2004;99(468):909-17.

32. Smyth GK. Linear models and empirical bayes methods for assessing differential expression in microarray experiments. Stat Appl Genet Mol Biol. 2004;3:Article3.

33. Lee HK, Braynen W, Keshav K, Pavlidis P. ErmineJ: tool for functional analysis of gene expression data sets. BMC Bioinformatics. 2005;6:269.

34. Subramanian A, Tamayo P, Mootha VK, Mukherjee S, Ebert BL, Gillette MA, et al. Gene set enrichment analysis: a knowledge-based approach for interpreting genome-wide expression profiles. Proceedings of the National Academy of Sciences of the United States of America. 2005 Oct 25;102(43):15545-50.

35. Dahlquist KD, Salomonis N, Vranizan K, Lawlor SC, Conklin BR. GenMAPP, a new tool for viewing and analyzing microarray data on biological pathways. Nat Genet. 2002 May;31(1):19-20.

36. Kanehisa M, Goto S. KEGG: kyoto encyclopedia of genes and genomes. Nucleic Acids Res. 2000 Jan 1;28(1):27-30.

37. Hellemans J, Mortier G, Van Steen K, De Paepe A, Speleman F, Vandesompele J. qBase relative quantification software for management and automated analysis of real-time quantitative PCR data, in preparation.

38. Vandesompele J, De Preter K, Pattyn F, Poppe B, Van Roy N, De Paepe A, et al. Accurate normalization of real-time quantitative RT-PCR data by geometric averaging of multiple internal control genes. Genome biology. 2002 Jun 18;3(7):RESEARCH0034.

39. Folch J, Lees M, Sloane Stanley GH. A simple method for the isolation and purification of total lipides from animal tissues. The Journal of biological chemistry. 1957 May;226(1):497-509.

40. Watkins SM, Lin TY, Davis RM, Ching JR, DePeters EJ, Halpern GM, et al. Unique phospholipid metabolism in mouse heart in response to dietary docosahexaenoic or alpha-linolenic acids. Lipids. 2001 Mar;36(3):247-54.

41. Savage DB, Petersen KF, Shulman GI. Disordered lipid metabolism and the pathogenesis of insulin resistance. Physiological reviews. 2007 Apr;87(2):507-20.

42. Koves TR, Li P, An J, Akimoto T, Slentz D, Ilkayeva O, et al. Peroxisome proliferator-activated receptor-gamma co-activator 1alpha-mediated metabolic remodeling of skeletal myocytes mimics exercise training and reverses lipid-induced mitochondrial inefficiency. The Journal of biological chemistry. 2005 Sep 30;280(39):33588-98.

43. Zebedin E, Sandtner W, Galler S, Szendroedi J, Just H, Todt H, et al. Fiber type conversion alters inactivation of voltage-dependent sodium currents in murine $\mathrm{C} 2 \mathrm{C} 12$ skeletal muscle cells. Am J Physiol Cell Physiol. 2004 Aug;287(2):C270-80.

44. Pette D, Staron RS. Transitions of muscle fiber phenotypic profiles. Histochemistry and cell biology. 2001 May;115(5):359-72.

45. Patti ME, Butte AJ, Crunkhorn S, Cusi K, Berria R, Kashyap S, et al. Coordinated reduction of genes of oxidative metabolism in humans with insulin resistance and diabetes: Potential role of PGC1 and NRF1. Proceedings of the National Academy of Sciences of the United States of America. 2003 Jul 8;100(14):8466-71.

46. Sparks LM, Xie H, Koza RA, Mynatt R, Hulver MW, Bray GA, et al. A high-fat diet coordinately downregulates genes required for mitochondrial oxidative phosphorylation in skeletal muscle. Diabetes. 2005 Jul;54(7):1926-33.

47. Horton JD, Goldstein JL, Brown MS. SREBPs: activators of the complete program of cholesterol and fatty acid synthesis in the liver. The Journal of clinical investigation. 2002 May;109(9):1125-31. 
48. Eberle D, Hegarty B, Bossard P, Ferre P, Foufelle F. SREBP transcription factors: master regulators of lipid homeostasis. Biochimie. 2004 Nov;86(11):839-48.

49. Horton JD, Shah NA, Warrington JA, Anderson NN, Park SW, Brown MS, et al. Combined analysis of oligonucleotide microarray data from transgenic and knockout mice identifies direct SREBP target genes. Proceedings of the National Academy of Sciences of the United States of America. 2003 Oct 14;100(21):12027-32.

50. Commerford SR, Peng L, Dube JJ, O'Doherty RM. In vivo regulation of SREBP-1c in skeletal muscle: effects of nutritional status, glucose, insulin, and leptin. Am J Physiol Regul Integr Comp Physiol. 2004 Jul;287(1):R218-27.

51. Lelliott C, Vidal-Puig AJ. Lipotoxicity, an imbalance between lipogenesis de novo and fatty acid oxidation. Int J Obes Relat Metab Disord. 2004 Dec;28 Suppl 4:S22-8.

52. Nagaraju K. Immunological capabilities of skeletal muscle cells. Acta physiologica Scandinavica. 2001 Mar;171(3):215-23.

53. Wiendl H, Hohlfeld R, Kieseier BC. Immunobiology of muscle: advances in understanding an immunological microenvironment. Trends Immunol. 2005 Jul;26(7):373-80.

54. de Pablo MA, Alvarez de Cienfuegos G. Modulatory effects of dietary lipids on immune system functions. Immunol Cell Biol. 2000 Feb;78(1):31-9.

55. Hara Y, Miura S, Komoto S, Inamura T, Koseki S, Watanabe C, et al. Exposure to fatty acids modulates interferon production by intraepithelial lymphocytes. Immunol Lett. 2003 Apr 3;86(2):139-48.

56. Venkatraman JT, Pendergast DR. Effect of dietary intake on immune function in athletes. Sports Med. 2002;32(5):323-37.

57. Verwaerde C, Delanoye A, Macia L, Tailleux A, Wolowczuk I. Influence of high-fat feeding on both naive and antigen-experienced T-cell immune response in D010.11 mice. Scand J Immunol. 2006 Nov;64(5):457-66.

58. Bunger M, van den Bosch HM, van der Meijde J, Kersten S, Hooiveld GJ, Muller M. Genome-wide analysis of PPAR\{alpha\} activation in murine small intestine. Physiol Genomics. 2007 Apr 10.

59. Jump DB, Clarke SD. Regulation of gene expression by dietary fat. Annual review of nutrition. 1999;19:63-90.

60. Nunn AV, Bell J, Barter P. The integration of lipid-sensing and anti-inflammatory effects: how the PPARs play a role in metabolic balance. Nucl Recept. 2007 May 25;5(1):1.

61. Boumann HA, Gubbens J, Koorengevel MC, Oh CS, Martin CE, Heck AJ, et al. Depletion of phosphatidylcholine in yeast induces shortening and increased saturation of the lipid acyl chains: evidence for regulation of intrinsic membrane curvature in a eukaryote. Mol Biol Cell. 2006 Feb;17(2):1006-17.

62. Borkman M, Storlien LH, Pan DA, Jenkins AB, Chisholm DJ, Campbell LV. The relation between insulin sensitivity and the fatty-acid composition of skeletal-muscle phospholipids. N Engl J Med. 1993 Jan 28;328(4):238-44.

63. Senault C, Yazbeck J, Goubern M, Portet R, Vincent M, Gallay J. Relation between membrane phospholipid composition, fluidity and function in mitochondria of rat brown adipose tissue. Effect of thermal adaptation and essential fatty acid deficiency. Biochimica et biophysica acta. 1990 Apr 13;1023(2):283-9.

64. Schrauwen-Hinderling VB, Kooi ME, Hesselink MK, Jeneson JA, Backes WH, van Echteld CJ, et al. Impaired in vivo mitochondrial function but similar intramyocellular lipid content in patients with type 2 diabetes mellitus and BMI-matched control subjects. Diabetologia. 2007 Jan;50(1):113-20.

65. Kelley DE, He J, Menshikova EV, Ritov VB. Dysfunction of mitochondria in human skeletal muscle in type 2 diabetes. Diabetes. 2002 Oct;51(10):2944-50. 


\section{CHAPTER 3 \\ An 8-week high fat diet induces obesity and insulin resistance with small changes in the muscle transcriptome of $\mathrm{C} 57 \mathrm{BL} / 6 \mathrm{~J}$}

mice

Janneke de Wilde, Egbert Smit, Ronny Mohren, Mark V. Boekschoten, Philip de Groot, Sjoerd A.A. van den Berg, Silvia Bijland, Peter J. Voshol, Ko Willems van Dijk, Nicole W.J. de Wit, Annelies Bunschoten, Gert Schaart, Martijn F.M. Hulshof and Edwin C.M. Mariman

The Journal of Nutrigenetics and Nutrigenomics. 2010; 2(6): 280-291 


\begin{abstract}
The skeletal muscle is responsible for the majority of insulin-stimulated glucose uptake and metabolism. Therefore, it plays an important role in development of insulin resistance, one of the characteristics of the metabolic syndrome. As the prevalence of the metabolic syndrome is increasing there is an urgent need for more effective intervention strategies. C57BL/6J mice were fed an 8-week low fat diet (10 kcal\%; LFD) or high fat diet (45 kcal\%; HFD). Microarray analysis was performed by using two comparisons: (1) 8-week HFD transcriptome versus 8-week LFD transcriptome and (2) transcriptome of mice sacrificed at the start of the intervention versus 8-week LFD transcriptome and 8-week HFD transcriptome, respectively. An 8-week HFD induced obesity and impaired insulin sensitivity, HFD-responsive changes in the muscle transcriptome were relatively small $(<1.3$-fold). In fact, 8weeks of aging induced more pronounced changes than the HFD. One comparison revealed the transcriptional down-regulation of the MAPK cascade, whereas both comparisons showed the up-regulation of FA oxidation demonstrating that the two comparison strategies are confirmative as well as complementary. We suggest using complementary analysis strategies in the genome-wide search for gene expression changes induced by mild interventions, such as an HFD.
\end{abstract}




\section{Introduction}

The metabolic syndrome (MetS) is a multi-component metabolic disorder characterized by central obesity, high blood pressure, increased plasma triglycerides, decreased plasma HDL-cholesterol and insulin resistance and is associated with an increased risk for type 2 diabetes mellitus (T2DM) and cardiovascular diseases $(1,2)$. The increasing prevalence of the MetS is caused by a combination of lifestyle factors such as nutrition and limited physical activity, which are known to contribute to the pathogenesis of the MetS. While the etiology of the MetS is complex and still not fully elucidated, central obesity and insulin resistance are considered to be potential causative factors. Additionally, obesity is considered as the principal cause of insulin resistance $(3,4)$. Because the skeletal muscle is the major site of insulin-stimulated glucose metabolism, it might play an important role in the development of insulin resistance and the MetS. Two important ways by which central obesity can impair skeletal muscle insulin-stimulated glucose metabolism are by the ectopic storage of lipids and by alterations in the secretion of adipokines (5).

When adipose tissue expands, as in obesity, plasma levels of fatty acids (FA) and triacylglycerol (TAG) become elevated. This will lead to an increased flux of TAG and FA into the skeletal muscle (6). Negative correlations between high levels of intramuscular TAG and insulin sensitivity have been observed in both obese and T2DM subjects (7-10). Paradoxically, endurance training showed to improve insulin sensitivity together with increased levels of intramuscular TAG $(11,12)$. Therefore, it has been proposed that not TAG, but lipid intermediates such as long-chain fatty acyl CoAs, diacylglycerol and ceramides may act as signaling molecules interrupting insulin signaling and glucose metabolism which eventually results in insulin resistance $(13,14)$. In addition to the role of energy storage, adipose tissue functions as an endocrine organ that can respond to metabolic signals by secreting adipokines. These adipokines have different systemic effects including modulating energy metabolism in the skeletal muscle. Enlargement of adipose tissue and especially visceral fat depots will lead to alterations in the secretion of these adipokines. For example, increased plasma leptin levels and decreased plasma adiponectin levels are reported in both obese and insulin resistant subjects. As such, alterations in the secretion of these adipokines are linked to the impairment of insulin-stimulated glucose metabolism (15-17).

In the present study we performed microarray analysis of the skeletal muscle to get more insight in molecular mechanisms underlying the development of diet-induced obesity and insulin resistance in $\mathrm{C} 57 \mathrm{BL} / 6 \mathrm{~J}$ mice. To find high fat diet (HFD)responsive changes we compared the muscle transcriptome of mice fed an 8-week HFD with the muscle transcriptome of mice fed an 8-week low fat diet (LFD). Biological processes in the skeletal muscle affected by the HFD were assessed by the analyses of predefined gene sets based on Gene Ontology, biochemical, metabolic and 
signaling pathways. As nutritional interventions induce subtle changes in gene expression $(18,19)$, we used a second comparison strategy in which we compared the 8-week HFD muscle transcriptome as well as the 8-week LFD muscle transcriptome with the muscle transcriptome of mice sacrificed at the start of the intervention. By paralleling the outcomes of these comparisons we could find overlapping changes, suggesting that these changes are related to aging rather than the HFD, as well as HFD-specific responsive changes. Finally, we evaluated the results of the two comparison strategies demonstrating their confirmative as well as complementary use.

\section{Methods}

\section{Animals and diet}

Male C57BL/6J mice were obtained from Harlan (Horst, The Netherlands). At 9 weeks of age mice were switched to a run-in diet consisting of a LFD (10 kcal\% fat) for 3 weeks. Following the run-in period mice were randomly assigned to the LFD or the HFD ( $45 \mathrm{kcal} \%$ fat) for 8 weeks. Both diets contained fat in the form of palm oil (based on D12450B and D12451; Research Diet Services, Wijk bij Duurstede, The Netherlands) as described previously (20). Study 1: At the start of the intervention and after 8 weeks, mice ( $n=10$ per diet) were fasted for 6 hours and anaesthetized with a mixture of isofluorane (1.5\%), nitrous oxide (70\%) and oxygen (30\%). Blood was collected by orbital puncture, after which the mice were killed by cervical dislocation. The quadriceps muscle was dissected, snap-frozen in liquid nitrogen and stored at $-80^{\circ} \mathrm{C}$ until further analysis. Study 2 : After an overnight-fast, a hyperinsulinemic euglycemic clamp was performed to measure whole-body insulin resistance and tissue-specific insulin stimulated glucose uptake ( $n=5$ per diet) after 8 weeks of diet intervention. The animal studies were approved by the Local Committee for Care and Use of Laboratory Animals at Wageningen University.

\section{Assessment of body composition}

The percentage of body fat, lean body mass and total fat mass were measured with DEXA using the Lunar PIXImus densitometer (GE Lunar, Madison, USA) at the start of the intervention, after 4 weeks and after 8 weeks of the diet intervention. Prior to use, the Lunar PIXImus densitometer was calibrated according to the manufacturer's instructions. Mice were anaesthetized as described and measurements were performed on the whole body excluding the head area. 


\section{Plasma insulin, leptin and adiponectin measurements}

Blood was collected in EDTA-containing tubes (Sarstedt AG\&CO, Nümbrecht, Germany). Plasma was obtained after centrifugation at $11000 \mathrm{~g}$ for $10 \mathrm{~min}$ and stored at $-80^{\circ} \mathrm{C}$ for further analysis. Plasma insulin and leptin were measured simultaneously with the mouse serum adipokine Lincoplex kit (Linco Research, Nuclilab, Ede, The Netherlands) using the Luminex100 system (Applied Cytometry Systems, Sheffield, United Kingdom) with Starstation software (Applied Cytometry Systems) as described by van Schothorst et al. (21). Plasma adiponectin was measured with the mouse Adiponectin/Acrp30 Quantikine ELISA Kit (R\&D systems, Minneapolis, USA).

\section{Hyperinsulinemic euglycemic clamp}

The hyperinsulinemic euglycemic clamp, preparation of tissue homogenates, analytical procedures and calculations for stimulation whole-body glucose uptake, inhibition hepatic glucose production and tissue-specific glucose uptake were performed as described previously (22-24). Inhibition of lipolysis was calculated as the ratio between the plasma FA levels after and before the hyperinsulinemic euglycemic clamp.

\section{Affymetrix microarray analysis}

Total RNA from the complete quadriceps muscle was isolated and Affymetrix GeneChip ${ }^{\circledR}$ Mouse Genome 4302.0 arrays were used as described earlier with minor adaptations (25). Briefly, only probe sets with an average signal intensity $>20$, across all arrays, were selected for further analysis. Since nutritional interventions induce subtle changes in gene expression $(18,19)$ we used a fold change $>1.3$ to find differentially expressed genes. To determine the level of significance we used an FDR $<0.05$ which is used to correct for multiple-testing (26). Only genes that satisfied both criteria were considered as significantly differentially expressed. Changes in gene expression were related to functional changes by using ErmineJ (FDR < 0.001) (27) and Gene set enrichment analysis (GSEA; FDR < 0.05) (28). For the microarray analyses in this study we used two different comparison strategies; Strategy 1: To identify HFD-responsive genes we compared the muscle transcriptome of 8-week HFD mice with the muscle transcriptome of the 8-week LFD mice; Strategy 2: Comparison of the muscle transcriptome of mice sacrificed at the start of the intervention (start transcriptome) with the muscle transcriptome of 8-week LFD mice as well as the muscle transcriptome of 8-week HFD mice. Changes in gene expression, overrepresented GO classes and regulated gene sets that were only present in the 8-week HFD muscle transcriptome were considered as HFD-specific changes, whereas changes present in both the 8-week HFD muscle transcriptome 
and the 8-week LFD muscle transcriptome were considered as changes related to aging. Array data have been submitted to the Gene Expression Omnibus, GSE17576.

\section{Verification of microarray-detected changes}

To find verify micro-array detected changes we measured enzyme activity levels or performed Western blotting to determine protein expression.

\section{Enzyme activity measurements}

Activity levels of the enzymes $\beta$-hydroxyacyl-CoA dehydrogenase (HAD; $\beta$-oxidation) and citrate synthase (CS; TCA cycle) were determined in quadriceps muscle homogenates $(n=7)$ as described by Den Hoed et al (29).

\section{Western blotting}

To determine if microarray-detected changes in the skeletal muscle could be translated to the protein level we performed Western blotting as described earlier (25). Briefly, total protein was separated by SDSPAGE on $4-12 \%$ Bis-Tris Criterion gels at $150 \mathrm{~V}$ and transferred to a polyvinylidene fluoride membrane for $90 \mathrm{~min}$ at $100 \mathrm{~V}$. Blocking steps were performed in TBST supplemented with $5 \%$ nonfat dry milk (NFDM). Antibody (Ab) incubation steps of the membrane were performed in TBST supplemented with 5\% BSA or 5\% NFDM. Membranes were incubated overnight with an anti-mouse monoclonal OXPHOS Ab cocktail (1:2000; Mitosciences, Eugene, OR), a polyclonal p38 Ab (1:1000; Cell Signaling, Danvers, USA) or a monoclonal phospho-p38 MAPK (Thr180/Tyr182) Ab (1:1000; Cell Signaling) or a GAPDH Ab (1:3000; Cell Signaling) at $4^{\circ} \mathrm{C}$. After washing with TBST, membranes were incubated with a HRP-conjugated secondary $\mathrm{Ab}$ and signals were detected by ECL using Pierce reagents. Films were scanned with a GS800 densitometer (Bio-Rad) and signals were quantified with Quantity One software (Bio-Rad). As the Gapdh protein was stably expressed under the applied conditions, we used the Gapdh signal to calculate the relative protein abundance

\section{Statistical analyses}

All data are expressed as means \pm SE. Microarray data were analyzed as described above. All further statistical analyses were performed using Prism software (GraphPad Software, San Diego, CA, USA). An unpaired $t$ test was used to compare differences between the LFD mice and the HFD mice. As data for whole-body insulin resistance and tissue-specific glucose uptake were not normally distributed we used the non-parametric Mann Whitney test to find differences. Repeated measures ANOVA was used to find out if body composition of LFD mice and HFD mice changes during the diet intervention. When significant differences were found, a Tukey's 
post hoc test was used to determine the exact location of the difference. One-way ANOVA was used to compare the protein levels of p38 MAPK, phospho-p38 MAPK and the ratio phospho-p38 MAPK versus $\mathrm{p} 38$ between mice sacrificed the start of the intervention, LFD mice and HFD mice. When significant differences were found, a Tukey's post hoc test was used to determine the exact location of the difference. $P$ values $<0.05$ were considered as statistically significant.

\section{Results}

\section{HFD mice develop obesity}

After a 3 weeks run-in period, mice were put on an LFD or HFD for 8 weeks. After 3 weeks, HFD mice had a significantly higher body mass than the LFD mice (Figure 3.1).

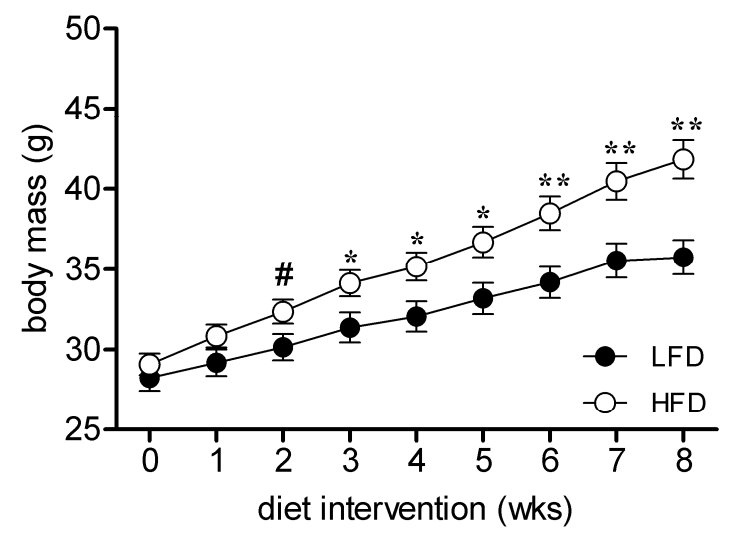

Figure 3.1 Body mass development of LFD mice and HFD mice during 8 weeks of diet intervention. Values are means $\pm \mathrm{SE}(\mathrm{n}=10), \#, *, * *$ and $* * *$ indicate differences with $p<$ $0.10, p<0.05, p<0.01$ and $p<$ 0.001 , respectively as obtained by using an unpaired $t$ test. LFD; low fat diet and HFD; high fat diet.

Dual-energy X-ray absorptiometry (DEXA) was used to examine differences in body composition throughout the diet intervention. During the first 4 weeks, both the LFD mice and the HFD mice significantly gained lean body mass (LBM) (LFD: +1.6 grams; HFD: +2.4 grams). From the fourth week onwards only the LFD mice significantly gained LBM (LFD: +0.8 grams). No significant differences in LBM between the LFD mice and the HFD mice were observed. Both the LFD mice and the HFD mice increased fat mass during the diet intervention. In this case, the HFD mice accumulated significantly more fat mass than the LFD mice (Table 3.1). 
Table 3.1 Body composition of LFD mice and HFD mice during the diet intervention

\begin{tabular}{|c|c|c|c|c|c|}
\hline \multicolumn{6}{|c|}{ Diet intervention } \\
\hline & \multirow[t]{2}{*}{0 weeks } & \multicolumn{2}{|c|}{4 weeks } & \multicolumn{2}{|c|}{8 weeks } \\
\hline & & LFD & HFD & LFD & HFD \\
\hline TFM (g) & $6.8 \pm 0.3$ & $9.8 \pm 0.6^{\text {SSS }}$ & $12.4 \pm 0.6^{* * ; \$ S \$}$ & $14.5 \pm 0.8^{\text {SSS }}$ & $20.1 \pm 0.9^{* * * ; \$ S S}$ \\
\hline LBM (g) & $22.7 \pm 0.4$ & $24.3 \pm 0.5^{\$ \$ \$}$ & $25.1 \pm 0.6^{\$}$ & $25.1 \pm 0.6^{\$}$ & $25.8 \pm 0.9$ \\
\hline fat (\%) & $23.0 \pm 0.7$ & $28.4 \pm 1.2^{\$ \$ \$}$ & $36.3 \pm 1.1^{* *} ; \$ \$ \$$ & $33.0 \pm 1.1^{\$ \$ \$}$ & $44.0 \pm 0.9^{* * * ; \$ \$ \$}$ \\
\hline
\end{tabular}

Body composition was measured by DEXA scanning at the start, after 4 weeks and after 8 weeks of the diet intervention. Values are means \pm SE (week $0: n=20$ and week 4-8: $n=10$ ). ${ }^{* *}$ and $* * *$ indicate significant differences between LFD mice and HFD mice with $p<0.01$ and $p<0.001$ as obtained with an unpaired t test. $\$$ and $\$ \$ \$$ indicate significant differences between time points $(0$ weeks vs. 4 weeks and 4 weeks vs. 8 weeks) with $p<0.05$ and $p<0.001$ obtained with repeated measures ANOVA. LFD; low fat diet; HFD; high fat diet; LBM, lean body mass; TFM, total fat mass.

\section{Plasma adiponectin, insulin and leptin levels}

Table 3.2 shows that at 8 weeks of diet intervention, adiponectin plasma levels were significantly lower in HFD mice than in LFD mice. Leptin levels were significantly higher in the HFD mice in comparison with the LFD mice. The difference in fat accumulation strongly correlated with plasma leptin levels (Pearson correlation = $0.713 ; p<0.001 ; 95 \%$ confidence interval: 0.39-0.88). Furthermore, we observed higher plasma insulin levels in the HFD mice than in the LFD mice.

Table 3.2 Plasma adiponectin, insulin and leptin levels in 8-week LFD mice and 8-week HFD mice

\begin{tabular}{lcc}
\hline & LFD & HFD \\
\hline adiponectin $(\mu \mathrm{g} / \mathrm{ml})$ & $5.7 \pm 0.1$ & $5.1 \pm 0.2^{*}$ \\
leptin $(\mathrm{ng} / \mathrm{ml})$ & $18.4 \pm 3.0$ & $37.4 \pm 5.8^{* *}$ \\
insulin $(\mathrm{ng} / \mathrm{ml})$ & $0.9 \pm 0.1$ & $1.3 \pm 0.2^{*}$ \\
\hline
\end{tabular}

Values are means $\pm \mathrm{SE}(\mathrm{n}=10)$ and ${ }^{*}$ and $* *$ indicate significant differences with $p \leq 0.05$ and $p<0.01$ obtained with an unpaired t test. LFD; low fat diet and HFD; high fat diet.

\section{An 8-week HFD induces insulin resistance}

After 8 weeks of diet intervention, whole-body insulin resistance was measured with a hyperinsulinemic euglycemic clamp. Whereas in the LFD mice whole-body glucose utilization increased by $50 \%$ after insulin infusion, in the HFD mice wholebody glucose utilization remained unaffected $(p=0.06)$. Insulin-induced inhibition of hepatic glucose production was not different between LFD mice and HFD mice, indicating that the liver was still insulin sensitive in HFD mice. A clear tendency towards decreased inhibition of lypolysis by insulin was observed in the HFD mice ( $p=$ 0.06), indicating insulin resistance of adipose tissue (Figure 3.2). Together these results point to peripheral insulin resistance. 


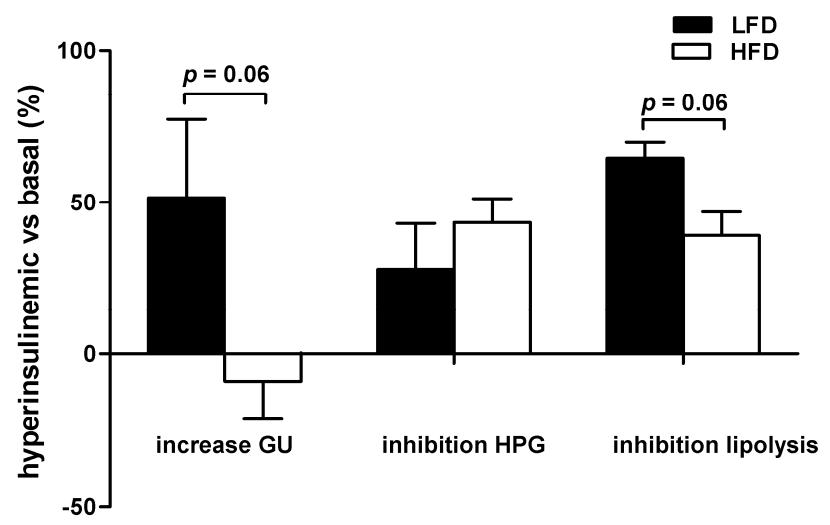

Figure 3.2 Increase of GU and inhibition of HPG and lypolysis after hyperinsulinemic conditions in LFD mice and HFD mice. Values are means $\pm S E(n=5)$ and $p$ values were obtained by using a Mann Withney test. GU; whole-body glucose utilization, HPG; hepatic glucose production, LFD; low fat diet and HFD; high fat diet

Tissue-specific glucose uptake was determined under hyperinsulinemic euglycemic conditions after a bolus of 2-deoxy-D-(3H) glucose. Glucose uptake was significantly lower in the visceral fat depots of the HFD mice as compared with the LFD mice. Glucose uptake was also lower in heart and skeletal muscle, however, this was not statistically significant (Figure 3.3).

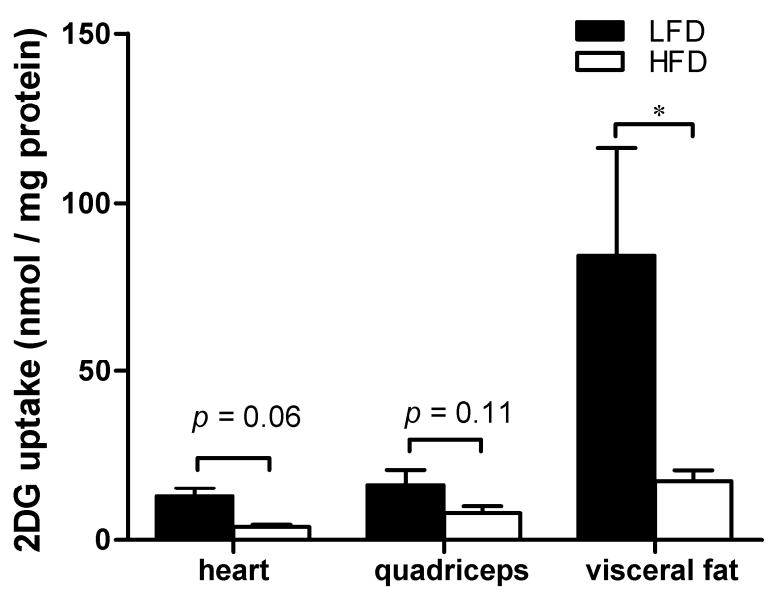

Figure 3.3 Tissue-specific glucose uptake in heart, quadriceps and visceral fat depots of LFD mice and HFD mice. Values are means $\pm S E(n=5)$ and * indicates a significant difference with $p<0.05$ as obtained using a Mann Withney test. LFD; low fat diet and HFD; high fat diet.

\section{Microarray analysis}

We showed that an 8-week HFD induces obesity, insulin resistance and disturbed plasma levels of adiponectin, insulin and leptin in C57BL/6J mice. To get more insight in molecular mechanisms underlying the development of diet-induced obesity and insulin resistance we performed microarray analysis of the skeletal muscle. To find HFD-responsive changes we compared the muscle transcriptome of mice fed an 8-week HFD with the muscle transcriptome of mice fed an 8-week LFD. Since nutri- 
tional interventions induce subtle changes in gene expression $(18,19)$, we used a second comparison strategy in which we compared the 8-week HFD muscle transcriptome as well as the 8-week LFD muscle transcriptome with the muscle transcriptome of mice sacrificed at the start of the intervention (start transcriptome). Regarding strategy 2, changes that were only present in the 8-week HFD muscle transcriptome were considered as HFD-specific changes, whereas changes that were found to be overlapping between the 8-week LFD muscle transcriptome and the 8week HFD muscle transcriptome were considered to be related to aging. To identify differentially expressed genes we used a fold change $>1.3$ and an FDR $<0.05$. ErmineJ was used to find overrepresented GO classes (FDR $<0.001$ ) and GSEA was applied to find regulated cellular processes (FDR $<0.05)$.

Fatty acid oxidation is the only responsive pathway in HFD mice as compared with LFD mice

Comparing the 8-week HFD muscle transcriptome with 8-week LFD muscle transcriptome by using the criteria of a fold change $>1.3$ and a FDR $<0.05$ we found no differentially expressed genes. Thus, an 8-week HFD induced changes in gene expression level that are relatively small. ErmineJ showed that only three GO classes, i.e., cytokine production (GO: 0001816), regulation of cellular biosynthetic process (GO: 0031326) and steroid metabolic process (GO: 0008202) were overrepresented in the 8-week HFD muscle transcriptome. By using GSEA we found that seven gene sets were up-regulated in the 8-week HFD transcriptome. Of these seven upregulated gene sets we could relate five gene sets to FA oxidation. The only gene set that was down-regulated was named RNA polymerase (Table 3.3).

Table 3.3 Changed gene sets in HFD transcriptome as compared with the LFD transcriptome

\begin{tabular}{|c|c|c|c|c|}
\hline & $\mathrm{N}$ & ES & NES & FDR \\
\hline \multicolumn{5}{|c|}{ Up-regulated cellular processes } \\
\hline mitochondrial fatty acid oxidation $^{1}$ & 29 & 0.72 & 2.36 & $<0.001$ \\
\hline Ecm receptor interaction ${ }^{2}$ & 80 & 0.51 & 2.11 & 0.006 \\
\hline Fatty acid beta oxidation meta ${ }^{3}$ & 34 & 0.59 & 2.06 & 0.008 \\
\hline Mitochondrial fatty acid beta oxidation ${ }^{3}$ & 15 & 0.71 & 2.02 & 0.009 \\
\hline Tissues blood and lymph $1^{3}$ & 32 & 0.60 & 2.02 & 0.008 \\
\hline Fatty acid beta oxidation $^{3}$ & 29 & 0.60 & 1.95 & 0.012 \\
\hline Fatty acid metabolism ${ }^{2}$ & 36 & 0.53 & 1.84 & 0.041 \\
\hline \multicolumn{5}{|c|}{ Down-regulated cellular processes } \\
\hline RNA polymerase ${ }^{2}$ & 20 & -0.70 & -2.26 & 0.001 \\
\hline
\end{tabular}

GSEA was applied to identify up-regulated and down-regulated processes after an 8-week HFD. Presented are regulated processes with an FDR $<0.05$. An FDR was calculated to adjust for multiple hypotheses testing. Sources of the gene sets: ${ }^{1} \mathrm{SK}$ manual, ${ }^{2} \mathrm{KEGG},{ }^{3} \mathrm{GENMAPP} . \mathrm{N}$, number of genes; $E S$, enrichment score for the gene set that reflects the degree to which a gene set is overrepresented at the top or bottom of the ranked list; NES, normalized enrichment score, i.e., the normalized ES to account for the size of the gene set. LFD; low fat diet and HFD; high fat diet. 
Descriptors for cell-cell interaction and development are regulated in muscle of both 8-week LFD mice and 8-week HFD mice, whereas MAPK cascade and FA oxidation are only regulated in 8-week HFD mice

When we compared the 8-week LFD muscle transcriptome to the start transcriptome, 72 genes were identified as differentially expressed (fold change $>1.3$ and FDR < 0.05). ErmineJ showed that $20 \mathrm{GO}$ classes were overrepresented in the 8week LFD muscle transcriptome. This list contained descriptors for development, signaling and cell-cell interaction (Table 3.4). GSEA revealed that only two gene sets were up-regulated in the 8-week LFD muscle transcriptome. Nine gene sets were down-regulated, including four genes sets corresponding to cell-cell interaction and two gene sets named "Tissue blood and lymph" (Table 3.5).

Table 3.4 Overrepresented Gene Ontology classes in the LFD transcriptome and the HFD transcriptome as compared with the start transcriptome

\begin{tabular}{|c|c|c|c|c|c|c|}
\hline \multirow[b]{3}{*}{ GO ID } & \multirow[b]{3}{*}{ GO class } & \multirow[b]{3}{*}{$\mathrm{N}$} & \multicolumn{2}{|c|}{ 8- week LFD } & \multicolumn{2}{|c|}{ 8-week HFD } \\
\hline & & & Raw & & Raw & \\
\hline & & & Score & FDR & Score & FDR \\
\hline GO:0030199 & collagen fibril organization & 14 & 2.03 & $1.2 \mathrm{E}-10$ & & \\
\hline GO:0006817 & phosphate transport & 61 & 1.53 & $1.5 \mathrm{E}-10$ & 1.08 & $7.48 \mathrm{E}-11$ \\
\hline GO:0030111 & $\begin{array}{l}\text { regulation of Wnt receptor } \\
\text { signaling pathway }\end{array}$ & 19 & 1.22 & $8.0 \mathrm{E}-04$ & & \\
\hline GO:0030198 & $\begin{array}{l}\text { extracellular matrix organization } \\
\text { and biogenesis }\end{array}$ & 50 & 1.21 & $2.0 \mathrm{E}-10$ & 0.85 & $8.54 \mathrm{E}-11$ \\
\hline GO:0043062 & $\begin{array}{l}\text { extracellular structure organiza- } \\
\text { tion and biogenesis }\end{array}$ & 85 & 0.94 & $2.4 \mathrm{E}-10$ & 0.77 & $1.09 \mathrm{E}-10$ \\
\hline GO:0007160 & cell-matrix adhesion & 55 & 0.85 & $4.0 \mathrm{E}-10$ & & \\
\hline GO:0031589 & cell-substrate adhesion & 59 & 0.81 & $1.2 \mathrm{E}-09$ & & \\
\hline GO:0042060 & wound healing & 72 & 0.80 & 1.7E-10 & & \\
\hline GO:0009968 & $\begin{array}{l}\text { negative regulation of signal } \\
\text { transduction }\end{array}$ & 81 & 0.78 & $4.6 \mathrm{E}-04$ & & \\
\hline GO:0016055 & Wnt receptor signaling pathway & 107 & 0.75 & $1.3 \mathrm{E}-10$ & 0.66 & $2.49 \mathrm{E}-04$ \\
\hline GO:0008361 & regulation of cell size & 91 & 0.74 & 4.3E-04 & & \\
\hline GO:0007229 & $\begin{array}{l}\text { integrin-mediated signaling } \\
\text { pathway }\end{array}$ & 74 & 0.73 & $9.0 \mathrm{E}-04$ & & \\
\hline GO:0016049 & cell growth & 79 & 0.72 & $5.0 \mathrm{E}-04$ & & \\
\hline GO:0021700 & developmental maturation & 79 & 0.72 & $5.4 \mathrm{E}-04$ & & \\
\hline GO:0007519 & striated muscle development & 103 & 0.71 & $3.0 \mathrm{E}-10$ & 0.68 & $2.72 \mathrm{E}-04$ \\
\hline GO:0046849 & bone remodeling & 89 & 0.71 & 7.0E-04 & & \\
\hline GO:0015674 & $\begin{array}{l}\text { di-, tri-valent inorganic cation } \\
\text { transport }\end{array}$ & 112 & 0.68 & $6.0 \mathrm{E}-10$ & 0.63 & $6.47 \mathrm{E}-04$ \\
\hline GO:0043085 & $\begin{array}{l}\text { positive regulation of enzyme } \\
\text { activity }\end{array}$ & 118 & 0.66 & $9.4 \mathrm{E}-04$ & 0.65 & $2.99 \mathrm{E}-10$ \\
\hline GO:0008202 & steroid metabolic process & 122 & 0.64 & $6.6 \mathrm{E}-04$ & 0.82 & 7.04E-11 \\
\hline GO:0051338 & regulation of transferase activity & 121 & 0.64 & $7.5 \mathrm{E}-04$ & 0.70 & $1.99 \mathrm{E}-10$ \\
\hline GO:0006635 & fatty acid beta-oxidation & 12 & & & 2.39 & $5.70 \mathrm{E}-11$ \\
\hline GO:0019395 & fatty acid oxidation & 19 & & & 1.72 & $9.20 \mathrm{E}-11$ \\
\hline
\end{tabular}


Table 3.4 Overrepresented Gene Ontology classes in the LFD transcriptome and the HFD transcriptome as compared with the start transcriptome

\begin{tabular}{|c|c|c|c|c|c|c|}
\hline \multirow{3}{*}{ GO ID } & \multirow[b]{3}{*}{ GO class } & \multirow[b]{3}{*}{$\mathrm{N}$} & \multicolumn{2}{|c|}{ 8- week LFD } & \multicolumn{2}{|c|}{ 8-week HFD } \\
\hline & & & Raw & & Raw & \\
\hline & & & Score & FDR & Score & FDR \\
\hline GO:0009636 & response to toxin & 18 & & & 1.40 & $3.99 \mathrm{E}-04$ \\
\hline GO:0046486 & glycerolipid metabolic process & 21 & & & 1.18 & $6.30 \mathrm{E}-04$ \\
\hline GO:0006941 & striated muscle contraction & 30 & & & 1.10 & 1.20E-09 \\
\hline GO:0016126 & sterol biosynthetic process & 25 & & & 1.06 & 8.16E-04 \\
\hline GO:0008203 & cholesterol metabolic process & 54 & & & 1.00 & $1.50 \mathrm{E}-10$ \\
\hline GO:0060047 & heart contraction & 41 & & & 0.97 & $2.39 \mathrm{E}-10$ \\
\hline GO:0000160 & $\begin{array}{l}\text { two-component signal transduc- } \\
\text { tion system (phosphorelay) }\end{array}$ & 33 & & & 0.96 & 7.29E-04 \\
\hline GO:0016125 & sterol metabolic process & 61 & & & 0.94 & $6.30 \mathrm{E}-11$ \\
\hline GO:0006469 & $\begin{array}{l}\text { negative regulation of protein } \\
\text { kinase activity }\end{array}$ & 35 & & & 0.90 & 7.97E-04 \\
\hline GO:0006936 & muscle contraction & 69 & & & 0.88 & $5.98 \mathrm{E}-10$ \\
\hline GO:0006694 & steroid biosynthetic process & 61 & & & 0.87 & $1.33 \mathrm{E}-10$ \\
\hline GO:0030324 & lung development & 59 & & & 0.85 & $9.97 \mathrm{E}-11$ \\
\hline GO:0030324 & lung development & 59 & & & 0.85 & $9.97 \mathrm{E}-11$ \\
\hline GO:0030323 & respiratory tube development & 60 & & & 0.84 & $1.20 \mathrm{E}-10$ \\
\hline GO:0008015 & circulation & 84 & & & 0.83 & $1.71 \mathrm{E}-10$ \\
\hline GO:0006766 & vitamin metabolic process & 56 & & & 0.79 & 7.12E-04 \\
\hline GO:0043405 & regulation of MAPK activity & 55 & & & 0.78 & $4.98 \mathrm{E}-04$ \\
\hline GO:0042445 & hormone metabolic process & 71 & & & 0.78 & $2.39 \mathrm{E}-04$ \\
\hline GO:0006869 & lipid transport & 64 & & & 0.76 & 4.12E-04 \\
\hline GO:0046942 & carboxylic acid transport & 55 & & & 0.75 & $5.44 \mathrm{E}-04$ \\
\hline GO:0006725 & $\begin{array}{l}\text { aromatic compound metabolic } \\
\text { process }\end{array}$ & 102 & & & 0.74 & 7.97E-11 \\
\hline GO:0048637 & skeletal muscle development & 61 & & & 0.74 & $8.72 \mathrm{E}-04$ \\
\hline GO:0000165 & MAPKKK cascade & 108 & & & 0.73 & $6.64 \mathrm{E}-11$ \\
\hline GO:0045859 & $\begin{array}{l}\text { regulation of protein kinase } \\
\text { activity }\end{array}$ & 115 & & & 0.72 & $5.98 \mathrm{E}-11$ \\
\hline GO:0006006 & glucose metabolic process & 80 & & & 0.72 & $2.60 \mathrm{E}-04$ \\
\hline GO:0002526 & acute inflammatory response & 67 & & & 0.71 & 5.13E-04 \\
\hline GO:0043549 & regulation of kinase activity & 120 & & & 0.71 & $3.99 \mathrm{E}-10$ \\
\hline GO:0030098 & lymphocyte differentiation & 81 & & & 0.70 & $6.13 \mathrm{E}-04$ \\
\hline GO:0045860 & $\begin{array}{l}\text { positive regulation of protein } \\
\text { kinase activity }\end{array}$ & 74 & & & 0.70 & $6.95 \mathrm{E}-04$ \\
\hline GO:0006470 & $\begin{array}{l}\text { protein amino acid dephos- } \\
\text { phorylation }\end{array}$ & 93 & & & 0.68 & $4.43 \mathrm{E}-04$ \\
\hline GO:0051347 & $\begin{array}{l}\text { positive regulation of trans- } \\
\text { ferase activity }\end{array}$ & 79 & & & 0.68 & 8.91E-04 \\
\hline
\end{tabular}

ErmineJ was used to identify significantly overrepresented GO classes in the muscle of LFD mice and HFD mice, respectively. For the concept biological processes we selected classes with an FDR $<0.001$. For this analysis only classes containing 8 through 125 genes were taken into account. $\mathrm{N}$, number of genes in $\mathrm{GO}$ class; LFD; low fat diet; HFD, high fat diet. 
The comparison of the 8-week HFD muscle transcriptome with the start muscle transcriptome resulted in the identification of 92 differentially expressed genes (fold change $>1.3$ and FDR $<0.05$ ). By using ErmineJ we found that $48 \mathrm{GO}$ classes were overrepresented in the 8-week HFD muscle transcriptome. This included descriptors for cell-cell interaction, contraction, development, FA oxidation and the MAPK cascade (Table 3.4). GSEA showed that nine gene sets were up-regulated in the 8-week HFD muscle transcriptome. This list contained five gene sets that were related to FA oxidation. The other four gene sets corresponded to protein metabolism and PPAR signaling. Four gene sets related to cell-cell interaction, one gene set describing the MAPK cascade and one gene set named "Tissue blood and lymph" were downregulated (Table 3.5).

Table 3.5 Changed gene sets in the LFD transcriptome and the HFD transcriptome as compared with the start transcriptome

\begin{tabular}{|c|c|c|c|c|c|c|c|}
\hline & \multirow[b]{2}{*}{$\mathrm{N}$} & \multicolumn{3}{|c|}{ 8-week LFD } & \multicolumn{3}{|c|}{ 8-week HFD } \\
\hline & & ES & NES & FDR & ES & NES & FDR \\
\hline \multicolumn{8}{|c|}{ Up-regulated cellular processes } \\
\hline Proteasome $^{2}$ & 24 & 0.63 & 2.08 & 0.017 & 0.70 & 2.16 & $<0.001$ \\
\hline Olfactorty transduction ${ }^{2}$ & 28 & 0.59 & 2.00 & 0.028 & & & \\
\hline Mitochondrial fatty acid oxidation ${ }^{1}$ & 29 & & & & 0.76 & 2.47 & $<0.001$ \\
\hline Fatty acid beta oxidation meta ${ }^{3}$ & 34 & & & & 0.61 & 2.08 & 0.003 \\
\hline PPAR signaling pathway ${ }^{2}$ & 63 & & & & 0.53 & 2.04 & 0.005 \\
\hline Fatty acid metabolism ${ }^{2}$ & 36 & & & & 0.56 & 1.92 & 0.016 \\
\hline $\begin{array}{l}\text { Mitochondrial fatty acid beta } \\
\text { oxidation }^{3}\end{array}$ & 15 & & & & 0.71 & 1.93 & 0.018 \\
\hline Fatty acid beta oxidation ${ }^{3}$ & 29 & & & & 0.57 & 1.89 & 0.026 \\
\hline Tyrosine metabolism $^{2}$ & 46 & & & & 0.52 & 1.86 & 0.030 \\
\hline Proteasome degradation ${ }^{3}$ & 59 & & & & 0.46 & 1.80 & 0.048 \\
\hline \multicolumn{8}{|c|}{ Down-regulated cellular processes } \\
\hline Cell communication ${ }^{2}$ & 91 & -0.66 & -2.73 & $<0.001$ & -0.56 & -2.34 & $<0.001$ \\
\hline ECM receptor interaction ${ }^{2}$ & 80 & -0.67 & -2.68 & $<0.001$ & -0.57 & -2.30 & $<0.001$ \\
\hline Focal adhesion ${ }^{2}$ & 170 & -0.57 & -2.57 & $<0.001$ & -0.48 & -2.20 & $<0.001$ \\
\hline Focal adhesion $^{3}$ & 182 & -0.56 & -2.52 & $<0.001$ & -0.46 & -2.08 & 0.002 \\
\hline MAPK cascade ${ }^{3}$ & 30 & & & & -0.60 & -2.00 & 0.007 \\
\hline Tissue blood and lymph $1^{3}$ & 15 & -0.77 & -2.09 & 0.001 & -0.69 & -1.94 & 0.016 \\
\hline Prostaglandin synthesis regulation ${ }^{3}$ & 31 & -0.63 & -2.10 & 0.001 & & & \\
\hline Tissue blood and lymph $2^{3}$ & 32 & -0.58 & -1.92 & 0.012 & & & \\
\hline Inflammatory response pathway ${ }^{3}$ & 40 & -0.56 & -1.93 & 0.013 & & & \\
\hline $\begin{array}{l}\text { Induction of apoptosis through Dr3 } \\
\text { and } \operatorname{Dr} 45 \text { death receports }\end{array}$ & 27 & -0.60 & -1.89 & 0.017 & & & \\
\hline
\end{tabular}

GSEA was applied to identify up-regulated and down-regulated processes after an 8-week LFD and after an 8-week HFD, respectively. Presented are regulated processes with an FDR $<0.05$. An FDR was calculated to adjust for multiple hypotheses testing. Sources of the gene sets: 1SK manual, 2KEGG, 3GENMAPP, 4BIOCARTA. N, number of genes; ES, enrichment score for the gene set that reflects the degree to which a gene set is overrepresented at the top or bottom of the ranked list; NES, normalized enrichment score, i.e., the normalized ES to account for the size of the gene set. LFD, low fat diet; HFD, high fat diet 
When we paralleled the outcomes of the comparison 8-week LFD muscle transcriptome vs. start transcriptome with the comparison 8-week HFD muscle transcriptome vs. start transcriptome we observed that a total of 39 genes showed an overlap. From the overrepresented GO classes we identified nine GO classes, including striated muscle development and descriptors for cell-cell interaction that were overlapping (Table 3.4). From the outcomes of GSEA we found that one upregulated gene set and five down-regulated gene sets were overlapping. Three down-regulated gene sets corresponded to cell-cell interaction and one gene set was "Tissue blood and lymph".

Altogether, the outcomes of microarray analyses of the skeletal muscle can be summarized as follows: HFD-specific changes in gene expression are smaller than 1.3 fold; 8-weeks of aging induces more pronounced changes in the muscle transcriptome than an HFD; the muscle responds to an 8-week HFD with changes in the regulation of FA oxidation and MAPK cascade; changes in the regulation of cell-cell interaction and muscle development are observed in both LFD mice and HFD mice and are thus related to aging. An overview of the microarray-detected changes is shown in Figure 3.4. A complete list of regulated genes is available in supplement 1 at the website of the Journal of Nutrigenetics and Nutrigenomics.

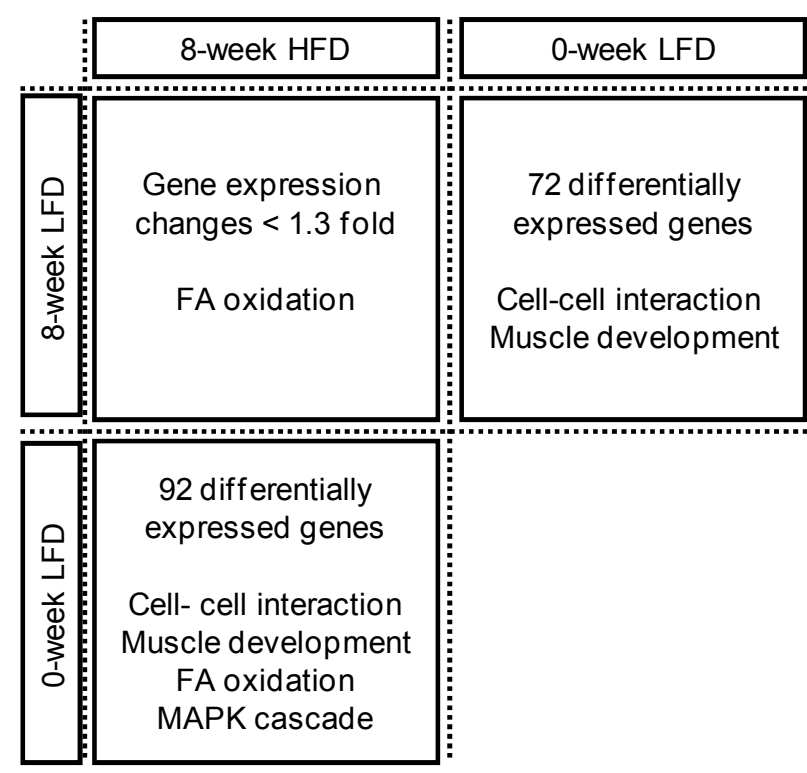

Figure 3.4 Overview of the microarray analysis as performed by two different comparison strategies. Comparison strategy 1: To find HFD-responsive changes we compared the 8-week HFD muscle transcriptome vs. 8-week LFD muscle transcriptome. Comparison strategy 2: the 8-week HFD muscle transcriptome as well as the 8-week LFD muscle transcriptome with the muscle transcriptome of mice sacrificed at the start of the intervention. Overlaps between the different comparisons are depicted in identical colors. LFD; low fat diet and HFD; high fat diet. 


\section{Verification of microarray-detected changes}

To verify microarray-detected changes we measured enzyme activities or performed Western blotting to analyze protein expression. First, we verified the transcription up-regulation of FA oxidation in 8-week HFD mice vs. 8-week LFD mice. Activity of HAD ( $\beta$-oxidation) in HFD mice was comparable to LFD mice (7.2 \pm 2.0 vs. $6.8 \pm 1.4 \mu \mathrm{mol} / \mathrm{min} / \mathrm{g}$ protein with $\mathrm{p}=0.88$ in HFD vs. LFD). Also, activity of CS (TCA cycle) in HFD mice was not different from LFD mice $(24.1 \pm 3.5$ vs. $21.5 \pm 3.0$ $\mu \mathrm{mol} / \mathrm{min} / \mathrm{g}$ protein with $\mathrm{p}=0.58$ in HFD vs. LFD). Furthermore, protein levels of subunits of the five complexes of oxidative phosphorylation (OXPHOS) were not detectably changed in the HFD mice as compared with the LFD mice (complex I: 0.64 \pm 0.10 vs. $0.60 \pm 0.09$; complex II: $1.00 \pm 0.07$ vs. $0.98 \pm 0.12$; complex III: $0.85 \pm 0.07$ vs. $0.86 \pm 0.13$; complex IV: $0.85 \pm 0.14$ vs. $0.80 \pm 0.13$ and complex V: $0.84 \pm 0.08$ vs. $0.87 \pm 0.09)$.

Secondly, we verified the transcriptional down-regulation of the MAPK cascade in muscle of 8-week HFD mice vs. mice sacrificed at the start of the intervention. The gene with the strongest regulation of the MAPK cascade was found to be Mek6 which is actually involved in the activation p38 MAPK via phosphorylation (30). To find out if down-regulation of Mek6 gene expression influenced the activity of the p38 MAPK cascade, we analyzed protein levels of p38 MAPK as well as phospho-p38 MAPK in protein extracts of mice sacrificed at the start of the diet intervention, in 8week LFD mice and 8-week HFD mice. Western blotting showed that the 8-week HFD significantly decreased p38 MAPK protein levels in the skeletal muscle. The phospho-p38 MAPK protein level was not different in the HFD mice as compared to mice sacrificed at the start of the diet intervention and 8-week LFD mice. However, activation of p38 MAPK, which is expressed as the ratio phospho-p38 MAPK vs. p38MAPK, tended to be higher in the HFD mice than in mice sacrificed at the start of the intervention ( $p=0.09$ ) (Figure 3.5). 
A

LFD week 0 LFD week 8 HFD week 8

p38

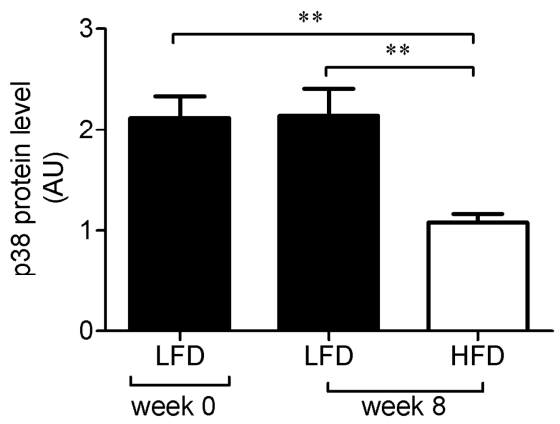

C

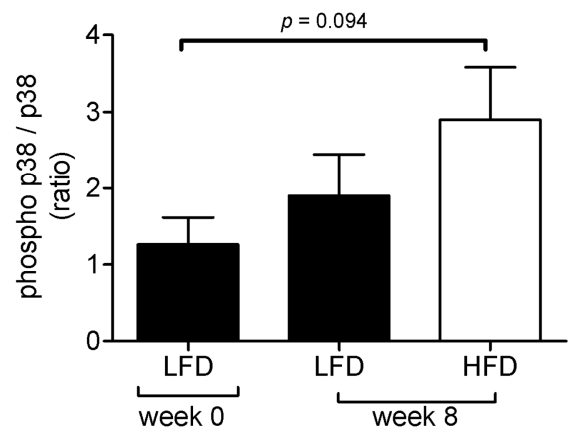

B

LFD week 0 LFD week 8 HFD week 8 pp38

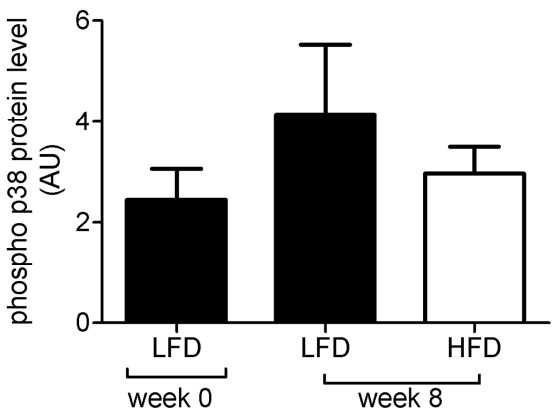

Figure 3.5 Activation of p-38 MAPK in the skeletal muscle of LFD mice and HFD mice. Western blotting was used to determine the protein abundance of p38 MAPK (A) and phospho-p38 MAPK (B) and the ratio phospho-p38 MAPK vs. p38 MAPK in muscle protein extracts of mice sacrificed at the start of the intervention (LFD week 0 ), LFD mice (LFD week 8 ) and HFD mice (HFD week 8). Values are means \pm SE $(n=6-8)$ and $* *$ indicates a significant difference with $p<$ 0.01 as obtained with Tukey's post hoc test. LFD; low fat diet and HFD; high fat diet.

\section{Discussion}

In the present study we demonstrated that an 8-week HFD induces obesity, reduces whole-body insulin sensitivity and decreases insulin sensitivity of heart, muscle and visceral fat depots. Furthermore, plasma levels of the adipokines leptin and adiponectin were significantly increased and decreased, respectively. To get more insight in the underlying molecular mechanisms we performed microarray analysis of the skeletal muscle using an unique combination of two comparison strategies. First, we compared the 8-week HFD muscle transcriptome with the 8-week LFD muscle transcriptome. We found that differences in gene expression were relatively small and FA oxidation was the only regulated pathway. Secondly, we compared the start transcriptome with the 8-week HFD muscle transcriptome and the 8-week LFD muscle transcriptome, respectively. Irrespective of the diet, we found that cell-cell interaction and development were regulated when considering the possible effect of 8 
weeks of aging. Interestingly, the up-regulation of FA oxidation and the downregulation of the MAPK cascade appeared to be specific for the HFD intervention.

Obesity is the outcome of a prolonged positive energy balance caused by energy intake exceeding energy expenditure. The excess of energy is stored as TAG in adipose tissue. Adipose tissue secretes a variety of adipokines like leptin and adiponectin. Leptin serves as a metabolic signal of energy sufficiency regulating energy homeostasis. Furthermore, leptin also regulates peripheral metabolic mechanisms in muscle, liver, pancreas and other tissues. Adiponectin has been implicated as modulator of glucose and lipid metabolism in muscle and liver (17). The observed strong correlation between obesity and leptin is in line with results of earlier studies describing that diet-induced obesity is accompanied by a state of leptin resistance (31). Low circulating adiponectin levels have been demonstrated in diet-induced obese rodents as well as in obese human subjects (15). Although only slightly lower, adiponectin levels were significant different in HFD mice as compared to LFD mice in the present study.

Insulin resistance is manifested by decreased insulin-stimulated glucose uptake and metabolism in fat depots and skeletal muscle and by an impaired suppression of hepatic glucose production (5). Indeed, the HFD impaired the insulin-stimulated uptake of glucose in visceral fat depots and muscle. Park et al. (32) showed that a 3week HFD, based on corn oil, induces the development of insulin resistance simultaneously in liver, adipose tissue and skeletal muscle in young adult C57BL/6 mice, whereas Kraegen et al. (33) found that diet-induced insulin resistance develops in liver and adipose tissue before it develops in the skeletal muscle during a safflower oil-based HFD intervention in adult male Wistar rats. Here, we showed that an 8week palm oil based HFD does not induce insulin resistance in liver. Possible explanations for these different findings are differences in studied species, age of the animals, but also the composition of the diet.

Previously, we showed that both a 3-day HFD as well as a 4-week HFD significantly changes the expression level of more than a thousand genes in the quadriceps muscle of mice (25). Since the 8-week HFD mice developed obesity and insulin resistance, we expected to find a considerable number of differentially expressed genes in the skeletal muscle of these mice as well. However, no genes were found with a significantly changed expression level of more than 1.3 fold. Despite the relatively small changes in gene expression, FA oxidation was identified by both microarray analysis strategies as one of two responsive pathways in muscle of HFD mice. Although mitochondrial dysfunction has been observed in insulin resistance and type 2 diabetes, we observed that an HFD induces an up-regulation of FA oxidation suggesting a metabolic adaptation. This is in line with numerous studies $(25,34-36)$. Hoeks et al. (34) described that an 8-week HFD did not change mitochondrial function in rats as assessed by respirometry. In fact, a tendency towards a higher respiratory control rate on lipid substrate was observed, suggesting increased mitochon- 
drial FA oxidative capacity (34). Also lossa et al. (35) reported an increased lipid oxidative capacity in HFD rats. In addition, two groups that assessed several markers for mitochondrial FA oxidative capacity during HFD interventions observed rather an increased than a decreased mitochondrial FA oxidative capacity $(25,36)$. Altogether, these results suggest that skeletal muscle tissue can metabolically adapt to an increased lipid load. As such, the muscle can buffer the increased lipid supply. However, in this study we showed that the transcriptional up-regulation of FA oxidative genes did not result in increased activity of HAD, an enzyme involved in $\beta$-oxidation. Additionally, CS activity (marker for the TCA cycle) and OXPHOS protein expression in HFD mice was comparable to LFD mice. Finally, the mitochondrial copy number, which is another indirect marker for mitochondrial oxidative capacity, was not changed in the HFD mice (data not shown). These results suggest that the capacity to oxidize lipids was still sufficient to handle the increased supply of fat. Whether an HFD intervention results in impaired oxidative capacity in the long run is currently under investigation.

The other HFD-responsive pathway was identified as MAPK cascade. MAPK cascades are involved in the initiation of various cellular processes such as proliferation, differentiation and development in response to extracellular stimuli (37-39). We observed a down-regulation of the MAPK cascade in muscle of HFD mice. The gene with the strongest regulation was identified as the Mek6 gene (1.59-fold; FDR < 0.001). Mek6 is involved in the activation of the p38 MAPK cascade via the phosphorylation of p38 MAPK (30). Since different in vitro studies have shown that activation of the p38 MAPK cascade decreases the uptake of glucose under influence of insulin or exercise, it has been hypothesized that p38 MAPK is a negative regulator of the stimulated uptake of glucose in muscle (40-42). Corresponding with the decreased gene expression level of Mek6, we found that p38 MAPK protein levels were decreased after an 8-week HFD. Since phospho-p38 MAPK protein levels were not changed we observed an increased activation of the p38 MAPK cascade in the muscle of HFD mice. This is in line with results of Li et al. who observed an increased activation of p38 MAPK activation in heart tissue of HFD rats (43). Since in the present study the HFD mice were also insulin resistant, we consider these results as supportive for the hypothesis that p38 MAPK may act as a negative regulator of stimulated-uptake of glucose.

We showed that 8-weeks of aging induces more pronounced changes the muscle transcriptome than an HFD. In the muscle transcriptome of both LFD mice and HFD mice we detected changes in the regulation of cell-cell interaction. Interactions between cells as well as interactions between cells and the extracellular matrix are critical for the development, organization, maintenance and function of cells in a certain tissue (44). We also observed that genes involved in muscle developmentrelated processes were changed in LFD mice as well as HFD mice. Indeed, throughout the 8-week intervention period LFD mice and HFD mice showed an increase in 
lean body mass as was evidenced by DEXA scanning. Since the mass of the skeleton increased only marginally ( 0.09 grams, data not shown), we consider the increase of the amount of lean body mass as an actual increase of muscle mass. Thus, within a period of 8 weeks, irrespective of diet, mice develop more muscle mass as reflected in the muscle transcriptome.

In conclusion, an 8-week HFD induces obesity and reduced insulin sensitivity in C57BL/6J mice. However, HFD-responsive changes in the muscle transcriptome were relatively small. In fact, eight weeks of aging induced more pronounced changes in the muscle transcriptome than an HFD. Only one strategy revealed the transcriptional down-regulation of the MAPK cascade, whereas both strategies showed the up-regulation of FA oxidation demonstrating that the two comparison strategies are confirmative as well as complementary. Therefore, we suggest using complementary analysis strategies in the genome-wide search for gene expression changes induced by mild interventions, such as an HFD.

\section{Acknowledgements}

We thank Bert Weijers, Mechteld Grootte Bromhaar and Shohreh Keshtkar Ghiasabadi for excellent technical assistance with the animal experiment, hybridization of the microarrays and RNA isolations. Dr. Ping Wang is thanked for useful discussions. This study was funded by the Top Institute Food and Nutrition, with financial support by the Dutch government.

\section{References}

1. Alberti KG, Zimmet $P$, Shaw J. Metabolic syndrome--a new world-wide definition. A Consensus Statement from the International Diabetes Federation. Diabet Med. 2006 May;23(5):469-80.

2. Zimmet P, Magliano D, Matsuzawa Y, Alberti G, Shaw J. The metabolic syndrome: a global public health problem and a new definition. J Atheroscler Thromb. 2005;12(6):295-300.

3. Eckel RH, Grundy SM, Zimmet PZ. The metabolic syndrome. Lancet. 2005 Apr 16-22;365(9468):141528.

4. Laaksonen DE, Niskanen L, Lakka HM, Lakka TA, Uusitupa M. Epidemiology and treatment of the metabolic syndrome. Annals of medicine. 2004;36(5):332-46.

5. Kahn BB, Flier JS. Obesity and insulin resistance. The Journal of clinical investigation. 2000 Aug;106(4):473-81.

6. Goossens $\mathrm{GH}$. The role of adipose tissue dysfunction in the pathogenesis of obesity-related insulin resistance. Physiology \& behavior. 2008 May 23;94(2):206-18.

7. Jacob S, Machann J, Rett K, Brechtel K, Volk A, Renn W, et al. Association of increased intramyocellular lipid content with insulin resistance in lean nondiabetic offspring of type 2 diabetic subjects. Diabetes. 1999 May;48(5):1113-9. 
8. Krssak M, Falk Petersen K, Dresner A, DiPietro L, Vogel SM, Rothman DL, et al. Intramyocellular lipid concentrations are correlated with insulin sensitivity in humans: a $1 \mathrm{H}$ NMR spectroscopy study. Diabetologia. 1999 Jan;42(1):113-6.

9. Pan DA, Lillioja S, Kriketos AD, Milner MR, Baur LA, Bogardus C, et al. Skeletal muscle triglyceride levels are inversely related to insulin action. Diabetes. 1997 Jun;46(6):983-8.

10. Sinha R, Dufour S, Petersen KF, LeBon V, Enoksson S, Ma YZ, et al. Assessment of skeletal muscle triglyceride content by (1) $\mathrm{H}$ nuclear magnetic resonance spectroscopy in lean and obese adolescents: relationships to insulin sensitivity, total body fat, and central adiposity. Diabetes. 2002 Apr;51(4):1022-7.

11. Goodpaster BH, He J, Watkins S, Kelley DE. Skeletal muscle lipid content and insulin resistance: evidence for a paradox in endurance-trained athletes. The Journal of clinical endocrinology and metabolism. 2001 Dec;86(12):5755-61.

12. Phillips SM, Green HJ, Tarnopolsky MA, Heigenhauser GJ, Grant SM. Progressive effect of endurance training on metabolic adaptations in working skeletal muscle. The American journal of physiology. 1996 Feb;270(2 Pt 1):E265-72.

13. Petersen KF, Shulman GI. Etiology of insulin resistance. The American journal of medicine. 2006 May;119(5 Suppl 1):S10-6.

14. Hegarty BD, Furler SM, Ye J, Cooney GJ, Kraegen EW. The role of intramuscular lipid in insulin resistance. Acta physiologica Scandinavica. 2003 Aug;178(4):373-83.

15. Trujillo ME, Scherer PE. Adipose tissue-derived factors: impact on health and disease. Endocrine reviews. 2006 Dec;27(7):762-78.

16. Nawrocki AR, Scherer PE. The delicate balance between fat and muscle: adipokines in metabolic disease and musculoskeletal inflammation. Current opinion in pharmacology. 2004 Jun;4(3):281-9.

17. Kershaw EE, Flier JS. Adipose tissue as an endocrine organ. The Journal of clinical endocrinology and metabolism. 2004 Jun;89(6):2548-56.

18. Muller M, Kersten S. Nutrigenomics: goals and strategies. Nat Rev Genet. 2003 Apr;4(4):315-22.

19. Afman L, Muller M. Nutrigenomics: from molecular nutrition to prevention of disease. J Am Diet Assoc. 2006 Apr;106(4):569-76.

20. de Wit NJ, Bosch-Vermeulen H, de Groot PJ, Hooiveld GJ, Bromhaar MM, Jansen J, et al. The role of the small intestine in the development of dietary fat-induced obesity and insulin resistance in C57BL/6J mice. BMC medical genomics. 2008;1:14.

21. van Schothorst EM, Bunschoten A, Schrauwen P, Mensink RP, Keijer J. Effects of a high-fat, lowversus high-glycemic index diet: retardation of insulin resistance involves adipose tissue modulation. Faseb J. 2009 Apr;23(4):1092-101.

22. Heijboer AC, Donga E, Voshol PJ, Dang ZC, Havekes LM, Romijn JA, et al. Sixteen hours of fasting differentially affects hepatic and muscle insulin sensitivity in mice. Journal of lipid research. 2005 Mar;46(3):582-8.

23. Voshol PJ, Haemmerle G, Ouwens DM, Zimmermann R, Zechner R, Teusink B, et al. Increased hepatic insulin sensitivity together with decreased hepatic triglyceride stores in hormone-sensitive lipasedeficient mice. Endocrinology. 2003 Aug;144(8):3456-62.

24. Voshol PJ, Jong MC, Dahlmans VE, Kratky D, Levak-Frank S, Zechner R, et al. In muscle-specific lipoprotein lipase-overexpressing mice, muscle triglyceride content is increased without inhibition of insulin-stimulated whole-body and muscle-specific glucose uptake. Diabetes. 2001 Nov;50(11):258590.

25. de Wilde J, Mohren R, van den Berg S, Boekschoten M, Dijk KW, de Groot P, et al. Short-term high fat-feeding results in morphological and metabolic adaptations in the skeletal muscle of $\mathrm{C} 57 \mathrm{BL} / 6 \mathrm{~J}$ mice. Physiol Genomics. 2008 Feb 19;32(3):360-9.

26. Storey JD, Tibshirani R. Statistical significance for genomewide studies. Proceedings of the National Academy of Sciences of the United States of America. 2003 Aug 5;100(16):9440-5.

27. Lee HK, Braynen W, Keshav K, Pavlidis P. ErmineJ: tool for functional analysis of gene expression data sets. BMC Bioinformatics. 2005;6:269. 
28. Subramanian A, Tamayo P, Mootha VK, Mukherjee S, Ebert BL, Gillette MA, et al. Gene set enrichment analysis: a knowledge-based approach for interpreting genome-wide expression profiles. Proceedings of the National Academy of Sciences of the United States of America. 2005 Oct 25;102(43):15545-50.

29. den Hoed M, Hesselink MK, van Kranenburg GP, Westerterp KR. Habitual physical activity in daily life correlates positively with markers for mitochondrial capacity. J Appl Physiol. 2008 Aug;105(2):561-8.

30. Stein B, Brady H, Yang MX, Young DB, Barbosa MS. Cloning and characterization of MEK6, a novel member of the mitogen-activated protein kinase kinase cascade. The Journal of biological chemistry. 1996 May 10;271(19):11427-33.

31. Flier JS. Obesity wars: molecular progress confronts an expanding epidemic. Cell. 2004 Jan 23;116(2):337-50.

32. Park SY, Cho YR, Kim HJ, Higashimori T, Danton C, Lee MK, et al. Unraveling the temporal pattern of diet-induced insulin resistance in individual organs and cardiac dysfunction in C57BL/6 mice. Diabetes. 2005 Dec;54(12):3530-40.

33. Kraegen EW, Clark PW, Jenkins AB, Daley EA, Chisholm DJ, Storlien LH. Development of muscle insulin resistance after liver insulin resistance in high-fat-fed rats. Diabetes. 1991 Nov;40(11):1397403.

34. Hoeks J, Briede JJ, de Vogel J, Schaart G, Nabben M, Moonen-Kornips E, et al. Mitochondrial function, content and ROS production in rat skeletal muscle: Effect of high-fat feeding. FEBS letters. 2008 Feb 20;582(4):510-6.

35. Iossa S, Mollica MP, Lionetti L, Crescenzo R, Botta M, Liverini G. Skeletal muscle oxidative capacity in rats fed high-fat diet. Int J Obes Relat Metab Disord. 2002 Jan;26(1):65-72.

36. Turner N, Bruce CR, Beale SM, Hoehn KL, So T, Rolph MS, et al. Excess lipid availability increases mitochondrial fatty acid oxidative capacity in muscle: evidence against a role for reduced fatty acid oxidation in lipid-induced insulin resistance in rodents. Diabetes. 2007 Aug;56(8):2085-92.

37. Han J, Lee JD, Bibbs L, Ulevitch RJ. A MAP kinase targeted by endotoxin and hyperosmolarity in mammalian cells. Science (New York, NY. 1994 Aug 5;265(5173):808-11.

38. Rouse J, Cohen P, Trigon S, Morange M, Alonso-Llamazares A, Zamanillo D, et al. A novel kinase cascade triggered by stress and heat shock that stimulates MAPKAP kinase-2 and phosphorylation of the small heat shock proteins. Cell. 1994 Sep 23;78(6):1027-37.

39. Seger R, Krebs EG. The MAPK signaling cascade. Faseb J. 1995 Jun;9(9):726-35.

40. Fujishiro $M$, Gotoh $Y$, Katagiri $H$, Sakoda $H$, Ogihara $T$, Anai $M$, et al. Three mitogen-activated protein kinases inhibit insulin signaling by different mechanisms in 3T3-L1 adipocytes. Molecular endocrinology (Baltimore, Md. 2003 Mar;17(3):487-97.

41. Fujishiro $M$, Gotoh $Y$, Katagiri $H$, Sakoda $H$, Ogihara $T$, Anai $M$, et al. MKK6/3 and p38 MAPK pathway activation is not necessary for insulin-induced glucose uptake but regulates glucose transporter expression. The Journal of biological chemistry. 2001 Jun 8;276(23):19800-6.

42. Ho RC, Alcazar O, Fujii N, Hirshman MF, Goodyear LJ. p38gamma MAPK regulation of glucose transporter expression and glucose uptake in $\mathrm{L} 6$ myotubes and mouse skeletal muscle. Am J Physiol Regul Integr Comp Physiol. 2004 Feb;286(2):R342-9.

43. Li SY, Liu Y, Sigmon VK, McCort A, Ren J. High-fat diet enhances visceral advanced glycation end products, nuclear O-Glc-Nac modification, p38 mitogen-activated protein kinase activation and apoptosis. Diabetes, obesity \& metabolism. 2005 Jul;7(4):448-54.

44. Jamora C, Fuchs E. Intercellular adhesion, signalling and the cytoskeleton. Nature cell biology. 2002 Apr;4(4):E101-8. 



\section{CHAPTER 4}

\section{High fat diet-induced changes in mouse muscle mitochondrial phospholipid composition and function are unrelated to insulin resistance}

Janneke de Wilde, Joris Hoeks, Egbert Smit, Sjoerd A.A. van den Berg, Gert Schaart, Ko Willems van Dijk Martijn F.M. Hulshof and Edwin C.M. Mariman 


\begin{abstract}
An increased fat intake contributes to skeletal muscle insulin resistance, changes in fatty acid (FA) composition of muscle phospholipids and possibly mitochondrial dysfunction. Here, we examined the hypothesis that prolonged consumption of a high fat diet (HFD) results in increased saturation of muscle mitochondrial membrane phospholipids causing impaired mitochondrial function and eventually insulin resistance. C57BL/6J mice were fed an 8-week or 20-week low fat diet (10 kcal\%; LFD) or HFD (45 kcal\%). FA composition of skeletal muscle mitochondrial phospholipids was analyzed by thin-layer chromatography followed by gas chromatography. Mitochondrial function was assessed by high-resolution respirometry. Insulin sensitivity was estimated by HOMA-IR. At 8 weeks, mono-unsaturated FA (16:1n7, $18: 1 \mathrm{n} 7$ and $18: 1 \mathrm{n} 9)$ were decreased $(-4.0 \%, p<0.001)$, whereas saturated FA $(16: 0)$ were increased $(+3.2 \%, p<0.001)$ in HFD muscle mitochondria vs. LFD muscle mitochondria. Interestingly, at week 20, mono-unsaturated FA were decreased while n-6 poly-unsaturated FA $(18: 2 n 6,20: 4 n 6,22: 5 n 6)(+4.0 \%, p<0.001)$ showed a pronounced increase. Despite the increase of saturated FA at week 8 , mitochondrial function was similar between LFD and HFD mice. At 20 weeks, the increase of n-6 poly-unsaturated FA was accompanied by an elevated mitochondrial lipid oxidative capacity (maximal mitochondrial respiratory capacity: $+49 \%, p=0.002$ ). Insulin sensitivity in HFD mice was reduced at both 8 and 20 weeks. HFD-induced changes in mouse muscle mitochondrial phospholipid composition and function are unrelated to the induction and deterioration of insulin sensitivity.
\end{abstract}




\section{Introduction}

Insulin resistance and type 2 diabetes are both associated with impaired skeletal muscle mitochondrial function $(1,2)$. In skeletal muscle of type 2 diabetic patients reduced mitochondrial density as well as decreased expression levels of genes of the mitochondrial respiration chain are observed (3-6). Interestingly, reduced skeletal muscle mitochondrial function is also observed in so called pre-diabetic subjects: insulin resistant offspring of type 2 diabetic subjects $(1,7)$. It is now generally accepted that a mitochondrial defect exists in type 2 diabetes, although its primary role in the pathogenesis of the disease is under debate $(8,9)$.

The factors involved in impairing mitochondrial function are not completely understood, but an increased lipid supply to the muscle is considered a potential cause. Indeed, acute elevation of plasma free fatty acids (FA) in healthy subjects by lipid infusion decreased the expression of skeletal muscle $P g c 1 \alpha, P g c 1 \beta$, (important transcriptional co-factors for mitochondrial biogenesis) as well as of other genes involved in mitochondrial metabolism $(10,11)$. Furthermore, the same approach also led to a reduced insulin-stimulated increase in ATP synthase flux in skeletal muscle as assessed by NMR spectroscopy (12). In line with these observations, a 3-day high fat diet (HFD) reduced the expression of mitochondrial oxidative genes and Pgc1 $\alpha$ and $P g c 1 \beta$ in muscle of young healthy subjects (13).

However, in contrast to these observations in humans, several rodent studies have shown that a HFD does not decrease, but rather increases whole-body lipid oxidation, mitochondrial FA oxidation, mitochondrial respiration, activity of mitochondrial enzymes and markers for mitochondrial density. Despite this increase of mitochondrial density and oxidative capacity, the HFD caused insulin resistance (14-18), thus questioning the concept that mitochondrial dysfunction is the cause of insulin resistance $(19,20)$.

A relation between insulin sensitivity and the FA composition of skeletal muscle membrane phospholipids has been demonstrated (21). Increased levels of saturated FA (SFA) are related to impaired insulin action, whereas polyunsaturated FA (PUFA), especially n-3 PUFA, protect against the development of obesity and insulin resistance (22-24). Interestingly, a link between the FA composition of the mitochondrial phospholipids and mitochondrial function has been described. In rats, aging increases the proportion of SFA in testis mitochondria which was accompanied by a decreased activity of the mitochondrial respiratory enzymes (25). Furthermore, we recently found that a 4-week palm oil-based HFD resulted in an increased saturation of the skeletal muscle phospholipids (17). Whether these changes contribute to the development of mitochondrial dysfunction and insulin resistance is currently unknown.

Therefore, the aim of the present study was to test the hypothesis that a HFD induces an increased saturation of the skeletal muscle mitochondrial phospholipids 
resulting in impaired mitochondrial function and eventually insulin resistance. To study the mid-term and long-term HFD-induced effects, C57BL/6J mice were fed a palm oil-based HFD for 8 or 20 weeks. Specifically, we analyzed the FA composition of skeletal muscle mitochondrial phospholipids, performed mitochondrial respirometry and measured markers for mitochondrial density and insulin sensitivity.

\section{Methods}

\section{Animals, diets and tissue collection}

Male C57BL/6J mice were obtained from Harlan (Horst, the Netherlands). Animal studies were approved by the Local Committees for Care and Use of Laboratory Animals at Maastricht University and Wageningen University. At 9 weeks of age mice were fed the run-in diet consisting of the low fat diet (10 kcal\%; LFD) for 3 weeks. Following this run-in period mice were randomly assigned to the LFD or the HFD (45 kcal \%) for 8 or 20 weeks. Both diets contained fat in the form of palm oil (based on D12450B and D12451; Research Diet Services, Wijk bij Duurstede, the Netherlands) as described previously (26). The FA composition of palm oil is shown in Table 4.1. Diets and tap water were provided ad libitum.

Table 4.1 Fatty acid composition of palm oil

\begin{tabular}{ccccc}
\hline \multicolumn{5}{c}{ fatty acid composition (\%) } \\
\hline Mystric acid & Palmitic acid & Stearic acid & Oleic acid & Linoleic acid \\
1 & 45 & 4 & 40 & 10 \\
\hline
\end{tabular}

Food intake and body mass were recorded weekly. During week 7 and 19 of dietary intervention faecal samples were collected for 1 week. To calculate net energy intake during this last week of the dietary intervention, faecal samples were freezedried and, together with samples from the diet, analyzed for gross energy content using adiabatic bomb calorimetry (Ika-calorimeter system C4000, Heitersheim, Germany).

\section{Tissue collection and mitochondrial isolation}

Mice ( $n=8$ per time point) were sedated by a mixture of $79 \% \mathrm{CO}_{2}$ and $21 \% \mathrm{O}_{2}$ and sacrificed by decapitation. Skeletal muscle tissue of both hind limbs was rapidly dissected and placed into ice-cold mitochondrial isolation buffer ( $10 \mathrm{ml}$ ) containing $100 \mathrm{mM}$ sucrose, $50 \mathrm{mM} \mathrm{KCl}, 20 \mathrm{mM} \mathrm{K}^{+}-\mathrm{TES}, 1 \mathrm{mM}$ EDTA and 0.2\% (w/v) BSA. Skeletal muscle mitochondria were isolated as described previously $(18,27,28)$. Freshly 
isolated mitochondria were used for respiration experiments. The tibialis anterior (TA) muscle was dissected separately, snap-frozen in liquid nitrogen en stored at $80^{\circ} \mathrm{C}$ for further analysis.

\section{Mitochondrial respiration}

The mitochondrial protein concentrations were measured using fluorescamine (Fluram , Fluka, Zwijndrecht, the Netherlands) with BSA as a standard (29). The freshly isolated mitochondria were immediately used for respiration experiments. Mitochondrial respiration rates were measured as described earlier $(18,27,28)$ using a two-chamber Oxygraph (Oroboros Instruments, Innsbruck, Austria). Pyruvate (5 $\mathrm{mM}$ ) was used as carbohydrate-derived substrate and $2 \mathrm{mM}$ carnitine $+50 \mu \mathrm{M}$ palmitoyl-CoA was used as FA substrate.

Remaining mitochondria were stored at $-80^{\circ} \mathrm{C}$ for analysis of the FA composition of mitochondrial phospholipids.

\section{Fatty acid composition of mitochondrial phospholipids}

Phospholipids were isolated from frozen mitochondrial samples by thin-layer chromatography, subsequently hydrolyzed and methylated into their corresponding FA methyl esters. These FA methyl esters were separated and quantified by gas chromatography as described previously (30). The unsaturation index was calculated according to the following formula (31): Unsaturation index $=\Sigma \%$ of unsaturated FA * number of double bounds of each unsaturated FA.

\section{Measures of mitochondrial density}

As parameters for mitochondrial density we measured mitochondrial DNA copy number, protein levels of structural components of the five complexes of the respiratory chain and activity levels of two mitochondrial enzymes in the TA muscle.

\section{Mitochondrial DNA copy number}

Total DNA was isolated from the TA muscle using the DNeasy Blood \& Tissue Kit (Qiagen, Venlo, the Netherlands) according to the manufacturer's instructions. The relative mitochondrial copy number was measured with minor adaptations as described (32). Briefly, the amount of nuclear DNA (nDNA) and mitochondrial DNA (mtDNA) from 1.25ng total DNA were determined by qPCR with primers specific for mtDNA (Cytb) and nDNA (Rn18S). The relative mitochondrial copy number is presented as the ratio of mtDNA to nDNA. 
Western blotting of protein levels of mitochondrial respiration chain complexes Protein levels of subunits of complexes of the mitochondrial respiration chain were detected in TA muscle protein extracts $(n=6)$ as described (17) by using an antimouse monoclonal Ab cocktail (1:2000; Mitosciences, Eugene, OR, USA). The five protein bands were visualized by chemiluminescence and analyzed by densitometry using Quantity One software (Biorad, Veenendaal, the Netherlands). The Gapdh protein was used for normalization (17).

Activity of mitochondrial enzymes

Activity levels of the mitochondrial enzymes $\beta$-hydroxyacyl-CoA dehydrogenase (HAD; $\beta$-oxidation) and citrate synthase (CS; TCA cycle) were determined in TA homogenates $(n=6-8)$ as described by Den Hoed et al (33).

\section{Plasma parameters and glucose homeostasis}

Blood was obtained by orbital puncture and collected in EDTA-containing tubes (Sarstedt AG\&CO, Nümbrecht, Germany). Plasma was obtained after centrifugation at $11000 \times \mathrm{g}$ for $10 \mathrm{~min}$ and stored at $-80^{\circ} \mathrm{C}$. Plasma insulin levels were determined by the Insulin (Mouse) Ultrasensitive EIA (Alpco Diagnostics, Salem, NH, USA) and plasma leptin levels were measured with the Quantikine Mouse Leptin Immunoassay (R\&D systems, Minneapolis, MN, USA). Every two weeks, plasma glucose levels were measured with the Accu-Chek (Roche Diagnostics, Almere, the Netherlands) after a 6-hour fast. Finally, we calculated the HOMA-IR index from fasting glucose and fasting insulin levels (fasting glucose * fasting insulin / 22.5).

\section{Statistical analyses}

All data are expressed as means \pm SEM. Statistical analysis was performed using SPSS for Windows version 15.0 software (SPSS Inc., Chicago, IL, USA). Two-way ANOVA with univariate analysis of variance was performed to analyze effects of diet (HFD vs. LFD), time (week 20 vs. week 8) and interaction (diet* time).

\section{Results}

\section{Body mass and net energy intake}

Table 4.2 shows body mass and parameters of energy metabolism of HFD mice and LFD mice at week 7 and week 19. Body mass of HFD mice was significantly higher than body mass of LFD mice. Gross energy intake was significantly higher in HFD mice than LFD mice (7-week: $+49 \%$ and 19 -week: $+50 \%$. Additionally, energy intake 
significantly increased between week and week 19. Neither diet nor time significantly changed energy loss. Altogether, net energy intake was significantly increased in HFD mice as compared to LFD mice (7-week: $+56 \%$ and 19 -week: $+58 \%$ ). Furthermore, net energy intake significantly increased between week 7 and week 19.

Table 4.2 Energy metabolism in week 7 and week 19 of diet intervention

\begin{tabular}{|c|c|c|c|c|c|c|c|}
\hline & \multicolumn{2}{|c|}{ Week 7} & \multicolumn{2}{|c|}{ Week 19} & \multicolumn{3}{|c|}{$P$ value } \\
\hline & LFD & HFD & LFD & LFD & diet & time & diet $*$ time \\
\hline Body mass & $28.1 \pm$ & $32.5 \pm$ & $31.4 \pm$ & $42.9 \pm$ & $<0.001$ & $<0.001$ & 0.014 \\
\hline (g) & 0.9 & 1.5 & 0.6 & 2.0 & & & \\
\hline Food intake & $19.1 \pm$ & $16.5 \pm$ & $22.0 \pm$ & $19.1 \pm$ & 0.013 & 0.013 & 0.900 \\
\hline (g/week) & 2.0 & 1.9 & 1.0 & 1.8 & & & \\
\hline Gross energy & $261 \pm$ & $388 \pm$ & $300 \pm$ & $450 \pm$ & $<0.001$ & 0.020 & 0.547 \\
\hline intake (kJ/week) & 27 & 45 & 14 & 43 & & & \\
\hline Feces & $1.8 \pm$ & $1.8 \pm$ & $2.3 \pm$ & $2.2 \pm$ & 0.656 & 0.005 & 0.961 \\
\hline (g/week) & 0.3 & 0.2 & 0.2 & 0.2 & & & \\
\hline Energy loss & $31.0 \pm$ & $32.2 \pm$ & $36.1 \pm$ & $35.6 \pm$ & 0.916 & 0.150 & 0.753 \\
\hline (kJ/week) & 5.3 & 4.9 & 6.9 & 4.1 & & & \\
\hline Net energy & $229 \pm$ & $356 \pm$ & $263 \pm$ & $415 \pm$ & $<0.001$ & 0.023 & 0.493 \\
\hline intake (kJ/week) & 23 & 41 & 20 & 41 & & & \\
\hline
\end{tabular}

\section{Fatty acid composition of skeletal muscle mitochondrial phospholipids}

Changes in the relative amounts of saturated, mono-unsaturated and polyunsaturated fatty acids

Table 4.3 shows the relative amounts of SFA, mono-unsaturated FA (MUFA), PUFA, the $n-3$ vs. $n-6$ PUFA ratio and the unsaturation index in skeletal muscle mitochondrial phospholipids of HFD mice and LFD mice, respectively. Mitochondrial phospholipids of HFD mice contained significantly more SFA than LFD mice. Additionally, a significant diet * time effect was found, with a decrease in SFA over time in HFD mice which was not observed in LFD mice (HFD: $42.8 \%$ vs. $41.3 \%$ and LFD: $39.8 \%$ vs. $40.2 \%$ in 8 -week vs. 20-week). The relative amount of MUFA was lower in mitochondrial phospholipids of HFD than LFD mice $(p<0.001)$. The relative amount of PUFA was significantly higher in mitochondrial phospholipids of HFD mice than LFD mice. In addition, a significant diet * time interaction was found, with a time-related increase in PUFA in HFD mice which was not found in LFD mice (HFD: $46.1 \%$ vs. $47.4 \%$ and LFD: $45.4 \%$ vs. $44.4 \%$ in 8 -week vs. 20 -week). 
Table 4.3 Relative amounts of SFA, MUFA, PUFA, n-3 PUFA, n-6 PUFA, the ratio n-3 vs. n- 6 and the unsaturation index in skeletal muscle mitochondrial phospholipids.

\begin{tabular}{|c|c|c|c|c|c|c|c|}
\hline & \multicolumn{2}{|c|}{ Week 8} & \multicolumn{2}{|c|}{ Week 20} & \multicolumn{3}{|c|}{$P$ value } \\
\hline & LFD & HFD & LFD & HFD & diet & time & diet $*$ time \\
\hline SFA & $\begin{array}{c}39.8 \pm \\
0.3\end{array}$ & $\begin{array}{c}42.8 \pm \\
0.3\end{array}$ & $\begin{array}{c}40.2 \pm \\
0.1\end{array}$ & $\begin{array}{c}41.3 \pm \\
0.3\end{array}$ & $<0.001$ & 0.038 & 0.001 \\
\hline MUFA & $\begin{array}{c}15.0 \pm \\
0.1\end{array}$ & $\begin{array}{c}11.0 \pm \\
0.1\end{array}$ & $\begin{array}{c}15.4 \pm \\
0.2\end{array}$ & $\begin{array}{c}11.3 \pm \\
0.1\end{array}$ & $<0.001$ & 0.010 & 0.470 \\
\hline PUFA & $\begin{array}{c}45.2 \pm \\
0.4\end{array}$ & $\begin{array}{c}46.1 \pm \\
0.3\end{array}$ & $\begin{array}{c}44.4 \pm \\
0.2\end{array}$ & $\begin{array}{c}47.4 \pm \\
0.2\end{array}$ & $<0.001$ & 0.421 & 0.002 \\
\hline n-3 PUFA & $\begin{array}{c}17.1 \pm \\
0.2\end{array}$ & $\begin{array}{c}16.0 \pm \\
0.3\end{array}$ & $\begin{array}{c}17.2 \pm \\
0.4\end{array}$ & $\begin{array}{c}16.3 \pm \\
0.4\end{array}$ & 0.004 & 0.465 & 0.797 \\
\hline n-6 PUFA & $\begin{array}{c}27.6 \pm \\
0.5\end{array}$ & $\begin{array}{c}29.6 \pm \\
0.2\end{array}$ & $\begin{array}{c}26.7 \pm \\
0.4\end{array}$ & $\begin{array}{c}30.6 \pm \\
0.3\end{array}$ & $<0.001$ & 0.921 & 0.017 \\
\hline $\begin{array}{l}n-3 \text { vs. } n- \\
6\end{array}$ & $\begin{array}{c}0.63 \pm \\
0.02\end{array}$ & $\begin{array}{c}0.54 \pm \\
0.01\end{array}$ & $\begin{array}{c}0.65 \pm \\
0.02\end{array}$ & $\begin{array}{c}0.53 \pm \\
0.02\end{array}$ & $<0.001$ & 0.572 & 0.343 \\
\hline UI & $\begin{array}{c}209 \pm \\
1.3\end{array}$ & $\begin{array}{c}208 \pm \\
1.9\end{array}$ & $\begin{array}{c}208 \pm \\
1.3\end{array}$ & $\begin{array}{c}213 \pm \\
1.9\end{array}$ & 0.400 & 0.185 & 0.093 \\
\hline
\end{tabular}

Values are relative amounts expressed as percentage (moles of a FA as a percentage of total mol of FA in mitochondrial phospholipids) and are means \pm SE $(n=8)$. HFD, high fat diet; LFD low fat diet; MUFA, mono-unsaturated fatty acids; PUFA, poly-unsaturated fatty acids; SFA, saturated fatty acids; $\mathrm{UI}$, unsaturation index.

Whereas the relative amount of $n-3$ PUFA was significantly lower in mitochondrial phospholipids of HFD mice than LFD mice, the amount of $n-6$ PUFA was significantly higher in HFD mice than LFD mice. Furthermore, a significant diet * time interaction for $n-6$ PUFA was found with an increase of $n-6$ PUFA over time in HFD mice, but not in LFD mice. A significantly lower n-3 vs. n-6 PUFA ratio was found in HFD mice than in LFD mice. Finally, a tendency for a diet * time interaction for the unsaturation index was found $(p=0.09)$, with a time-related increase in HFD mice vs. LFD mice (HFD: 208 vs. 213, LFD: 209 vs. 208 in 8-week vs. 20-week).

In summary, relatively less MUFA were found in skeletal muscle mitochondrial phospholipids of HFD mice vs. LFD mice at both 8 and 20 weeks. The HFD-induced increase in SFA was more pronounced at week 8 . The HFD-induced increase in PUFA was more pronounced at week 20. A lower n-3 vs. n-6 PUFA ratio was found in HFD mice than LFD mice. Finally, between week 8 and week 20 an increase of the unsaturation index was observed in HFD mice and not in LFD mice.

\section{Changes in the relative amounts of individual fatty acids}

Only FA with an relative amount $>\mathbf{2 \%}$ in skeletal muscle mitochondrial phospholipids were further analyzed. The most abundant FA were palmitic acid (16:0), palmitoleic aid (16:1n7), stearic acid (18:0), vaccenic acid (18:1n7), oleic acid (18:1n9), linoleic acid (18:2n6), arachidonic acid (20:4n6), docosapentaenoic acid (22:5n6) and docosahexaenoic acid (22:6n3) as shown in Table 4.4. 
Table 4.4 Relative amount of most abundant fatty acids in skeletal muscle mitochondrial phospholipids

\begin{tabular}{|c|c|c|c|c|c|c|c|}
\hline & \multicolumn{2}{|c|}{ Week 8} & \multicolumn{2}{|c|}{ Week 20} & \multicolumn{3}{|c|}{$P$ value } \\
\hline & LFD & HFD & LFD & HFD & diet & time & diet $*$ time \\
\hline $16: 0$ & $\begin{array}{c}24.0 \pm \\
0.2\end{array}$ & $\begin{array}{c}27.2 \pm \\
0.2\end{array}$ & $\begin{array}{c}24.8 \pm \\
0.2\end{array}$ & $\begin{array}{c}26.5 \pm \\
0.2\end{array}$ & $<0.001$ & 0.933 & 0.002 \\
\hline $16: 1 n 7$ & $\begin{array}{c}3.1 \pm \\
0.1\end{array}$ & $\begin{array}{c}1.2 \pm \\
0.1\end{array}$ & $\begin{array}{c}3.2 \pm \\
0.1\end{array}$ & $\begin{array}{c}1.3 \pm \\
0.1\end{array}$ & $<0.001$ & 0.141 & 1.000 \\
\hline 18:0 & $\begin{array}{c}14.4 \pm \\
0.1\end{array}$ & $\begin{array}{c}14.7 \pm \\
0.2\end{array}$ & $\begin{array}{c}14.0 \pm \\
0.2\end{array}$ & $\begin{array}{c}13.9 \pm \\
0.2\end{array}$ & 0.648 & 0.002 & 0.291 \\
\hline $18: 1 n 7$ & $\begin{array}{c}5.1 \pm \\
0.0\end{array}$ & $\begin{array}{c}3.6 \pm \\
0.1\end{array}$ & $\begin{array}{c}4.8 \pm \\
0.1\end{array}$ & $\begin{array}{c}3.4 \pm \\
0.0\end{array}$ & $<0.001$ & 0.002 & 0.447 \\
\hline $18: 1 n 9$ & $\begin{array}{c}6.1 \pm \\
0.1\end{array}$ & $\begin{array}{c}5.6 \pm \\
0.1\end{array}$ & $\begin{array}{c}6.7 \pm \\
0.1\end{array}$ & $\begin{array}{c}6.0 \pm \\
0.1\end{array}$ & $<0.001$ & $<0.001$ & 0.280 \\
\hline $18: 2 \mathrm{n} 6$ & $\begin{array}{c}10.0 \pm \\
0.2\end{array}$ & $\begin{array}{c}10.2 \pm \\
0.3\end{array}$ & $\begin{array}{c}9.4 \pm \\
0.3\end{array}$ & $\begin{array}{c}11.1 \pm \\
0.3\end{array}$ & 0.001 & 0.547 & 0.009 \\
\hline $20: 4 n 6$ & $\begin{array}{c}11.7 \pm \\
0.2\end{array}$ & $\begin{array}{c}12.4 \pm \\
0.1\end{array}$ & $\begin{array}{c}11.3 \pm \\
0.2\end{array}$ & $\begin{array}{c}12.0 \pm \\
0.2\end{array}$ & $<0.001$ & 0.025 & 1.000 \\
\hline $22: 5 n 6$ & $\begin{array}{c}3.4 \pm \\
0.1\end{array}$ & $\begin{array}{c}4.5 \pm \\
0.1\end{array}$ & $\begin{array}{c}3.6 \pm \\
0.1\end{array}$ & $\begin{array}{c}4.9 \pm \\
0.2\end{array}$ & $<0.001$ & 0.032 & 0.380 \\
\hline $22: 6 n 3$ & $\begin{array}{c}15.6 \pm \\
0.2\end{array}$ & $\begin{array}{c}14.6 \pm \\
0.2\end{array}$ & $\begin{array}{c}16.0 \pm \\
0.3\end{array}$ & $\begin{array}{c}15.0 \pm \\
0.3\end{array}$ & 0.002 & 0.206 & 0.916 \\
\hline
\end{tabular}

Values are relative amounts expressed as percentage (moles of a FA as a percentage of total mol of FA in mitochondrial phospholipids) and are means \pm SE ( $n=8)$. FA, fatty acids; HFD, high fat diet; LFD, low fat diet.

Mitochondrial phospholipids of HFD mice contained significantly more 16:0 than LFD mice. Additionally, a significant diet * time effect was found for 16:0. The relative amount of 16:0 increased in LFD mice between week 8 and week 20, whereas a decrease was found in HFD mice (LFD: $24.0 \%$ vs. $24.8 \%$ and HFD: $27.2 \%$ vs. $26.5 \%$ in 8-week vs. 20-week). For 18:0, a significant time-related decrease was found. The relative amounts of $16: 1 \mathrm{n} 7,18: 1 \mathrm{n} 7$ and $18: 1 \mathrm{n} 9$ were significantly lower in mitochondrial phospholipids of HFD mice than in LFD mice. Furthermore, the relative amounts of the n-6 PUFA 18:2n6, 20:4n6 and 22:5n6 were all significantly higher in HFD mice than LFD mice. For $18: 2 \mathrm{n} 6$, a significant diet * interaction effect was found, with an increase in 18:2n6 with time in HFD mice vs. LFD mice (HFD: $10.2 \%$ vs. $11.1 \%$ and LFD: 10.0 vs. $9.4 \%$ in 8 -week vs. 20 -week). Finally, the relative amount of 22:6n3 was lower in mitochondrial phospholipids of HFD mice than LFD mice ( $p=$ $0.002)$.

In summary, skeletal muscle mitochondrial phospholipids of HFD mice contained relatively more 16:0, 18:2n6, 20:4n6 and 22:5n6 and less 16:1n7, 18:1n7, 18:1n9 and 22:6n3 than LFD mice. The HFD-induced increase of 16:0 was more pronounced at week 8. For 18:2n6, the HFD-induced increase was most pronounced at week 20 . The absolute amounts of all described FA are shown in Supplemental Table 4.1. 


\section{Mitochondrial respiration}

Neither diet, nor time significantly changed mitochondrial respiration fuelled by pyruvate, i.e. state 3 , state 4 and maximally uncoupled respiration were comparable between diets and time points (Figure $4.1 \mathrm{~A}-\mathrm{C}$ ). State 3 respiration on palmitoylCoA + carnitine was higher in HFD mice than in LFD mice (8-week: $+3.8 \%$ and 20 -week: $+33 \%$ ), although this difference did not reach statistical significance ( $p=0.127$ ) (Figure 4.1D). Additionally, a significant time-induced decrease in state 3 respiration was found. State 4 respiration significantly increased with time (Figure 4.1E). Maximal respiration in state uncoupled was significantly higher in HFD mice than in LFD (8-week: $+9.5 \%$ and 20 -week: $+49 \%$ with $p<0.01$ ). Also a significant time-induced increase was observed for maximal respiration in state uncoupled. Additionally, a significant diet * time effect was found, with a stronger increase in maximal respiration in state uncoupled with time in HFD mice than LFD mice $(+42 \%$ vs. $+4.0 \%$ in HFD vs. LFD) (Figure 4.1F). 
A

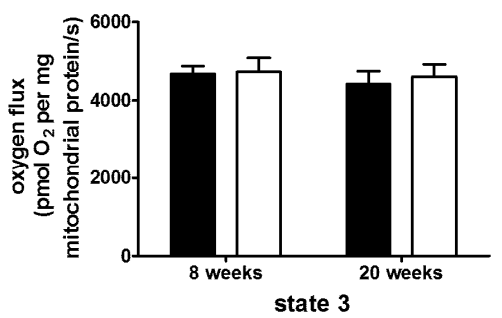

B

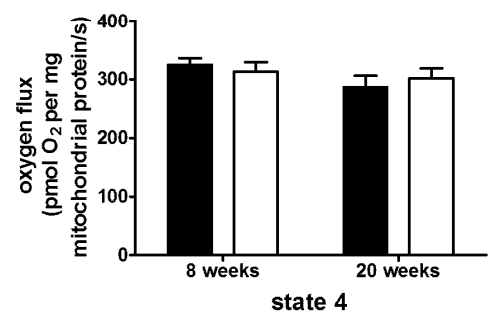

C

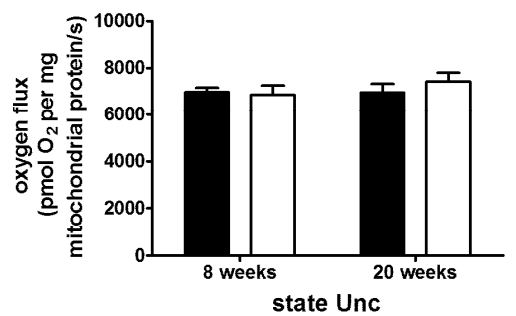

D

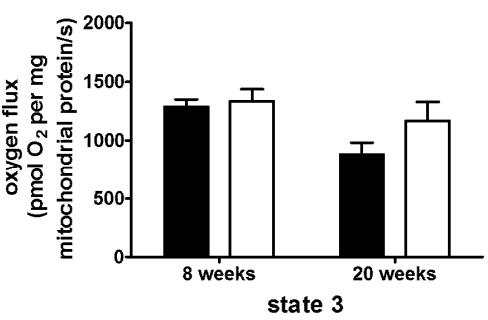

$\mathrm{E}$

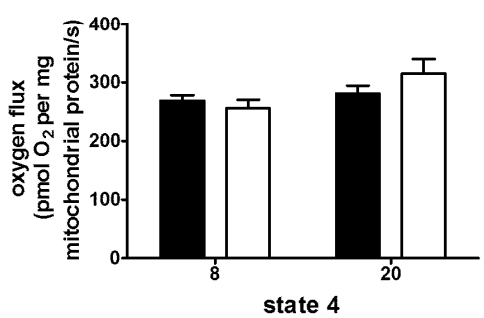

$\mathrm{F}$

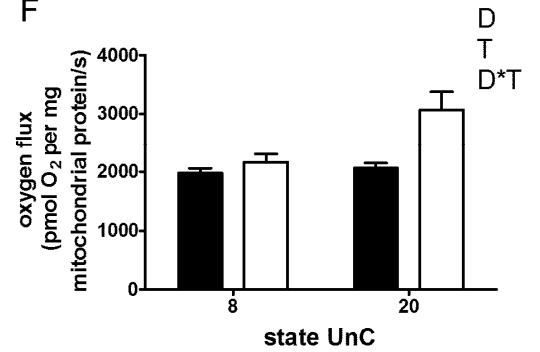

Figure 4.1 Respiration of skeletal muscle mitochondria respiring on (A) state 3 on pyruvate, (B) state 4 on pyruvate, (C) state UnC on pyruvate, (D) state 3 on palmitoylCoA + carnitine, (E) state 4 on palmitoyl$\mathrm{CoA}+$ carnitine and (F) state UnC on palmitoyl-CoA + carnitine. Black bars and white bars represent LFD mice and HFD mice, respectively. Values are means \pm SE $(n=7-8)$. $D$, significant diet effect with $p<0.01$; $\mathrm{T}$, significant time effect with $p<0.05$ in state 3 and state 4 and with $p<0.01$ in state UnC; $\mathrm{D}^{*} \mathrm{~T}$, significant diet * time effect with $p<0.05$; HFD, high fat diet; LFD, low fat diet; UnC, uncoupled. 


\section{Parameters of mitochondrial density}

Three parameters for mitochondrial density were analyzed in the TA muscle. First, only a significantly time-related increase of the mitochondrial DNA copy number was found (Table 5). Secondly, we determined the protein levels of subunits of the five complexes of the respiration chain by Western blotting, showing a significantly higher complex I-V combined protein level in HFD mice than LFD mice (8-week: $+41 \%$ and 20 -week: $+78 \%$ ). Furthermore, a significant diet $*$ time effect was observed, with a stronger increase in protein expression with time in HFD mice than LFD mice ( $+97 \%$ vs. $+57 \%$ in HFD vs. LFD) (Table 5 ). Representative examples of the Western blot are shown in Supplemental Figure 4.1. Thirdly, we measured the activity of two mitochondrial enzymes, CS and HAD. Neither diet, nor time significantly influenced CS activity. HAD activity was higher in HFD mice than LFD mice (8-week: $+30 \%$ and 20 -week: $+23 \%$ ), however, this difference was not statistically significant (Table 4.5). No correlations were found between the three different parameters.

Table 4.5 Parameters for mitochondrial density in the TA muscle.

\begin{tabular}{|c|c|c|c|c|c|c|c|}
\hline & \multicolumn{2}{|c|}{8 weeks } & \multicolumn{2}{|c|}{20 weeks } & \multicolumn{3}{|c|}{$P$ value } \\
\hline & LFD & HFD & LFD & HFD & diet & time & $\begin{array}{l}\text { diet } * \\
\text { time }\end{array}$ \\
\hline $\begin{array}{l}\text { Mitochdrial DNA copy } \\
\text { number (AU) }\end{array}$ & $\begin{array}{l}0.96 \pm \\
0.07\end{array}$ & $\begin{array}{c}0.99 \pm \\
0.11\end{array}$ & $\begin{array}{c}1.36 \pm \\
0.14\end{array}$ & $\begin{array}{c}1.19 \pm \\
0.05\end{array}$ & 0.469 & 0.007 & 0.336 \\
\hline $\begin{array}{l}\text { Sum of the } 5 \text { complexes } \\
\text { of respiratory chain (AU) }\end{array}$ & $\begin{array}{c}4.6 \pm \\
0.4\end{array}$ & $\begin{array}{c}6.5 \pm \\
0.5\end{array}$ & $\begin{array}{c}7.2 \pm \\
0.7\end{array}$ & $\begin{array}{c}12.8 \pm \\
0.9\end{array}$ & $<0.001$ & $<0.001$ & 0.012 \\
\hline $\begin{array}{l}\text { CS } \\
\text { ( } \mu \mathrm{mol} / \mathrm{min} / g \text { protein) }\end{array}$ & $\begin{array}{c}29.0 \pm \\
1.8\end{array}$ & $\begin{array}{c}31.5 \pm \\
2.1\end{array}$ & $\begin{array}{c}31.1 \pm \\
2.6\end{array}$ & $\begin{array}{c}32.6 \pm \\
2.7\end{array}$ & 0.399 & 0.488 & 0.828 \\
\hline $\begin{array}{l}\text { HAD } \\
\text { ( } \mu \mathrm{mol} / \mathrm{min} / g \text { protein) }\end{array}$ & $\begin{array}{c}8.7 \pm \\
1.2\end{array}$ & $\begin{array}{c}11.3 \pm \\
1.1\end{array}$ & $\begin{array}{c}10.2 \pm \\
1.3\end{array}$ & $\begin{array}{c}12.5 \pm \\
1.5\end{array}$ & 0.064 & 0.303 & 0.926 \\
\hline
\end{tabular}

Parameters in the TA muscle in LFD mice and HFD mice at 8 weeks and 20 weeks. Values are means \pm SE $(n=6-8)$. CS, citrate synthase; HAD, $\beta$-hydroxyacyl-CoA dehydrogenase; HFD, high fat diet; LFD, low fat diet; TA, tibialis anterior.

\section{Plasma parameters}

Fasting leptin, glucose and insulin levels as well as the calculated HOMA-IR are shown in Table 4.6. Plasma leptin, glucose and insulin were all significantly higher in HFD mice than LFD mice. Between week 8 and week 20 a significant increase of plasma leptin and insulin was found. Additionally, a significant diet * time interaction for insulin was observed, with a higher increase of plasma insulin with time in HFD mice as compared to LFD mice. HOMA-IR was significantly higher in HFD mice than LFD mice (8-week: 3.45-fold and 20-week: 5.26-fold). At week 20, the HOMA-IR was significantly higher than at week 8 . In addition, a significant diet * time interaction was found, with a more pronounced increase of HOMA IR with time in HFD as compared to LFD mice (2.36-fold vs. 1.55 -fold in HFD vs. LFD). 
Table 4.6 Plasma levels of leptin, glucose and insulin after 8 weeks and 20 weeks of diet intervention

\begin{tabular}{|c|c|c|c|c|c|c|c|}
\hline & \multicolumn{2}{|c|}{ Week 8} & \multicolumn{2}{|c|}{ Week 20} & \multicolumn{3}{|c|}{$P$ value } \\
\hline & LFD & HFD & LFD & HFD & diet & time & diet * time \\
\hline Fasting leptin & $7.3 \pm$ & $57.2 \pm$ & $14.9 \pm$ & $65.8 \pm$ & $<0.001$ & 0.031 & 0.902 \\
\hline (ng/ml) & 1.2 & 3.4 & 2.7 & 5.4 & & & \\
\hline Fasting glucose & $8.2 \pm$ & $10.3 \pm$ & $8.2 \pm$ & $9.2 \pm$ & $<0.001$ & 0.120 & 0.110 \\
\hline (mmol/l) & 0.4 & 0.3 & 0.3 & 0.3 & & & \\
\hline Fasting insulin & $12.3 \pm$ & $32.6 \pm$ & $17.6 \pm$ & $88.8 \pm$ & $<0.001$ & $<0.001$ & $<0.001$ \\
\hline$(\mu \mathrm{U} / \mathrm{ml})$ & 2.5 & 3.9 & 5.2 & 9.9 & & & \\
\hline HOMA IR & $4.4 \pm$ & $15.2 \pm$ & $6.8 \pm$ & $35.8 \pm$ & $<0.001$ & $<0.001$ & $<0.001$ \\
\hline & 0.7 & 2.0 & 1.8 & 3.8 & & & \\
\hline
\end{tabular}

Values are means \pm SE $(n=14-17)$. HFD, high fat diet; HOMA IR, the homeostasis model assessment of insulin resistance; LFD, low fat diet.

\section{Discussion}

In the present study we examined the hypothesis that an increased consumption of saturated fat results in more saturated mitochondrial phospholipids leading to mitochondrial dysfunction. As both mitochondrial dysfunction $(1,2,8,9)$ and FA composition of skeletal muscle membrane phospholipids $(22-24,34)$ have been associated with insulin resistance, we also assessed insulin sensitivity. We found that skeletal muscle mitochondrial phospholipids of HFD mice contained relatively less MUFA than mitochondrial phospholipids of LFD mice. Interestingly, the decrease in MUFA was accompanied by an increase in SFA at week 8 , whereas a prominent increase of n-6 PUFA was observed at 20 weeks. Despite the increase in SFA in mitochondrial phospholipids, mitochondrial function in 8-week HFD mice was comparable with LFD mice. At week 20, we found that respiration on palmitoyl-CoA was higher in HFD mice than LFD mice. Irrespective of these changes in mitochondrial membrane composition and function, HFD mice were insulin resistant at both 8 and 20 weeks.

Cellular membranes such as the mitochondrial membrane maintain and regulate ionic gradients, potential differences and uptake of substrates such as fatty acyl CoAs (35). The FA composition and the degree of saturation of these phospholipids are of great importance for fluidity, permeability and thus for proper function of the mitochondrial membrane $(35,36)$. Previously, we demonstrated that a 4-week HFD results in an increased saturation of skeletal muscle phospholipids. This increased saturation was especially evident in phosphatidylcholine and phosphatidylethanolamine (17), which make up more than 70 percent of the mitochondrial membrane of mouse skeletal muscle (data not shown). Here, we found that at 8 weeks skeletal muscle mitochondrial phospholipids of HFD mice contained less MUFA and more SFA, corroborating our previous findings (17). Numerous studies have linked the FA 
composition of skeletal muscle phospholipids and insulin sensitivity. A reduced insulin sensitivity is associated with a high amount of SFA and a low n-3 vs. n-6 PUFA ratio $(22-24,34)$. In line with this, we are the first to show that an increase in SFA and a decrease in the ratio n-3 vs. n-6 PUFA are also observed in skeletal muscle mitochondrial membrane phospholipids of HFD-induced insulin resistant mice.

Both the amount and type of dietary fat will influence the FA composition of phospholipids. Especially, the PUFA are strongly influenced by these dietary factors (21, $24,36)$. In the current study we used palm oil which contains primarily 16:0, 18:0, 18:1n9 and 18:2n6. As compared to LFD mice, mitochondrial phospholipids of HFD mice contained more 16:0 and 18:2n6. As 18:2n6 cannot be synthesized de novo by mammals such as mice $(21,37)$, these increases are most likely explained by an increased dietary intake. Despite an increased fat intake, relatively lower 18:1n9 levels were found in mitochondrial phospholipids of HFD mice than LFD mice. In comparison with $16: 0,18: 1 \mathrm{n} 9$ is preferably oxidized (38) or otherwise incorporated in TAG (39). This suggests that the decreased amount of 18:1n9 might be explained by differences in cellular fate. Also decreased amounts of 16:1n7 and 18:1n7 were found in mitochondrial phospholipids of HFD mice. Each MUFA can be synthesized by combined activity of desaturases and elongases $(37,40)$. As reduced gene expression of these enzymes has been detected in muscle of mice (17) it is possible that reduced activity of desaturases and elongases is responsible for the observed decline of MUFA in HFD mice. Altogether, the FA composition of mitochondrial phospholipids is influenced by numerous factors.

Mitochondrial respirometry was performed to test whether HFD-induced changes in FA composition of mitochondrial phospholipids lead to an altered mitochondrial function. At 8 weeks, 16:0 was increased in mitochondrial phospholipids of HFD mice. As increased levels of SFA are associated with decreased activity of mitochondrial enzymes (25) we anticipated an impaired mitochondrial function in HFD mice. Surprisingly, neither pyruvate-driven respiration nor respiration on palmitoyl-CoA was altered upon 8-week HFD. Thus, mitochondrial function was similar between HFD mice and LFD mice. At week 20, we found that the increase of n-6 PUFA and the higher unsaturation index in HFD mice coincided with enhanced mitochondrial capacity to oxidize lipids. An increased desaturation improves membrane fluidity and responsiveness of membrane-bound proteins $(21,36)$. Therefore, one could speculate that this increased desaturation of mitochondrial phospholipids has contributed to the enhanced mitochondrial respiration on palmitoyl-CoA. However, the increased desaturation did not improve pyruvate-driven respiration of HFD mice. These results indicate that it is not the mitochondrial phospholipid composition per se that alters mitochondrial function. Additionally, increased mitochondrial FA oxidative capacity in 20-week HFD mice was accompanied by increases of OXPHOS protein expression and HAD activity. As CS activity in HFD mice was comparable to LFD 
mice, these results point to a specific adaptation of FA oxidative capacity ( $\beta$ oxidation) in skeletal muscle of HFD mice.

To be able to measure both mitochondrial phospholipid composition and function in each individual mouse, we studied a mitochondrial pool derived from mixed muscle. In this context, we also determined the phospholipid composition of mitochondria isolated from individual muscles, the gastrocnemius and quadriceps muscle in a parallel experiment. The results show similar changes in response to the dietary interventions, when compared to the mixed mitochondrial pool (Supplemental Tables 4.2 and 4.3). Additionally, we did not observe striking differences between the gastrocnemius and quadriceps muscle with respect to the parameters of mitochondrial density. As small discrepancies were observed (Supplemental Table 4.4), we cannot fully exclude the possibility that the dietary intervention differentially affected mitochondrial function across various muscle types.

HOMA-IR was significantly higher in HFD mice than in LFD mice at both 8 weeks and 20 weeks. Moreover, de Wit et al. (26) demonstrated that a 7-week intervention with this specific HFD results in decreased glucose tolerance as assessed by OGTT. As HOMA-IR and OGTT are not specific for skeletal muscle insulin resistance we performed hyperinsulinemic-euglycemic clamps. The results of this experiment (Supplemental Figure 4.2) clearly indicate that this specific HFD induces peripheral insulin resistance already upon 5 weeks of dietary intervention. Interestingly, insulin resistance was characterized by an impaired peripheral insulin sensitivity only. As it is well known that the skeletal muscle is responsible for the majority of insulinstimulated glucose uptake and metabolism it is highly unlikely that skeletal muscle insulin sensitivity was not impaired by the HFD at week 8 or week 20.

Altogether, despite an improved capacity to oxidize lipids, peripheral insulin sensitivity was impaired in HFD mice at both 8 and 20 weeks. This is in line with numerous studies suggesting that an HFD does not induce insulin resistance by decreasing skeletal muscle mitochondrial FA oxidative capacity (14-18). However, we cannot exclude that changes in liver mitochondria occurred upon HFD as shown previously (41), possibly affecting liver insulin sensitivity and contributing to the elevated HOMA-IR.

In conclusion, an 8-week HFD results in more saturated skeletal muscle mitochondrial phospholipids, whereas an increased unsaturation is found at 20 weeks. Thus, an HFD induces positive adaptations in the FA composition of mitochondrial phospholipids in the long run. At both time points no evidence for mitochondrial dysfunction was observed. In fact, an adaptive increase of FA oxidative capacity was found after the 20-week HFD. Peripeheral insulin sensitivity in HFD mice was reduced at both time points. Altogether, a mid-term HFD results in a more saturated skeletal muscle mitochondrial membrane, not affecting mitochondrial function. A long-term HFD results in a more unsaturated mitochondrial membrane and an increased capacity to oxidize lipids. As these adaptations cannot prevent the occur- 
rence or progression of insulin resistance we conclude that HFD-induced changes in skeletal muscle mitochondrial phospholipids and function are unrelated to the deterioration of insulin sensitivity.

\section{Acknowledgements}

The authors would like to thank Bert Weijers and Nicole de Wit (both from the Nutrition, Metabolism and Genomics group, Wageningen University, Wageningen, the Netherlands) for their excellent help with the animal experiments. Ivar Gondrie is acknowledged (student Maastricht University Medical Centert, Maastricht, the Netherlands) for his excellent help with the mitochondrial respiration experiments. Finally, we would like to thank Hasibe Aydeniz, Joan Senden and Jos Stegen (all from Department of Human Biology, Maastricht University Medical Center+, Maastricht, the Netherlands) for their excellent technical assistance with the analysis of the fatty acid composition of mitochondrial phospholipids and the activity measurements of mitochondrial enzymes. This study was funded by the Top Institute Food and Nutrition, with financial support by the Dutch government. Joris Hoeks was supported by a grant from The Netherlands Organization for Health Research \& Development (ZonMw) (Grant No. 9120.6050). Sjoerd van den Berg was supported by the Netherlands Consortium for System Biology.

\section{References}

1. Phielix E, Schrauwen-Hinderling VB, Mensink M, Lenaers E, Meex R, Hoeks J, et al. Lower intrinsic ADP-stimulated mitochondrial respiration underlies in vivo mitochondrial dysfunction in muscle of male type 2 diabetic patients. Diabetes. 2008 Nov;57(11):2943-9.

2. Schrauwen-Hinderling VB, Kooi ME, Hesselink MK, Jeneson JA, Backes WH, van Echteld CJ, et al. Impaired in vivo mitochondrial function but similar intramyocellular lipid content in patients with type 2 diabetes mellitus and BMI-matched control subjects. Diabetologia. 2007 Jan;50(1):113-20.

3. Mootha VK, Lindgren CM, Eriksson KF, Subramanian A, Sihag S, Lehar J, et al. PGC-1alpha-responsive genes involved in oxidative phosphorylation are coordinately downregulated in human diabetes. Nat Genet. 2003 Jul;34(3):267-73.

4. Boushel R, Gnaiger E, Schjerling P, Skovbro M, Kraunsoe R, Dela F. Patients with type 2 diabetes have normal mitochondrial function in skeletal muscle. Diabetologia. $2007 \mathrm{Apr}$;50(4):790-6.

5. Kelley DE, He J, Menshikova EV, Ritov VB. Dysfunction of mitochondria in human skeletal muscle in type 2 diabetes. Diabetes. 2002 Oct;51(10):2944-50.

6. Patti ME, Butte AJ, Crunkhorn S, Cusi K, Berria R, Kashyap S, et al. Coordinated reduction of genes of oxidative metabolism in humans with insulin resistance and diabetes: Potential role of PGC1 and NRF1. Proceedings of the National Academy of Sciences of the United States of America. 2003 Jul 8;100(14):8466-71.

7. Petersen KF, Dufour S, Befroy D, Garcia R, Shulman GI. Impaired mitochondrial activity in the insulinresistant offspring of patients with type 2 diabetes. N Engl J Med. 2004 Feb 12;350(7):664-71. 
8. Lowell BB, Shulman GI. Mitochondrial dysfunction and type 2 diabetes. Science (New York, NY. 2005 Jan 21;307(5708):384-7.

9. Savage DB, Petersen KF, Shulman GI. Disordered lipid metabolism and the pathogenesis of insulin resistance. Physiological reviews. 2007 Apr;87(2):507-20.

10. Richardson DK, Kashyap S, Bajaj M, Cusi K, Mandarino SJ, Finlayson J, et al. Lipid infusion decreases the expression of nuclear encoded mitochondrial genes and increases the expression of extracellular matrix genes in human skeletal muscle. The Journal of biological chemistry. 2005 Mar 18;280(11):10290-7.

11. Hoeks J, Hesselink MK, Russell AP, Mensink M, Saris WH, Mensink RP, et al. Peroxisome proliferatoractivated receptor-gamma coactivator-1 and insulin resistance: acute effect of fatty acids. Diabetologia. 2006 Oct;49(10):2419-26.

12. Brehm A, Krssak M, Schmid Al, Nowotny P, Waldhausl W, Roden M. Increased lipid availability impairs insulin-stimulated ATP synthesis in human skeletal muscle. Diabetes. 2006 Jan;55(1):136-40.

13. Sparks LM, Xie H, Koza RA, Mynatt R, Hulver MW, Bray GA, et al. A high-fat diet coordinately downregulates genes required for mitochondrial oxidative phosphorylation in skeletal muscle. Diabetes. 2005 Jul;54(7):1926-33.

14. Hancock CR, Han DH, Chen M, Terada S, Yasuda T, Wright DC, et al. High-fat diets cause insulin resistance despite an increase in muscle mitochondria. Proceedings of the National Academy of Sciences of the United States of America. 2008 Jun 3;105(22):7815-20.

15. Iossa S, Mollica MP, Lionetti L, Crescenzo R, Botta M, Liverini G. Skeletal muscle oxidative capacity in rats fed high-fat diet. Int J Obes Relat Metab Disord. 2002 Jan;26(1):65-72.

16. Turner N, Bruce CR, Beale SM, Hoehn KL, So T, Rolph MS, et al. Excess lipid availability increases mitochondrial fatty acid oxidative capacity in muscle: evidence against a role for reduced fatty acid oxidation in lipid-induced insulin resistance in rodents. Diabetes. 2007 Aug;56(8):2085-92.

17. de Wilde J, Mohren R, van den Berg S, Boekschoten M, Dijk KW, de Groot P, et al. Short-term high fat-feeding results in morphological and metabolic adaptations in the skeletal muscle of C57BL/6J mice. Physiol Genomics. 2008 Feb 19;32(3):360-9.

18. Hoeks J, Briede JJ, de Vogel J, Schaart G, Nabben M, Moonen-Kornips E, et al. Mitochondrial function, content and ROS production in rat skeletal muscle: Effect of high-fat feeding. FEBS letters. 2008 Feb 20;582(4):510-6.

19. Holloszy JO. Skeletal muscle "mitochondrial deficiency" does not mediate insulin resistance. Am J Clin Nutr. 2009 January 1, 2009;89(1):463S-6.

20. Schrauwen P, Schrauwen-Hinderling VB, Hoeks J, Hesselink MKC. Mitochondrial dysfunction and lipotoxicity. Biochimica et biophysica acta. 2010;1801(3):266-71.

21. Hulbert AJ, Turner N, Storlien LH, Else PL. Dietary fats and membrane function: implications for metabolism and disease. Biol Rev Camb Philos Soc. 2005 Feb;80(1):155-69.

22. Vessby $B$, Tengblad S, Lithell $H$. Insulin sensitivity is related to the fatty acid composition of serum lipids and skeletal muscle phospholipids in 70-year-old men. Diabetologia. 1994 Oct;37(10):1044-50.

23. Pan DA, Lillioja S, Milner MR, Kriketos AD, Baur LA, Bogardus C, et al. Skeletal muscle membrane lipid composition is related to adiposity and insulin action. The Journal of clinical investigation. 1995 Dec;96(6):2802-8.

24. Haugaard SB, Madsbad S, Hoy CE, Vaag A. Dietary intervention increases n-3 long-chain polyunsaturated fatty acids in skeletal muscle membrane phospholipids of obese subjects. Implications for insulin sensitivity. Clin Endocrinol (Oxf). 2006 Feb;64(2):169-78.

25. Vazquez-Memije ME, Cardenas-Mendez MJ, Tolosa A, Hafidi ME. Respiratory chain complexes and membrane fatty acids composition in rat testis mitochondria throughout development and ageing. Exp Gerontol. 2005 Jun;40(6):482-90.

26. de Wit NJ, Bosch-Vermeulen H, de Groot PJ, Hooiveld GJ, Bromhaar MM, Jansen J, et al. The role of the small intestine in the development of dietary fat-induced obesity and insulin resistance in C57BL/6J mice. BMC medical genomics. 2008;1:14. 
27. Silva JP, Shabalina IG, Dufour E, Petrovic N, Backlund EC, Hultenby K, et al. SOD2 overexpression: enhanced mitochondrial tolerance but absence of effect on UCP activity. The EMBO journal. 2005;24(23):4061-70.

28. Shabalina IG, Hoeks J, Kramarova TV, Schrauwen P, Cannon B, Nedergaard J. Cold tolerance of UCP1ablated mice: A skeletal muscle mitochondria switch toward lipid oxidation with marked UCP3 upregulation not associated with increased basal, fatty acid- or ROS-induced uncoupling or enhanced GDP effects. Biochimica et biophysica acta. 2010 Mar 19.

29. Udenfriend S, Stein S, Bohlen P, Dairman W, Leimgruber W, Weigele M. Fluorescamine: a reagent for assay of amino acids, peptides, proteins, and primary amines in the picomole range. Science (New York, NY. 1972 Nov 24;178(63):871-2.

30. Goyens PL, Spilker ME, Zock PL, Katan MB, Mensink RP. Compartmental modeling to quantify alphalinolenic acid conversion after longer term intake of multiple tracer boluses. Journal of lipid research. 2005 Jul;46(7):1474-83.

31. Lemieux H, Blier PU, Tardif JC. Does membrane fatty acid composition modulate mitochondrial functions and their thermal sensitivities? Comp Biochem Physiol A Mol Integr Physiol. 2008 Jan;149(1):20-9.

32. Alaynick WA, Kondo RP, Xie W, He W, Dufour CR, Downes M, et al. ERRgamma directs and maintains the transition to oxidative metabolism in the postnatal heart. Cell metabolism. $2007 \mathrm{Jul} ; 6(1): 13-24$.

33. den Hoed M, Hesselink MK, van Kranenburg GP, Westerterp KR. Habitual physical activity in daily life correlates positively with markers for mitochondrial capacity. J Appl Physiol. 2008 Aug;105(2):561-8.

34. Borkman M, Storlien LH, Pan DA, Jenkins AB, Chisholm DJ, Campbell LV. The relation between insulin sensitivity and the fatty-acid composition of skeletal-muscle phospholipids. N Engl J Med. 1993 Jan 28;328(4):238-44.

35. Pan DA, Hulbert AJ, Storlien LH. Dietary fats, membrane phospholipids and obesity. The Journal of nutrition. 1994 Sep;124(9):1555-65.

36. Haag M, Dippenaar NG. Dietary fats, fatty acids and insulin resistance: short review of a multifaceted connection. Med Sci Monit. 2005 Dec;11(12):RA359-67.

37. Nakamura MT, Nara TY. STRUCTURE, FUNCTION, AND DIETARY REGULATION OF Î"6, Î”5, AND Î"9 DESATURASES. 2004:345-76.

38. Leyton J, Drury PJ, Crawford MA. Differential oxidation of saturated and unsaturated fatty acids in vivo in the rat. British Journal of Nutrition. 1987;57:383-93.

39. Listenberger LL, Han X, Lewis SE, Cases S, Farese RV, Jr., Ory DS, et al. Triglyceride accumulation protects against fatty acid-induced lipotoxicity. Proceedings of the National Academy of Sciences of the United States of America. 2003 Mar 18;100(6):3077-82.

40. Vessby B, Gustafsson IB, Tengblad S, Boberg M, Andersson A. Desaturation and elongation of Fatty acids and insulin action. Ann N Y Acad Sci. 2002 Jun;967:183-95.

41. Giudetti AM, Sabetta S, di Summa R, Leo M, Damiano F, Siculella L, et al. Differential effects of coconut oil- and fish oil-enriched diets on tricarboxylate carrier in rat liver mitochondria. Journal of lipid research. 2003 November 1, 2003;44(11):2135-41. 


\section{CHAPTER 5 Adipophilin protein expression in muscle: a possible protective role against insulin resistance}

Janneke de Wilde, Egbert Smit, Frank J.M. Snepvangers, Nicole W.J. de Wit, Ronny Mohren, Martijn F.M. Hulshof and Edwin C.M. Mariman

FEBS journal. 2010; 277(3): 761-773 


\begin{abstract}
Adipophilin is a $50 \mathrm{kDa}$ protein that belongs to the PAT family which are proteins involved in the coating of lipids droplets. Little is known about the functional role of adipophilin in muscle. Using the $\mathrm{C} 2 \mathrm{C} 12$ cell line as a model we demonstrate that palmitic acid-treated cells highly express the adipophilin protein in a dosedependent way. Next, we show that oleic acid is a more potent inducer of adipophilin protein levels than palmitic acid. Cells treated with oleic acid have higher adipophilin protein expression, higher triglyceride levels, but less impairment of insulin signaling than cells treated with palmitic acid. Additionally, we show that PPAR $\alpha$, PPAR $\beta / \delta$ and PPAR $\gamma$ agonists all increase the expression of the adipophilin protein in $\mathrm{C} 2 \mathrm{C} 12$ cells. This effect was most pronounced for the PPAR $\alpha$ agonist GW7647. Furthermore, expression of adipophilin as a $37 \mathrm{kDa} \mathrm{N}$-terminally truncated protein is higher in the gastrocnemius than in the quadriceps of C57BL/6J mice, especially after an 8-week high fat diet. The expression of adipophilin was higher in muscle of mice fed a 4-week high fat diet based on olive oil or safflower oil than a 4-week high fat diet based on palm oil. After 2 weeks of intervention, plasma glucose, plasma insulin and the homeostasis model assessment of insulin resistance (HOMA-IR) were lower in mice fed a 4-week high fat diet based on olive oil or safflower oil than a 4week high fat diet based on palm oil. Altogether, our results indicate that Adfp protein expression in muscle is involved in maintaining insulin sensitivity.
\end{abstract}




\section{Introduction}

The metabolic syndrome (MetS) is a multi-component metabolic disorder associated with an increased risk for type 2 diabetes mellitus (T2DM) and cardiovascular diseases $(1,2)$. The increasing prevalence of the MS is caused by a combination of lifestyle factors, such as nutrition and limited physical activity, which are known to contribute to the pathogenesis of the MetS (3). Two major characteristics underlying the MetS are obesity and insulin resistance $(4,5)$. Additionally, obesity is considered as the principal cause of insulin resistance $(3,4)$. Because the skeletal muscle is the major site of insulin-stimulated glucose metabolism, it plays an important role in the etiology of insulin resistance and the MetS (5).

Insulin promotes the uptake of glucose via the activation of the phosphatidylinositol 3-kinase (PI3K) pathway, which is responsible for most of the metabolic actions of insulin. Upon activation of PI3K, Akt/PKB is activated by phosphorylation. Consequently, glucose transporter 4 (GLUT4) is translocated to the cell membrane mediating the uptake of glucose (6). Impaired insulin signaling, as observed in obesity and T2DM, is strongly associated with excess accumulation of triacylglycerols (TAG) in the skeletal muscle (7-10). Paradoxically, endurance training has shown to improve insulin sensitivity, whereas levels of intramuscular TAG increased upon training $(11,12)$. Therefore, it has been proposed that it are not TAG per se, but lipid intermediates such as long-chain fatty acyl CoAs, diacylglycerol and ceramides that may act as signaling molecules which interrupt insulin signaling and glucose metabolism. Eventually this will result in insulin resistance $(13,14)$.

TAG are mainly stored as lipids droplets (LDs) surrounded by a phospholipid monolayer and coated with one or more proteins of the PAT family (Perilipin, Adipophilin (Adfp), TIP47, S3-12 and OXPAT) (15-17). The best-characterized member of the PAT family is perilipin. Perilipin is exclusively expressed in adipocytes and steroidogenic cells (17), where it is involved in the regulation of the storage and lipolysis of TAG (18-22). Whereas Adfp was originally discovered as one of the earliest markers of adipocyte development, today Adfp is known to be ubiquitously expressed including in skeletal muscle (23). Recent in vitro studies have provided more insight in the functional role of Adfp. In various cell types it has been shown that Adfp overexpression stimulates the uptake of fatty acids (FA) (24), increases the storage of TAG (25-27) and decreases the turnover rate of TAG (25). Expression of Adfp is regulated by the nuclear hormone receptors of the peroxisome proliferator-activated receptor (PPAR) family. The three PPAR family members PPAR $\alpha$, PPAR $\beta / \delta$ and PPAR $\gamma$ all increase the expression of Adfp (28), but little is known about regulation in the skeletal muscle. In mouse skeletal muscle, PPAR $\alpha$ is involved in the regulation of Adfp expression (29), whereas ambiguous results about the role of PPARy in regulation of Adfp expression in human skeletal muscle are reported $(30,31)$. 
In the present study, we searched for changes in the proteome of muscle cells exposed to palmitic acid. The $\mathrm{C} 2 \mathrm{C} 12$ cell line, which is commonly used to study the mouse skeletal muscle in vitro, was chosen as a model. By using two-dimensional gel electrophoresis (2-DE) we identified 14 proteins regulated by the incubation with palmitic acid. The protein with the strongest regulation was identified as Adfp. Additional experiments were performed to get more insight in the regulation of Adfp expression in muscle cells. We studied the effect of palmitic acid and oleic acid on insulin signaling and the accumulation of TAG in relation to Adfp protein levels. Furthermore, we examined the responsiveness of the $\mathrm{C} 2 \mathrm{C} 12$ cell line to different PPAR agonists. To assess the in vivo relevance of these findings, we measured the Adfp protein levels in two muscle groups of mice fed an 8-week low fat diet or high fat diet based on palm oil (LFD-P and HFD-P). Finally, we studied Adfp protein levels in muscle of mice fed a 4-week HFD based on palm oil (HFD-P), olive oil (HFD-O) and safflower oil (HFD-S).

\section{Methods}

\section{Materials}

The C2C12 cell line was obtained from the American Type Culture Collection (ATCC; order number: CRL-1772). Dulbecco's Modified Eagle Medium (DMEM), streptomycin and penicillin were obtained from Invitrogen (Leek, the Netherlands). Fetal calf serum (FCS) was obtained from Bodinco (Alkmaar, the Netherlands) and matrigel was from Beckton Dickinson (Nieuwegein, the Netherlands). Urea, SYPRO Ruby Protein Stain and all other reagents for SDS-PAGE and blotting were from Bio-Rad (Veenendaal, the Netherlands). The C-terminal specific Adfp antibody was from Bioconnect (Huissen, the Netherlands). The N-terminal specific Adfp antibody was from Fitzgerald Industries International (Conrad, USA). The total Akt, pAkt(Ser473) and GAPDH antibodies were obtained from Cell Signaling Technologies (Bioké, Leiden, the Netherlands). Secondary antibodies were purchased from Dako (Glostrup, Denmark). Cellular accumulation of triglycerides was determined in cell lysates using an enzymatic triglyceride assay (Sigma). Unless otherwise indicated, all chemicals were obtained from Sigma (Zwijndrecht, the Netherlands).

\section{C2C12 cell culture}

C2C12 cells were cultured in DMEM with $10 \%(\mathrm{v} / \mathrm{v})$ FCS supplemented with penicillin $(100 \mu \mathrm{g} / \mathrm{ml})$ and streptomycin $(100 \mu \mathrm{g} / \mathrm{ml})$ at $37^{\circ} \mathrm{C}$ in a humidified atmosphere of $5 \% \mathrm{CO}_{2}$ in air. Differentiation was induced as described and experiments were performed in 7-day differentiated myotubes (32). All experiments were performed as 
triplicates with the exception of the transcriptional regulatory pathway experiment which was performed in duplicate.

\section{Fatty acid incubations}

Stock solutions (40 mM) were made in ethanol for both palmitic acid and oleic acid. FA were conjugated to BSA by diluting the FA stock solution 1:100 with differentiation medium containing $0.1 \%$ FA-free BSA. After incubating at $37{ }^{\circ} \mathrm{C}$ for $1 \mathrm{~h}$, solutions were filter-sterilized. Before applying to cells, solutions were diluted with differentiation medium containing $0.1 \%$ FA-free BSA to appropriate concentrations (50 $400 \mu \mathrm{M})$. As control condition we used differentiation medium with $0.1 \%$ FA-free BSA.

\section{Examination of palmitic acid effects on protein expression profiles of $\mathrm{C2C12}$ cells}

C2C12 cells were incubated with $0 \mu \mathrm{M}$ or $400 \mu \mathrm{M}$ palmitic acid for $16 \mathrm{~h}$. C2C12 cells were harvested in classical lysis buffer (CLB; $8 \mathrm{M}$ urea, 2\% w/v CHAPS, $65 \mathrm{mM}$ dithiothreitol). The protein concentrations of the samples were measured with a protein assay kit (Bio-Rad), based on the method of Bradford. Aliquots were stored at $-80^{\circ} \mathrm{C}$. Protein samples were analyzed by 2-DE as described (33), but with $24-\mathrm{cm} \mathrm{pH} 3-10$ NL strips. Gels were stained with SYPRO Ruby Protein Stain according to the manufacturer's protocol. Proteins were visualized by gel scanning using the Molecular Imager FX (Bio-Rad). Examination of differentially expressed proteins was performed using the image analysis software PDQuest 8.0 (Bio-Rad). Data were normalized with respect to total density of the gel image. A spot was regarded significantly differentially expressed if the average spot density differed $\geq 1.5$ fold with a $p$ value $<0.05$ (obtained from an unpaired $t$ test) or when the spot was absent in one of the two conditions. Differentially expressed spots were excised from the gel with an automated Spot Cutter (Bio-Rad). Excised protein spots were subjected to tryptic ingel digestion and MALDI-TOF-MS (Waters, Manchester, UK). A peptide mass list was generated by MassLynx 4.0.5 (Waters) for subsequent database search. This peptide mass list was searched with the Mascot search engine (version 2.2.04; Matrix Science, London, UK) against the Swiss-Prot database (SwissProt release 56.5; 402482 sequences) for protein identification. One miss-cleavage was tolerated, carbamidomethylation was set as a fixed modification and oxidation of methionine as an optional modification. The peptide mass tolerance was set to $100 \mathrm{ppm}$. No restrictions were made on the protein molecular weight and the isoelectric point. Taxonomy was set to Mus musculus and MASCOT probability scores were calculated using the peaks with highest signal intensity, excluding trypsin peaks. A protein was regarded as identified with a significant MASCOT probability score, i.e., protein 
scores greater than $54(p<0.05)$ and with at least 4 peptides, excluding different forms of the same peptide, assigned to the protein.

\section{The effect of palmitic acid and oleic acid on Adfp protein levels}

C2C12 cells were incubated with $0,50,100,200$ and $400 \mu \mathrm{M}$ palmitic acid or oleic acid for $16 \mathrm{~h}$. C2C12 cells were harvested in CLB and Western blotting was performed as described earlier (34). Briefly, total protein was separated by SDS-PAGE on 4-12\% Bis-Tris Criterion gels at $150 \mathrm{~V}$ and transferred to a polyvinylidene fluoride membrane for $90 \mathrm{~min}$ at $100 \mathrm{~V}$. Blocking steps were performed in TBST supplemented with $5 \%$ non-fat dry milk. Antibody incubation steps of the membrane were performed in TBST supplemented with 5\% BSA. Membranes were incubated overnight with C-terminal specific Adfp and GAPDH antibodies at $4^{\circ} \mathrm{C}$. After washing with TBST, membranes were incubated with a HRP-conjugated secondary Ab and signals were detected by ECL using Pierce reagents. Films were scanned with a GS800 densitometer (Bio-Rad) and signals were quantified with Quantity One software (BioRad). The signal intensity of Gapdh or Acta1 was used to calculate the relative protein level.

\section{Determination of insulin signaling}

C2C12 cells were incubated with $0,50,100,200$ and $400 \mu \mathrm{M}$ palmitic acid or oleic acid for $16 \mathrm{~h}$. During the final 15 minutes of the FA incubation period, C2C12 cells were exposed to insulin (17.2nM). C2C12 cells were harvested in CLB and protein levels of total Akt and pAkt(ser473) were analyzed by Western blotting as described above.

\section{Measurement of intracellular triglycerides}

C2C12 cells were incubated with, $400 \mu \mathrm{M}$ palmitic acid, $400 \mu \mathrm{M}$ oleic acid or $0.1 \%$ BSA (control) for $16 \mathrm{~h}$. C2C12 cells were harvested in PBS containing $1 \% \mathrm{NP}-40$ and $1 \%$ deoxycholaat. Intracellular triglyceride levels were measured in cell lysates using an enzymatic triglyceride assay according the manufacturer's instructions. Triglyceride levels were corrected for endogenous glycerol levels. The protein concentration of a sample was used to normalize for the number of cells. Reported are triglycerides per mg of protein.

\section{The effect of PPAR agonists on Adfp protein levels in C2C12 cells}

All three PPAR subtypes ( $\alpha, \beta / \delta$ and $\gamma$ ) have been reported to increase Adfp expression, but with significant differences between tissues. Therefore, we analyzed the 
responsiveness of $\mathrm{C} 2 \mathrm{C} 12$ cells to different PPAR agonists. For $16 \mathrm{~h}, \mathrm{C} 2 \mathrm{C} 12$ cells were cultured in differentiation medium containing one of the following agonists: $1 \mu \mathrm{M}$ GW7647 (PPAR $\alpha$; Sigma), $10 \mu \mathrm{M}$ WY14643 (PPAR $\alpha$; BIOMOL, Heerhugowaard, the

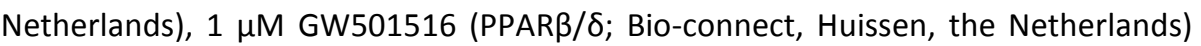
and $10 \mu \mathrm{M}$ rosiglitazone (PPARY; LKT laboratories, Lausen, Switzerland). The proteasome inhibitor MG132 (VWR, Amsterdam, the Netherlands) was added to prevent degradation of Adfp (35). C2C12 cells were harvested in CLB and Western blotting was performed as described above.

\section{Adfp protein levels in muscle tissue from diet-induced obese mice}

Study 1: Male C57BL/6J mice were obtained from Harlan (Horst, the Netherlands). At 9 weeks of age mice were switched to the LFD-P (10 kcal\% fat) for 3 weeks. Following the run-in period mice were randomly assigned to the LFD-P or HFD-P (45 kcal\% fat) for 8 weeks ( $n=6$ per diet). Both diets contained fat in the form of palm oil (based on D12450B and D12451; Research Diet Services, Wijk bij Duurstede, the Netherlands) as described previously (36).

Study 2: Male C57BL/6J mice were obtained from Harlan (Horst, the Netherlands). At 6 weeks of age mice were switched to a run-in diet consisting of a LFD-P (10 $\mathrm{kcal} \%$ fat) for 3 weeks. Following the run-in period mice were randomly assigned to HFD-P, HFD-O or HFD-S (45 kcal\% fat) for 4 weeks ( $n=6$ per diet). Diets contained fat in the form of palm oil (HFD-P), olive oil (HFD-O) or safflower oil (HFD-S) (based on D12451; Research Diet Services, Wijk bij Duurstede, the Netherlands). After 2 weeks, mice were fasted for 6 hours and plasma glucose levels were measured with the Accu-Chek (Roche Diagnostics, Almere, the Netherlands).Additionally, blood was collected in EDTA-containing tubes (Sarstedt AG\&CO, Nümbrecht, Germany). Plasma was obtained after centrifugation at $11000 \mathrm{~g}$ for $10 \mathrm{~min}$ and stored at $-80^{\circ} \mathrm{C}$ for further analysis. Plasma insulin levels were detected by the Insulin (Mouse) Ultrasensitive EIA (Alpco Diagnostics, Salem, NH, USA). Finally, we calculated the HOMAIR index from fasting glucose and fasting insulin levels (fasting glucose * fasting insulin / 22.5).

Mice were fasted for $6 \mathrm{~h}$ and anaesthetized with a mixture of isofluorane (1.5\%), nitrous oxide (70\%) and oxygen (30\%). Mice were killed by cervical dislocation and quadriceps and gastrocnemius muscles were dissected, snap-frozen in liquid nitrogen and stored at $-80^{\circ} \mathrm{C}$ until further analysis. Protein samples were obtained as described (34) with minor adaptations for the lysis buffer (10\% (wt/vol) SDS, $5 \mathrm{mM}$ DTT, $20 \mathrm{mM}$ Tris base, $1 \mathrm{mM}$ PMSF, phosphatase inhibitor cocktail 1 (1:100) and protease inhibitor cocktail (1:100)). Total protein was used for Western blotting of Adfp with C-terminal specific and N-terminal specific Ab as described above. The animal studies were approved by the Local Committee for Care and Use of Laboratory Animals at Wageningen University. 


\section{Statistical analyses}

All data are expressed as means \pm SEM. All statistical analyses were performed using Prism software (GraphPad Software, San Diego, CA, USA). An unpaired t test was used (1) to compare spot intensities between cells treated with and without palmitic acid (2-DE analysis), (2) to compare Adfp and pAkt(ser473)/total Akt protein levels between palmitic acid-treated and oleic acid-treated C2C12 cells and ( 3 ) to compare Adfp protein levels in untreated $\mathrm{C} 2 \mathrm{C} 12$ cells with the PPAR agonist-treated $\mathrm{C} 2 \mathrm{C} 12$ cells. One-way ANOVA was used (1) to analyze the concentration effect of palmitic acid on Adfp protein levels, (2) to compare the differences in TAG accumulation between the control condition, the $400 \mu \mathrm{M}$ palmitic acid-treated cells and the 400 $\mu \mathrm{M}$ oleic acid-treated cells and (3) to compare Adfp protein levels in mice fed an HFD-P, HFD-O and HFD-S for 4 wks, respectively. When significant differences were found, a Tukey's post hoc test was used to determine the exact location of the difference. Two-way ANOVA was performed for statistical analysis of differences in Adfp protein levels between quadriceps and gastrocnemius muscles of mice fed an LFD-P or HFD-P for 8 weeks. When significant differences were found, a Bonferroni post hoc test was used to determine the exact location of the difference. $P$ values < 0.05 were considered as statistically significant.

\section{Results}

\section{Effect of palmitic acid on protein profiles of $\mathrm{C} 2 \mathrm{C} 12$ cells: identification of Adfp}

To search for palmitic acid-dependent changes in the muscle proteome, we exposed differentiated $\mathrm{C} 2 \mathrm{C} 12$ cells to $0 \mu \mathrm{M}$ or $400 \mu \mathrm{M}$ of palmitic acid for $16 \mathrm{~h}$. Subsequently, proteins were isolated from the cells and separated by 2-DE. PDQuest was used to discover statistically significant differences in protein expression between cells treated with or without palmitic acid. Comparison of 2-DE profiles resulted in 104 differentially expressed protein spots from which 26 protein spots were selected for identification. Figure 5.1A shows a representative example of the proteome of C2C12 cells treated with palmitic acid in which the identified proteins, 14 in total, are indicated. Exposure to palmitic acid increased the abundance of five proteins and decreased the abundance of nine proteins (Table 5.1). The protein with the strongest regulation was identified as Adfp which was highly expressed in palmitic acid-treated muscle cells, but completely absent in the untreated muscle cells (Figure 5.1B). 
A

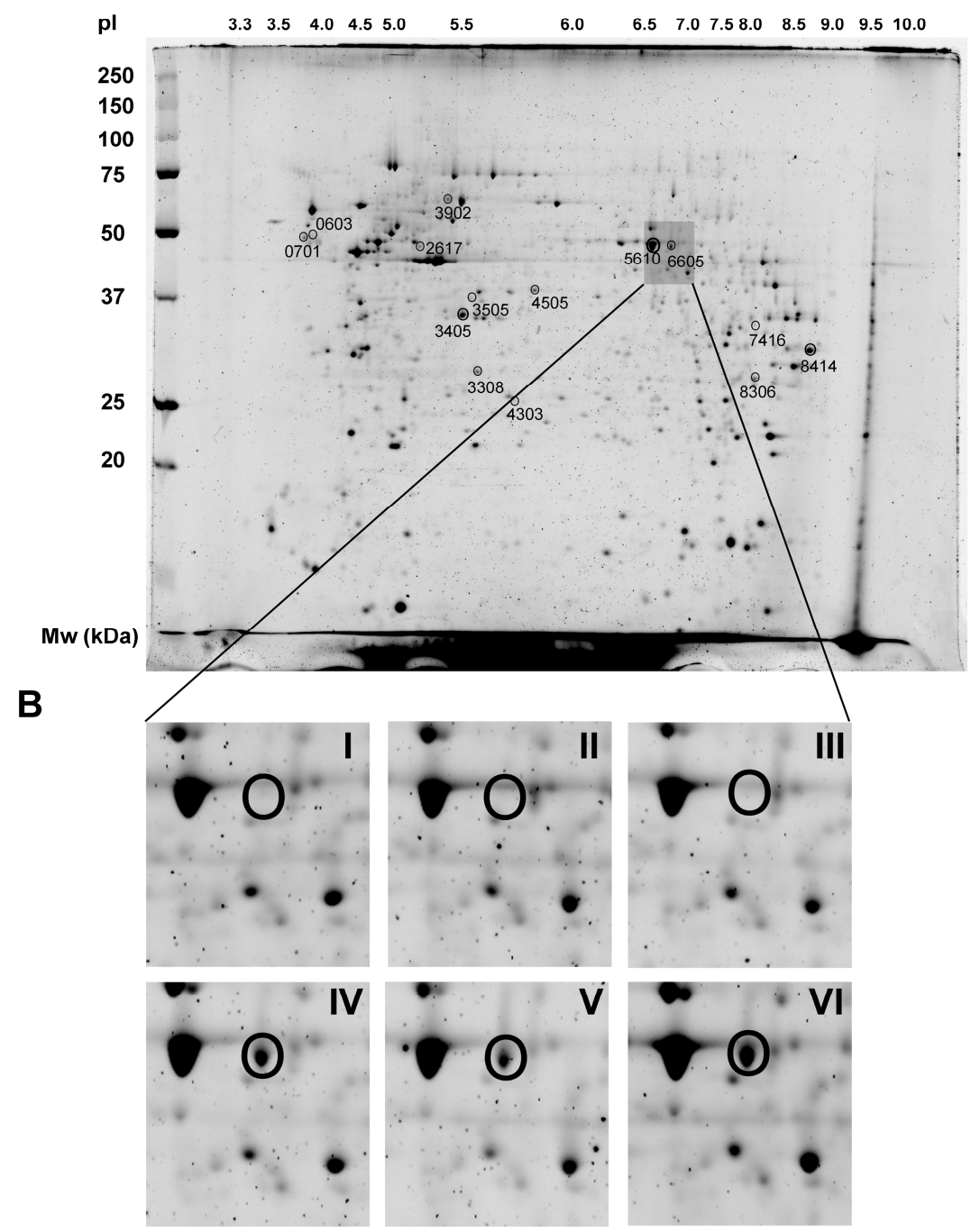

Figure 5.1 Representative example of proteome map of $\mathrm{C} 2 \mathrm{C} 12$ cells treated with palmitic acid. $\mathrm{C} 2 \mathrm{C} 12$ cells were incubated with or without $400 \mu \mathrm{M}$ palmitic acid for $16 \mathrm{~h}$. Total protein was isolated and used for 2-DE analysis. Representative example of proteome map of C2C12 cells treated with palmitic acid including molecular weight markers and PI range is shown. The encircled spots indicate spots that could be identified by MALDI-TOF-MS. The square indicates the area in which Adfp was found (A). This area is enlarged and shown for cells treated without (I-III) and with (IV-VI) palmitic acid $(n=3)(\mathrm{B})$. 
Table 5.1 List of identified differentially expressed proteins in C2C12 cells treated with palmitic acid

\begin{tabular}{|c|c|c|c|c|c|c|c|c|}
\hline Spot & $\begin{array}{l}\text { Swiss- } \\
\text { Prot } \\
\text { accession } \\
\text { number }\end{array}$ & Protein name & $\begin{array}{l}\text { Gene } \\
\text { Symbol }\end{array}$ & $\begin{array}{l}\text { Mascot } \\
\text { score }\end{array}$ & $\begin{array}{l}\text { Sequence } \\
\text { coverage } \\
(\%)\end{array}$ & $\begin{array}{l}\text { Matched } \\
\text { peptides }\end{array}$ & $\begin{array}{c}\text { Fold } \\
\text { change }\end{array}$ & $P$ \\
\hline 603 & Q9DAG4 & $\begin{array}{l}\text { Protein TSC21 } \\
\text { (Testis-specific } \\
\text { conserved pro- } \\
\text { tein of } 21 \mathrm{kDa} \text { ) }\end{array}$ & $T s c 21$ & 66 & 42 & 6 & -3.21 & 0.010 \\
\hline 701 & P14211 & Calreticulin & Calr & 60 & 12 & 6 & -2.49 & 0.036 \\
\hline 2617 & Q91W90 & $\begin{array}{l}\text { Thioredoxin } \\
\text { domain- } \\
\text { containing pro- } \\
\text { tein } 5 \text { precursor }\end{array}$ & Txndc5 & 62 & 21 & 7 & -2.16 & 0.024 \\
\hline 3308 & P67778 & Prohibitin & Phb & 68 & 24 & 6 & 1.64 & 0.028 \\
\hline 3405 & Q9CY33 & $\begin{array}{l}\text { Tubulin beta-5 } \\
\text { chain }\end{array}$ & Tbb5 & 86 & 29 & 9 & -1.69 & 0.043 \\
\hline 3505 & P68373 & $\begin{array}{l}\text { Tubulin alpha-1C } \\
\text { chain }\end{array}$ & Tuba1c & 69 & 22 & 8 & -2.26 & 0.045 \\
\hline 3902 & P63038 & $\begin{array}{l}60 \mathrm{kDa} \text { heat } \\
\text { shock protein, } \\
\text { mitochondrial } \\
\text { precursor }\end{array}$ & Hspd1 & 67 & 28 & 12 & 2.40 & 0.001 \\
\hline 4303 & P10107 & Annexin A1 & Anxa1 & 64 & 29 & 9 & -2.05 & 0.014 \\
\hline 4505 & P09411 & $\begin{array}{l}\text { Phosphoglycerate } \\
\text { kinase } 1\end{array}$ & Pgk1 & 64 & 28 & 8 & -1.68 & 0.038 \\
\hline 5610 & P17182 & Alpha-enolase & Eno1 & 90 & 48 & 10 & 1.51 & 0.029 \\
\hline 7416 & P05064 & $\begin{array}{l}\text { Fructose- } \\
\text { bisphosphate } \\
\text { aldolase A }\end{array}$ & Aldoa & 72 & 35 & 9 & -2.36 & 0.008 \\
\hline 8306 & Q3U9G0 & $\begin{array}{l}\text { Heat shock } \\
\text { cognate } 71 \text { kDa } \\
\text { protein }\end{array}$ & Hspa8 & 106 & 25 & 13 & -2.47 & 0.015 \\
\hline 8414 & Q60932 & $\begin{array}{l}\text { Voltage- } \\
\text { dependent anion- } \\
\text { selective channel } \\
\text { protein } 1\end{array}$ & Vdac1 & 91 & 40 & 9 & 2.33 & 0.030 \\
\hline 6605 & P43883 & Adipophilin & $A d f p$ & 67 & 24 & 6 & $\#$ & \\
\hline
\end{tabular}

Fold changes and $p$ values are calculated for differences in average spot intensities induced by palmitic acid incubation for 16h. \#: spot 6605 was only present in palmitic acid-treated cells, no fold change and $p$ value could be calculated. 


\section{Oleic acid is a stronger inducer of Adfp than palmitic acid in C2C12 cells}

To get more insight in the effect of palmitic acid on Adfp protein levels, C2C12 cells were exposed to different concentrations $(0,50,100,200$ and $400 \mu \mathrm{M})$ of palmitic acid. Western blotting showed that treating C2C12 cells with $200 \mu \mathrm{M}$ or with 400 $\mu \mathrm{M}$ palmitic acid resulted in significantly higher Adfp levels as compared with 0, 50 and $100 \mu \mathrm{M}$ palmitic acid, respectively (Figure 5.2).

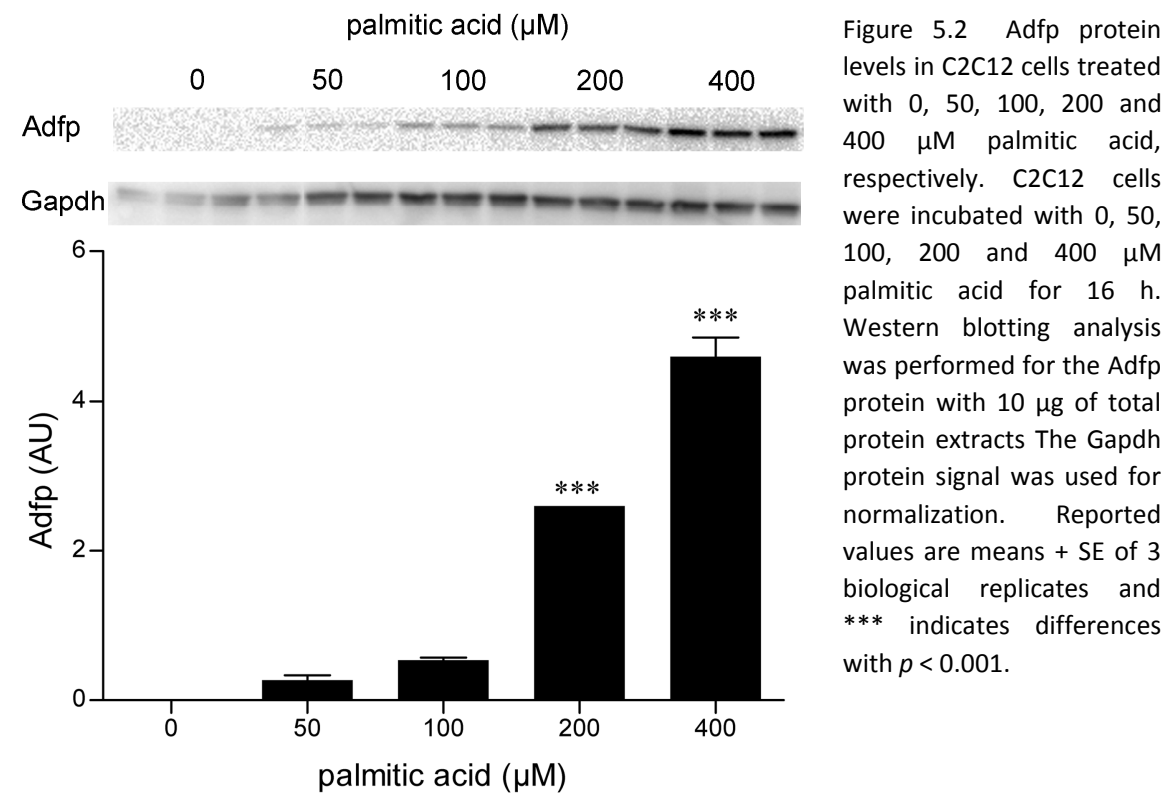

Exposure of $\mathrm{C} 2 \mathrm{C} 12$ cells to various concentrations (50, 100, 200 and $400 \mu \mathrm{M})$ of oleic acid gave a different result. No Adfp protein could be detected in C2C12 cells treated with $50 \mu \mathrm{M}$ palmitic acid, whereas Adfp protein was expressed in $\mathrm{C} 2 \mathrm{C} 12$ cells treated with $50 \mu \mathrm{M}$ oleic acid. Furthermore, at concentrations of $100 \mu \mathrm{M}$ and $200 \mu \mathrm{M}$ we observed significantly higher Adfp levels in the oleic acid-treated C2C12 cells as compared with the palmitic acid-treated cells. C2C12 cells treated with 400 $\mu \mathrm{M}$ oleic instead of $400 \mu \mathrm{M}$ palmitic acid showed a strong tendency $(p=0.06)$ for higher Adfp protein levels (Figure 5.3A). 
A $\begin{array}{lcccccccc}\text { palmitic acid }(\mu \mathrm{M}) & - & 50 & - & 100 & - & 200 & - & 400 \\ \text { oleic acid }(\mu \mathrm{M}) & 50 & - & 100 & - & 200 & - & 400 & -\end{array}$ Adfp Gapdh

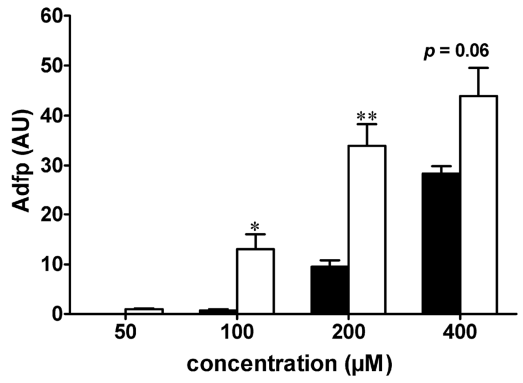

B

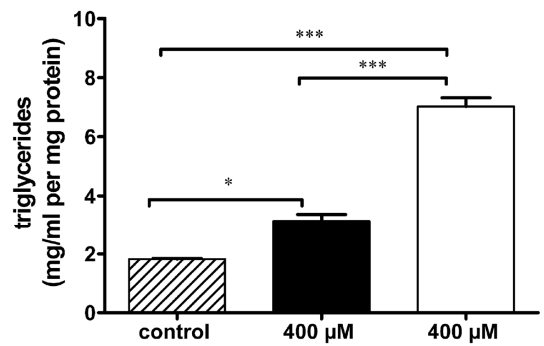

C $\begin{array}{lcccccccc}\text { palmitic acid }(\mu \mathrm{M}) & - & 50 & - & 100 & - & 200 & - & 400 \\ \text { oleic acid }(\mu \mathrm{M}) & 50 & - & 100 & - & 200 & - & 400 & -\end{array}$
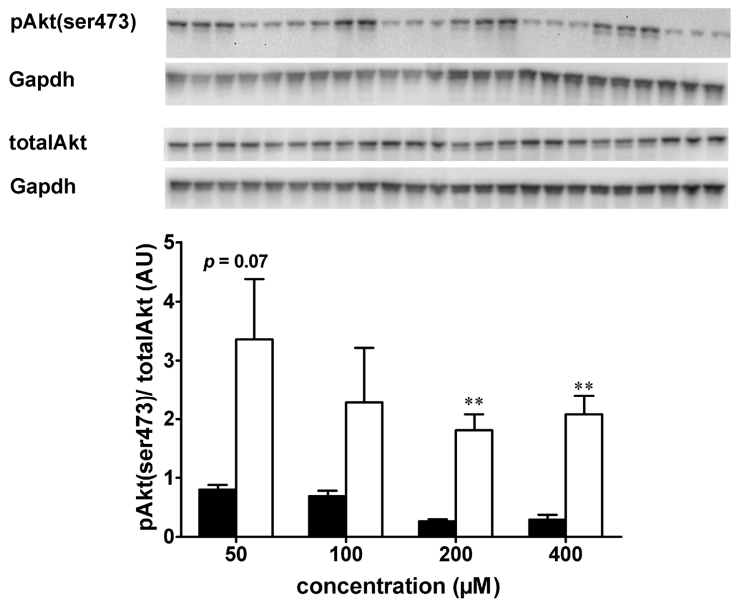

Figure 5.3 Adfp protein levels, cellular triglyceride levels and pAkt(ser473) versus totalAkt ratio in $\mathrm{C} 2 \mathrm{C} 12$ cells treated with $0,50,100,200$ and $400 \mu \mathrm{M}$ palmitic acid or oleic acid. Adfp protein levels in $\mathrm{C} 2 \mathrm{C} 12$ cells incubated with 0, 50, 100, 200 and $400 \mu \mathrm{M}$ palmitic acid or oleic acid for $16 \mathrm{~h}$. Western blotting analysis was performed with $10 \mu \mathrm{g}$ of total protein extracts. The Gapdh protein signal was used for normalization (A). Cellular triglyceride levels in $\mathrm{C} 2 \mathrm{C} 12$ cells incubated with $0 \mu \mathrm{M}$ fatty acid (control), $400 \mu \mathrm{M}$ palmitic acid and 400 $\mu \mathrm{M}$ oleic acid. Triglyceride levels are expressed as $\mathrm{mg} / \mathrm{ml}$ per $\mathrm{mg}$ protein (B). The pAkt(ser473) versus totalAkt ratio in $\mathrm{C} 2 \mathrm{C} 12$ cells incubated with $0,50,100$, 200 and $400 \mu \mathrm{M}$ palmitic acid or oleic acid for $16 \mathrm{~h}$. Western blotting analysis was performed with $10 \mu \mathrm{g}$ of total protein extracts. The pAkt(ser473) versus totalAkt ratio was calculated after normalization of the protein signals with the Gapdh protein signal (C). Reported values are means + SE of 3 biological replicates and $*, * *$ and $* * *$ indicate differences with $p<0.05, p<0.01$ and $p<$ 0.001 , respectively. Dashed bars, black bars and white bars represent the control condition, palmitic acid-treated cells and oleic acid-treated cells, respectively. 


\section{Oleic acid induces higher TAG levels, but less impaired insulin signaling, than palmitic acid in C2C12 cells}

Western blotting showed that the Adfp protein was more highly expressed in oleic acid-treated cells than in palmitic acid-treated cells. Since increased Adfp levels are associated with increased cellular TAG levels we hypothesized that oleic acidtreated cells are accumulating more TAG than palmitic acid-treated cells. To look into this, we exposed $\mathrm{C} 2 \mathrm{C} 12$ cells to $0 \mu \mathrm{M}$ FA, $400 \mu \mathrm{M}$ palmitic acid and $400 \mu \mathrm{M}$ oleic acid and measured intracellular TAG levels. Cellular TAG levels were significantly higher in both palmitic acid-treated and oleic acid-treated C2C12 cells as compared with the control condition ( $p<0.05$ and $p<0.001$, respectively), but oleic acid-treated $\mathrm{C} 2 \mathrm{C} 12$ cells accumulated significantly more cellular TAG than palmitic acid-treated cells ( $p<0.001$ ) (Figure 5.3B).

As increased TAG levels in muscle cells are implicated in the development of insulin resistance, we studied the effect of palmitic acid and oleic acid on insulin signaling. A critical step in the translocation of GLUT4 to the cell membrane, is the full activation of Akt/PKB by the phosphorylation of serine residue 473 (6). Western blotting was performed for total Akt and phosphorylated Akt at serine residue 473 (pAkt(ser473)). The ratio between pAkt and total Akt was calculated as indicator of insulin sensitivity. Figure $5.3 \mathrm{C}$ shows that the ratio pAkt(ser473)/total Akt is significantly lower in the palmitic acid-treated cells than in the oleic acid-treated cells at concentrations of $200 \mu \mathrm{M}$ and $400 \mu \mathrm{M}$. A strong tendency for a lower pAkt(ser473)/total Akt ratio in palmitic acid-treated cells was observed at a concentration of $50 \mu \mathrm{M}(p=0.07)$. Altogether, these results show less impairment of insulin signaling in oleic acid-treated cells than in palmitic acid treated-cells.

\section{PPAR $\alpha$, PPAR $\beta / \delta$ and PPAR $\gamma$ increase Adfp protein expression in $\mathrm{C} 2 \mathrm{C} 12$ cells}

To further elaborate on the regulation of Adfp in muscle cells we cultured $\mathrm{C} 2 \mathrm{C} 12$ cells in differentiation medium containing one of the following agonists: GW7647 (PPAR $\alpha$ ), WY14643 (PPAR $\alpha$ ), GW501516 (PPAR $\beta / \delta)$ and rosiglitazone (PPAR $)$ ). Since Adfp is degraded in the absence of FA we added the proteasome inhibitor MG132 (35). As the Gapdh protein was not stably expressed we used Acta1 as a loading control in this experiment. Figure 5.4 shows that GW7647, GW501516 and rosiglitazone significantly increased Adfp protein expression. A strong tendency for increased Adfp protein expression was observed when $\mathrm{C} 2 \mathrm{C} 12$ cells were treated with WY14643. The strongest up-regulation was found in GW7647-stimulated cells, followed by GW501516-stimulated cells and WY1463-stimulated cells. The lowest upregulation of Adfp protein expression was observed in rosiglitazone-stimulated cells. 


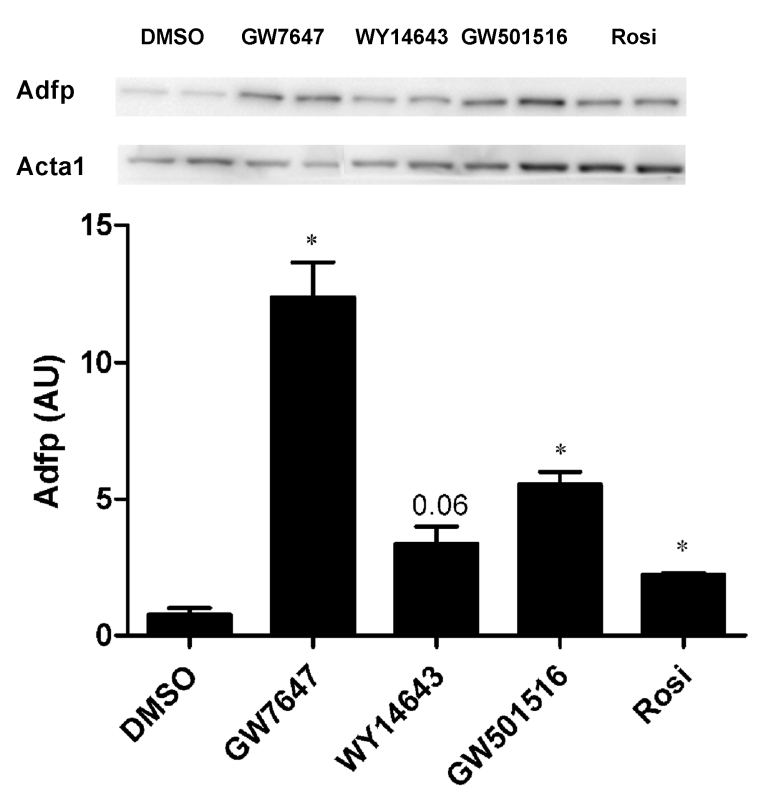

Figure 5.4 Adfp protein levels in $\mathrm{C} 2 \mathrm{C} 12$ cells treated with different PPAR agonists. To study the responsiveness of C2C12 cells to different PPAR agonist $\mathrm{C} 2 \mathrm{C} 12$ cells were incubated with agonists for 16h. Western blotting analysis was performed with $10 \mu \mathrm{g}$ of total protein extracts. The Acta1 protein signal was used for normalization. Reported values are means + SE of 2 biological replicates. $*$ indicates a significant difference with $p<0.05$. GW 7647; PPAR $\alpha$ agonist, WY 14643; PPAR $\alpha$ agonist, GW 501516; PPARß/ठ agonist and Rosi(glitazone); PPARy agonist

\section{Mouse muscle expresses an N-terminal truncated form of Adfp}

By using a C-terminal specific antibody we detected Adfp as a truncated protein with a molecular weight of $\sim 37 \mathrm{kDa}$ in skeletal muscle of mice, whereas mouse liver and $\mathrm{C} 2 \mathrm{C} 12$ cells expressed the full-length protein of 50kDa (Figure 5.5A). Recently, it was described that mammary glands of both Adfp knock-out mice and wild type mice express a 37kDa N-terminally truncated form of Adfp (37). Our finding raised the possibility that also mouse skeletal muscle expresses an $\mathrm{N}$-terminally truncated form of Adfp. To look into this, we performed an additional Western blot with an antibody directed against the N-terminus of the Adfp protein. Figure 5. 5B shows that this antibody detected a single band at $~ 50 \mathrm{kDa}$ in liver and C2C12 cells, but failed to detect any bands in protein extracts of quadriceps and gastrocnemius muscle of wild type mice. Altogether, these results indicate that mouse skeletal muscle does express the Adfp protein as an N-terminally truncated form of the Adfp protein. 


\section{A C-terminal specific Adfp antibody}



Gapdh

\section{B N-terminal specific Adfp antibody}

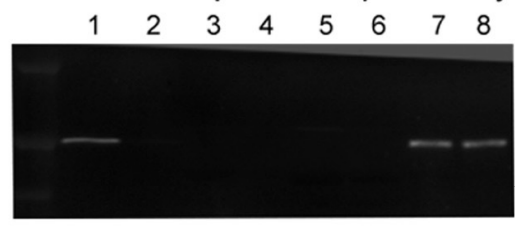

Gapdh

$37-$

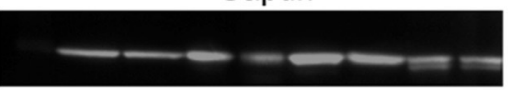

37 -



Figure 5.5 Mouse skeletal muscle expresses an N-terminal truncated form of Adfp. Western blotting of equal amounts of liver (1-2), quadriceps (3-4), gastrocnemius (5-6) and C2C12 cell (7-8) protein extracts. The C-terminal specific Adfp antibody detects a single band at $\sim 50 \mathrm{kDa}$ in liver and C2C12 cell protein extracts, whereas a single band is detected at $\sim 37 \mathrm{kDa}$ in muscle protein extracts $(\mathrm{A})$. The N-terminal specific Adfp antibody detects a single band at $\sim 50 \mathrm{kDa}$ in liver and $\mathrm{C} 2 \mathrm{C} 12$ cells protein extracts, but failed to detect any bands in the muscle protein extracts (B).

\section{Adfp protein levels in mouse skeletal muscle are affected by dietary fat and muscle type}

To assess the in vivo relevance of our findings we determined Adfp protein levels in the quadriceps and gastrocnemius of mice fed an LFD-P or HFD-P for 8 weeks. The Adfp protein was expressed at equal levels in the LFD-P quadriceps and the HFD-P quadriceps. Although not statistically significant, higher Adfp protein levels were observed in the HFD-P gastrocnemius than in the LFD-P gastrocnemius. Significantly higher Adfp protein levels were observed in the gastrocnemius than in the quadriceps of LFD-P mice as well as HFD-P mice (Figure 5.6). 

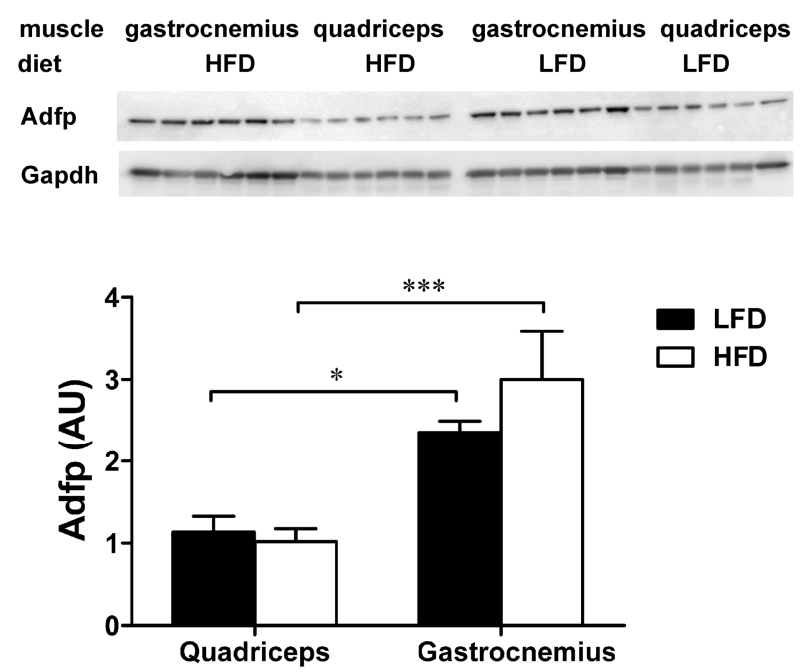

Figure 5.6 Adfp protein levels in the quadriceps and gastrocnemius of LFD-P mice and HFD-P mice. Male C57BL/6J mice were fed a low fat diet or a high fat diet for 8 weeks. Both diets contained fat in the form of palm oil. Western blotting analysis was performed with $10 \mu \mathrm{g}$ of total protein extracts from quadriceps or gastrocnemius muscle. The Gapdh protein signal was used for normalization. Reported values are means + SE of 6 biological replicates and $*$ and $* * *$ indicate differences with $p<$ 0.05 and $p<0.001$. LFD, low fat diet; HFD, high fat diet.

Additionally, we measured Adfp protein expression in the quadriceps muscle of mice fed an HFD-P, HFD-O or HFD-S for 4 weeks. The unsaturated/saturated FA ratio and FA composition of diets is shown in Table 5.2.

Table 5.2 Unsaturation level and fatty acid composition of the three high fat diets.

\begin{tabular}{lllllll}
\hline & & \multicolumn{4}{c}{ fatty acid composition (\%) } \\
& fat source & $\begin{array}{l}\text { unsaturated/saturated } \\
\text { fatty acid ratio }\end{array}$ & $16: 0$ & $18: 0$ & $18: 1$ & $18: 2$ \\
\hline HFD-P & palm oil & 1.0 & 45 & 4 & 40 & 10 \\
HFD-O & olive oil & 4.6 & 13 & 3 & 71 & 10 \\
HFD-S & safflower oil & 10.1 & 7 & 2 & 13 & 78 \\
\hline
\end{tabular}

After two weeks, fasting plasma glucose and insulin level were measured. Although not statistically significant different, glucose and insulin plasma levels tended to be lower in both mice fed the HFD-O and HFD-S than in mice fed the HFD-P (glucose: $14.5 \pm 0.7$ vs. $12.7 \pm 0.8$ vs. $12.1 \pm 0.5 \mathrm{mmol} / \mathrm{l}$ and insulin: $9.1 \pm 2.0$ vs. $5.3 \pm 1.6$ vs. $5.9 \pm 1.1 \mu \mathrm{U} / \mathrm{ml}$ in HFD-P vs. HFD-O vs. HFD-S). As a result, the HOMA-IR index (calculated from fasting glucose and fasting insulin levels: fasting glucose * fasting insulin / 22.5) was decreased in both HFD-O mice and HFD-S mice as compared with HFD-P mice (HOMA-IR: $5.6 \pm 1.0$ vs. $3.2 \pm 1.1$ vs. $3.2 \pm 0.6$ in HFD-P vs. HFD-O vs. HFD-S). However, this was not significantly different. After 4 weeks Adfp protein levels were measured in the quadriceps muscle of these mice. Figure 5.7 shows that 
Adfp protein expression was increased in both HFD-O mice and HFD-S mice compared to HFD-P mice. However, this was only significant for HFD-O as compared to HFD-P. Adfp protein levels were comparable between HFD-O mice and HFD-S mice.



Figure 5.7 Adfp protein levels in the quadriceps of HFD-P, HFD-O and HFD-S mice. Male $\mathrm{C} 57 \mathrm{BL} / 6 \mathrm{~J}$ mice were fed a high fat diet based on palm oil, olive oil and safflower oil for 8 weeks. Western blotting analysis was performed with $10 \mu \mathrm{g}$ of total protein extracts from quadriceps muscle. The Gapdh protein signal was used for normalization. Reported values are means + SE of 6 biological replicates and * and $* * *$ indicate differences with $p<0.05$ and $p<0.001$. HFD-P: high fat palm oil diet; HFD-O: high fat olive oil diet; HFD-S: high fat safflower diet.

\section{Discussion}

In the present study, we searched for changes in the proteome of muscle cells exposed to palmitic acid. Comparison of 2-D cellular protein profiles resulted in 104 differentially expressed protein spots. A total of 26 protein spots were selected for further analysis by mass spectrometry yielding a total of 14 protein identities. Among these proteins we found that the protein levels of Aldoa1 and Pgk1, which are two enzymes that play a role in the glycolysis, were reduced in the palmitic acidtreated cells. Additionally, the protein level of prohibitin was increased in palmitic acid-treated cells. Prohibitin is involved in the inhibition pyruvate carboxylase, the enzyme that catalyzes the conversion from pyruvate to oxaloactetate (38). Prohibitin is increased when pyruvate is preferably converted to acetyl-CoA at conditions of low pyruvate production (39). Altogether these observations indicate reduced glucose metabolism which is implicated in insulin resistance. As shown here, palmitic acid indeed impaired insulin signaling in C2C12 cells which is in line with numerous studies addressing the effect of palmitic acid on various aspects of insulin sensitivity (40-42).

The protein with the strongest regulation was identified as Adfp. Adfp was highly expressed in palmitic acid-treated muscle cells, but completely absent in the untreated muscle cells. Although it has been demonstrated that Adfp is physically 
associated with intramuscular triglycerides (IMTG) in both rat and human muscle $(43,44)$, less is known about the functional role of Adfp in skeletal muscle. We found that oleic acid-treated cells have higher intracellular TAG levels together with higher Adfp levels, but less impairment of insulin signaling than palmitic acidtreated cells. This may be explained by differences in cellular metabolic fate between palmitic acid and oleic acid. Listenberger et al. (45) showed that oleic acid leads to TAG accumulation and is well tolerated, whereas palmitic acid is poorly incorporated in TAG and causes apoptosis (45). In addition, experiments with C2C12 cells revealed that palmitic acid induces increased levels of diacylglycerol (DAG) and impairments of insulin signaling, whereas oleic acid does not $(46,47)$. Co-incubation of $\mathrm{C} 2 \mathrm{C} 12$ cells with palmitic acid and oleic acid reversed impairment of insulin signaling by channeling palmitic acid into TAG, thus reducing the incorporation of palmitic acid in DAG (47). As we also observed higher Adfp levels in oleic acid-treated cells than in palmitic acid-treated cells, we hypothesize that Adfp protects the muscle against detrimental effects of FA on insulin signaling via their incorporation in LDs as TAG

The expression of Adfp is regulated by nuclear hormone receptors of the PPAR family. PPAR $\alpha$, PPAR $\beta / \delta$ and PPAR $\gamma$ all increase Adfp expression, but in a tissue-specific way (28). In liver and hepatocyte-derived cell lines Adfp is transcriptionally regulated by PPAR $\alpha(48,49)$, whereas PPAR $\beta / \delta$ activates Adfp in macrophages (50-52). In mouse skeletal muscle, PPAR $\alpha$ is involved in the regulation of Adfp expression (29). Indeed, the strongest up-regulation of Adfp protein expression in C2C12 cells was achieved through activation of PPAR $\alpha$. A more pronounced effect for GW7647 than WY14643 was observed. This can be explained by differences in the half maximal effective concentration (EC $\mathrm{EC}_{50}$ GW7647: $0.006 \mu \mathrm{M}$ and $\mathrm{EC}_{50}$ WY14643: 5.0 $\mu M)(53)$, indicating that GW7647 is a more potent PPAR $\alpha$ agonist than WY14643. Also the PPAR $\beta / \delta$ agonist GW501516 increased Adfp protein expression in $\mathrm{C} 2 \mathrm{C} 12$ cells. PPAR $\beta / \delta$ plays a role in the generation of the more oxidative fiber types (54, $55)$. In human and rat muscle, Adfp expression is particularly high in the more oxidative fibers which have a higher capacity to store lipids $(30,44)$. As such, the increase of Adfp protein levels induced by activation of PPAR $\beta / \delta$ may be the consequence of a switch towards a more oxidative fiber type. The smallest up-regulation was induced by the PPARY agonist rosiglitazone. Rosiglitazone belongs to the thiazolidinediones (TZD) which have antidiabetic effects and are therefore commonly used for insulin-sensitizer therapy in T2DM subjects (56). Based on the putative functions of Adfp in lipid storage and control of lipolysis $(15,28)$ it has been hypothesized that higher Adfp protein levels can be expected after insulin-sensitizer therapy with TZD. Indeed, Philips et al. (31) showed that an improved insulin sensitivity induced by troglitazone goes together with increased Adfp protein expression in skeletal muscle of obese diabetic subjects. However, Minnaard et al. (30) found that rosiglitazone improved insulin sensitivity, but decreased skeletal muscle Adfp 
protein expression in T2D patients. Our finding of increased Adfp protein expression after stimulating $\mathrm{C} 2 \mathrm{C} 12$ cells with rosiglitazone is in contrast with the latter finding. To assess the in vivo relevance of our findings we analyzed the effect of muscle type (gastrocnemius vs. quadriceps) and amount of dietary fat (10 kcal\% vs. $45 \mathrm{kcal} \%$ ) on Adfp protein levels. The gastrocnemius and quadriceps are both muscle groups that consist of predominantly type II fibers $(55,57)$. However, we found significantly higher Adfp protein levels in the gastrocnemius than in the quadriceps which was especially evident under HFD-P conditions. Recently, Minnaard et al. (30) found that Adfp protein levels in rat skeletal muscle are highest in type IIA fibers, intermediate in type I fibers and almost absent in type IIB fibers which corresponded well with the IMTG content of these fibers (30). Western blotting revealed higher Myh2 protein levels, which is a marker for the oxidoglycolytic type IIA fibers, in the gastrocnemius than in the quadriceps (data not shown). In line with Minnaard et al. (30) we hypothesize that differences in Adfp protein content between muscle types can be explained by differences in fiber type composition. Additionally, we analyzed the effect of the type of dietary fat on Adfp protein levels (palm oil vs. olive oil vs. safflower oil). Palm oil contains large amounts of palmitic acid and oleic acid and the ratio between unsaturated FA and saturated FA is 1.0. The predominant FA in olive oil is oleic acid and the unsaturated/saturated FA ratio is 4.6. Safflower oil contains oleic acid and linoleic acid and the ratio between unsaturated FA and saturated FA is 10.1. We found increased Adfp protein levels in the quadriceps muscle of the olive oil-based or safflower-based HFD as compared to the palm oil-based HFD. Interestingly, fasting glucose levels, fasting insulin levels and HOMA-IR suggested better insulin sensitivity in mice fed the olive oil-based or safflower oil-based HFD than in mice fed the palm oil-based HFD. Thus, in line with the in vitro experiments we were able to show in vivo that a high level of Adfp protein is associated with improved insulin sensitivity.

Surprisingly, we found that the Adfp protein is expressed as a $37 \mathrm{kD} \mathrm{N}$-terminally truncated form in mouse skeletal muscle. Two domains that are N-terminally located are the PAT domain and the 11-mer repeat regions (7). Whereas it has been clearly demonstrated that the PAT domain is not a prerequisite for targeting Adfp to LDs, results for the 11-mer repeat region are less unambiguous (58-60). Recently, Russell et al. (37) reported the finding that Adfp-null mice as well as wild type C57BL/6J mice also express a 37kD N-terminal truncated form of Adfp in mammary glands. Interestingly, this truncated form localized correctly to LDs in mammary glands and these LDs were correctly secreted as milk fat globules (37). Thus, we think that this N-terminally truncated form of Adfp is still functionally active in muscle, although reduced affinity for LDs cannot be excluded.

To summarize, by using 2-DE we identified Adfp as a highly regulated protein in C2C12 cells treated with palmitic acid. Further in vitro experiments revealed that cells treated with oleic acid have higher Adfp protein levels, higher cellular TAG 
levels and less impairment of the insulin signaling pathway than cells treated with palmitic acid. In vivo, we found that Adfp protein expression in skeletal muscle of mice is influenced by muscle type with higher levels in muscle types with a more oxidative character. Additionally, we found that when mice are fed an HFD with a higher unsaturated/saturated FA ratio, Adfp protein expression in muscle is increased accompanied by indications for better insulin sensitivity. Altogether, the results in the present study indicate that Adfp expression in muscle plays a role in maintaining insulin sensitivity.

\section{Ackownledgements}

This study was funded by the Top Institute Food and Nutrition, with financial support by the Dutch government. We thank Freek Bouwman for excellent technical support with the MALDI-TOF-MS (Department of Human Biology, Maastricht University, the Netherlands). We greatly appreciate the gift of the PPAR $\alpha$, PPAR $\beta / \delta$ and PPARY agonists from Dr. Heleen de Vogel-van den Bosch (Department of Physiology, Maastricht University, the Netherlands).

\section{References}

1. Alberti KG, Zimmet $P$, Shaw J. Metabolic syndrome--a new world-wide definition. A Consensus Statement from the International Diabetes Federation. Diabet Med. 2006 May;23(5):469-80.

2. Zimmet $P$, Magliano D, Matsuzawa $Y$, Alberti G, Shaw J. The metabolic syndrome: a global public health problem and a new definition. J Atheroscler Thromb. 2005;12(6):295-300.

3. Laaksonen DE, Niskanen L, Lakka HM, Lakka TA, Uusitupa M. Epidemiology and treatment of the metabolic syndrome. Annals of medicine. 2004;36(5):332-46.

4. Eckel RH, Grundy SM, Zimmet PZ. The metabolic syndrome. Lancet. 2005 Apr 16-22;365(9468):141528.

5. Kahn BB, Flier JS. Obesity and insulin resistance. The Journal of clinical investigation. 2000 Aug;106(4):473-81.

6. Taniguchi CM, Emanuelli B, Kahn CR. Critical nodes in signalling pathways: insights into insulin action. Nature reviews. 2006 Feb;7(2):85-96.

7. Jacob S, Machann J, Rett K, Brechtel K, Volk A, Renn W, et al. Association of increased intramyocellular lipid content with insulin resistance in lean nondiabetic offspring of type 2 diabetic subjects. Diabetes. 1999 May;48(5):1113-9.

8. Krssak M, Falk Petersen K, Dresner A, DiPietro L, Vogel SM, Rothman DL, et al. Intramyocellular lipid concentrations are correlated with insulin sensitivity in humans: a $1 \mathrm{H} N M R$ spectroscopy study. Diabetologia. 1999 Jan;42(1):113-6.

9. Pan DA, Lillioja S, Kriketos AD, Milner MR, Baur LA, Bogardus C, et al. Skeletal muscle triglyceride levels are inversely related to insulin action. Diabetes. 1997 Jun;46(6):983-8.

10. Sinha R, Dufour S, Petersen KF, LeBon V, Enoksson S, Ma YZ, et al. Assessment of skeletal muscle triglyceride content by $(1) \mathrm{H}$ nuclear magnetic resonance spectroscopy in lean and obese adolescents: relationships to insulin sensitivity, total body fat, and central adiposity. Diabetes. 2002 Apr;51(4):1022-7. 
11. Goodpaster BH, He J, Watkins S, Kelley DE. Skeletal muscle lipid content and insulin resistance: evidence for a paradox in endurance-trained athletes. The Journal of clinical endocrinology and metabolism. 2001 Dec;86(12):5755-61.

12. Phillips SM, Green HJ, Tarnopolsky MA, Heigenhauser GJ, Grant SM. Progressive effect of endurance training on metabolic adaptations in working skeletal muscle. The American journal of physiology. 1996 Feb;270(2 Pt 1):E265-72.

13. Petersen KF, Shulman GI. Etiology of insulin resistance. The American journal of medicine. 2006 May;119(5 Suppl 1):S10-6.

14. Hegarty BD, Furler SM, Ye J, Cooney GJ, Kraegen EW. The role of intramuscular lipid in insulin resistance. Acta physiologica Scandinavica. 2003 Aug;178(4):373-83.

15. Brasaemle DL. Thematic review series: adipocyte biology. The perilipin family of structural lipid droplet proteins: stabilization of lipid droplets and control of lipolysis. Journal of lipid research. 2007 Dec;48(12):2547-59.

16. Ducharme NA, Bickel PE. Lipid droplets in lipogenesis and lipolysis. Endocrinology. 2008 Mar;149(3):942-9.

17. Martin S, Parton RG. Lipid droplets: a unified view of a dynamic organelle. Nature reviews. 2006 May;7(5):373-8.

18. Brasaemle DL, Rubin B, Harten IA, Gruia-Gray J, Kimmel AR, Londos C. Perilipin A increases triacylglycerol storage by decreasing the rate of triacylglycerol hydrolysis. The Journal of biological chemistry. 2000 Dec 8;275(49):38486-93.

19. Mottagui-Tabar S, Ryden M, Lofgren P, Faulds G, Hoffstedt J, Brookes AJ, et al. Evidence for an important role of perilipin in the regulation of human adipocyte lipolysis. Diabetologia. 2003 Jun;46(6):789-97.

20. Miyoshi H, Souza SC, Zhang HH, Strissel KJ, Christoffolete MA, Kovsan J, et al. Perilipin promotes hormone-sensitive lipase-mediated adipocyte lipolysis via phosphorylation-dependent and independent mechanisms. The Journal of biological chemistry. 2006 Jun 9;281(23):15837-44.

21. Tansey JT, Sztalryd C, Gruia-Gray J, Roush DL, Zee JV, Gavrilova O, et al. Perilipin ablation results in a lean mouse with aberrant adipocyte lipolysis, enhanced leptin production, and resistance to dietinduced obesity. Proceedings of the National Academy of Sciences of the United States of America. 2001 May 22;98(11):6494-9.

22. Sztalryd C, Xu G, Dorward H, Tansey JT, Contreras JA, Kimmel AR, et al. Perilipin A is essential for the translocation of hormone-sensitive lipase during lipolytic activation. The Journal of cell biology. 2003 Jun 23;161(6):1093-103.

23. Murphy DJ. The biogenesis and functions of lipid bodies in animals, plants and microorganisms. Progress in lipid research. 2001 Sep;40(5):325-438.

24. Gao J, Serrero G. Adipose differentiation related protein (ADRP) expressed in transfected COS-7 cells selectively stimulates long chain fatty acid uptake. The Journal of biological chemistry. 1999 Jun 11;274(24):16825-30.

25. Listenberger LL, Ostermeyer-Fay AG, Goldberg EB, Brown WJ, Brown DA. Adipocyte differentiationrelated protein reduces the lipid droplet association of adipose triglyceride lipase and slows triacylglycerol turnover. Journal of lipid research. 2007 Dec;48(12):2751-61.

26. Imamura M, Inoguchi T, Ikuyama S, Taniguchi S, Kobayashi K, Nakashima N, et al. ADRP stimulates lipid accumulation and lipid droplet formation in murine fibroblasts. Am J Physiol Endocrinol Metab. 2002 Oct;283(4):E775-83.

27. Larigauderie G, Furman C, Jaye M, Lasselin C, Copin C, Fruchart JC, et al. Adipophilin enhances lipid accumulation and prevents lipid efflux from THP-1 macrophages: potential role in atherogenesis. Arteriosclerosis, thrombosis, and vascular biology. 2004 Mar;24(3):504-10.

28. Bickel PE, Tansey JT, Welte MA. PAT proteins, an ancient family of lipid droplet proteins that regulate cellular lipid stores. Biochimica et biophysica acta. 2009 Jun;1791(6):419-40. 
29. Yamaguchi T, Matsushita S, Motojima K, Hirose F, Osumi T. MLDP, a novel PAT family protein localized to lipid droplets and enriched in the heart, is regulated by peroxisome proliferator-activated receptor alpha. The Journal of biological chemistry. 2006 May 19;281(20):14232-40.

30. Minnaard R, Schrauwen P, Schaart G, Jorgensen JA, Lenaers E, Mensink M, et al. Adipocyte Differentiation-Related Protein and OXPAT in rat and human skeletal muscle: involvement in lipid accumulation and Type 2 Diabetes Mellitus. The Journal of clinical endocrinology and metabolism. 2009 Jul 14.

31. Phillips SA, Choe CC, Ciaraldi TP, Greenberg AS, Kong AP, Baxi SC, et al. Adipocyte differentiationrelated protein in human skeletal muscle: relationship to insulin sensitivity. Obesity research. 2005 Aug;13(8):1321-9.

32. Xu G, Sztalryd C, Lu X, Tansey JT, Gan J, Dorward H, et al. Post-translational regulation of adipose differentiation-related protein by the ubiquitin/proteasome pathway. The Journal of biological chemistry. 2005 Dec 30;280(52):42841-7.

33. Russell TD, Palmer CA, Orlicky DJ, Bales ES, Chang BH, Chan L, et al. Mammary glands of adipophilinnull mice produce an amino-terminally truncated form of adipophilin that mediates milk lipid droplet formation and secretion. Journal of lipid research. 2008 Jan;49(1):206-16.

34. Vessal M, Mishra S, Moulik S, Murphy L. Prohibitin attenuates insulin-stimulated glucose and fatty acid oxidation in adipose tissue by inhibition of pyruvate carboxylase. The FEBS journal. 2006 Feb;273(3):568-76.

35. Claessens M, Saris WHM, Bouwman FG, Evelo CTA, Hul GBJ, Blaak EE, et al. Differential valine metabolism in adipose tissue of low and high fat-oxidizing obese subjects. Proteomics Clin Appl. 2007;1:1306-55.

36. Hirabara SM, Curi R, Maechler P. Saturated fatty acid-induced insulin resistance is associated with mitochondrial dysfunction in skeletal muscle cells. Journal of cellular physiology. 2009 Sep 24.

37. Ragheb R, Shanab GM, Medhat AM, Seoudi DM, Adeli K, Fantus IG. Free fatty acid-induced muscle insulin resistance and glucose uptake dysfunction: Evidence for PKC activation and oxidative stressactivated signaling pathways. Biochemical and biophysical research communications. 2009 Aug 23.

38. Wang C, Liu M, Riojas RA, Xin X, Gao Z, Zeng R, et al. Protein kinase C theta (PKCtheta)-dependent phosphorylation of PDK1 at Ser504 and Ser532 contributes to palmitate-induced insulin resistance. The Journal of biological chemistry. 2009 Jan 23;284(4):2038-44.

39. Prats C, Donsmark M, Qvortrup K, Londos C, Sztalryd C, Holm C, et al. Decrease in intramuscular lipid droplets and translocation of HSL in response to muscle contraction and epinephrine. Journal of lipid research. 2006 Nov;47(11):2392-9.

40. Shaw CS, Sherlock M, Stewart PM, Wagenmakers AJ. Adipophilin distribution and colocalisation with lipid droplets in skeletal muscle. Histochemistry and cell biology. 2009 Jan 24.

41. Listenberger LL, Han X, Lewis SE, Cases S, Farese RV, Jr., Ory DS, et al. Triglyceride accumulation protects against fatty acid-induced lipotoxicity. Proceedings of the National Academy of Sciences of the United States of America. 2003 Mar 18;100(6):3077-82.

42. Chavez JA, Summers SA. Characterizing the effects of saturated fatty acids on insulin signaling and ceramide and diacylglycerol accumulation in 3T3-L1 adipocytes and C2C12 myotubes. Arch Biochem Biophys. 2003 Nov 15;419(2):101-9.

43. Coll T, Eyre E, Rodriguez-Calvo R, Palomer X, Sanchez RM, Merlos M, et al. Oleate reverses palmitateinduced insulin resistance and inflammation in skeletal muscle cells. The Journal of biological chemistry. 2008 Apr 25;283(17):11107-16.

44. Dalen KT, Ulven SM, Arntsen BM, Solaas K, Nebb HI. PPARalpha activators and fasting induce the expression of adipose differentiation-related protein in liver. Journal of lipid research. 2006 May;47(5):931-43.

45. Targett-Adams P, McElwee MJ, Ehrenborg E, Gustafsson MC, Palmer CN, McLauchlan J. A PPAR response element regulates transcription of the gene for human adipose differentiation-related protein. Biochimica et biophysica acta. 2005 Apr 5;1728(1-2):95-104. 
46. Chawla A, Lee CH, Barak Y, He W, Rosenfeld J, Liao D, et al. PPARdelta is a very low-density lipoprotein sensor in macrophages. Proceedings of the National Academy of Sciences of the United States of America. 2003 Feb 4;100(3):1268-73.

47. Lee $\mathrm{CH}$, Chawla A, Urbiztondo N, Liao D, Boisvert WA, Evans RM, et al. Transcriptional repression of atherogenic inflammation: modulation by PPARdelta. Science (New York, NY. 2003 Oct 17;302(5644):453-7.

48. Vosper H, Patel L, Graham TL, Khoudoli GA, Hill A, Macphee CH, et al. The peroxisome proliferatoractivated receptor delta promotes lipid accumulation in human macrophages. The Journal of biological chemistry. 2001 Nov 23;276(47):44258-65.

49. Brown PJ, Stuart LW, Hurley KP, Lewis MC, Winegar DA, Wilson JG, et al. Identification of a subtype selective human PPAR(alpha) agonist through parallel-array synthesis. Bioorganic \& Medicinal Chemistry Letters. 2001;11(9):1225-7.

50. Luquet S, Lopez-Soriano J, Holst D, Fredenrich A, Melki J, Rassoulzadegan M, et al. Peroxisome proliferator-activated receptor delta controls muscle development and oxidative capability. Faseb J. 2003 Dec;17(15):2299-301.

51. Wang YX, Zhang CL, Yu RT, Cho HK, Nelson MC, Bayuga-Ocampo CR, et al. Regulation of muscle fiber type and running endurance by PPARdelta. PLoS biology. 2004 Oct;2(10):e294.

52. Kersten S, Desvergne B, Wahli W. Roles of PPARs in health and disease. Nature. 2000 May 25;405(6785):421-4.

53. Chanseaume E, Malpuech-Brugere C, Patrac V, Bielicki G, Rousset P, Couturier K, et al. Diets high in sugar, fat, and energy induce muscle type-specific adaptations in mitochondrial functions in rats. The Journal of nutrition. 2006 Aug;136(8):2194-200.

54. McManaman JL, Zabaronick W, Schaack J, Orlicky DJ. Lipid droplet targeting domains of adipophilin. Journal of lipid research. 2003 Apr;44(4):668-73.

55. Nakamura N, Fujimoto T. Adipose differentiation-related protein has two independent domains for targeting to lipid droplets. Biochemical and biophysical research communications. 2003 Jun 27;306(2):333-8.

56. Targett-Adams P, Chambers D, Gledhill S, Hope RG, Coy JF, Girod A, et al. Live cell analysis and targeting of the lipid droplet-binding adipocyte differentiation-related protein. The Journal of biological chemistry. 2003 May 2;278(18):15998-6007.

57. Langen RC, Schols AM, Kelders MC, Wouters EF, Janssen-Heininger YM. Enhanced myogenic differentiation by extracellular matrix is regulated at the early stages of myogenesis. In vitro cellular \& developmental biology. 2003 Mar-Apr;39(3-4):163-9.

58. Bouwman F, Renes J, Mariman E. A combination of protein profiling and isotopomer analysis using matrix-assisted laser desorption/ionization-time of flight mass spectrometry reveals an active metabolism of the extracellular matrix of 3T3-L1 adipocytes. Proteomics. 2004 Dec;4(12):3855-63.

59. de Wilde J, Mohren R, van den Berg S, Boekschoten M, Dijk KW, de Groot P, et al. Short-term high fat-feeding results in morphological and metabolic adaptations in the skeletal muscle of C57BL/6J mice. Physiol Genomics. 2008 Feb 19;32(3):360-9.

60. de Wit NJ, Bosch-Vermeulen H, de Groot PJ, Hooiveld GJ, Bromhaar MM, Jansen J, et al. The role of the small intestine in the development of dietary fat-induced obesity and insulin resistance in C57BL/6J mice. BMC medical genomics. 2008;1:14. 



\section{CHAPTER 6 \\ The embryonic genes Dkk3, Hoxd8, Hoxd9 and Tbx1 identify muscle types in a diet-independent and fiber type- unrelated way}

Janneke de Wilde, Egbert Smit, Mark V. Boekschoten, Philip de Groot, Martijn F.M. Hulshof and Edwin C.M. Mariman

BMC genomics. 2010; 11: 176-187 


\begin{abstract}
The mouse skeletal muscle is composed of four distinct fiber types that differ in contractile function, number of mitochondria and metabolism. Every muscle type has a specific composition and distribution of the four fiber types. To find novel genes involved in specifying muscle types, we used microarray analysis to compare the gastrocnemius with the quadriceps from mice fed a low fat diet (LFD) or high fat diet (HFD) for 8 weeks. Additional qPCR analysis were performed in the gastrocnemius, quadriceps and soleus muscle from mice fed an LFD or HFD for 20 weeks. In mice fed the 8-week LFD 162 genes were differentially expressed in the gastrocnemius vs. the quadriceps. Genes with the strongest differences in expression were markers for oxidative fiber types (e.g. Tnni1) and genes which are known to be involved in embryogenesis (Dkk3, Hoxd8, Hoxd9 and Tbx1). Also Dkk2, Hoxa5, Hoxa10, Hoxc9, Hoxc10, Hoxc6 and Tbx15 were detectably, but not differentially expressed in adult muscle tissue. Expression of differentially expressed genes was not influenced by an 8-week or 20-week HFD. Comparing gastrocnemius, quadriceps and soleus, expression of Hoxd8 and Hoxd9 was not related with expression of markers for the four different fiber types. We found that the expression of both Hoxd8 and Hoxd9 was much higher in the gastrocnemius than in the quadriceps or soleus, whereas the expression of $D k k 3$ was high in quadriceps, but low in both gastrocnemius and soleus. Finally, expression of $T b x 1$ was high in quadriceps, intermediate in soleus and low in gastrocnemius. We found that genes from the Dkk family, Hox family and Tbx family are detectably expressed in adult mouse muscle. Interestingly, expression of $D k k 3$, Hoxd8, Hoxd9 and $T b x 1$ was highly different between gastrocnemius, quadriceps and soleus. In fact, every muscle type showed a unique combination of expression of these four genes which was not influenced by diet. Altogether, we conclude that genes important for embryogenesis identify mouse muscle types in a diet-independent and fiber type-unrelated manner.
\end{abstract}




\section{Introduction}

The mouse skeletal muscle is composed of four distinct fiber types, i.e., the type I, $\mathrm{Ila}$, IIx and IIb fibers that differ in respect to contractile function, the number of mitochondria and metabolism. The slow type I fibers can sustain prolonged low power work, contain more mitochondria and exhibit higher rates of fat oxidative metabolism. The fast type IIx and IIb fibers are adapted to brief and intense contractions, contain fewer mitochondria and generate energy mainly through glycolysis. The type lla fibers exhibit an intermediate contractile function and are oxidoglycolytic (1-4). Every muscle type has a specific composition and distribution of the four different fiber types. The soleus contains the highest number of type I fibers, whereas both the quadriceps and gastrocnemius are muscle groups that contain predominantly type II fibers $(5,6)$. However, varying percentages of type I fibers ranging from $0-45 \%$ for the quadriceps and $1-8 \%$ for the gastrocnemius are reported (7). Numerous genes have been identified playing a role in the generation of more oxidative muscle types $(6,8-13)$. The most extensively studied gene is calcineurin $(C n A)$. In the $\mathrm{C} 2 \mathrm{C} 12$ cell line, $\mathrm{CnA}$ up-regulates the mRNA levels of genes that are markers for the slow fiber types. Additionally, studies with $C n A$ transgenic mice have reported an increase of oxidative fibers in the skeletal muscle $(8,9)$. PGC1 $\alpha$ is another well-established factor that induces remodeling of skeletal muscle fiber type composition. Lin et al. (10) showed that when PGC1 $\alpha$ is expressed at physiological levels in muscle groups normally rich in type II fibers a fiber type conversion occurs from type II fibers to type I fibers (10). In line with this, Mortensen et al. (11) showed that $P G C 1 \alpha$ overexpression in primary rat skeletal muscle cells induces a switch towards a more oxidative fiber type. Finally, muscle-specific overexpression of PPAR $\delta$ resulted in the increase of the number of oxidative fibers and in higher expression levels of several markers of oxidative metabolism $(6,12)$.

The first aim of the present study was to find novel genes that may play a role in specifying muscle types. Therefore we compared gene expression profiles of the gastrocnemius with the quadriceps at the level of the whole-transcriptome. Functional implications were assessed by the analyses of predefined gene sets based on Gene Ontology, biochemical, metabolic and signaling pathways. Recently, we studied the effects of a short-term high fat diet (HFD) on skeletal muscle gene and protein expression. Since both gene and protein levels of markers of the more oxidative fiber types were increased in the quadriceps of HFD mice we hypothesized that an HFD can induce a conversion towards a more oxidative fiber type via a transcriptional mechanism (14). The second aim of the present study therefore was to explore the diet-sensitivity of genes that are involved in the determination of muscle types. We compared expression patterns of genes that are differentially expressed between muscle types in mice fed a low fat diet (LFD) with mice fed an HFD. 


\section{Methods}

\section{Mice and diet}

Male C57BL/6J mice were obtained from Harlan (Horst, The Netherlands). At 9 weeks of age mice were switched to a run-in diet consisting of an LFD (10 kcal\% fat) for 3 weeks. Following the run-in period mice were randomly assigned to the LFD or the HFD (45 kcal\% fat). Both diets contained fat in the form of palm oil (based on D12450B and D12451; Research Diet Services, Wijk bij Duurstede, the Netherlands) as described previously (15).

\section{Study 1}

After 8 weeks of diet intervention, mice ( $n=10$ per diet) were fasted for 6 hours, anesthetized with a mixture of isofluorane (1.5\%), nitrous oxide $(70 \%)$ and oxygen $(30 \%)$ and killed by cervical dislocation. Gastrocnemius and quadriceps muscles were dissected, snap-frozen in liquid nitrogen and stored at $-80^{\circ} \mathrm{C}$ until further analysis.

\section{Study 2}

After 20 weeks of diet intervention, mice ( $n=5$ per diet) were fasted for 6 hour, anaesthetized and killed as described. Quadriceps, gastrocnemius and soleus muscles were dissected, snap-frozen in liquid nitrogen and stored at $-80^{\circ} \mathrm{C}$ until further analysis.

Both animal studies were approved by the Local Committee for Care and Use of Laboratory Animals at Wageningen University.

\section{RNA isolation}

Mouse total RNA was isolated from gastrocnemius, quadriceps and soleus muscles by mechanically homogenization in Trizol reagent (Invitrogen, Breda, the Netherlands). RNA was purified with the RNeasy Mini Kit (Qiagen, Venlo, the Netherlands) and contaminating genomic DNA was removed with the RNase-free DNase set (Qiagen). RNA quantity and purity was measured with the ND-1000 spectrophotometer (Isogen Life Science B.V., IJsselstein, the Netherlands). An A260/A280 ratio between 2.04 and 2.16 was found for all RNA samples. RNA integrity was checked on an Agilent 2100 BioAnalyzer (Agilent Technologies, Amsterdam, The Netherlands) using nanochips according to the manufacturer's instructions. All RNA samples showed an RIN value between 7.5 and 9.0 . 


\section{Affymetrix microarray analysis}

RNA isolated from the gastrocnemius and quadriceps of mice fed an 8-week LFD or HFD was used for performing Affymetrix GeneChip ${ }^{\circledR}$ Mouse Genome 4302.0 arrays as described previously (14). Array images were processed using packages from the Bioconductor project (16) and probe sets were redefined according to Dai et al. (17). In this method probes are annotated using up-to-date databases and assigned to unique gene identifiers, in this case Entrez ID's, instead of the 'classic' GeneChip probe sets. This results in a less ambiguous and more accurate annotation. Arrays were normalized using quantile normalization, and expression estimates were calculated using GC-RMA, implementing the empirical Bayes estimate for non-specific binding (18). Differentially expressed probe sets were identified using linear models, applying moderated t-statistics that implement empirical Bayes regularization of standard errors (19). Comparisons were made between the gastrocnemius and quadriceps muscles using the fold change threshold method. In this method, most false-positives are caused by genes with low signal intensity and/or absent call ( $50 \%$ of all genes). Thus, filtering out this constant noise before performing data analysis will improve the power to discriminate true changes from noise in the foldchange threshold method (20). We manually set the signal threshold at 20 , across all arrays, filtering out $60 \%$ of the genes. Probe sets that satisfied the criteria of a fold change $>1.3$ and a false discover rate (FDR) $<0.05$, correcting for multipletesting (21), were considered as differentially expressed.

To relate changes in gene expression to functional changes two complementary methods were used. The first method is based on overrepresentation of Gene Ontology (GO) terms, which uses a gene score resampling (GSR) method (22). Full resampling was run with 200,000 iterations. Only classes with a FDR $<0.001$ and with minimal 8 and maximal 125 genes were taken into account. The second method, gene set enrichment analysis (GSEA), is focused on predefined gene sets, that is, groups of genes that share biological function, chromosomal location or regulation (23). The 'functional catalogue' constructed by Subramanian et al. was modified to contain only 505 well-defined murine, biochemical, metabolic and signal pathways compiled from the following publicly available, curated databases: BioCarta (BioCarta. BioCarta, 2005, p. http://www.biocarta.com.), GenMAPP (24), Kyoto Encyclopedia of Genes and Genomes (KEGG) (25), Sigma-Aldrich pathways (Sigma-Aldrich. Sigma-Aldrich Metabolic and Cell Signaling pathways, 2005.) and Signal Transduction Knowledge Environment (STKE; Signal Transduction Knowledge Environment. In: http://stke.sciencemag.org/. 2005.). The analysis was run using 1000 permutations per gene set. Gene sets with a FDR $<0.05$ were considered as significantly regulated. The advantage is that both methods are unbiased and a score is computed based on all genes in a GO term or gene set.

The diet-sensitivity of differentially expressed genes, overrepresented GO classes and regulated gene sets was studied by comparing the gastrocnemius with the qua- 
driceps under HFD conditions. Also in this comparison we used the criteria of a fold change $>1.3$ and an FDR $<0.05$. A heatmap of log-transformed microarray signal intensities was generated by using GeneMaths XT software (Sint-Martens-Latem, Belgium). Array data have been submitted to the Gene Expression Omnibus, accession number GSE18127.

\section{Quantitative real-time PCR for RNA}

To validate microarray-detected changes as well as extrapolating microarraydetected changes to the gastrocnemius, quadriceps and soleus of 20-week LFD mice and HFD mice quantitative real-time PCR (qPCR) was performed using individual cDNA samples. RNA (1 $\mu \mathrm{g}$ in $20 \mu \mathrm{l}$ ) was reverse transcribed using the iScript cDNA synthesis kit (Biorad, Veenendaal, the Netherlands) containing RNase $\mathrm{H}+$ iScript reverse transcriptase, a premixed RNase inhibitor to prevent indiscriminate degradation of RNA template, and a unique blend of oligo(dT) and random primers. cDNA was synthesized using a 3-step program ( 5 minutes $(\min )$ at $25^{\circ} \mathrm{C}, 30 \mathrm{~min}$ at $42^{\circ} \mathrm{C}$ and $5 \mathrm{~min}$ at $85^{\circ} \mathrm{C}$ ). Primer sequences were retrieved from the online PrimerBank database (26), or otherwise designed using Beacon Designer5 (Biorad). Primers were tested for specificity by BLAST analysis. The qPCR reactions were performed in a volume of $25 \mu \mathrm{l}$ containing $12.5 \mathrm{ng}$ cDNA, 1x IQ SYBR Green Supermix (100 mM $\mathrm{KCl}, 40 \mathrm{mM}$ Tris- $\mathrm{HCl}, 6 \mathrm{mM} \mathrm{MgCl}, 0.4 \mathrm{mM}$ of each dNTP, 50 units/ml iTaq DNA polymerase, SYBR Green I and $20 \mathrm{nM}$ fluoresein; Biorad) and $400 \mathrm{nM}$ of gene-specific forward and reverse primers (Biolegio, Nijmegen, the Netherlands). cDNA was amplified using a 2-step program (40 cycles of 10 seconds (sec) at $95^{\circ} \mathrm{C}$ and $45 \mathrm{sec}$ at $60^{\circ} \mathrm{C}$ ) with a MyiQ system (Biorad). Specificity of amplification was verified by melt curve analysis and evaluation of efficiency of PCR amplification. PCR reactions were performed in duplicate and gene expression levels were determined using iQ5 software (Biorad) using a $\Delta$-Cq relative quantification model with PCR efficiency correction and multiple reference gene normalization $(27,28)$. As the Canx, Hprt1 and Arbp genes were identified as most stably expressed reference genes, we used the geometric mean of these three reference genes as normalization factor. Supplement 4 at the website of BMC Genomics shows all relevant primer information.

\section{Statistical analyses}

All data are expressed as means \pm SE. Microarray data were analyzed as described above. All other statistical analyses were performed using Prism software (GraphPad Software, San Diego, CA, USA). Two-way ANOVA was used to test gene expression levels of Dkk3, Hoxd8, Hoxd9, Myh1, Myh2, Myh4, Myh7 and Tbx1 between muscle types and diets. When significant differences were found, a Bonferroni post 
hoc test was used to determine the exact location of the differences. A $p$ value $\leq$ 0.05 was considered as statistically significant.

\section{Results}

\section{Microarray analysis shows that the majority of genes involved in the determination of muscle types are not influenced by diet}

To obtain more insight in genes involved in specifying muscle types we compared the gastrocnemius transcriptome with the quadriceps transcriptome of 8-week LFD mice. When using the criteria of a fold change $>1.3$ and an FDR $<0.05$, we found 91 genes with an increased expression and 71 genes with a decreased expression in the gastrocnemius as compared to the quadriceps. The ten genes with the strongest increased and decreased expression levels are shown in Table 6.1 and Figure 6.1.

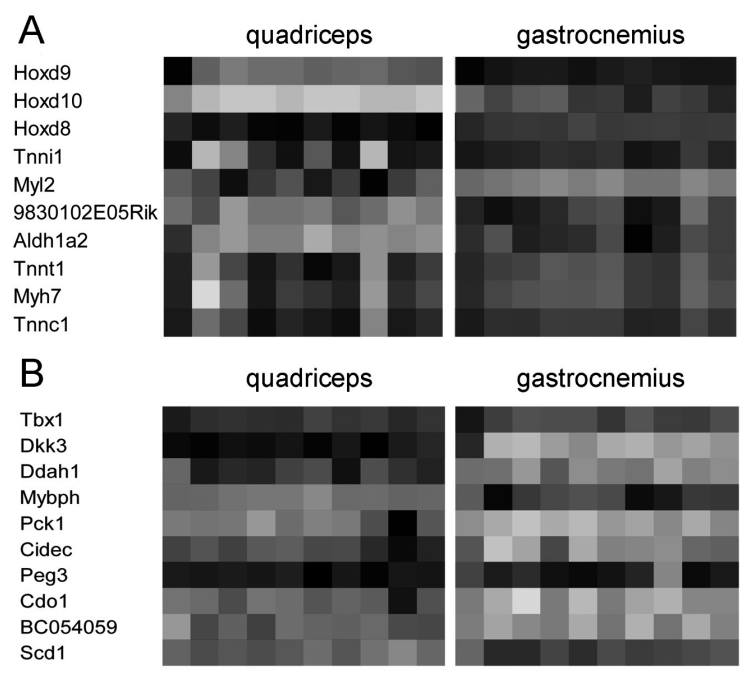

Figure 6.1 Heatmap of the ten genes with the strongest difference in expression between gastrocnemius and quadriceps. Heatmap of the log-transformed microarray signal intensity values of the ten genes that showed the strongest increased (A) and decreased (B) expression level in the gastrocnemius as compared to the quadriceps of 10 LFD mice. The heatmap was generated by using GeneMaths XT software. Signal intensities are shown by a color range; bright red, black, and bright green represent high, average, and low levels of gene expression, respectively.

The ten genes with the strongest increased expression included markers of oxidative fiber types (Tnnc1, Tnni1, Tnnt1 and Myh7), but also genes from the Hox family (Hoxd8, Hoxd9 and Hoxd10). In fact, Hoxd8, Hoxd9 and Hoxd10 were the genes with the strongest increased expression in the gastrocnemius. The ten genes with the strongest decreased expression contained a variety of genes such as Scd1 and Cidec, which are involved in lipogenesis, and Pck1, which plays a role in gluconeogenesis, but also the $D k k 3$ and $T b x 1$ genes, which are important during embryogenesis. A 
complete list of all differentially expressed genes is available in supplement 1. qPCR analyses were performed for 13 genes validating the microarray results (supplement 2). Supplement 1 and 2 can be found at the website of BMC genomics

Table 6.1 Ten genes that showed the strongest increased or decreased expression in gastrocnemius compared to quadriceps

\begin{tabular}{|c|c|c|c|c|c|}
\hline probe set & gene name & gene description & $\begin{array}{l}\text { Accession } \\
\text { (EntrezID) }\end{array}$ & $\begin{array}{c}\text { Fold } \\
\text { change }\end{array}$ & FDR \\
\hline \multicolumn{6}{|c|}{ Strongest up-regulated genes } \\
\hline 15438_at & Hoxd9 & homeo box D9 & 15438 & 7.70 & 0.000 \\
\hline 15430_at & Hoxd10 & homeo box D10 & 15430 & 7.36 & 0.000 \\
\hline 15437_at & Hoxd8 & homeo box D8 & 15437 & 4.78 & 0.000 \\
\hline 21952_at & Tnni1 & troponin I, skeletal, slow 1 & 21952 & 4.46 & 0.005 \\
\hline 17906_at & Myl2 & $\begin{array}{l}\text { myosin, light polypeptide } 2 \text {, regula- } \\
\text { tory, cardiac, slow }\end{array}$ & 17906 & 3.89 & 0.004 \\
\hline 277898_at & 9830102E05Rik & RIKEN cDNA 9830102E05 gene & 277898 & 3.69 & 0.002 \\
\hline 19378_at & Aldh1a2 & $\begin{array}{l}\text { aldehyde dehydrogenase family } 1 \text {, } \\
\text { subfamily A2 }\end{array}$ & 19378 & 3.61 & 0.000 \\
\hline 21955_at & Tnnt1 & troponin T1, skeletal, slow & 21955 & 3.56 & 0.024 \\
\hline 140781_at & Myh7 & $\begin{array}{l}\text { myosin, heavy polypeptide } 7, \\
\text { cardiac muscle, beta }\end{array}$ & 140781 & 3.26 & 0.039 \\
\hline 21924_at & Tnnc1 & $\begin{array}{l}\text { troponin C, cardiac/slow skeletal } \\
\text { Strongest down-regulated genes }\end{array}$ & 21924 & 3.05 & 0.020 \\
\hline 21380_at & Tbx1 & $\begin{array}{l}\text { T-box } 1 \\
\text { dickkopf homolog } 3 \text { (Xenopus }\end{array}$ & 21380 & -7.27 & 0.000 \\
\hline 50781_at & Dkk3 & $\begin{array}{l}\text { laevis) } \\
\text { dimethylarginine dimethylamino- }\end{array}$ & 50781 & -5.40 & 0.000 \\
\hline 69219_at & Ddah1 & hydrolase 1 & 69219 & -2.91 & 0.000 \\
\hline 53311_at & Mybph & $\begin{array}{l}\text { myosin binding protein } \mathrm{H} \\
\text { phosphoenolpyruvate car- }\end{array}$ & 53311 & -2.66 & 0.002 \\
\hline 18534_at & Pck1 & $\begin{array}{l}\text { boxykinase } 1 \text {, cytosolic } \\
\text { cell death-inducing DFFA-like }\end{array}$ & 18534 & -2.62 & 0.015 \\
\hline 14311_at & Cidec & effector c & 14311 & -2.57 & 0.009 \\
\hline 18616_at & Peg3 & paternally expressed 3 & 18616 & -2.49 & 0.005 \\
\hline 12583_at & Cdo1 & cysteine dioxygenase 1 , cytosolic & 12583 & -2.45 & 0.004 \\
\hline 246747_at & BC054059 & cDNA sequence BC054059 & 246747 & -1.96 & 0.010 \\
\hline 20249_at & Scd1 & stearoyl-Coenzyme A desaturase 1 & 20249 & -1.79 & 0.018 \\
\hline
\end{tabular}

By microarray analysis we found 161 that were differentially expressed in the gastrocnemius as compared with the quadriceps from mice fed an 8-week LFD. This table shows the ten strongest upregulated and ten strongest down-regulated genes in the gastrocnemius as compared with the quadriceps $(n=10)$.

To relate changes in gene expression to biological changes we applied ErmineJ and GSEA. By using Ermine J we identified $68 \mathrm{GO}$ classes that were overrepresented in the gastrocnemius (Table 6.2). These overrepresented GO classes were mainly descriptors for contraction, morphogenesis, remodeling and development. Other 
overrepresented GO classes included descriptors for calcium homeostasis, immune function and metabolic processes.

Table 6.2 Overrepresented Gene Ontology classes in the gastrocnemius as compared to the quadriceps

\begin{tabular}{|c|c|c|c|c|}
\hline GO ID & GO class & $\mathrm{N}$ & $\begin{array}{l}\text { Raw } \\
\text { Score }\end{array}$ & FDR \\
\hline GO:0001974 & blood vessel remodeling & 15 & 1.99 & $2.39 \mathrm{E}-10$ \\
\hline GO:0006776 & vitamin A metabolic process & 15 & 1.92 & 9.95E-11 \\
\hline GO:0051705 & behavioral interaction between organisms & 18 & 1.63 & $3.89 \mathrm{E}-04$ \\
\hline GO:0006775 & fat-soluble vitamin metabolic process & 20 & 1.57 & 4.17E-04 \\
\hline GO:0048705 & skeletal morphogenesis & 17 & 1.41 & 8.14E-04 \\
\hline GO:0009855 & determination of bilateral symmetry & 31 & 1.30 & 5.97E-11 \\
\hline GO:0003007 & heart morphogenesis & 29 & 1.28 & 8.53E-11 \\
\hline GO:0014033 & neural crest cell differentiation & 31 & 1.28 & $3.98 \mathrm{E}-10$ \\
\hline GO:0006936 & muscle contraction & 69 & 1.19 & $1.49 \mathrm{E}-10$ \\
\hline GO:0006937 & regulation of muscle contraction & 25 & 1.19 & 7.35E-04 \\
\hline GO:0043010 & camera-type eye development & 56 & 1.14 & 7.02E-11 \\
\hline GO:0007368 & determination of left/right symmetry & 30 & 1.14 & 8.02E-04 \\
\hline GO:0048762 & mesenchymal cell differentiation & 38 & 1.13 & 9.19E-11 \\
\hline GO:0008016 & regulation of heart contraction & 34 & 1.13 & 3.23E-04 \\
\hline GO:0060047 & heart contraction & 41 & 1.11 & 1.09E-10 \\
\hline GO:0007498 & mesoderm development & 44 & 1.06 & $1.33 \mathrm{E}-10$ \\
\hline GO:0001654 & eye development & 82 & 1.03 & 7.46E-11 \\
\hline GO:0048592 & eye morphogenesis & 37 & 1.02 & 6.97E-04 \\
\hline GO:0006766 & vitamin metabolic process & 56 & 1.01 & $6.28 \mathrm{E}-11$ \\
\hline GO:0009952 & anterior/posterior pattern formation & 86 & 0.96 & 4.59E-11 \\
\hline GO:0016055 & Wnt receptor signaling pathway & 107 & 0.94 & 4.98E-11 \\
\hline GO:0042445 & hormone metabolic process & 71 & 0.92 & $1.71 \mathrm{E}-04$ \\
\hline GO:0048771 & tissue remodeling & 104 & 0.92 & $1.71 \mathrm{E}-10$ \\
\hline GO:0006875 & cellular metal ion homeostasis & 57 & 0.92 & 2.99E-04 \\
\hline GO:0048637 & skeletal muscle development & 61 & 0.92 & 7.96E-11 \\
\hline GO:0006959 & humoral immune response & 52 & 0.92 & 7.46E-04 \\
\hline GO:0007519 & striated muscle development & 103 & 0.91 & 1.19E-10 \\
\hline GO:0055065 & metal ion homeostasis & 58 & 0.91 & 1.99E-04 \\
\hline GO:0030324 & lung development & 59 & 0.89 & 4.07E-04 \\
\hline GO:0007178 & $\begin{array}{l}\text { transmembrane receptor protein serine/threonine } \\
\text { kinase signaling pathway }\end{array}$ & 67 & 0.89 & 1.93E-04 \\
\hline GO:0006575 & amino acid derivative metabolic process & 70 & 0.88 & 5.69E-11 \\
\hline GO:0030323 & respiratory tube development & 60 & 0.88 & 4.78E-04 \\
\hline GO:0007229 & integrin-mediated signaling pathway & 74 & 0.88 & 2.91E-04 \\
\hline GO:0048469 & cell maturation & 66 & 0.87 & 4.68E-04 \\
\hline GO:0006817 & phosphate transport & 61 & 0.86 & 2.84E-04 \\
\hline GO:0055074 & calcium ion homeostasis & 53 & 0.86 & 7.58E-04 \\
\hline GO:0045786 & negative regulation of progression through cell cycle & 101 & 0.85 & 5.19E-11 \\
\hline GO:0048732 & gland development & 63 & 0.85 & $6.85 \mathrm{E}-04$ \\
\hline GO:0044271 & nitrogen compound biosynthetic process & 61 & 0.84 & 3.98E-04 \\
\hline GO:0030003 & cellular cation homeostasis & 87 & 0.84 & $1.99 \mathrm{E}-10$ \\
\hline GO:0021700 & developmental maturation & 79 & 0.84 & 2.21E-04 \\
\hline
\end{tabular}


Table 6.2 Overrepresented Gene Ontology classes in the gastrocnemius as compared to the quadri-

\begin{tabular}{|c|c|c|c|c|}
\hline GO ID & GO class & $\mathrm{N}$ & $\begin{array}{l}\text { Raw } \\
\text { Score }\end{array}$ & FDR \\
\hline GO:0016311 & dephosphorylation & 105 & 0.83 & $5.97 \mathrm{E}-10$ \\
\hline GO:0055080 & cation homeostasis & 88 & 0.83 & $2.13 \mathrm{E}-04$ \\
\hline GO:0055082 & cellular chemical homeostasis & 90 & 0.82 & $5.43 \mathrm{E}-11$ \\
\hline GO:0006470 & protein amino acid dephosphorylation & 93 & 0.82 & $6.63 \mathrm{E}-11$ \\
\hline GO:0050778 & positive regulation of immune response & 75 & 0.81 & $3.32 \mathrm{E}-04$ \\
\hline GO:0051240 & $\begin{array}{l}\text { positive regulation of multicellular organismal } \\
\text { process }\end{array}$ & 94 & 0.81 & $1.76 \mathrm{E}-04$ \\
\hline GO:0008015 & circulation & 84 & 0.81 & $5.43 \mathrm{E}-04$ \\
\hline GO:0050776 & regulation of immune response & 88 & 0.80 & 1.87E-04 \\
\hline GO:0002684 & positive regulation of immune system process & 77 & 0.80 & 4.59E-04 \\
\hline GO:0050801 & ion homeostasis & 103 & 0.79 & $2.99 \mathrm{E}-10$ \\
\hline GO:0002682 & regulation of immune system process & 90 & 0.79 & 2.06E-04 \\
\hline GO:0001503 & ossification & 80 & 0.79 & 4.51E-04 \\
\hline GO:0045165 & cell fate commitment & 94 & 0.78 & $4.42 \mathrm{E}-04$ \\
\hline GO:0015674 & di-, tri-valent inorganic cation transport & 112 & 0.78 & 1.19E-09 \\
\hline GO:0031214 & biomineral formation & 81 & 0.78 & 7.21E-04 \\
\hline GO:0046849 & bone remodeling & 89 & 0.78 & $3.81 \mathrm{E}-04$ \\
\hline GO:0008361 & regulation of cell size & 91 & 0.77 & $4.78 \mathrm{E}-11$ \\
\hline GO:0030005 & cellular di-, tri-valent inorganic cation homeostasis & 81 & 0.77 & 7.08E-04 \\
\hline GO:0043062 & extracellular structure organization and biogenesis & 85 & 0.77 & $6.28 \mathrm{E}-04$ \\
\hline GO:0009968 & negative regulation of signal transduction & 81 & 0.77 & $6.74 \mathrm{E}-04$ \\
\hline GO:0040008 & regulation of growth & 117 & 0.77 & $1.81 \mathrm{E}-04$ \\
\hline GO:0006816 & calcium ion transport & 85 & 0.75 & $8.78 \mathrm{E}-04$ \\
\hline GO:0002009 & morphogenesis of an epithelium & 103 & 0.73 & 4.87E-04 \\
\hline GO:0002252 & immune effector process & 106 & 0.73 & $6.40 \mathrm{E}-04$ \\
\hline GO:0043549 & regulation of kinase activity & 120 & 0.72 & $3.14 \mathrm{E}-04$ \\
\hline GO:0045859 & regulation of protein kinase activity & 115 & 0.72 & 3.73E-04 \\
\hline GO:0051338 & regulation of transferase activity & 121 & 0.72 & $3.06 \mathrm{E}-04$ \\
\hline
\end{tabular}

ErmineJ was used to identify significantly overrepresented GO classes in the gastrocnemius as compared with the quadriceps from LFD mice $(n=10)$. For the concept biological process we selected GO classes with a FDR $<0.001$. For this analysis only classes containing 8 through 125 genes were taken into account. $\mathrm{N}$, number of genes in $\mathrm{GO}$ class.

A parallel GSEA was used to identify up- or down-regulated processes. GSEA revealed that ten gene sets were down-regulated including three gene sets related to the cell cycle, two gene sets describing amino acid metabolism and two gene sets corresponding to immune function. Only the gene sets "striated muscle contraction" and "ribosome" were up-regulated in the gastrocnemius as compared with the quadriceps. Among the core-enriched genes in the gene set "striated muscle contraction" were genes that are markers for oxidative fiber types, whereas all coreenriched genes in the gene set "ribosome" were ribosomal proteins which are involved in translation (Table 6.3). 
Table 6.3 Changed gene sets in the gastrocnemius versus quadriceps.

\begin{tabular}{|c|c|c|c|c|}
\hline & $\mathrm{N}$ & ES & NES & FDR \\
\hline \multicolumn{5}{|c|}{ Up-regulated cellular processes } \\
\hline Striated muscle contraction ${ }^{1}$ & 41 & 0.68 & 2.37 & 0.000 \\
\hline Ribosome $^{2}$ & 20 & 0.71 & 2.05 & 0.005 \\
\hline \multicolumn{5}{|c|}{ Down-regulated cellular processes } \\
\hline Tissues, muscle, fat, bone and connective $2^{1}$ & 47 & -0.57 & -2.14 & 0.003 \\
\hline Cell cycle ${ }^{1}$ & 85 & -0.52 & -2.14 & 0.003 \\
\hline CTCF first multivalent nuclear factor ${ }^{3}$ & 17 & -0.71 & -2.07 & 0.006 \\
\hline Valine, leucine and isoleucine degradation ${ }^{2}$ & 40 & -0.59 & -2.16 & 0.006 \\
\hline Cell cycle $\mathrm{G} 1$ to $\mathrm{S}$ control reactome ${ }^{2}$ & 69 & -0.49 & -2.01 & 0.013 \\
\hline Antigen processing and presentation ${ }^{2}$ & 51 & -0.52 & -2.01 & 0.014 \\
\hline Mets affect on macrophage differentiation ${ }^{3}$ & 16 & -0.69 & -1.97 & 0.014 \\
\hline Amino acid metabolism ${ }^{1}$ & 46 & -0.52 & -1.95 & 0.016 \\
\hline Porphyrin and Chlorophyll metabolism ${ }^{2}$ & 19 & -0.64 & -1.88 & 0.033 \\
\hline DNA replication reactome ${ }^{1}$ & 40 & -0.51 & -1.86 & 0.038 \\
\hline
\end{tabular}

GSEA was applied to identify up-regulated and down-regulated processes in the gastrocnemius as compared with the quadriceps in LFD mice. Presented are regulated processes with a false discovery rate (FDR) < 0.05. An FDR was calculated to adjust for multiple hypothesis testing. Sources of the gene sets: ${ }^{1}$ GenMAPP, ${ }^{2}$ KEGG, ${ }^{3}$ Biocarta. N, number of genes; ES, enrichment score for the gene set, that reflects the degree to which a gene set is overrepresented at the top or bottom of the ranked list; FDR, NES, normalized enrichment score, that is, the normalized ES to account for the size of the set.

The diet-sensitivity of differentially expressed genes, overrepresented GO classes and regulated gene sets was studied by comparing the gastrocnemius with the quadriceps under HFD conditions (supplement 3 at the website of BMC genomics). In the HFD mice we found 215 differentially expressed genes in the gastrocnemius as compared to the quadriceps. A total of 128 genes was overlapping with the differentially expressed genes in the LFD mice. Interestingly, these overlapping genes were all regulated in the same direction with a comparable fold change. A total of 87 genes was only differentially expressed in HFD mice, whereas 34 genes were differentially expressed in LFD mice suggesting that these genes are diet-dependent. Under HFD conditions, ErmineJ revealed that $193 \mathrm{GO}$ classes were overrepresented in the gastrocnemius as compared to the quadriceps. A total of $67 \mathrm{GO}$ classes showed an overlap with the overrepresented GO classes under LFD conditions. The other overrepresented GO classes corresponded also to contraction, morphogenesis, remodeling, development, calcium homeostasis, immune function and metabolic processes. GSEA showed that 11 gene sets were down-regulated including five gene sets describing cell cycle and four gene sets related to amino acid metabolism. Only one gene set "striated muscle contraction" was up-regulated in the gastrocnemius vs. the quadriceps. A total of six gene sets (five down-regulated and one upregulated) were overlapping between the LFD and HFD condition. 
To summarize, we showed that a considerable number of genes is differentially expressed in the gastrocnemius as compared with the quadriceps. The genes with the strongest regulations were markers for oxidative fiber types (Tnnc1, Tnni1, Tnnt1 and Myh7) and genes which are known to be involved in embryogenesis (Dkk3, Hoxd8, Hoxd9, Hoxd10 and Tbx1). The differentially expressed genes corresponded to a variety of process including morphogenesis and contraction, but also amino acid metabolism, cell cycle and immune function. Finally, we found more differentially expressed genes and more overrepresented GO classes under HFD conditions than under LFD conditions. However, this did not result in the identification of other regulated processes indicating that diet has only a very small effect on the difference between gastrocnemius and quadriceps.

\section{Numerous genes involved in embryogenesis are detectably expressed in adult mouse muscle tissue}

One of the most interesting findings of the comparison between gastrocnemius and quadriceps was the fact that genes of the Dkk family (Dkk3), Hox family (Hoxd8, Hoxd9 and Hoxd10) and Tbx family (Tbx1) were detectably expressed in adult mouse muscle tissue. To find out if also other genes from these three gene families are detectably expressed in adult mouse muscle tissue we analyzed the microarray signal intensities of all members, which were present on the microarray, in the gastrocnemius and quadriceps. An average microarray signal intensity $>20$ was used as cut off. Figure 6.2A shows that four members of the Dkk gene family were present on the microarray. In addition to $D k k 3$, we found that also $D k k 2$ was detectably expressed in both gastrocnemius and quadriceps (22.5 vs. 23.4 in gastrocnemius vs. quadriceps). From the Hox family 34 members were present on the microarray. Eight genes of the Hox family, including Hoxd8, Hoxd9 and Hoxd10, were expressed in adult muscle tissue. Hoxa5, Hoxa10, Hoxc9, Hoxc10, Hoxd8 and Hoxd9 were detectably expressed in both the gastrocnemius and quadriceps. Furthermore, Hoxc6 was detectably expressed in the quadriceps and not in the gastrocnemius (29.1 versus 16.9), whereas Hoxd10 was detectably expressed in the gastrocnemius and not in the quadriceps (36.2 versus 4.9 ). The gene with the highest expression level was identified as the Hoxc10 gene (Figure 6.2B). Figure 6.2C shows that from the $T b x$ family 12 members were present on the microarray. Additionally to $T b x 1$, we found that $T b x 15$ was highly expressed in the gastrocnemius as well as in the quadriceps (654.8 vs. 836.4, respectively). Altogether, these results show that some genes that are known to play an important role in embryogenesis are also detectably expressed in adult mouse muscle tissue. 


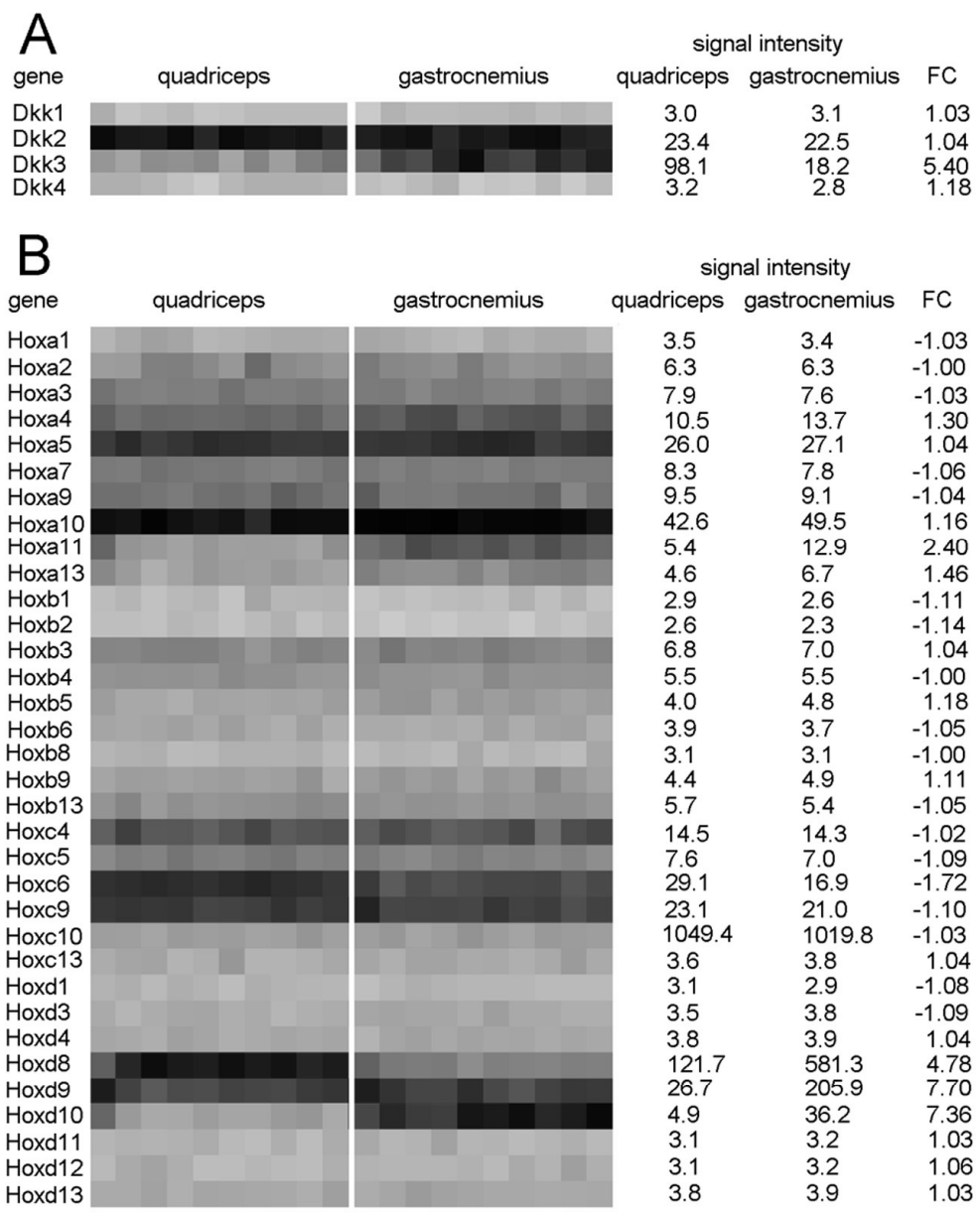
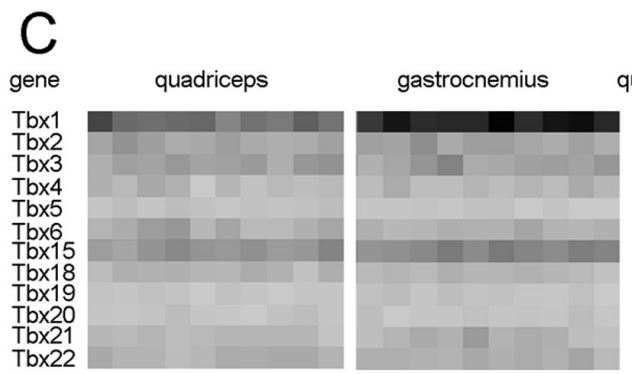

\begin{tabular}{rcr} 
quadriceps & gastrocnemius & \multicolumn{1}{l}{ FC } \\
437.5 & 60.2 & -7.27 \\
5.7 & 5.9 & 1.03 \\
6.1 & 6.3 & 1.02 \\
4.2 & 4.3 & 1.02 \\
3.5 & 3.3 & -1.06 \\
5.1 & 4.6 & -1.10 \\
836.4 & 654.8 & -1.28 \\
4.5 & 4.2 & -1.05 \\
3.3 & 3.5 & 1.04 \\
3.4 & 3.4 & 1.01 \\
4.1 & 4.6 & 1.12 \\
4.8 & 4.8 & 1.01
\end{tabular}

Figure 6.2 Heatmap of Dkk genes, Hox genes and Tbx genes in gastrocnemius and quadriceps. Heatmap of the log-transformed microarray signal intensity values of (A) Dkk genes, (B) Hox genes and (C) Tbx genes in the quadriceps and the gastrocnemius of 10 LFD mice. A heatmap was generated by using GeneMaths XT software. Signal intensities are shown by a color range; bright red, black, and bright green represent high, average, and low levels of gene expression, respectively. Values are means $(n=10)$. 


\section{The Tbx1 gene is a muscle-type specific marker}

Dkk3, Hoxd8, Hoxd9 and Tbx1 were relatively high and differentially expressed in the gastrocnemius as compared to the quadriceps of mice fed an 8-week LFD. To extrapolate our result to a third muscle type we analyzed the expression level of these genes in quadriceps, gastrocnemius and soleus muscle of 20-week LFD mice and 20-week HFD mice. None of the genes was significantly influenced by diet which is in line with the earlier described observations (Figure 6.3A-D). Hoxd8 and Hoxd9 were highly expressed in the gastrocnemius, but low gene expression levels were observed in the quadriceps and soleus (Figure 6.3A-B). Dkk3 was significantly higher expressed in the quadriceps than in the gastrocnemius and soleus. Although not significantly, $D k k 3$ gene expression was lower in the soleus than in the gastrocnemius (Figure $6.3 \mathrm{C}$ ). The highest expression levels of the $T b \times 1$ gene was found in the quadriceps. Intermediate expression levels were measured in the soleus and the lowest expression level was found in the gastrocnemius. The $T b x 1$ expression levels between the three muscle types were all significantly different (Figure 6.3D).
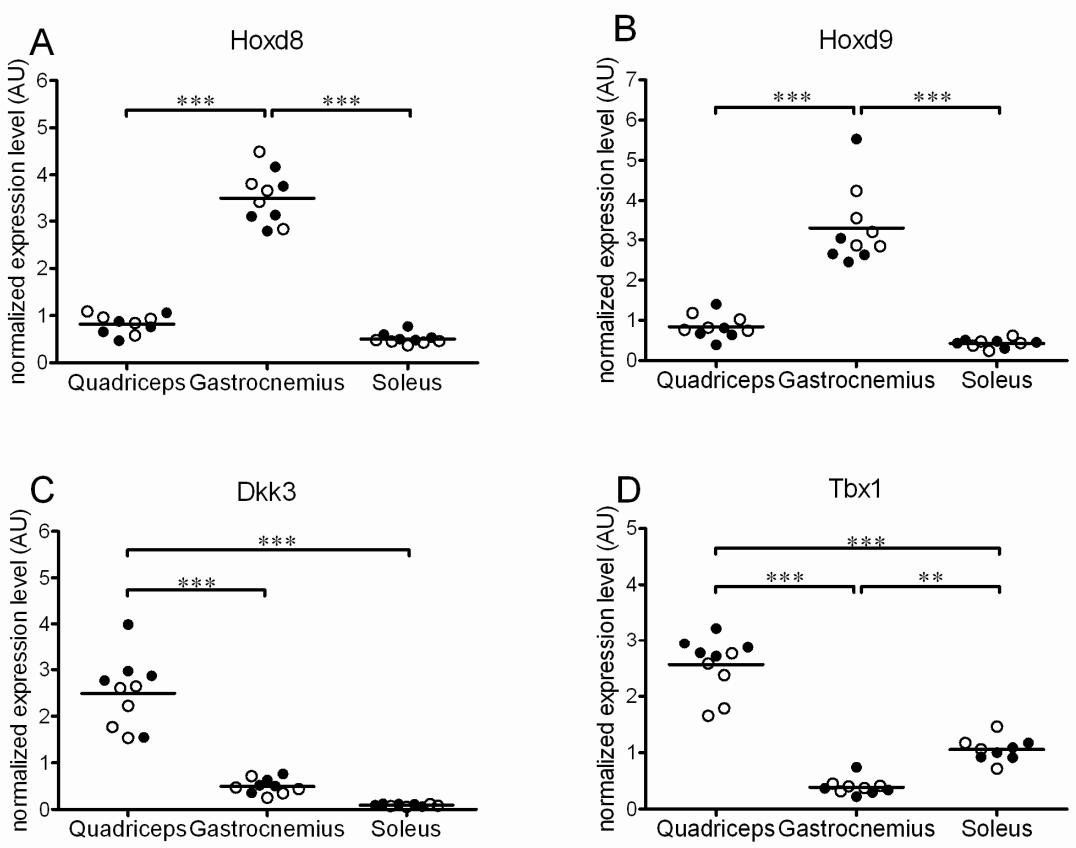

Figure 6.3 Expression of Hoxd8, Hoxd9, Dkk3 and Tbx1 in quadriceps, gastrocnemius and soleus. Gene expression levels of (A) Hoxd8, (B) Hoxd9, (C) Dkk3 and (D) Tbx1 in quadriceps, gastrocnemius and soleus of 20-week LFD mice and 20-week HFD mice. Black dots represent the 20-week LFD mice $(n=5)$; open dots represent the 20 -week HFD mice $(n=5)$, lines represent grand mean values. $* * *$ Indicate significant differences with $p<0.001$ obtained with two-way ANOVA. 


\section{Gene expression patterns of Hoxd8 and Hoxd9 do not correlate with expression patterns of markers for the different fiber types}

We found that markers for the oxidative fiber types as well as members of the Hoxd gene cluster were higher expressed in the gastrocnemius than in the quadriceps. To find out if these Hoxd genes play a role in specifying more oxidative muscle types we compared genes expression levels of Hoxd8, Hoxd9 and markers for different fiber types (type I: Myh7; type Ila: Myh2; type IIx: Myh1 and type IIb: Myh4) in quadriceps, gastrocnemius and soleus muscle of 20-week LFD mice and 20-week HFD mice. Expression levels of markers for the different fiber types were not affected by diet. Whereas Hoxd8 and Hoxd9 showed increased expression in the gastrocnemius as compared to quadriceps and soleus, expression levels of Myh7 was significantly higher in the soleus than in the quadriceps and gastrocnemius, respectively. Also the Myh2 expression level was higher in the soleus than in the quadriceps and gastrocnemius. For both Myh7 and Myh2 no differences between the quadriceps and the gastrocnemius were observed. Myh1 gene expression levels were comparable between the three muscle types. Finally, the expression level of the Myh4 gene was significantly lower in the soleus than in the quadriceps and gastrocnemius, respectively. Myh4 gene expression levels were similar in the quadriceps and gastrocnemius (Figure 6.4). Altogether, the expression patterns of Hoxd8 and Hoxd9 did not correspond with the expression patterns of one of the markers for the different fiber types.

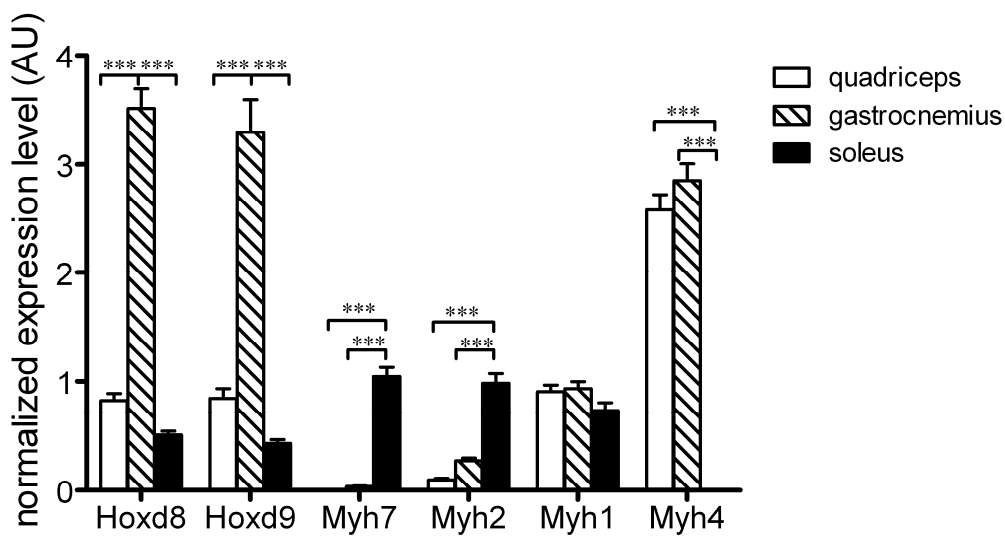

Figure 6.4. Expression of Hoxd8, Hoxd9, Myh7, Myh2, Myh1 and Myh4 in quadriceps, gastrocnemius and soleus. Gene expression levels of Hoxd8, Hoxd9, Myh7, Myh2, Myh1 and Myh4 in quadriceps, gastrocnemius and soleus of 20-week LFD and HFD mice. The genes Myh7, Myh2, Myh1 and Myh4 are markers for type I, Ila, IIx and IIb fiber types, respectively. White bars, dashed bars and black bars represent quadriceps, gastrocnemius and soleus, respectively. Bars represent grand mean values of 20-week LFD mice and 20-week HFD mice. ${ }^{* * *}$ Indicate significant differences with $p<0.001$ obtained with two-way ANOVA 


\section{Discussion}

In the present study we searched for novel genes that are involved in specifying muscle types. Additionally, we studied the diet-sensitivity of differentially expressed genes. By comparing the gastrocnemius with the quadriceps we identified 162 differentially expressed genes corresponding to a variety of biological processes. Especially processes involved in cell cycle, contraction, development, differentiation, morphogenesis and remodeling were differentially regulated in the gastrocnemius vs. the quadriceps. Both the gastrocnemius and the quadriceps are muscle groups that consist of predominantly type II fibers. In the present study we found that Myh7, Tnnc1, Tnni1 and Tnnt1, which are all markers for the more oxidative fiber types, are strongly up-regulated in the gastrocnemius as compared to the quadriceps. Western blotting showed that protein levels of myosin heavy chain, slow fiber type protein (marker for the oxidative type I fibers) were similar between the gastrocnemius and the quadriceps, whereas the protein level of Myh2 (marker for the oxidoglycolytic type IIA fibers) was higher in the gastrocnemius than in the quadriceps (data not shown). Therefore, we propose that in this study the gastrocnemius had a more oxidative character than the quadriceps.

Recently, we showed that a 4-week HFD intervention results in increased gene expression and protein levels of markers for the oxidative fiber types in the quadriceps of mice. Based on these findings we suggested that the skeletal muscle can adapt to an increased lipid load by inducing a switch to a more oxidative phenotype (14). Although the adult skeletal muscle is known to have the capacity to adapt to functional demands including exercise, hormones, innervation and mechanical loading $(29,30)$, a link between HFD and a switch of fiber type was not yet described. However, in the present study we showed that an 8-week HFD has none or only minor effects on expression levels of genes that play a role in specifying different muscle types including the markers for oxidative fiber types. Therefore we speculate that the up-regulation of markers for the oxidative fiber types is an early response of the skeletal muscle to the HFD which is not maintained in the long run.

Among the strongest regulated genes we found five genes (Dkk3, Hoxd8, Hoxd9, Hoxd10 and $T b x 1$ ) which are especially known for their critical role during embryogenesis. The skeletal muscle is a dynamic tissue containing different types of stem cells such as satellite cells, side-population (SP) cells and muscle-derived stem cells (MDSC) $(31,32)$. To exclude the possibility that expression of these five embryogenesis-related genes originated from other cell types than myocytes we analyzed the expression of genes that specify satellite cells, SP cells and MDSC (satellite cells, pax7, myf5, cd34 and c-met; SP cells, sca1, sdc4 and pax3; MDSC, cd34 and Blc2 (31, 32)). We found that only three genes ( $c d 34$, sca1 and sdc4) were detectably expressed (microarray signal intensity $>20$ ) in the skeletal muscle of these mice. However, none of these detectably expressed markers differed more than 1.3 -fold be- 
tween the gastrocnemius and the quadriceps. Altogether, we cannot exclude the presence of cells other than myocytes, however, it is most unlikely that these cells have contributed to the different expression levels of Dkk3, Hoxd8, Hoxd9, Hoxd10 and $T b x 1$.

Two genes, $D k k 3$ and $T b x 1$, were expressed at a lower level in the gastrocnemius than in the quadriceps. Extrapolating our data to the soleus we found that $D k k 3$ expression in the soleus was lower than in the quadriceps or gastrocnemius. Interestingly, $T b x 1$ expression levels in the soleus were lower than in the quadriceps, but higher than in the gastrocnemius. During embryogenesis $D k k 3$ and $T b x 1$ are expressed in a variety of organs including the heart and $\operatorname{limb}$ buds $(33,34)$. Whereas the function of $D k k 3$ is still poorly understood (35), Tbx1 is well-studied especially in relation to heart development (34). Recently it was shown that $T b x 1$ is also involved in development of the limb buds by regulating the number of myocytes (36). Since further research revealed that $T b x 1$ is not necessary for skeletal muscle specification, differentiation, patterning or activation of the embryonic myogenic program, this is the only described function of $T b x 1$ in relation to embryonic muscle development (37). Both $D k k 3$ and $T b \times 1$ are reported to be detectably expressed in the adult skeletal muscle $(33,38)$, but until now nothing is known about their possible function. We speculate that the relatively high expression levels of $D k k 3$ and $T b \times 1$ in the quadriceps is involved in maintaining identity of this muscle type.

Three genes of the Hoxd gene cluster (Hoxd8, Hoxd9 and Hoxd10) were upregulated in the gastrocnemius as compared with the quadriceps. The Hox gene family consists of at least 39 Hox genes organized in four gene clusters ( $A, B, C$ and D) which are subdivided into parallel groups numbered 1 to 13 . The major function of Hox genes is the regulation of the formation of anterior-posterior patterning during embryonic development (39). Different groups have studied the expression levels of the Hox gene family in adult tissues of human origin. They found that each tissue displays a unique combination of detectable Hox gene expression levels which is altered when normal cells changes to malignant cancer cells (40-42). Thus, in addition to their critical role in embryonic development, Hox genes play an important role in adult cells by controlling critical processes like cellular identity and differentiation (43). Houghton et al. (44) have studied expression patterns of the Hox gene family in skeletal muscle tissue of adult mice. In line with our observations they reported that the Hoxa10, Hoxc6, Hoxc9 and Hoxc10 genes were detectably expressed. Furthermore, they could not detect Hoxd11 which also is consistent with our findings. Other members of the Hoxd gene cluster were not studied (44). Thus to our knowledge, we are the first to show that Hoxd8, Hoxd9 and Hoxd10 are detectably expressed in adult murine muscle tissue, with highly increased expression levels in the gastrocnemius as compared with the quadriceps.

Together with the higher Hoxd8 and Hoxd9 gene expression levels in the gastrocnemius we found increased gene expression levels of markers for the more oxida- 
tive fiber types. Therefore we hypothesized that Hoxd8 and Hoxd9 might be involved in the determination of more oxidative muscle types. However, when we extrapolated our data to the soleus muscle we could not find a corresponding expression pattern between Hoxd8, Hoxd9 and Myh7 (marker for type I fibers) and Tnni1 (marker for type I fibers; data not shown). In fact, Myh7 and Tnni1 were highly expressed in the soleus, whereas Hoxd8 and Hoxd9 expression in the soleus was as low as in the quadriceps. Also the expression patterns of Myh2, Myh1 and Myh4, which are markers for type IIA, IIX and IIB fibers, respectively, did not show any resemblance with the expression pattern of Hoxd8 and Hoxd9. Although we did not find any resemblances between expression patterns of Hoxd8, Hoxd9 and any of the fiber type-specific markers we could distinguish the gastrocnemius, quadriceps and soleus from each other. Altogether, we suggest that the high expression levels of the Hoxd8, Hoxd9 and possibly Hoxd10 genes are a specific characteristic of the molecular profile of the gastrocnemius and are not related to an oxidative phenotype.

We found that especially genes that are markers for oxidative fiber types and genes known to be important for embryogenesis were differentially expressed in the gastrocnemius vs. the quadriceps. The expression levels of these genes were not influenced by diet. Furthermore, expression of Hoxd8 and Hoxd9 was low and expression of $D k k 3$ and $T b x 1$ was high in the quadriceps. In the gastrocnemius we observed high expression of Hoxd8 and Hoxd9 and low expression of Dkk3 and Tbx1. Finally, in the soleus we found low expression of Hoxd8, Hoxd9 and Dkk3, but intermediate expression of $T b x 1$. Comparing gastrocnemius, quadriceps and soleus, the gene expression pattern of Hoxd8 and Hoxd9 did not correspond to the gene expression pattern of any of the fiber type-specific markers. Therefore, we conclude that the highly expressed embryonic genes Dkk3, Hoxd8, Hoxd9 and Tbx1 are involved in identifying muscle types in a diet-independent and fiber type-unrelated manner.

\section{Acknowledgements}

We thank Mechteld Grootte Bromhaar, Shohreh Keshtkar Ghiasabadi and Bert Weijers for excellent technical assistance. This study was funded by the Top Institute Food and Nutrition, with financial support by the Dutch government.

\section{References}

1. Liang H, Ward WF. PGC-1alpha: a key regulator of energy metabolism. Advances in physiology education. 2006 Dec;30(4):145-51. 
2. Scott W, Stevens J, Binder-Macleod SA. Human skeletal muscle fiber type classifications. Physical therapy. 2001 Nov;81(11):1810-6.

3. Berchtold MW, Brinkmeier H, Muntener M. Calcium ion in skeletal muscle: its crucial role for muscle function, plasticity, and disease. Physiological reviews. 2000 Jul;80(3):1215-65.

4. Booth FW, Thomason DB. Molecular and cellular adaptation of muscle in response to exercise: perspectives of various models. Physiological reviews. $1991 \mathrm{Apr} ; 71(2): 541-85$.

5. Chanseaume E, Malpuech-Brugere C, Patrac V, Bielicki G, Rousset P, Couturier K, et al. Diets high in sugar, fat, and energy induce muscle type-specific adaptations in mitochondrial functions in rats. The Journal of nutrition. 2006 Aug;136(8):2194-200.

6. Wang YX, Zhang CL, Yu RT, Cho HK, Nelson MC, Bayuga-Ocampo CR, et al. Regulation of muscle fiber type and running endurance by PPARdelta. PLoS biology. 2004 Oct;2(10):e294.

7. Kho AT, Kang PB, Kohane IS, Kunkel LM. Transcriptome-scale similarities between mouse and human skeletal muscles with normal and myopathic phenotypes. BMC musculoskeletal disorders. 2006;7:23.

8. Naya FJ, Mercer B, Shelton J, Richardson JA, Williams RS, Olson EN. Stimulation of slow skeletal muscle fiber gene expression by calcineurin in vivo. The Journal of biological chemistry. 2000 Feb $18 ; 275(7): 4545-8$.

9. Talmadge RJ, Otis JS, Rittler MR, Garcia ND, Spencer SR, Lees SJ, et al. Calcineurin activation influences muscle phenotype in a muscle-specific fashion. BMC cell biology. 2004 Jul 28;5:28.

10. Lin J, Wu H, Tarr PT, Zhang CY, Wu Z, Boss O, et al. Transcriptional co-activator PGC-1 alpha drives the formation of slow-twitch muscle fibres. Nature. 2002 Aug 15;418(6899):797-801.

11. Mortensen $\mathrm{OH}$, Frandsen L, Schjerling P, Nishimura E, Grunnet N. PGC-1alpha and PGC-1beta have both similar and distinct effects on myofiber switching toward an oxidative phenotype. Am J Physiol Endocrinol Metab. 2006 Oct;291(4):E807-16.

12. Luquet S, Lopez-Soriano J, Holst D, Fredenrich A, Melki J, Rassoulzadegan M, et al. Peroxisome proliferator-activated receptor delta controls muscle development and oxidative capability. Faseb J. 2003 Dec;17(15):2299-301.

13. Hakimi P, Yang J, Casadesus G, Massillon D, Tolentino-Silva F, Nye CK, et al. Overexpression of the Cytosolic Form of Phosphoenolpyruvate Carboxykinase (GTP) in Skeletal Muscle Repatterns Energy Metabolism in the Mouse. Journal of Biological Chemistry. 2007 November 9, 2007;282(45):3284455.

14. de Wilde J, Mohren R, van den Berg S, Boekschoten M, Dijk KW, de Groot P, et al. Short-term high fat-feeding results in morphological and metabolic adaptations in the skeletal muscle of C57BL/6J mice. Physiol Genomics. 2008 Feb 19;32(3):360-9.

15. de Wit NJ, Bosch-Vermeulen H, de Groot PJ, Hooiveld GJ, Bromhaar MM, Jansen J, et al. The role of the small intestine in the development of dietary fat-induced obesity and insulin resistance in C57BL/6J mice. BMC medical genomics. 2008;1:14.

16. Gentleman RC, Carey VJ, Bates DM, Bolstad B, Dettling M, Dudoit S, et al. Bioconductor: open software development for computational biology and bioinformatics. Genome biology. 2004;5(10):R80.

17. Dai M, Wang P, Boyd AD, Kostov G, Athey B, Jones EG, et al. Evolving gene/transcript definitions significantly alter the interpretation of GeneChip data. Nucleic Acids Res. 2005;33(20):e175.

18. Wu Z, Irizarry R, Gentleman R, Martinez-Murillo F, Spencer F. A model-based background adjustment for oligonucleotide expression arrays Journal of the American Statistical Association 2004;99(468):909-17.

19. Smyth GK. Linear models and empirical bayes methods for assessing differential expression in microarray experiments. Stat Appl Genet Mol Biol. 2004;3:Article3.

20. Xinmin L, Kim J, Zhou J, Gu W, Quigg R. Use of signal thresholds to determine significant changes in microarray data analyses. Genetics and Molecular Biology. 2005;28:191-200.

21. Storey JD, Tibshirani R. Statistical significance for genomewide studies. Proceedings of the National Academy of Sciences of the United States of America. 2003 Aug 5;100(16):9440-5. 
22. Lee HK, Braynen W, Keshav K, Pavlidis P. ErmineJ: tool for functional analysis of gene expression data sets. BMC Bioinformatics. 2005;6:269.

23. Subramanian A, Tamayo P, Mootha VK, Mukherjee S, Ebert BL, Gillette MA, et al. Gene set enrichment analysis: a knowledge-based approach for interpreting genome-wide expression profiles. Proceedings of the National Academy of Sciences of the United States of America. 2005 Oct 25;102(43):15545-50.

24. Dahlquist KD, Salomonis N, Vranizan K, Lawlor SC, Conklin BR. GenMAPP, a new tool for viewing and analyzing microarray data on biological pathways. Nat Genet. 2002 May;31(1):19-20.

25. Kanehisa M, Goto S. KEGG: kyoto encyclopedia of genes and genomes. Nucleic Acids Res. 2000 Jan $1 ; 28(1): 27-30$.

26. Wang X, Seed B. A PCR primer bank for quantitative gene expression analysis. 2003:e154-.

27. Vandesompele J, De Preter K, Pattyn F, Poppe B, Van Roy N, De Paepe A, et al. Accurate normalization of real-time quantitative RT-PCR data by geometric averaging of multiple internal control genes. Genome biology. 2002 Jun 18;3(7):RESEARCH0034.

28. Hellemans J, Mortier G, De Paepe A, Speleman F, Vandesompele J. qBase relative quantification framework and software for management and automated analysis of real-time quantitative PCR data. Genome biology. 2007;8(2):R19.

29. Pette D, Staron RS. Myosin isoforms, muscle fiber types, and transitions. Microscopy research and technique. 2000 Sep 15;50(6):500-9.

30. Pette D, Staron RS. Transitions of muscle fiber phenotypic profiles. Histochemistry and cell biology. 2001 May;115(5):359-72.

31. Otto A, Collins-Hooper $\mathrm{H}$, Patel $\mathrm{K}$. The origin, molecular regulation and therapeutic potential of myogenic stem cell populations. Journal of anatomy. 2009;215(5):477-97.

32. Figeac N, Daczewska M, Marcelle C, Jagla K. Muscle stem cells and model systems for their investigation. Development dynamics. 2007;236(12):3332-42.

33. Monaghan AP, Kioschis $P, W u$ W, Zuniga A, Bock D, Poustka A, et al. Dickkopf genes are co-ordinately expressed in mesodermal lineages. Mech Dev. 1999;87(1-2):45 - 56.

34. Stennard FA, Harvey RP. T-box transcription factors and their roles in regulatory hierarchies in the developing heart. Development (Cambridge, England). 2005 Nov;132(22):4897-910.

35. Niehrs C. Function and biological roles of the Dickkopf family of Wnt modulators. Oncogene. 2006 Dec 4;25(57):7469-81.

36. Dastjerdi A, Robson L, Walker R, Hadley J, Zhang Z, Rodriguez-Niedenfuhr M, et al. Tbx1 regulation of myogenic differentiation in the limb and cranial mesoderm. Dev Dyn. 2007 Feb;236(2):353-63.

37. Grifone R, Jarry T, Dandonneau M, Grenier J, Duprez D, Kelly RG. Properties of branchiomeric and somite-derived muscle development in Tbx1 mutant embryos. Dev Dyn. 2008 Oct;237(10):3071-8.

38. Chieffo C, Garvey N, Gong W, Roe B, Zhang G, Silver L, et al. Isolation and characterization of a gene from the DiGeorge chromosomal region homologous to the mouse Tbx1 gene. Genomics. 1997 Aug 1;43(3):267-77.

39. Svingen T, Tonissen KF. Hox transcription factors and their elusive mammalian gene targets. Heredity. 2006 Aug;97(2):88-96.

40. Calvo R, West J, Franklin W, Erickson P, Bemis L, Li E, et al. Altered HOX and WNT7A expression in human lung cancer. Proceedings of the National Academy of Sciences of the United States of America. 2000 Nov 7;97(23):12776-81.

41. Cantile M, Pettinato G, Procino A, Feliciello I, Cindolo L, Cillo C. In vivo expression of the whole HOX gene network in human breast cancer. Eur J Cancer. 2003 Jan;39(2):257-64.

42. Cillo C. HOX genes in human cancers. Invasion \& metastasis. 1994;14(1-6):38-49.

43. Cillo C, Cantile M, Faiella A, Boncinelli E. Homeobox genes in normal and malignant cells. Journal of cellular physiology. 2001 Aug;188(2):161-9.

44. Houghton L, Rosenthal N. Regulation of a muscle-specific transgene by persistent expression of Hox genes in postnatal murine limb muscle. Dev Dyn. 1999 Dec;216(4-5):385-97. 


\section{CHAPTER 7 \\ General discussion}




\section{Introduction}

The metabolic syndrome (MetS) is a cluster of metabolic abnormalities including obesity and insulin resistance which are all associated with an increased risk for type 2 diabetes mellitus (T2DM) and cardiovascular diseases (CVD) (1-4). In the Western world the prevalence of the MetS in adults, adolescents and childeren is rapidly increasing $(5,6)$. As this will have major economic and societal consequences, there is an urgent need for better intervention and treatment strategies. Until now, the underlying mechanisms of the MetS are still unclear and more molecular reseach is necessary. This will contribute to a better understanding and eventually to the development of better preventive nutritional strategies.

One of the factors responsible for the increasing prevalence of the MetS is an excessive intake of dietary fat. Therefore, it is essential to obtain a comprehensive view of molecular profiles under high fat diet (HFD) conditions. Studying the effects of a specific nutrient, food component or diet at the gene, protein and metabolite level is defined as nutrigenomics $(7,8)$. A major aim of nutrigenomics is the prevention of chronic diseases such as CVD and the MetS. This goal is based on the concept that nutritional strategies should focus on health and the earliest phase of disease development, whereas pharmacological therapy should target the pathophysiological aspects of disease (Figure 7.1). In order to effectively apply nutritional strategies, thereby recovering homeostasis or preventing further progression towards disease, new biomarkers are needed that identify this "so-called" pre-disease state (7-9).

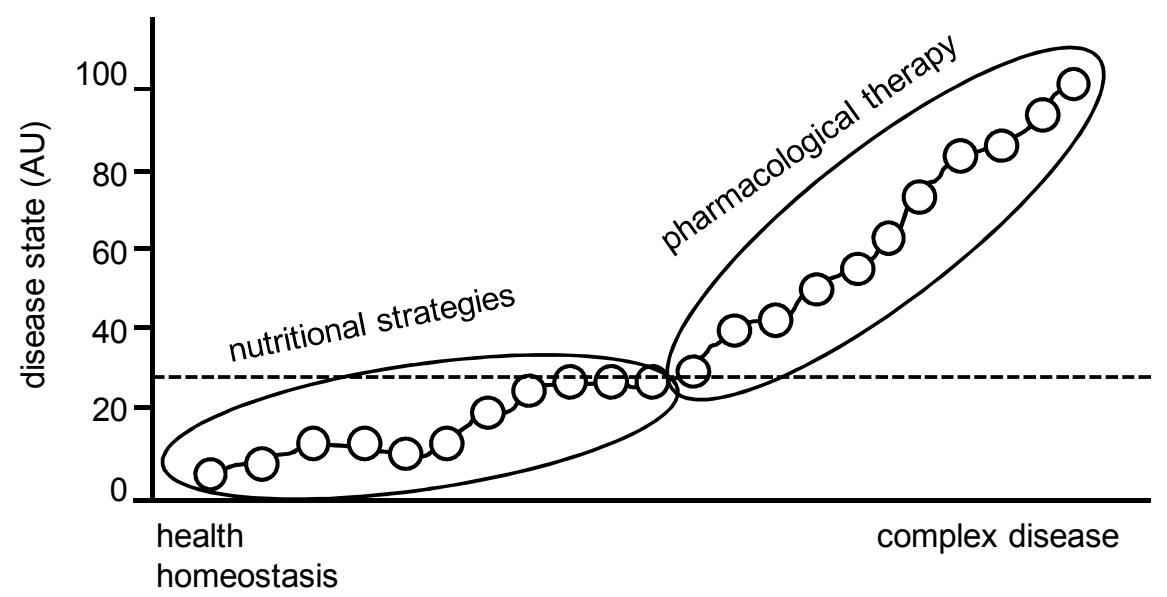

Figure 7.1 Nutrigenomics focuses on health and the earliest phase of disease pathology. In this predisease state, nutritional strategies can still be effective, whereas pharmacological therapy is necessary to target the pathophysiological aspects of the disease. Dotted line indicates the threshold above which there can be no restoration of homeostasis. (Adapted from Afman, Journal of the American Dietetic Association, 2006). 
The MetS is a complex disorder in that different tissues including adipose tissue, liver, small intestine and skeletal muscle are involved in the pathology. Obesity is strongly associated with T2DM and CVD (10-12) and therefore, adipose tissue is considered one of the key targets for unraveling mechanisms underlying the MetS. Microarray analysis of adipose tissue of human obese subjects revealed a strong increase of the expression of pro-inflammatory genes as well as macrophagespecific genes which might point to the infiltration of macrophages. Furthermore, up-regulation of extracellular matrix components was observed suggesting that pathophysiological tissue remodeling takes place during obesity (reviewed in (13)). Within the Dutch Nutrigenomics Consortium molecular changes in the liver, small intestine and skeletal muscle have been studied in a frequently-used model for the MetS, the diet-induced obese C57BL/6J mouse. Microarray analysis of the liver showed that dietary fat induces the expression of genes related to cell cycle, inflammation, lipid metabolism, oxidative stress and fibrosis (Kersten et al., personal communication). In the small intestine dietary fat has the most pronounced effect on biological processes related to lipid metabolism (up-regulated; chylomicron synthesis, fatty acid (FA) transport, FA oxidation and down-regulated; cholesterol efflux), cell cycle (up-regulated; genes essential for progression through cell cycle and down-regulated; apoptosis-related genes) and inflammation (inconsistent results) (14). The role of the skeletal muscle in the early onset of the MetS was examined in this thesis. Specifically, we studied molecular changes in the skeletal muscle under influence of HFD conditions at the mRNA, protein and metabolite level, respectively. Additionally, we measured changes in physiological parameters including body composition, insulin sensitivity and mitochondrial function. The next paragraphs will give a comprehensive overview of the main findings described in this thesis which will be discussed in light of recent research in the field.

\section{The fate of fat in the skeletal muscle cell}

The majority of dietary fat enters the body as triacylglycerols (TAG). Digestion of TAG occurs in the small intestine by emulsification under influence of bile salts resulting in 2-monoacylglycerols (MAG) and non-esterfied FA. In the form of micelles, FA and MAG, are carried to the microvilli, taken up by diffusion and re-esterfied into TAG within the enterocytes. These TAG are stabilized with phospholipids and apoproteins, secreted into the intestinal lymph vessels as chylomicrons which enter the circulation via the thoracic duct. Chylomicrons are removed from the circulation by the enzyme lipoprotein lipase which is present in the capillary endothelium. Lipoprotein lipase hydrolyzes TAG into FA and glycerol which are taken up by cells of adipose tissue, the heart or the skeletal muscle $(15,16)$. In the skeletal muscle, the uptake of FA occurs via a mechanism that resembles the uptake of glucose. Thus, an 
acute stimulus like insulin and muscle contraction activates the translocation of specific FA transporters to the cellular membrane facilitating the uptake of FA (17). Within the muscle cell, FA are degraded by $\beta$-oxidation which occurs mainly in mitochondria. In repetitive reduction reaction the FA chain is shortened by two carbon atoms every round releasing these as acetyl-CoA. Acetyl-CoA enters the TCA cycle for further degradation leading to the formation of the reducing equivalents NADH and FADH2. These reducing equivalents can undergo oxidative phosphorylation (OXPHOS) by the respiratory chain leading to the formation of ATP $(15,16)$. Prolonged increased fluxes of FA into the muscle cell can result in the accumulation of FA as long chain acyl CoAs, diacylglycerols (DAG) and TAG. Increased intramuscular levels of TAG are observed in insulin resistant humans (18-21) as well as in welltrained, highly insulin sensitive athletes $(22,23)$. Therefore, it has been suggested that it are not the TAG, but lipid intermediates such as DAG that interfere with the insulin signaling pathway (24-28). In addition to oxidation and accumulation, FA can be used for the synthesis of other lipids such as phospholipids, which are the main components of cellular membranes.

\section{Increased fatty acid oxidative capacity: a beneficial adaptation to high fat conditions?}

In human insulin resistant subjects, the skeletal muscle is characterized by a reduced FA oxidative capacity (29-31). Additionally, insulin resistance and T2DM are both associated with impaired skeletal muscle mitochondrial function (32-35). Therefore, it has been suggested that mitochondrial dysfunction is a possible cause of reduced FA oxidative capacity. The factors involved in impairing mitochondrial function are not completely understood. It has been suggested that an increased supply of fat to the skeletal muscle is a possible cause. Indeed, lipid infusion, which acutely increases plasma free FA, decreases the expression of mitochondrial genes in the skeletal muscle of healthy human subjects $(36,37)$. Additionally, Sparks et al. (38) showed that a 3-day HFD reduces the expression of mitochondrial genes in the skeletal muscle of young healthy subjects. These observations were confirmed in the skeletal muscle of C57BL/6J mice fed a 3-week HFD (38). However, data presented in chapter $\mathbf{2}$ showed that a HFD does not decrease, but rather increases the expression of genes involved in FA oxidation and OXPHOS in the skeletal muscle of mice. This transcriptional up-regulation was more pronounced at day 3 than at week 4. However, we found significantly increased protein levels of the respiratory chain complexes (as marker for OXPHOS) in the skeletal muscle of the 4-week HFD mice. These results indicate that expression of fat metabolism-related genes tends to decrease over time, whereas protein levels are maintained. A decreased expression of genes of the mitochondrial respiration chain is found in the skeletal muscle of T2DM patients (39-42). Therefore, we hypothesized that this trend will continue, 
ultimately resulting in lower protein levels of the respiratory chain complexes which will lead to decreased FA oxidative capacity in the long run.

As described in chapter 3 we found that an 8-week HFD reduces insulin sensitivity accompanied by a small, but consistent transcriptional up-regulation of FA oxidation in the mouse skeletal muscle. However, activity of $\beta$-hydroxyacyl-CoA dehydrogenase (as marker for $\beta$-oxidation) in the skeletal muscle of HFD mice was comparable to LFD mice. In addition, activity of citrate synthase (as a marker of TCA cycle activity) and protein levels of the respiratory chain complexes in HFD mice were not different from LFD mice. Therefore, we speculated that the capacity to oxidize fat was still sufficient to handle the increased fat load. Indeed, in a subsequent study (chapter 4) we found that mitochondrial FA oxidative capacity in mice fed an 8week HFD was similar to LFD mice. After 20 weeks of HFD however, we observed an adaptive increase of mitochondrial capacity to oxidize lipids in HFD mice as compared to LFD mice. Although this finding is in line with numerous other studies (4347), it is in contrast with our expectations based on the decreasing trend observed for the expression of fat metabolism-related genes (chapter 2 ). Alterations in mRNA levels are critical for controlling the flux of a nutrient or metabolite through a biochemical pathway. However, the abundance or activity of the corresponding proteins does not necessarily change in parallel. Especially post-translational modifications like phosphorylation and acetylation are known to influence protein activity.

The competition between glucose and FA as substrate for oxidation has been known for many decades (48-50). Thus, when oxidation of FA increases, glucose oxidation consequently decreases. Recently, Koves et al. (51) found a strong link between incomplete FA oxidation and skeletal muscle insulin resistance. In HFD rats, an enhanced rate of FA $\beta$-oxidation exceeding the capacity of the TCA cycle as well as the respiratory chain was found. As a result, FA were only partially degraded causing an increased accumulation of acylcarnitines in skeletal muscle of these rats. Additionally, a reduced capacity of pyruvate to inhibit the oxidation of oleate was observed pointing to metabolic inflexibility which is observed in the skeletal muscle of insulin resistant human subjects (reviewed in (52-55)). Thus, although an enhanced fat oxidative capacity might be considered as beneficial in conditions of lipid surplus, increasing oxidation of FA as treatment for insulin resistance should be applied with caution.

Under high fat conditions the mouse skeletal muscle is characterized by an increased capacity to oxidize lipids. This metabolic adaptation is initiated at the transcriptional level, leading to increased protein expression of respiratory chain complexes and finally an enhanced mitochondrial lipid oxidative capacity. As this adaptation does not prevent the progression of insulin resistance, it is unlikely that a HFD contributes to insulin resistance by impairing skeletal muscle mitochondrial function. 


\section{Adipophilin and intramuscular lipid accumulation: for better or worse?}

In obesity, plasma levels of FA and TAG are elevated leading to increased fluxes of FA into non-adipose tissue such as the skeletal muscle. When fat oxidative capacity is not sufficient, lipids will accumulate as TAG (56) which are stored in lipid droplets (LDs) $(57,58)$. LDs were initially considered as static structures in which fat is stored. However, now it is clear that LDs are very dynamic structures that are complexly regulated (59). LDs consist of a core of neutral lipids such as TAG and sterols which is surround by a phospholipid monolayer coated with one of more proteins of the PAT family (Perilipin, Adipophilin (Adfp), TIP47, S3-12 and OXPAT). The proteins that coat LDs change during LD biogenesis and are dependent on multiple factors including tissue-specific expression (57-59). Although it has been demonstrated that Adfp facilitates the storage of TAG in LDs by stimulating FA uptake and decreasing the turnover of TAG (60-63), little is known about the regulation of Adfp in the skeletal muscle.

Data presented in chapter $\mathbf{5}$ show that in the mouse muscle cells Adfp protein levels are regulated by nuclear hormone receptors of the PPAR family, dietary fat type, amount of dietary fat and muscle type. In vitro as well as in vivo experiments showed that increased Adfp protein expression is associated with improved insulin sensitivity. Therefore, we hypothesize that Adfp protects the muscle against detrimental effects of FA on insulin signaling via incorporation in LDs as TAG. As such, insulin sensitivity of the skeletal muscle can be maintained (chapter 5 ). This hypothesis is in line with work by Farese et al. (64) who recently proposed that by compartmentalizing lipids, LDs protect cells from the toxic effects of increased fat levels. Interestingly, increased intramuscular TAG levels are observed in both insulin resistant human subjects (18-21) and insulin sensitive endurance-trained athletes (22, 23). As endurance-trained athletes not only have increased intramuscular TAG levels, but also an increased capacity to oxidize lipids (65-67), differences in muscle oxidative capacity might explain this apparent paradox. Another explanation for this paradox might be differences in capacity to properly store fat. The skeletal muscle of well-trained athletes contains higher proportions of the more oxidative fiber types (68). These oxidative fibers not only have a higher capacity to store fat (69, $70)$, but also a higher expression of $\operatorname{Adfp}(71,72)$ than the glycolytic fibers. It has been suggested that Adfp, just as perilipin in adipose tissue, decreases TAG turnover by providing a barrier on LDs that restricts the access of lipases to stored TAG. As such, lipolysis of TAG resulting in formation of DAG and FA (57), which may impair insulin action $(73,74)$, is prevented (57). In line with this, Philips et al. (75) showed that weight loss resulted in improved insulin sensitivity and increased Adfp protein expression in the skeletal muscle of obese diabetic subjects, whereas intramuscular TAG levels were not affected.

Adfp might be involved in protecting the neutral TAG stores against lipases. When levels of Adfp do not match the amount of intramuscular fat, neutral TAG stores are 
no longer protected against lipases. This might lead to increased lipolysis resulting in elevated levels of the lipid intermediates DAG and FA and eventually insulin resistance.

\section{Does the composition of the mitochondrial membrane influence mitochondrial function?}

Cellular membranes such as the mitochondrial membrane are involved in maintaining and regulating ionic gradients, potential differences, signal transduction and the uptake of hormones, substrates and nutrients which are all essential for the cell to function properly. The major components of cellular membranes are phospholipids $(76,77)$. Phospholipids are synthesized the novo in the mitochondria (cardiolipin, phosphatidylethanolamine (PE) and phosphatidylglycerol) (78), in the endoplasmic reticulum or Golgi apparatus. Additionally, remodeling of phospholipids can take place via the deacetylation-reacetylation pathway (79). The FA composition and saturation degree of phospholipids determine membrane fluidity and permeability which are both of great importance for normal membrane function $(27,80,81)$.

Skeletal muscle phospholipids of mice fed a 4-week HFD were more saturated than the skeletal muscle phospholipids of LFD mice (chapter 2). This is in line with numerous studies describing a link between a high amount of saturated FA (SFA) in human skeletal muscle phospholipids and reduced insulin sensitivity $(77,82-84)$. Interestingly, the increase of SFA in mouse skeletal muscle phospholipids was especially evident in phosphatidylcholine (PC) and PE. As shown in Figure 7.2, PC and PE are the predominant phospholipids in the mitochondrial membrane of mouse skeletal muscle. As the FA composition and saturation degree influences membrane function $(27,80,81)$ we hypothesized that a more saturated mitochondrial membrane results in mitochondrial dysfunction.

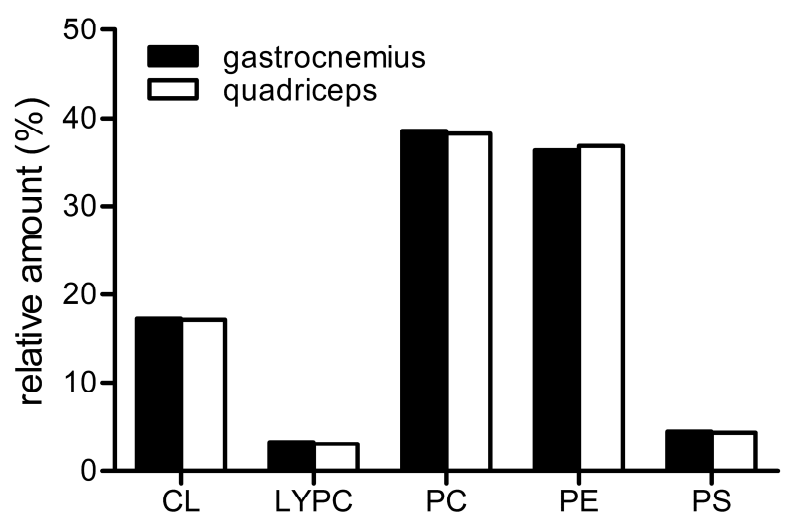

Figure $\quad 7.2$ Relative amounts of the different phospholipids CL, LYPC, $P C, P E$ and $P S$ in the mitochondrial membrane of the gastrocnemius and quadriceps muscle of mice at 12 weeks of age. $\mathrm{CL}$, cardiolipin; LYPC, lysophosphatidylcholine; PC, phosphatidylcholine; PE, phosphatidylethanolamine; PS, phosphatidylserine 
Corroborating the results presented in chapter 2, we found more saturated skeletal muscle mitochondrial phospholipids in 8-week HFD mice than LFD mice (chapter 4). Vazquez-Memije et al. found that more saturated testis mitochondrial phospholipids are associated with lower activity levels of mitochondrial enzymes (85). However, we observed that skeletal muscle mitochondrial function of HFD mice was comparable to LFD mice. Both the 4-week and 8-week HFD induced an increase in SFA, whereas a pronounced increase in $n-6$ poly-unsaturated FA (PUFA) was observed in skeletal muscle mitochondrial phospholipids in 20-week HFD mice. The resulting increased unsaturation index was accompanied by an increased mitochondrial capacity to oxidize lipids (chapter 4). This is in line with findings that a higher unsaturation improves responsiveness of the membrane-bound proteins such as the complexes of the respiratory chain $(27,86)$. Interestingly, the increased unsaturation did not improve pyruvate-driven respiration of HFD mice. This is in accordance with the work of Lemieux et al. (87) who studied the effect of different fat types (coconut oil vs. olive oil vs. fish oil) on the FA composition and function of heart mitochondria in rats. Although the mitochondria of Lemieux's coconut oil and olive oil groups contained a relatively lower amount of the n-3 PUFA than the fish oil group, pyruvate-driven oxidation was comparable between the three groups (87). Our results combined with the findings of Lemieux et al. (87) indicate that it is not the mitochondrial phospholipid composition per se that influences mitochondrial function.

\section{Can a more oxidative muscle type counteract the progression of insulin resistance?}

The skeletal muscle is a dynamic tissue that is composed of fiber types that differ in contractile characteristics, metabolic properties and number of mitochondria. Aging, alterations in hormone levels and innervations, exercise, mechanical loading and unloading are all known to induce fiber type transitions (88-90). That exposure to a HFD can induce a fiber type transition was shown in chapter 2. Both a 3-day HFD and 4-week HFD resulted in increased gene and protein levels of markers for the more oxidative fiber types. These results suggest that the skeletal muscle morphologically adapts to a HFD by a transition towards a more oxidative character via a transcriptional mechanism. That this transcriptional up-regulation is not maintained in the long run was shown in chapter 6 . Prolonged HFD interventions ( 8 and 20 weeks) did not or minimally affect gene expression levels of markers for oxidative fiber types. Thus, the HFD-induced transcriptional up-regulation of oxidative fiber type markers in the skeletal muscle of mice is an early and rapid response.

Recently, Shortreed et al. (91) showed that a HFD actually induces a transition to a more oxidative skeletal muscle. By performing histochemical analyses they ob- 
served that an 8-week HFD (60 kcal\% fat) results in an increased proportion of type I and IIA fibers in the gastrocnemius/plantarius muscle together with decreased proportions of type IID and IIB fibers. Although the increase of type I and IIA fibers was not found in the soleus muscle, an increase of the cross-sectional area of both oxidative fiber types was found in the HFD soleus. Furthermore, these increases were not observed in the tibialis anterior muscles of HFD mice (91). The transition to a more oxidative fiber type was also observed in a genetic model for obesity (C57BL/6J-ob/ob). By performing electrophoretic analysis Kemp et al. (92) found that in $o b / o b$ mice the sternomastoid, extensor digitorum longus and soleus muscles all contain a higher proportion of the slower, more oxidative MHC isoforms than muscles of lean C57BL/6J mice. Additionally, they found an increased amount of hybrid fibers in muscles of ob/ob mice as compared to the lean C57BL/6J mice (92). Combining our own results with those of Shortreed et al. (91) and Kemp et al. (92) leads us to hypothesize that an increase in oxidative fiber types will result in a more oxidative character of the skeletal muscle and eventually an increased capacity to oxidize fat.

Several animal studies have shown that there is remarkable heterogeneity in insulin sensitivity among muscle types composed of different fiber types. It has been proposed that type I fibers are the most insulin sensitive types, followed by type IIA fibers and type IIB fibers (93-95). More recently, it was shown that a calcineurininduced transition to a more oxidative muscle phenotype coincided with a shift to a more insulin sensitive phenotype $(96,97)$. Thus, in addition to increased FA oxidation, a more oxidative character of the skeletal muscle could also improve insulin sensitivity.

Changes in fiber type have also been analyzed in maturing Zucker diabetic fatty $(\mathrm{ZDF}, f a / f a)$ rats, a genetic model of progressive insulin resistance and development of T2DM during maturation. In the skeletal muscle of the heterozygous lean litter mates $(Z D F, f a /+)$ a switch to a more oxidative phenotype was observed during maturation. Interestingly, this switch was completely absent in maturating ZDF $(\mathrm{fa} / \mathrm{fa}$ ) rats (98). Also in human subjects, obesity, insulin resistance and T2DM are associated with decreases of the oxidative type I fibers and with increases of the glycolytic type IIB fibers (99-102). These results indicate that in subjects with established T2DM the skeletal muscle is characterized by a more glycolytic phenotype as compared to controls.

In the early phase of obesity and insulin resistance, a transition to a more oxidative phenotype can be observed in the skeletal muscle. This is initiated by a transcriptional mechanism increasing the expression of genes that are markers for oxidative fiber types. This transition may provide temporary benefits like increased FA oxidative capacity and improved insulin sensitivity aimed at battling the increased lipid load to which non-adipose tissues are exposed in obesity. 


\section{What is the function of embryogenic genes in adult mouse muscle?}

A major strength of transcriptomics is that all genes active in the tissue under investigation can be identified. As such, genes that were formerly not related to a particular tissue can be identified as shown in chapter 6 . By performing microarray analysis we found that genes from the Dkk, Hox and Tbx family, which are particularly known for their critical role in embryogenesis (103-105), are detectably expressed in adult mouse muscle. Interestingly, expression of $D k k 3, H o x d 8, H o x d 9$ and $T b x 1$ was highly different between gastrocnemius, quadriceps and soleus. In fact, every muscle type showed a unique combination of expression of these four genes which was not influenced by diet. According to our knowledge, nothing is known about the possible function of $D k k 3$ and $T b x 1$ in adult tissue. As the expression of Hox genes is altered in malignant cancer cells (106-108) it has been proposed that Hox genes play an important role in adult tissue by controlling critical processes including cellular identity and differentiation (109). Therefore, we speculate that the highly expressed embryogenic genes $D k k 3, H o x d 8, H o x d 9$ and $T b x 1$ are involved in maintaining identity of the muscle types.

\section{Transcriptomics in the battle against the metabolic syndrome}

The influence of a HFD on the mouse muscle transcriptome was studied after 3 days, 4 weeks (chapter 2) and 8 weeks (chapter $\mathbf{3}$ ) of dietary intervention. Whereas more than a thousand differentially expressed genes were found at day 3 and week 4 , no genes were differentially expressed at week 8 . This might be explained by the use of adjusted selection criteria for microarray data analysis in chapter $\mathbf{3}$ as compared to chapter 2. However, when these adjusted criteria were applied to the microarray data of chapter 2 still hundreds of differentially expressed genes were found at day 3 and week 4 of the dietary intervention (Figure 7.3). Changes in gene expression are rapidly established and therefore, it might be possible that at 8 weeks alterations in gene expression have returned to basal level. Whether changed gene expression levels are present in the long run when a more pronounced disease-state can be expected, e.g. at 20 weeks, requires further investigation. Furthermore, it might be possible that differences in protein abundance are still visible at 8 weeks. Analysis of the muscle proteome by two-dimensional gel electrophoresis (2-DE) combined with matrix-assisted laser desorption/ionization-time flight mass spectrometry or quantitative liquid chromatography tandem mass spectrometry could shed more light on this issue. 


\begin{tabular}{|c|c|c|}
\hline 3-day HFD & 4-week HFD & 8-week HFD \\
\hline 16539 genes & 16539 genes & 16539 genes \\
\hline $\begin{array}{l}\text { signal intensity } \\
>20\end{array}$ & $\begin{array}{c}\text { signal intensity } \\
>20\end{array}$ & $\begin{array}{c}\text { signal intensity } \\
>20\end{array}$ \\
\hline 8038 genes & 5745 genes & 6539 genes \\
\hline $\begin{array}{c}\text { fold change } \\
>1.3 \text { or }<-1.3\end{array}$ & $\begin{array}{c}\text { fold change } \\
>1.3 \text { or }<-1.3\end{array}$ & $\begin{array}{c}\text { fold change } \\
>1.3 \text { or }<-1.3\end{array}$ \\
\hline $\begin{array}{c}885 \text { genes } \\
(11.0 \%)\end{array}$ & $\begin{array}{c}753 \text { genes } \\
(13.1 \%)\end{array}$ & $\begin{array}{c}101 \text { genes } \\
(1.5 \%)\end{array}$ \\
\hline FDR $<0.05$ & FDR $<0.05$ & FDR $<0.05$ \\
\hline 361 genes & 559 genes & 0 genes \\
\hline
\end{tabular}

Figure 7.3 Differentially expressed genes in the muscle transcriptome of mice fed an 3-day, 4-week or 8-week HFD. Only probe sets with an average signal intensity > 20 across all arrays were selected for further analysis. The criteria of a fold change $>1.3$ or $<-1.3$ and an FDR $<0.05$ were used to find differentially expressed genes

One of the difficulties of nutrigenomics research is the fact that nutritional interventions are known to induce small changes in gene expression $(7,8,110)$. Increasing the number of replicates will result in more statistical power to identify these subtle changes. Otherwise, creative microarray data analysis strategies could be fruitful in searching for these small alterations. Our study of the effect of an 8-week HFD on the muscle transcriptome in chapter $\mathbf{3}$ is a good example of the fruitfulness of creative microarray data analysis. First, we compared the 8-week HFD muscle transcriptome with the 8-week LFD muscle transcriptome. With this comparison strategy we identified FA oxidation as the only regulated pathway. Secondly, we compared the 8-week HFD and the 8-week LFD muscle transcriptome with the muscle transcriptome of mice sacrificed at the start of the intervention. By paralleling the outcomes of the second comparison strategy we found that not only FA oxidation, but also the p38 MAPK cascade was regulated by the HFD. We could obtain more information with the second comparison strategy than with the first comparison which is commonly used in microarray data analyses (HFD transcriptome vs. LFD transcriptome). Therefore, the results of this study are also important with respect to microarray data analysis.

\section{The high fat rodent as model for human insulin resistance}

Although the insulin resistant state in humans is characterized by reduced FA oxidative capacity (29-31) and/or decreased skeletal muscle mitochondrial function (32$35)$, inconclusive results regarding the effect of a HFD on skeletal muscle mitochon- 
drial function in rodents are reported (Table 7.1). Several studies describe a decreased mitochondrial function in the skeletal muscle of rodents fed a HFD (38, 111), whereas we (chapter 2, 3 and 4) and others have observed an increased capacity to oxidize lipids (43-45). Finally, Hoeks et al. (47) found that a HFD does not affect mitochondrial function in the skeletal muscle of male Wistar rats.

The variability in these results can largely be explained by differences in study design such as variation in composition of the used diets. The first dietary factor that will have a strong influence on the outcome of the study is the type of fat used for the HFD. Generally, it is believed that dietary fat types rich in SFA induces obesity and insulin resistance, whereas dietary fat containing PUFA have beneficial effects on body composition and insulin sensitivity (112). Recently, the effect of a HFD based on coconut fat (medium-chain SFA), lard (long-chain saturated and monounsaturated FA), olive oil (mono-unsaturated FA) or fish oil (PUFA) on the development of obesity and insulin resistance was studied in Wistar rats. Compared with a chow diet they found the most pronounced obese and insulin resistant phenotype in rats fed the lard-based or olive oil-based HFD. Insulin sensitivity in rats fed the coconut fat-based or fish oil-based HFD was close to chow (113). Unfortunately, no literature is available that addresses the effect of different fat types on mitochondrial function.

Another dietary factor that might be important in explaining the variability in the results is the chosen control diet. This can be illustrated by two studies that both used a commercially available lard-based HFD, but reported opposite results regarding mitochondrial function $(38,45)$. Whereas Sparks et al. (38) used an LF variant of the HFD as control, a chow diet as control was chosen by Turner et al. (45). As the composition of a chow diet frequently changes, it is difficult to standardize the composition of this diet. When the effect of the amount of fat is studied, it is recommendable to choose an LF variant of the HFD as the control diet.

A final confounding dietary factor that will be discussed is the presence of sucrose in many diets. Dietary interventions with matched caloric intake, in which only the carbohydrate type varied, revealed that sucrose has a negative impact on insulin action (114-116). As an increased sucrose intake negatively affects mitochondrial respiration (117) it is important to match the amount of sucrose in the control diet to the experimental HFD. 


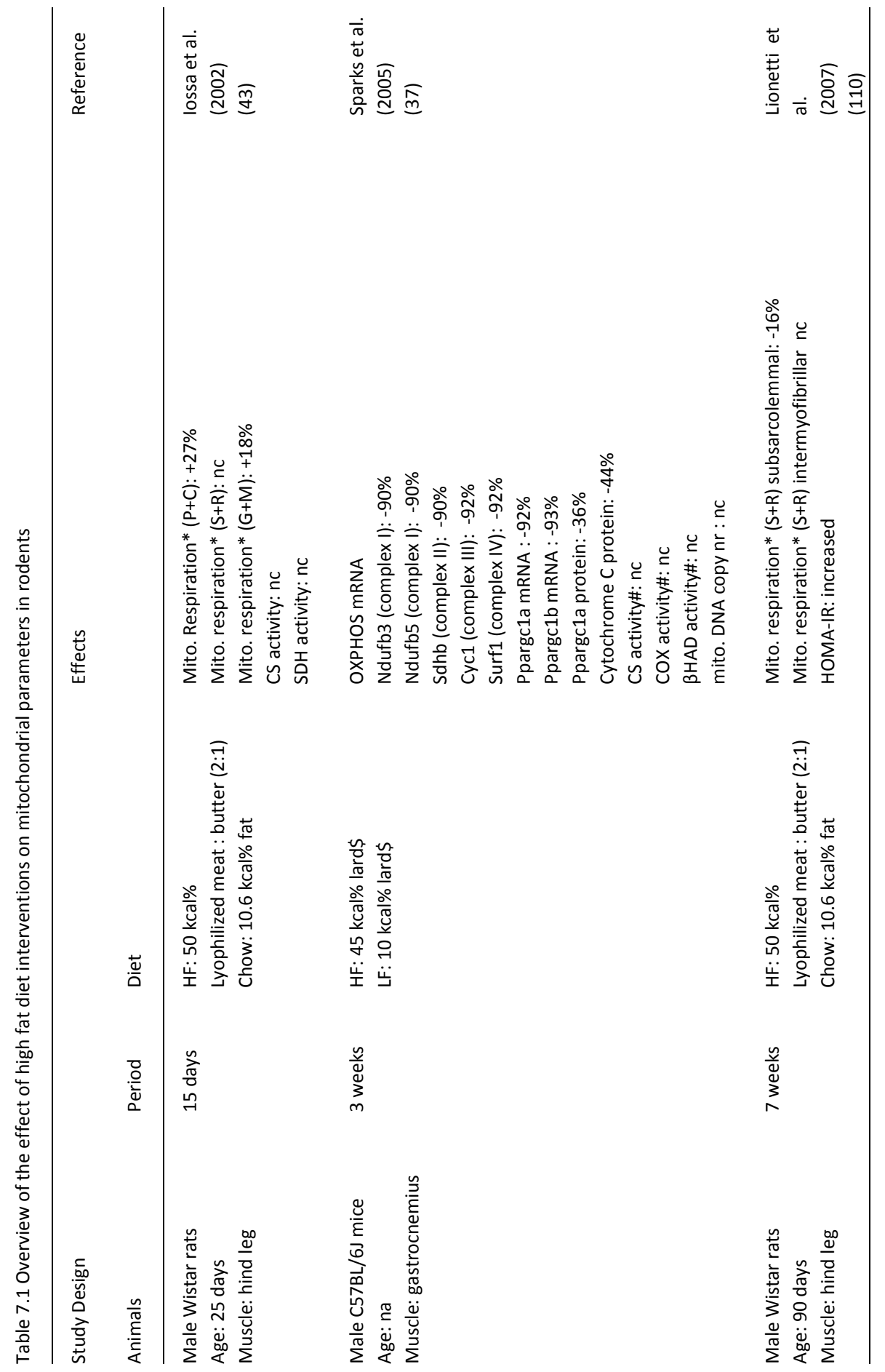




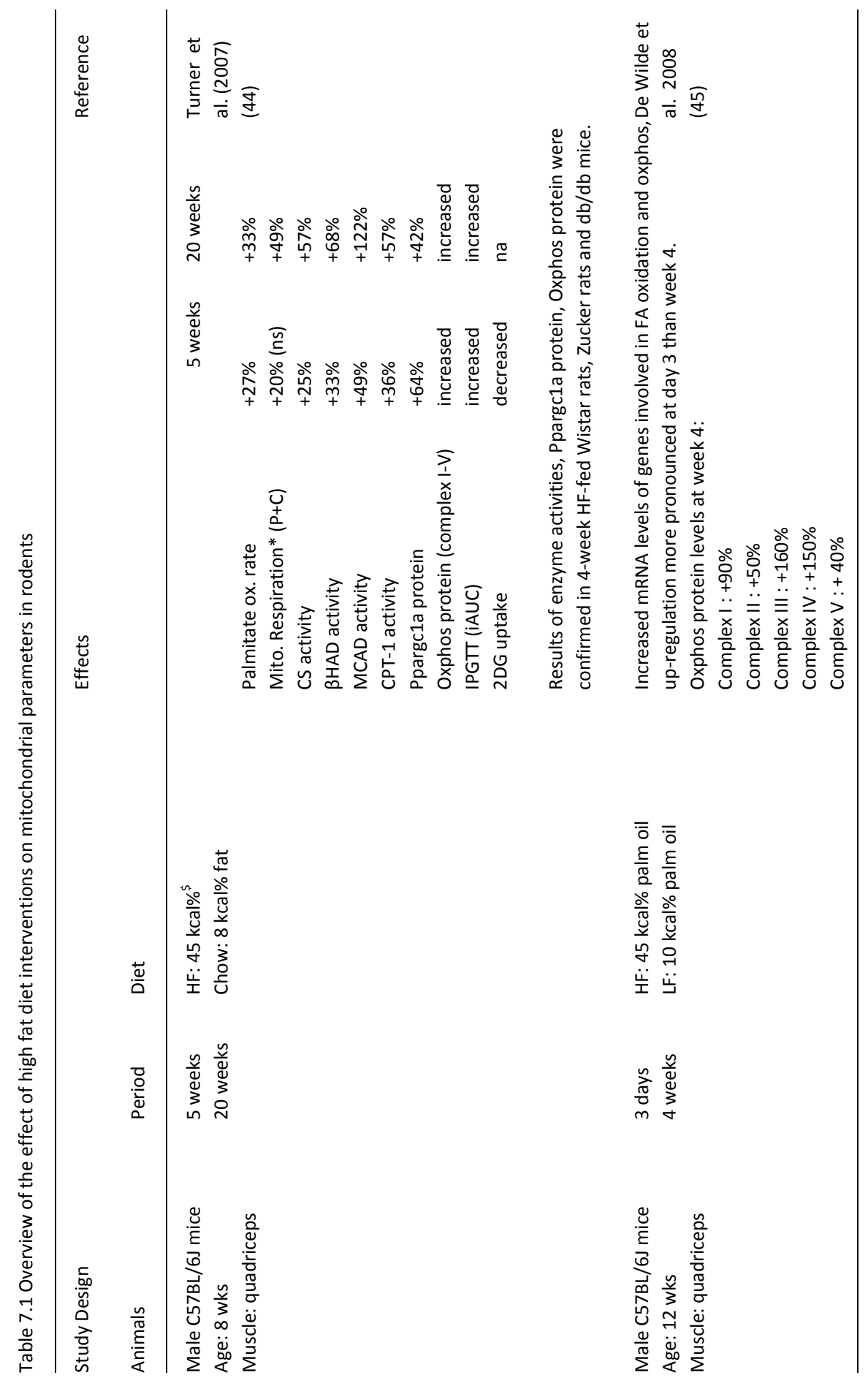




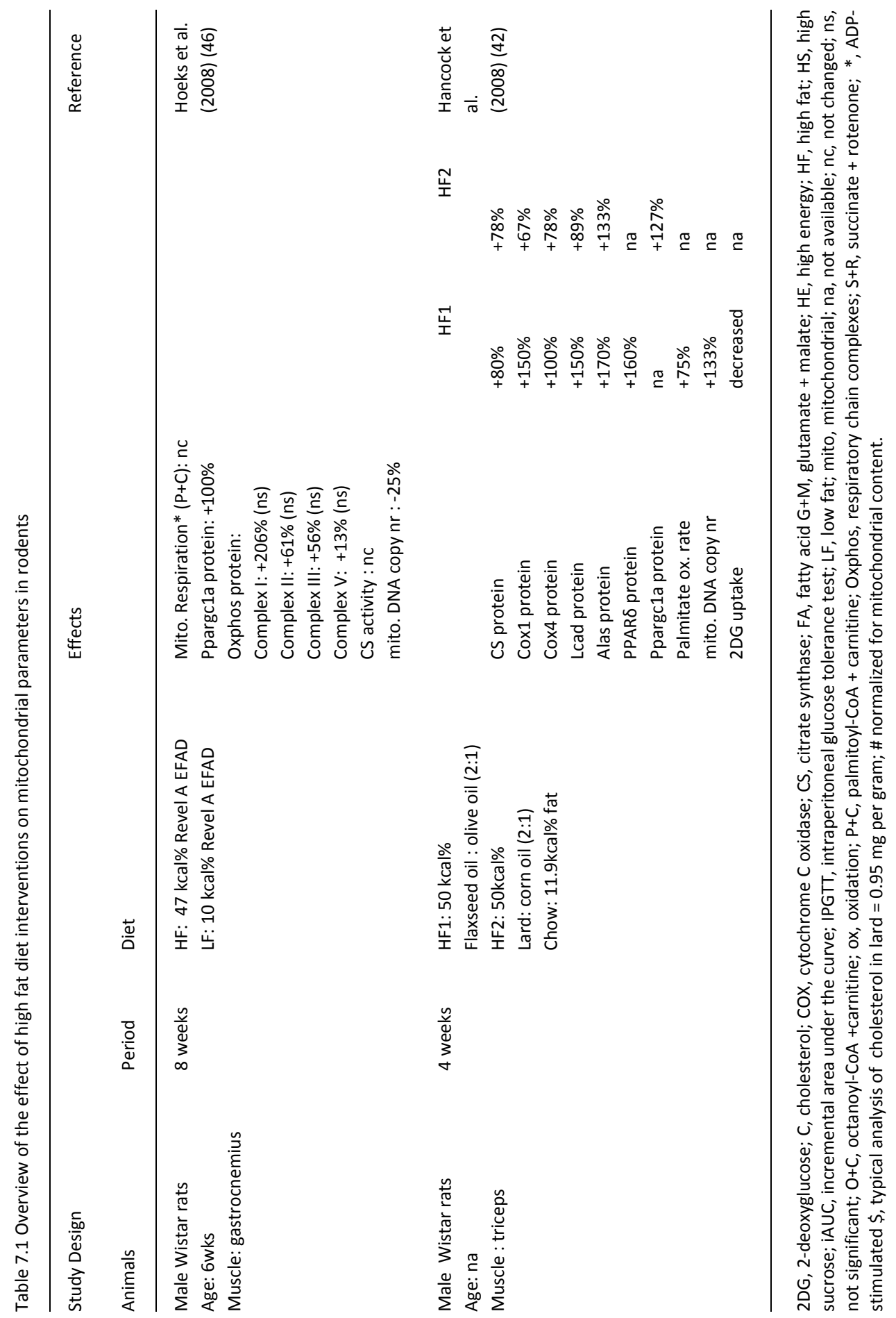


The diets that were used for the research described in this thesis were carefully designed. Palm oil was chosen as main fat type because it contains palmitic acid which is the most common SFA in Western-style diets and plays an important role in the development of insulin resistance (118). Importantly, the energy density of all nutrients, except palm oil and corn starch, was similar between the LFD and HFD (Table 7.2).

Table 7.2 Composition of the palm oil-based low fat diet and high fat diet

\begin{tabular}{lll}
\hline Macronutrient & LFD (kcal \%) & HFD (kcal \%) \\
\hline Protein & 20 & 20 \\
Carbohydrate & 70 & 35 \\
Fat & 10 & 45 \\
& & \\
\hline Ingredient & LFD (kcal) & HFD (kcal) \\
\hline Casein, lactic & 800 & 800 \\
L-Cystine & 12 & 12 \\
Corn Starch & 1709 & 291 \\
Maltodextrin & 400 & 400 \\
Sucrose & 691 & 691 \\
Soybean Oil & 225 & 225 \\
Palm oil & 180 & 1598 \\
Mineral Mix S10026* & 0 & 0 \\
DiCalcium Phosphate & 0 & 0 \\
Calcium Carbonate & 0 & 0 \\
Potassium Citrate, 1 H2O & 0 & 0 \\
Vitamin Mix V10001* & 40 & 40 \\
Choline Bitartrate & 0 & 0 \\
\hline
\end{tabular}

Other aspects of a study design can also contribute to the observed variability in findings with respect to mitochondrial function. As the intervention period will determine the degree of obesity and insulin resistance, it will also influence the effect of a HFD on mitochondrial function. In this context, Bonnard et al. (119) observed that a high fat, high sucrose diet did not influence skeletal muscle mitochondrial respiration in the short run (4 weeks), whereas a decreased respiration was found in the long run (16 weeks) (119). With respect to the palm oil-based HFD, no effects were observed after 8 weeks, whereas an increased lipid oxidative capacity was observed after 20 weeks (chapter 4). Furthermore, variation in the studied muscle group is another feature of a study design that can have a confounding effect. With respect to this, the 8-week palm oil-based HFD did not alter protein levels of the respiratory chain complexes in the quadriceps muscle (chapter 3 ), whereas a significant up-regulation was found in the tibialis anterior muscle (chapter 4). In line with these findings, Chanseaume et al. (120) demonstrated that feeding Wistar rats a 6week high-energy HFD decreased mitochondrial respiration in the soleus muscle, whereas the tibialis muscle was not affected (120). Also the age of the animals at 
the start of the intervention is a factor that might influence the metabolic response to a HFD. Assessment of body composition revealed that in mice the amount of muscle mass increases until an age of 16 weeks (chapter 3 ). Whether young rodents have a better adaptive response to a HFD than adult rodents remains to be established.

In conclusion, many factors influence the effects that a HFD can have on skeletal muscle mitochondrial function. As such, well-controlled animal studies that are standardized with respect to diet composition, intervention period, studied muscle group and age are necessary to find more conclusive results about the role of a HFD in relation to mitochondrial function in insulin resistance.

\section{Relevance for the human situation}

From postprandial human studies we know that a single fat load lowers respiratory quotient ( $R Q$ ) indicating an adaptive increase of fat oxidation. This adaptive response was disturbed in T2DM patients or subjects with family history of T2DM (reviewed in (55)). Furthermore, Ukropcova et al. (121) have shown that human subjects with or without family history of T2DM both increase whole-body fat oxidation, after a 3-day HFD. However, this was less pronounced in the subjects with family history of T2DM (121). This adaptive increase of whole-body fat oxidation was also seen in lean human subjects fed a HFD for 7 days (122). These results indicate that also human subjects respond to an increased lipid load by increasing fat oxidation. To our knowledge, Sparks et al. (38) is the only group that has studied the effects of a short-term HFD on the skeletal muscle of both mice and healthy human subjects. Interestingly, the results obtained in the human study were in accordance with findings in the mouse experiments. All above-mentioned studies were performed for a relatively short period of time, which makes it difficult to compare these findings with the results obtained in our long-term HFD intervention studies. As prolonged HFD interventions in human subjects are not in accordance with ethical guidelines, we will have to rely on extrapolating the knowledge obtained in in vivo animal studies to the human situation.

\section{Conclusion}

Under high fat conditions the mouse skeletal muscle is characterized by molecular changes at the mRNA, protein and metabolite level pointing to an adaptive response to increase the capacity to oxidize lipids. As adaptations at the molecular level could be confirmed at the function level, the results described in this thesis are a unique example of how molecular research can be successfully integrated with functional-based research. This adaptive response could not prevent the deteriora- 
tion of insulin sensitivity indicating that an impaired fat oxidative capacity is rather a consequence than a cause of insulin resistance.

\section{Suggestions for further research}

Based on results obtained in our in vitro cell studies and in vivo mouse studies we propose that Adfp might protect muscle cells against the detrimental effects of FA on insulin sensitivity via the incorporation in LDs as TAG. Otherwise Adfp can be involved in restricting access of lipases to the LDs and as such prevents the accumulation of lipid intermediates such as DAG. A possible way to test these hypotheses is the use of RNA interference, which induces gene silencing by targeting mRNA for degradation, for in vitro cell experiments. For in vivo studies DNA electroporation, which is a transfection technique using an electric pulse to increase membrane permeability for the introduction of the gene of interest, could be possible approach.

A final remark concerns the highly expressed embryogenic genes in adult mouse muscle tissue. At present, little known about the exact function of these genes in the skeletal muscle of adult mice. A possible approach to obtain more information about the function of these genes could be development of a knockout mouse model for these specific genes. For the Hoxd8 gene a knock out mouse model has been described which has not yet been studied yet with respect to the muscle transcriptome (123). This could be a promising lead to unravel to role of Hoxd8 in muscle identity.

\section{References}

1. Kahn R, Buse J, Ferrannini E, Stern M. The metabolic syndrome: time for a critical appraisal: joint statement from the American Diabetes Association and the European Association for the Study of Diabetes. Diabetes care. 2005 Sep;28(9):2289-304.

2. Alberti KG, Zimmet P, Shaw J. Metabolic syndrome--a new world-wide definition. A Consensus Statement from the International Diabetes Federation. Diabet Med. 2006 May;23(5):469-80.

3. Zimmet P, Magliano D, Matsuzawa Y, Alberti G, Shaw J. The metabolic syndrome: a global public health problem and a new definition. J Atheroscler Thromb. 2005;12(6):295-300.

4. Grundy SM, Brewer HB, Jr., Cleeman JI, Smith SC, Jr., Lenfant C. Definition of metabolic syndrome: Report of the National Heart, Lung, and Blood Institute/American Heart Association conference on scientific issues related to definition. Circulation. 2004 Jan 27;109(3):433-8.

5. Balkau B, Vernay M, Mhamdi L, Novak M, Arondel D, Vol S, et al. The incidence and persistence of the NCEP (National Cholesterol Education Program) metabolic syndrome. The French D.E.S.I.R. study. Diabetes Metab. 2003 Nov;29(5):526-32.

6. Weiss R, Dziura J, Burgert TS, Tamborlane WV, Taksali SE, Yeckel CW, et al. Obesity and the metabolic syndrome in children and adolescents. N Engl J Med. 2004 Jun 3;350(23):2362-74.

7. Afman L, Muller M. Nutrigenomics: from molecular nutrition to prevention of disease. J Am Diet Assoc. 2006 Apr;106(4):569-76.

8. Muller M, Kersten S. Nutrigenomics: goals and strategies. Nat Rev Genet. 2003 Apr;4(4):315-22. 
9. García-Cañas V, Simó C, León C, Cifuentes A. Advances in Nutrigenomics research: Novel and future analytical approaches to investigate the biological activity of natural compounds and food functions. Journal of Pharmaceutical and Biomedical Analysis. 2010;51(2):290-304.

10. Lavie CJ, Milani RV, Ventura HO. Obesity and cardiovascular disease: risk factor, paradox, and impact of weight loss. J Am Coll Cardiol. 2009 May 26;53(21):1925-32.

11. Marinou K, Tousoulis D, Antonopoulos AS, Stefanadi E, Stefanadis C. Obesity and cardiovascular disease: From pathophysiology to risk stratification. Int J Cardiol. 2009 Apr 25.

12. Venables $M C$, Jeukendrup AE. Physical inactivity and obesity: links with insulin resistance and type 2 diabetes mellitus. Diabetes Metab Res Rev. 2009 Sep;25 Suppl 1:S18-23.

13. Morine MJ, O'Brien C, Roche HM. Session 2: Personalised nutrition Transcriptomic signatures that have identified key features of metabolic syndrome. Proceedings of the nutrition society. 2008;67(04):395-403.

14. de Wit NJ, Bosch-Vermeulen H, de Groot PJ, Hooiveld GJ, Bromhaar MM, Jansen J, et al. The role of the small intestine in the development of dietary fat-induced obesity and insulin resistance in C57BL/6J mice. BMC medical genomics. 2008;1:14.

15. Guyton A, Hall J. Textbook of Medical Physiology. 10 ed. Philadelphia: W.B. SAUNDERS COMPANY 2000.

16. Garrow J, James W, Ralph A. Human Nutrition and Dietetics. 10 ed. Edinburgh: Churchill Livingstone 2001.

17. Glatz JF, Luiken JJ, Bonen A. Membrane fatty acid transporters as regulators of lipid metabolism: implications for metabolic disease. Physiological reviews. 2010 Jan;90(1):367-417.

18. Jacob S, Machann J, Rett K, Brechtel K, Volk A, Renn W, et al. Association of increased intramyocellular lipid content with insulin resistance in lean nondiabetic offspring of type 2 diabetic subjects. Diabetes. 1999 May;48(5):1113-9.

19. Krssak M, Falk Petersen K, Dresner A, DiPietro L, Vogel SM, Rothman DL, et al. Intramyocellular lipid concentrations are correlated with insulin sensitivity in humans: a $1 \mathrm{H}$ NMR spectroscopy study. Diabetologia. 1999 Jan;42(1):113-6.

20. Pan DA, Lillioja S, Kriketos AD, Milner MR, Baur LA, Bogardus $C$, et al. Skeletal muscle triglyceride levels are inversely related to insulin action. Diabetes. 1997 Jun;46(6):983-8.

21. Sinha R, Dufour S, Petersen KF, LeBon V, Enoksson S, Ma YZ, et al. Assessment of skeletal muscle triglyceride content by $(1) \mathrm{H}$ nuclear magnetic resonance spectroscopy in lean and obese adolescents: relationships to insulin sensitivity, total body fat, and central adiposity. Diabetes. 2002 Apr;51(4):1022-7.

22. Goodpaster BH, He J, Watkins S, Kelley DE. Skeletal muscle lipid content and insulin resistance: evidence for a paradox in endurance-trained athletes. The Journal of clinical endocrinology and metabolism. 2001 Dec;86(12):5755-61.

23. Phillips SM, Green HJ, Tarnopolsky MA, Heigenhauser GJ, Grant SM. Progressive effect of endurance training on metabolic adaptations in working skeletal muscle. The American journal of physiology. 1996 Feb;270(2 Pt 1):E265-72.

24. Assimacopoulos-Jeannet F. Fat storage in pancreas and in insulin-sensitive tissues in pathogenesis of type 2 diabetes. Int J Obes Relat Metab Disord. 2004 Dec;28 Suppl 4:S53-7.

25. Ciapaite J, van Bezu J, van Eikenhorst G, Bakker SJ, Teerlink T, Diamant M, et al. Palmitate and oleate have distinct effects on the inflammatory phenotype of human endothelial cells. Biochimica et biophysica acta. 2007 Feb;1771(2):147-54.

26. Gormsen LC, Jessen N, Gjedsted J, Gjedde S, Norrelund H, Lund S, et al. Dose-response effects of free fatty acids on glucose and lipid metabolism during somatostatin blockade of growth hormone and insulin in humans. The Journal of clinical endocrinology and metabolism. 2007 Mar 6.

27. Haag M, Dippenaar NG. Dietary fats, fatty acids and insulin resistance: short review of a multifaceted connection. Med Sci Monit. 2005 Dec;11(12):RA359-67.

28. Manco M, Calvani M, Mingrone G. Effects of dietary fatty acids on insulin sensitivity and secretion. Diabetes, obesity \& metabolism. 2004 Nov;6(6):402-13. 
29. Blaak EE. Basic disturbances in skeletal muscle fatty acid metabolism in obesity and type 2 diabetes mellitus. The Proceedings of the Nutrition Society. 2004 May;63(2):323-30.

30. Corpeleijn E, Saris WH, Blaak EE. Metabolic flexibility in the development of insulin resistance and type 2 diabetes: effects of lifestyle. Obes Rev. 2009 Mar;10(2):178-93.

31. Stump CS, Henriksen EJ, Wei Y, Sowers JR. The metabolic syndrome: role of skeletal muscle metabolism. Annals of medicine. 2006;38(6):389-402.

32. Lowell BB, Shulman GI. Mitochondrial dysfunction and type 2 diabetes. Science (New York, NY. 2005 Jan 21;307(5708):384-7.

33. Savage DB, Petersen KF, Shulman GI. Disordered lipid metabolism and the pathogenesis of insulin resistance. Physiological reviews. 2007 Apr;87(2):507-20.

34. Phielix E, Schrauwen-Hinderling VB, Mensink M, Lenaers E, Meex R, Hoeks J, et al. Lower intrinsic ADP-stimulated mitochondrial respiration underlies in vivo mitochondrial dysfunction in muscle of male type 2 diabetic patients. Diabetes. 2008 Nov;57(11):2943-9.

35. Schrauwen-Hinderling VB, Kooi ME, Hesselink MK, Jeneson JA, Backes WH, van Echteld CJ, et al. Impaired in vivo mitochondrial function but similar intramyocellular lipid content in patients with type 2 diabetes mellitus and BMI-matched control subjects. Diabetologia. 2007 Jan;50(1):113-20.

36. Richardson DK, Kashyap S, Bajaj M, Cusi K, Mandarino SJ, Finlayson J, et al. Lipid infusion decreases the expression of nuclear encoded mitochondrial genes and increases the expression of extracellular matrix genes in human skeletal muscle. The Journal of biological chemistry. 2005 Mar 18;280(11):10290-7.

37. Hoeks J, Hesselink MK, Russell AP, Mensink M, Saris WH, Mensink RP, et al. Peroxisome proliferatoractivated receptor-gamma coactivator-1 and insulin resistance: acute effect of fatty acids. Diabetologia. 2006 Oct;49(10):2419-26.

38. Sparks LM, Xie H, Koza RA, Mynatt R, Hulver MW, Bray GA, et al. A high-fat diet coordinately downregulates genes required for mitochondrial oxidative phosphorylation in skeletal muscle. Diabetes. 2005 Jul;54(7):1926-33.

39. Mootha VK, Lindgren CM, Eriksson KF, Subramanian A, Sihag S, Lehar J, et al. PGC-1alpha-responsive genes involved in oxidative phosphorylation are coordinately downregulated in human diabetes. Nat Genet. 2003 Jul;34(3):267-73.

40. Boushel R, Gnaiger E, Schjerling P, Skovbro M, Kraunsoe R, Dela F. Patients with type 2 diabetes have normal mitochondrial function in skeletal muscle. Diabetologia. 2007 Apr;50(4):790-6.

41. Kelley DE, He J, Menshikova EV, Ritov VB. Dysfunction of mitochondria in human skeletal muscle in type 2 diabetes. Diabetes. 2002 Oct;51(10):2944-50.

42. Patti ME, Butte AJ, Crunkhorn S, Cusi K, Berria R, Kashyap S, et al. Coordinated reduction of genes of oxidative metabolism in humans with insulin resistance and diabetes: Potential role of PGC1 and NRF1. Proceedings of the National Academy of Sciences of the United States of America. 2003 Jul 8;100(14):8466-71.

43. Hancock CR, Han DH, Chen M, Terada S, Yasuda T, Wright DC, et al. High-fat diets cause insulin resistance despite an increase in muscle mitochondria. Proceedings of the National Academy of Sciences of the United States of America. 2008 Jun 3;105(22):7815-20.

44. Iossa S, Mollica MP, Lionetti L, Crescenzo R, Botta M, Liverini G. Skeletal muscle oxidative capacity in rats fed high-fat diet. Int J Obes Relat Metab Disord. 2002 Jan;26(1):65-72.

45. Turner N, Bruce CR, Beale SM, Hoehn KL, So T, Rolph MS, et al. Excess lipid availability increases mitochondrial fatty acid oxidative capacity in muscle: evidence against a role for reduced fatty acid oxidation in lipid-induced insulin resistance in rodents. Diabetes. 2007 Aug;56(8):2085-92.

46. de Wilde J, Mohren R, van den Berg S, Boekschoten M, Dijk KW, de Groot P, et al. Short-term high fat-feeding results in morphological and metabolic adaptations in the skeletal muscle of C57BL/6J mice. Physiol Genomics. 2008 Feb 19;32(3):360-9.

47. Hoeks J, Briede JJ, de Vogel J, Schaart G, Nabben M, Moonen-Kornips E, et al. Mitochondrial function, content and ROS production in rat skeletal muscle: Effect of high-fat feeding. FEBS letters. 2008 Feb 20;582(4):510-6. 
48. Randle PJ, Garland PB, Hales CN, Newsholme EA. The glucose fatty-acid cycle. Its role in insulin sensitivity and the metabolic disturbances of diabetes mellitus. Lancet. 1963 Apr 13;1(7285):785-9.

49. Randle PJ. Regulatory interactions between lipids and carbohydrates: the glucose fatty acid cycle after 35 years. Diabetes Metab Rev. 1998 Dec;14(4):263-83.

50. Sidossis LS, Wolfe RR. Glucose and insulin-induced inhibition of fatty acid oxidation: the glucose-fatty acid cycle reversed. The American journal of physiology. 1996 Apr;270(4 Pt 1):E733-8.

51. Koves TR, Ussher JR, Noland RC, Slentz D, Mosedale M, Ilkayeva O, et al. Mitochondrial overload and incomplete fatty acid oxidation contribute to skeletal muscle insulin resistance. Cell metabolism. 2008 Jan; $7(1): 45-56$.

52. Storlien L, Oakes ND, Kelley DE. Metabolic flexibility. The Proceedings of the Nutrition Society. 2004 May;63(2):363-8.

53. Cahova M, Vavrinkova $H$, Kazdova L. Glucose-fatty acid interaction in skeletal muscle and adipose tissue in insulin resistance. Physiological research / Academia Scientiarum Bohemoslovaca. 2007;56(1):1-15.

54. Kelley DE, Mandarino $L$. Fuel selection in human skeletal muscle in insulin resistance: a reexamination. Diabetes. 2000 May;49(5):677-83.

55. Galgani JE, Moro C, Ravussin E. Metabolic flexibility and insulin resistance. Am J Physiol Endocrinol Metab. 2008 Nov;295(5):E1009-17.

56. Goossens GH. The role of adipose tissue dysfunction in the pathogenesis of obesity-related insulin resistance. Physiology \& behavior. 2008 May 23;94(2):206-18.

57. Brasaemle DL. Thematic review series: adipocyte biology. The perilipin family of structural lipid droplet proteins: stabilization of lipid droplets and control of lipolysis. Journal of lipid research. 2007 Dec;48(12):2547-59.

58. Ducharme NA, Bickel PE. Lipid droplets in lipogenesis and lipolysis. Endocrinology. 2008 Mar;149(3):942-9.

59. Martin S, Parton RG. Lipid droplets: a unified view of a dynamic organelle. Nature reviews. 2006 May;7(5):373-8.

60. Gao J, Serrero G. Adipose differentiation related protein (ADRP) expressed in transfected COS-7 cells selectively stimulates long chain fatty acid uptake. The Journal of biological chemistry. 1999 Jun 11;274(24):16825-30.

61. Listenberger LL, Ostermeyer-Fay AG, Goldberg EB, Brown WJ, Brown DA. Adipocyte differentiationrelated protein reduces the lipid droplet association of adipose triglyceride lipase and slows triacylglycerol turnover. Journal of lipid research. 2007 Dec;48(12):2751-61.

62. Imamura M, Inoguchi T, Ikuyama S, Taniguchi S, Kobayashi K, Nakashima N, et al. ADRP stimulates lipid accumulation and lipid droplet formation in murine fibroblasts. Am J Physiol Endocrinol Metab. 2002 Oct;283(4):E775-83.

63. Larigauderie G, Furman C, Jaye M, Lasselin C, Copin C, Fruchart JC, et al. Adipophilin enhances lipid accumulation and prevents lipid efflux from THP-1 macrophages: potential role in atherogenesis. Arteriosclerosis, thrombosis, and vascular biology. 2004 Mar;24(3):504-10.

64. Farese RV, Walther TC. Lipid droplets finally get a little r-e-s-p-e-c-t. Cell. 2009 Nov 25;139:855-60.

65. Proctor DN, Sinning WE, Walro JM, Sieck GC, Lemon PW. Oxidative capacity of human muscle fiber types: effects of age and training status. J Appl Physiol. 1995 Jun;78(6):2033-8.

66. Jong-Yeon K, Hickner RC, Dohm GL, Houmard JA. Long- and medium-chain fatty acid oxidation is increased in exercise-trained human skeletal muscle. Metabolism: clinical and experimental. 2002 Apr;51(4):460-4.

67. Dube JJ, Amati F, Stefanovic-Racic M, Toledo FG, Sauers SE, Goodpaster BH. Exercise-induced alterations in intramyocellular lipids and insulin resistance: the athlete's paradox revisited. Am J Physiol Endocrinol Metab. 2008 May;294(5):E882-8.

68. van Loon L, Koopman R, Manders R, van der Weegen W, van Kranenburg GP, Keizer HA. Intramyocellular lipid content in type 2 diabetes patients compared with overweight sedentary men and highly trained endurance athletes. Am J Physiol Endocrinol Metab. 2004 Sep;287(3):E558-65. 
69. De Feyter HM, Schaart G, Hesselink MK, Schrauwen P, Nicolay K, Prompers JJ. Regional variations in intramyocellular lipid concentration correlate with muscle fiber type distribution in rat tibialis anterior muscle. Magn Reson Med. 2006 Jul;56(1):19-25.

70. Malenfant P, Joanisse DR, Theriault R, Goodpaster BH, Kelley DE, Simoneau JA. Fat content in individual muscle fibers of lean and obese subjects. Int J Obes Relat Metab Disord. 2001 Sep;25(9):131621.

71. Minnaard R, Schrauwen P, Schaart G, Jorgensen JA, Lenaers E, Mensink M, et al. Adipocyte Differentiation-Related Protein and OXPAT in rat and human skeletal muscle: involvement in lipid accumulation and Type 2 Diabetes Mellitus. The Journal of clinical endocrinology and metabolism. 2009 Jul 14;94:4077-85.

72. Shaw CS, Sherlock M, Stewart PM, Wagenmakers AJ. Adipophilin distribution and colocalisation with lipid droplets in skeletal muscle. Histochemistry and cell biology. 2009 Jan 24;131:575-81.

73. Petersen KF, Shulman GI. Etiology of insulin resistance. The American journal of medicine. 2006 May;119(5 Suppl 1):S10-6.

74. Hegarty BD, Furler SM, Ye J, Cooney GJ, Kraegen EW. The role of intramuscular lipid in insulin resistance. Acta physiologica Scandinavica. 2003 Aug;178(4):373-83.

75. Phillips SA, Choe CC, Ciaraldi TP, Greenberg AS, Kong AP, Baxi SC, et al. Adipocyte differentiationrelated protein in human skeletal muscle: relationship to insulin sensitivity. Obesity research. 2005 Aug;13(8):1321-9.

76. Pan DA, Hulbert AJ, Storlien LH. Dietary fats, membrane phospholipids and obesity. The Journal of nutrition. 1994 Sep;124(9):1555-65.

77. Pan DA, Lillioja S, Milner MR, Kriketos AD, Baur LA, Bogardus C, et al. Skeletal muscle membrane lipid composition is related to adiposity and insulin action. The Journal of clinical investigation. 1995 Dec;96(6):2802-8.

78. Gohil VM, Greenberg ML. Mitochondrial membrane biogenesis: phospholipids and proteins go hand in hand. Journal of cell biology. 2009;184(4):469-72.

79. Schmid PC, Deli E, Schmid HH. Generation and remodeling of phospholipid molecular species in rat hepatocytes. Arch Biochem Biophys. 1995 May 10;319(1):168-76.

80. Vessby B, Gustafsson IB, Tengblad S, Boberg M, Andersson A. Desaturation and elongation of Fatty acids and insulin action. Ann N Y Acad Sci. 2002 Jun;967:183-95.

81. Boumann HA, Gubbens J, Koorengevel MC, Oh CS, Martin CE, Heck AJ, et al. Depletion of phosphatidylcholine in yeast induces shortening and increased saturation of the lipid acyl chains: evidence for regulation of intrinsic membrane curvature in a eukaryote. Mol Biol Cell. 2006 Feb;17(2):1006-17.

82. Borkman M, Storlien LH, Pan DA, Jenkins AB, Chisholm DJ, Campbell LV. The relation between insulin sensitivity and the fatty-acid composition of skeletal-muscle phospholipids. N Engl J Med. 1993 Jan 28;328(4):238-44.

83. Vessby B, Tengblad S, Lithell H. Insulin sensitivity is related to the fatty acid composition of serum lipids and skeletal muscle phospholipids in 70-year-old men. Diabetologia. 1994 Oct;37(10):1044-50.

84. Haugaard SB, Madsbad S, Hoy CE, Vaag A. Dietary intervention increases n-3 long-chain polyunsaturated fatty acids in skeletal muscle membrane phospholipids of obese subjects. Implications for insulin sensitivity. Clin Endocrinol (Oxf). 2006 Feb;64(2):169-78.

85. Vazquez-Memije ME, Cardenas-Mendez MJ, Tolosa A, Hafidi ME. Respiratory chain complexes and membrane fatty acids composition in rat testis mitochondria throughout development and ageing. Exp Gerontol. 2005 Jun;40(6):482-90.

86. Hulbert AJ, Turner N, Storlien LH, Else PL. Dietary fats and membrane function: implications for metabolism and disease. Biol Rev Camb Philos Soc. 2005 Feb;80(1):155-69.

87. Lemieux H, Blier PU, Tardif JC. Does membrane fatty acid composition modulate mitochondrial functions and their thermal sensitivities? Comp Biochem Physiol A Mol Integr Physiol. 2008 Jan;149(1):20-9.

88. Pette D, Staron RS. Myosin isoforms, muscle fiber types, and transitions. Microscopy research and technique. 2000 Sep 15;50(6):500-9. 
89. Pette D, Staron RS. Transitions of muscle fiber phenotypic profiles. Histochemistry and cell biology. 2001 May;115(5):359-72.

90. Malisoux L, Francaux M, Theisen D. What do single-fiber studies tell us about exercise training? Medicine and science in sports and exercise. $2007 \mathrm{Jul}$;39(7):1051-60.

91. Shortreed KE, Krause MP, Huang JH, Dhanani D, Moradi J, Ceddia RB, et al. Muscle-Specific Adaptations, Impaired Oxidative Capacity and Maintenance of Contractile Function Characterize DietInduced Obese Mouse Skeletal Muscle. PLoS ONE. 2009;4(10):e7293.

92. Kemp JG, Blazev R, Stephenson DG, Stephenson GM. Morphological and biochemical alterations of skeletal muscles from the genetically obese (ob/ob) mouse. International journal of obesity (2005). 2009 Aug;33(8):831-41.

93. James $D E$, Jenkins $A B$, Kraegen EW. Heterogeneity of insulin action in individual muscles in vivo: euglycemic clamp studies in rats. The American journal of physiology. 1985 May;248(5 Pt 1):E567-74.

94. Henriksen EJ, Bourey RE, Rodnick KJ, Koranyi L, Permutt MA, Holloszy JO. Glucose transporter protein content and glucose transport capacity in rat skeletal muscles. The American journal of physiology. 1990 Oct;259(4 Pt 1):E593-8.

95. Kern M, Wells JA, Stephens JM, Elton CW, Friedman JE, Tapscott EB, et al. Insulin responsiveness in skeletal muscle is determined by glucose transporter (Glut4) protein level. The Biochemical journal. 1990 Sep 1;270(2):397-400.

96. Naya FJ, Mercer B, Shelton J, Richardson JA, Williams RS, Olson EN. Stimulation of slow skeletal muscle fiber gene expression by calcineurin in vivo. The Journal of biological chemistry. 2000 Feb 18;275(7):4545-8.

97. Ryder JW, Bassel-Duby R, Olson EN, Zierath JR. Skeletal muscle reprogramming by activation of calcineurin improves insulin action on metabolic pathways. The Journal of biological chemistry. 2003 Nov 7;278(45):44298-304.

98. Lenaers E, De Feyter HM, Hoeks J, Schrauwen P, Schaart G, Nabben M, et al. Adaptations in Mitochondrial Function Parallel, but Fail to Rescue, the Transition to Severe Hyperglycemia and Hyperinsulinemia: A Study in Zucker Diabetic Fatty Rats. Obesity (Silver Spring, Md. 2009 Oct 29.

99. He J, Watkins S, Kelley DE. Skeletal muscle lipid content and oxidative enzyme activity in relation to muscle fiber type in type 2 diabetes and obesity. Diabetes. $2001 \mathrm{Apr} ; 50(4): 817-23$.

100.Nyholm B, Qu Z, Kaal A, Pedersen SB, Gravholt CH, Andersen JL, et al. Evidence of an increased number of type Ilb muscle fibers in insulin-resistant first-degree relatives of patients with NIDDM. Diabetes. 1997 Nov;46(11):1822-8.

101. Hickey MS, Carey JO, Azevedo JL, Houmard JA, Pories WJ, Israel RG, et al. Skeletal muscle fiber composition is related to adiposity and in vitro glucose transport rate in humans. The American journal of physiology. 1995 Mar;268(3 Pt 1):E453-7.

102.Tanner CJ, Barakat HA, Dohm GL, Pories WJ, MacDonald KG, Cunningham PR, et al. Muscle fiber type is associated with obesity and weight loss. Am J Physiol Endocrinol Metab. 2002 Jun;282(6):E1191-6.

103.Niehrs C. Function and biological roles of the Dickkopf family of Wnt modulators. Oncogene. 2006 Dec 4;25(57):7469-81.

104.Stennard FA, Harvey RP. T-box transcription factors and their roles in regulatory hierarchies in the developing heart. Development (Cambridge, England). 2005 Nov;132(22):4897-910.

105.Svingen T, Tonissen KF. Hox transcription factors and their elusive mammalian gene targets. Heredity. 2006 Aug;97(2):88-96.

106.Calvo R, West J, Franklin W, Erickson P, Bemis L, Li E, et al. Altered HOX and WNT7A expression in human lung cancer. Proceedings of the National Academy of Sciences of the United States of America. 2000 Nov 7;97(23):12776-81.

107.Cantile M, Pettinato G, Procino A, Feliciello I, Cindolo L, Cillo C. In vivo expression of the whole HOX gene network in human breast cancer. Eur J Cancer. 2003 Jan;39(2):257-64.

108. Cillo C. HOX genes in human cancers. Invasion \& metastasis. 1994;14(1-6):38-49.

109. Cillo C, Cantile M, Faiella A, Boncinelli E. Homeobox genes in normal and malignant cells. Journal of cellular physiology. 2001 Aug;188(2):161-9. 
110.Kussmann M, Raymond F, Affolter M. OMICS-driven biomarker discovery in nutrition and health. J Biotechnol. 2006 Aug 5;124(4):758-87.

111.Lionetti L, Mollica MP, Crescenzo R, D'Andrea E, Ferraro M, Bianco F, et al. Skeletal muscle subsarcolemmal mitochondrial dysfunction in high-fat fed rats exhibiting impaired glucose homeostasis. International journal of obesity (2005). 2007 Oct;31(10):1596-604.

112.Storlien LH, Higgins JA, Thomas TC, Brown MA, Wang HQ, Huang XF, et al. Diet composition and insulin action in animal models. Br J Nutr. 2000 Mar;83 Suppl 1:S85-90.

113.Buettner R, Parhofer KG, Woenckhaus M, Wrede CE, Kunz-Schughart LA, Scholmerich J, et al. Defining high-fat-diet rat models: metabolic and molecular effects of different fat types. J Mol Endocrinol. 2006 Jun;36(3):485-501.

114.Santure M, Pitre M, Marette A, Deshaies Y, Lemieux C, Lariviere R, et al. Induction of insulin resistance by high-sucrose feeding does not raise mean arterial blood pressure but impairs haemodynamic responses to insulin in rats. Br J Pharmacol. 2002 Sep;137(2):185-96.

115.Ghafoorunissa, Ibrahim A, Rajkumar L, Acharya V. Dietary (n-3) long chain polyunsaturated fatty acids prevent sucrose-induced insulin resistance in rats. The Journal of nutrition. 2005 Nov;135(11):2634-8.

116.Storlien LH, Kraegen EW, Jenkins AB, Chisholm DJ. Effects of sucrose vs starch diets on in vivo insulin action, thermogenesis, and obesity in rats. Am J Clin Nutr. 1988 Mar;47(3):420-7.

117.Lambert K, Py G, Robert E, Mercier J. Does high-sucrose diet alter skeletal muscle and liver mitochondrial respiration? Horm Metab Res. 2003 Sep;35(9):546-50.

118. Kien CL. Dietary interventions for metabolic syndrome: role of modifying dietary fats. Curr Diab Rep. 2009 Feb;9(1):43-50.

119.Bonnard C, Durand A, Peyrol S, Chanseaume E, Chauvin MA, Morio B, et al. Mitochondrial dysfunction results from oxidative stress in the skeletal muscle of diet-induced insulin-resistant mice. The Journal of clinical investigation. $2008 \mathrm{Feb} ; 118(2): 789-800$.

120.Chanseaume E, Malpuech-Brugere C, Patrac V, Bielicki G, Rousset P, Couturier K, et al. Diets high in sugar, fat, and energy induce muscle type-specific adaptations in mitochondrial functions in rats. The Journal of nutrition. 2006 Aug;136(8):2194-200.

121.Ukropcova B, Sereda O, de Jonge L, Bogacka I, Nguyen T, Xie H, et al. Family History of Diabetes Links Impaired Substrate Switching and Reduced Mitochondrial Content in Skeletal Muscle. Diabetes. 2007 March 2007;56(3):720-7.

122.Schrauwen P, van Marken Lichtenbelt WD, Saris WH, Westerterp KR. Changes in fat oxidation in response to a high-fat diet. The American Journal of Clinical Nutrition. 1997 August 1, 1997;66(2):276-82.

123.van den Akker E, Fromental-Ramain C, de Graaff W, Le Mouellic H, Brulet P, Chambon P, et al. Axial skeletal patterning in mice lacking all paralogous group 8 Hox genes. Development (Cambridge, England). 2001 May;128(10):1911-21. 


Summary 


\section{Summary}

The metabolic syndrome (MetS) is a cluster of metabolic abnormalities which includes obesity and insulin resistance. Since the increasing prevalence of the MetS will have major economic and societal consequences there is an urgent need for better intervention and treatment strategies. Until now, the underlying mechanisms of the MetS are still unclear and more molecular research is necessary. One of the factors responsible for the increasing prevalence of the MetS is an increased dietary fat intake. Therefore, it is essential to obtain a comprehensive view of molecular profiles under high fat diet (HFD) conditions. Examining the effects of a specific nutrient, food component or diet at the gene, protein and metabolite levels is defined as nutrigenomics. The aim of the research described in this thesis was to characterize molecular changes in the skeletal muscle, which is a tissue of major importance in the metabolism of dietary fat, in the early onset of the MetS. Specifically, changes at the gene, protein and metabolite level were studied in the mouse skeletal muscle under influence of HFD conditions.

The effects of a short-term HFD on the mouse muscle transcriptome were studied in chapter 2. By performing microarray analysis we found that genes involved in a variety of biological processes including fat metabolism were up-regulated by the HFD. This transcriptional up-regulation was more pronounced at day 3 than week 4. However, protein levels of markers for oxidative phosphorylation were increased in muscle of 4-week HFD mice. These results indicate that expression of genes involved in fat metabolism tends to decrease over time, whereas protein levels are maintained. The skeletal muscle of human insulin resistant subjects is characterized by a reduced fat oxidative capacity and impaired mitochondrial function. Therefore, we hypothesized that after an early positive adaptation, a continued transcriptional down-regulation of genes related to fat metabolism will result in reduced fat oxidative capacity in the long run.

In chapter $\mathbf{3}$ we combined extensive characterization of physiological changes with muscle transcriptomics. The 8-week HFD induced obesity impaired whole-body insulin sensitivity and reduced insulin sensitivity of heart, visceral fat depots and muscle. Furthermore, plasma leptin was increased and plasma adiponectin was decreased in HFD mice as compared with LFD mice. Microarray analysis revealed that the HFD induced a small, but consistent up-regulation of genes involved in fat metabolism. As markers for $\beta$-oxidation, TCA cycle and oxidative phosphorylation were not affected by this 8-week HFD, we speculated that fat oxidative capacity was still sufficient to handle the increased fat load. Indeed, in chapter $\mathbf{4}$ we observed that fat oxidative capacity was not affected by an 8-week HFD. After 20 weeks however, an adaptive increase of lipid oxidative capacity was found in muscle of HFD 
mice as compared to LFD mice. The HFD impaired insulin sensitivity and thus as such these findings do not confirm our expectations based on the results from chapter 2. Altogether, under HFD conditions the mouse skeletal muscle is characterized by a metabolic adaptation, i.e. increased fat oxidative capacity. Despite this metabolic adaptation the occurrence and progression of insulin resistance cannot be prevented. Therefore, it is unlikely that a HFD contributes to insulin resistance by impairing skeletal muscle fat oxidative capacity.

The most common fatty acid in Western style diets is palmitic acid. To get more insight in the effects of palmitic acid on muscle cells we performed in vitro studies with the $\mathrm{C} 2 \mathrm{C} 12$ cell line as a model. By using two-dimensional gel electrophoresis we identified adipophilin (Adfp) as the strongest regulated protein in cells exposed to palmitic acid (chapter 5). Adfp is one of the proteins of the PAT family (Perilipin, Adfp, TIP47, S3-12 and OXPAT) which is involved in coating the triglyceridecontaining lipid core of lipid droplets. Further in vitro experiments revealed that cells treated with oleic acid have higher Adfp protein levels, higher cellular triglyceride levels, but less impairment of the insulin signaling pathway than cells treated with palmitic acid. In vivo, we found that Adfp protein expression is influenced by muscle type with higher levels in muscle types with a more oxidative character. This was especially evident under HFD conditions. Additionally, we found that when mice are fed a HFD with a higher unsaturated vs. saturated fatty acid ratio, Adfp protein expression in muscle is increased which was accompanied by indications for better insulin sensitivity. Based on these results we hypothesize that Adfp protein expression in muscle is involved in maintaining insulin sensitivity. A possible in vitro approach to test this hypothesis can be the use of RNA interference to known down the expression of Adfp. For in vivo studies DNA electroporation to increase Adfp expression or a combination of both methods could be a possible approach.

Cellular membranes such as the mitochondrial membrane maintain and regulate ionic gradients, potential differences and uptake of substrates such as fatty acyl CoAs. In chapter 2 we demonstrated that a 4-week HFD increases the saturation of skeletal muscle phospholipids which was especially evident in phosphatidylcholine (PC) and phosphatidylethanolamine (PE). PC and PE are the predominant phospholipids in the mitochondrial membrane. The fatty acid composition and the saturation degree of phospholipids are of great importance for proper membrane function. Increased saturation of membrane phospholipids reduces fluidity of the membrane which interferes with membrane-bound processes. It is conceivable that an increase in mitochondrial membrane phospholipid saturation interferes with mitochondrial function and thereby skeletal muscle metabolic function. This hypothesis was examined in chapter 4 . The 8-week HFD increased the saturation degree of muscle mitochondrial phospholipids, but skeletal muscle mitochondrial function 
was comparable in HFD and LFD mice. The 20-week HFD however, increased the amount of $n-6$ polyunsaturated fatty acids in skeletal muscle mitochondrial phospholipids. The increased unsaturation index was accompanied by an increased fat oxidative capacity. Interestingly, this increased unsaturation did not improve pyruvate-stimulated respiration in HFD mice. These results indicate it is not the mitochondrial phospholipid composition per se that influences mitochondrial function.

Several factors including aging, exercise and alterations in muscle innervations are known to induce fiber type transitions. That a HFD can also induce a fiber type conversion was shown in chapter 2. A 3-day HFD as well as a 4-week HFD increased the expression level of genes and protein that are markers for the more oxidative fiber types. These results indicate that the skeletal muscle morphologically adapts to a HFD by the transition to a more oxidative character via a transcriptional mechanism. Data presented in chapter 6 revealed that this up-regulation is not maintained in the long run. Both the 8-week and 20-week HFD did not, or minimally, affect the expression of genes that are known to be markers for the more oxidative fiber types. Thus, the HFD-induced transcriptional up-regulation of oxidative fiber type markers is un early and rapid response.

A major strength of transcriptomics is that all genes active in the tissue under investigation can be identified. As such, genes that were formerly not related to a particular tissue can be identified as shown in chapter 6 . By performing microarray analyses we found that the $D k k 3, \operatorname{Hoxd} 8, \operatorname{Hoxd} d 9$ and $T b x 1$ genes, which are known for their critical role in embryogenesis, are detectably and differentially expressed in the gastrocnemius, quadriceps and soleus muscles of adult mice. The expression of these genes was not influenced by the HFD. Little is known about the function of these embryogenic genes in adult muscle tissue. It may be possible that these genes are involved in maintaining the identity of the muscle groups. To obtain more information about the function of these genes the development of tissue-specific knock-out mouse models for the indicated genes could be a possible approach in an attempt to determine their function.

To conclude, under HFD conditions the skeletal muscle is characterized by changes at the mRNA, protein and lipid metabolite level pointing to an adaptive response to increase the fat oxidative capacity. Because adaptations at the molecular level could be confirmed at the functional level, results described in this thesis are a unique example of how molecular research can be successfully integrated with more functional-based research such as mitochondrial respirometry. 
Samenvatting 


\section{Samenvatting}

Het metabool syndroom (MetS) is een verzameling van metabole aandoeningen zoals obesitas en insuline resistentie. Het MetS komt wereldwijd steeds meer voor en dit heeft grote economische en maatschappelijke gevolgen zoals bijvoorbeeld een stijging van de medische kosten. $\mathrm{Er}$ is dan ook een dringende behoefde aan zowel betere preventieve als aan betere behandelingsstrategieën. Aangezien de onderliggende oorzaken van het MetS nog steeds onduidelijk zijn is meer moleculair onderzoek noodzakelijk. Eén van deze oorzaken is een verhoogde inname van vetrijke voeding. Om inzicht te krijgen in de effecten die een vette voeding heeft op het lichaam is het dus essentieel om onderliggende moleculaire veranderingen die veroorzaakt worden door een verhoogde vetinname in kaart te brengen. Het bestuderen van de effecten van een nutriënt of specifiek dieet op gen, eiwit of metaboliet niveau wordt gedefinieerd als nutrigenomics. Het doel van het onderzoek in dit proefschrift was het bestuderen van moleculaire veranderingen in de skeletspier, die een belangrijke rol speelt in het vetmetabolisme, tijdens de vroege ontwikkeling van het MetS. Daarvoor zijn muizen blootgesteld aan een vetrijk dieet en zijn veranderingen op gen, eiwit en metaboliet niveau in de skelet spier geanalyseerd.

In hoofdstuk 2 zijn de korte termijn effecten van een vetrijk dieet op het transcriptoom van de spier bestudeerd. Deze studie toonde aan dat de expressie van meer dan duizend genen veranderd was na zowel 3 dagen als 4 weken vetrijke voeding. Deze genen konden worden gerelateerd aan verschillende biologische processen waaronder het vetmetabolisme. De verhoogde expressie van genen betrokken bij het vetmetabolisme was sterker na 3 dagen dan na 4 weken. Echter, het eiwit niveau van markers voor oxidatieve fosforylering was verhoogd na 4 weken vetrijke voeding. Deze resultaten suggereren dat de expressie van genen die een rol spelen in het vetmetabolisme afneemt in de tijd, terwijl eiwitniveaus gehandhaafd blijven. De skeletspier van mensen met insuline resistentie wordt gekenmerkt door een verminderde vet oxidatieve capaciteit en een verstoorde mitochondriële functie. Het is dus mogelijk dat na een vroege positieve adaptatie een voortdurende verlaging van de transcriptie van genen betrokken bij vetmetabolisme leidt tot een verminderde vet oxidatieve capaciteit op de lange termijn.

Een vetrijk dieet heeft niet alleen moleculaire effecten op het spiertranscriptoom, maar veroorzaakt ook veranderingen in de fysiologie. In hoofdstuk 3 zijn beide aspecten bestudeerd na een dieetinterventie van 8 weken. Deze studie toonde aan dat muizen na een vetrijk dieet van 8 weken obees zijn en een verminderde insuline gevoeligheid hebben. De plasmawaarde van leptine was verhoogd en die van adiponectine was verlaagd in de hoog vet gevoede muizen. Ondanks deze 
fysiologische veranderingen had het vetrijke dieet een minimaal effect op het transcriptoom van de spier. Wel vonden we een kleine, maar duidelijk toename van de expressie van genen die een rol spelen bij het vetmetabolisme. Echter, het vetrijke dieet veroorzaakte geen veranderingen in markers voor $\beta$-oxidatie, citroenzuurcyclus en oxidatieve fosforylering. Deze resultaten suggereren dat de vet oxidatieve capaciteit voldoende was voor de verhoogde vet aanvoer. Deze hypthese werd onderzocht na dieetinterventies van 8 en 20 weken zoals beschreven in hoofdstuk 4. Na 8 weken vonden we dat de vet oxidatieve capaciteit van vetrijk gevoede muizen vergelijkbaar was met de vet oxidatieve capaciteit van controle muizen. Echter, na 20 weken vonden we een verhoogde capaciteit voor vetoxidatie in muizen blootgesteld aan een vetrijk dieet. Aangezien het vetrijke dieet een verminderde insuline gevoeligheid veroorzaakte komen deze bevindingen niet overeen met onze verwachtingen gebaseerd op de resultaten beschreven in

\section{hoofdstuk 2.}

Samenvattend, tijdens een vetrijk dieet wordt de skeletspier van muizen gekenmerkt door een metabole aanpassing die een verhoging van de vet oxidatieve capaciteit veroorzaakt. Ondanks deze metabole aanpassing wordt een vermindering van de insuline gevoeligheid niet voorkomen. Het is dan ook onwaarschijnlijk dat een verstoorde vet oxidatieve capaciteit van de spier bijdraagt aan de ontwikkeling van verminderde insuline gevoeligheid tijdens vetrijke voeding, althans bij muizen.

Eén van de meest voorkomende vetzuren in een Westers dieet is palmitaat. Het effect van palmitaat op spiercellen is onderzocht in een in vitro model, de muizen C2C12 cellijn. Deze studie toonde aan dat Adipophilin (Adfp) het sterkst gereguleerde eiwit was in het 2-DE proteoom van spiercellen behandeld met palmitaat (hoofdstuk 5). Adfp behoort tot de PAT eiwit familie (Perilipin, Adfp, TIP47, S3-12 en OXPAT) die betrokken is bij het coaten van vetdruppeltjes. Ten op zichte van palmitaat verhoogde oleaat zowel het Adfp eiwit niveau als de hoeveelheid intracellulair vet in spiercellen. Echter, de insuline gevoeligheid was beter in cellen behandeld met oleaat dan in cellen die behandeld waren met palmitaat. In vivo vonden we dat het Adfp eiwit niveau samenhangt met het spiertype met een hoger niveau in de meer oxidatieve spieren. Dit kwam duidelijk naar voren in spieren van vetrijk gevoede muizen. Een aantal waarnemingen bij deze muizen sluit aan bij onze in vitro resultaten. Een vetrijk dieet bestaande uit een grotere hoeveelheid onverzadigde vetzuren verhoogde het Adfp eiwit niveau in de muizenspier. Tevens vonden we aanwijzingen voor een betere insuline gevoeligheid in muizen gevoed met een meer onverzadigd vetrijk dieet. Het is daarom mogelijk dat Adfp eiwit niveaus in de spier een rol spelen bij het handhaven van de insuline gevoeligheid. Deze hypothese kan in vitro getest worden door gebruik te maken van RNA interference, een techniek om de expressie van Adfp te verlagen. DNA electroporatie zou een optie zijn voor in vivo onderzoek. 
Cellulaire membranen zoals het mitochondriële membraan spelen een rol bij het handhaven van de ion gradiënt en het potentiaal verschil en bij het transport van substraten. Na 4 weken vetrijke voeding vonden we een toename van verzadiging van fosfolipiden van de skeletspier (hoofdstuk 2). Dit was met name duidelijk in de fosfolipiden phosphatidylcholine en phosphatidylethanolamine. Deze fosfolipiden zijn de meest voorkomende fosfolipiden in het mitochondriële membraan. De vetzuursamenstelling en de mate van verzadiging van fosfolipiden zijn belangrijk voor het correct functioneren van het membraan. Des te hoger de verzadiging des te lager de vloeibaarheid van het membraan en des te lastiger membraangebonden processen, waaronder het transport van substraat, kunnen plaatsvinden. Het is dus mogelijk dat een toename in de verzadiging van de mitochondriële fosfolipiden de processen in de mitochondriele membraan en daarmee de mitochondriële functie van de skeletspier verstoort. Deze hypothese werd onderzocht in hoofdstuk 4. De studie toonde aan dat mitochondriële fosfolipiden meer verzadigd waren na een vetrijk dieet van 8 weken. Echter, mitochondriële functie in spierweefsel van vetrijk gevoede muizen was vergelijkbaar met die van controle muizen. Na 20 weken vetrijke voeding vonden we een toename van de hoeveelheid $n-6$ meervoudig onverzadigde vetzuren in mitochondriële fosfolipiden van de skelet spier. Deze verminderde mate van verzadiging ging samen met een toename van de vet oxidatieve capaciteit. Deze resultaten suggereren dat vetrijke voeding bij muizen leidt tot een adaptatie van de oxidatieve capaciteit via de verhoging van het gehalte n-6 meervoudig onverzadigde vetzuren in het mitochondriële membraan. Echter, deze studie toonde ook aan dat oxidatieve capaciteit voor koolhydraten in spieren van vetrijk gevoede muizen vergelijkbaar was met die van de controle muizen. Samenvattend kan daarom gesteld worden dat het niet alleen de samenstelling van het mitochondriële membraan is die mitochondriële functie beïnvloedt.

Verschillende factoren zoals veroudering en training kunnen een verandering van het vezeltype veroorzaken. In hoofdstuk 2 lieten we zien dat ook een vetrijk dieet een dergelijke verandering kan veroorzaken. Zowel na 3 dagen als na 4 weken vonden we een verhoogde expressie van genen en eiwitten die markers zijn voor de meer oxidatieve vezeltypes. Deze bevindingen suggereren dat een transcriptioneel mechanisme verantwoordelijk is voor de morfologische adaptatie van de spier onder invloed van vetrijke voeding. Dat deze adaptie niet aanhoudt op de lange termijn werd aangetoond in hoofdstuk 6. Op 8 en 20 weken vonden we dat de genexpressie van markers van de meer oxidatieve verzeltypes niet of nauwelijks werd beïnvloed door het vetrijke dieet. Deze resultaten betekenen dat de verhoogde genniveau's van markers voor de meer oxidative vezeltypes vroege en snelle adaptaties zijn aan een vetrijk dieet. 
Een groot pluspunt van transcriptomics is dat alle actieve genen in het te onderzoeken weefsel aangetoond worden. Hierdoor kunnen genen die voorheen niet gerelateerd werden aan een specifiek weefsel worden geïdentificeerd zoals beschreven in hoofdstuk 6 . Deze studie liet zien dat de $D k k 3, \operatorname{Hoxd} 8, \operatorname{Hoxd} 9$ en Tbx1 genen, die bekend zijn om de cruciale rol in embryogenese, detecteerbaar en verschillend tot expressie komen in de gastrocnemius, quadriceps en soleus spieren van volwassen muizen. Tevens toonden we aan dat de niveau's van deze vier genen niet verandert onder invloed van een vetrijk dieet. Tot op heden is weinig bekend over de functie van deze embryonale genen in volwassen spierweefsel. Mogelijk spelen deze genen een rol bij het bepalen van de identiteit van de verschillende spiertypen. Om meer informatie te verzamelen over de functie van deze genen is de ontwikkeling van knock-out muis modellen voor genoemde genen een mogelijke werkwijze.

Concluderend, tijdens een vetrijk dieet wordt de skelet spier gekenmerkt door veranderingen op gen, eiwit en vetmetabolietniveau die duiden op een adaptatie met als doel de vet oxidative capaciteit te verhogen. Deze moleculaire adaptaties werden bevestigd op het meer functionele niveau. De bevindingen in dit proefschrift zijn dan ook een uniek voorbeeld dat laat zien hoe moleculair onderzoek succesvol geïntegreerd kan worden met meer toegepast onderzoek zoals mitochondriële respiratiemetingen. 

Supplemental data 


\section{Supplemental data}

\section{Supplemental data chapter 2}

Supplement 1, 2 and 3 can be found at the website of Physiological Genomics (http://physiolgenomics.physiology.org/cgi/content/full/32/3/360).

\section{Supplemental data chapter 3}

Supplement 1 can be found at the website of the Journal of Nutrigenetics and Nutrigenomics

(http://content.karger.com/ProdukteDB/miscArchiv/000/308/466/000308466_sm.h tml).

\section{Supplemental data chapter 4}

Supplemental Table 4.1

Absolute amounts of SFA, MUFA, PUFA, n-3 PUFA, n-6 PUFA, in mitochondrial phospholipids of the hind limb muscles

\begin{tabular}{|c|c|c|c|c|c|}
\hline & & \multicolumn{2}{|c|}{ Week 8} & \multicolumn{2}{|c|}{ Week 20} \\
\hline & & LFD & HFD & LFD & HFD \\
\hline \multirow{14}{*}{ 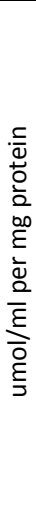 } & SFA & 0.132 & 0.142 & 0.134 & 0.150 \\
\hline & $16: 0$ & 0.080 & 0.090 & 0.083 & 0.096 \\
\hline & $18: 0$ & 0.048 & 0.048 & 0.047 & 0.050 \\
\hline & MUFA & 0.050 & 0.037 & 0.052 & 0.041 \\
\hline & $16: 1 n 7$ & 0.010 & 0.004 & 0.011 & 0.005 \\
\hline & $18: 1 n 7$ & 0.017 & 0.012 & 0.016 & 0.012 \\
\hline & $18: 1$ n9 & 0.020 & 0.019 & 0.022 & 0.022 \\
\hline & PUFA & 0.150 & 0.153 & 0.148 & 0.171 \\
\hline & n-3 PUFA & 0.057 & 0.053 & 0.058 & 0.059 \\
\hline & $22: 6 n 3$ & 0.052 & 0.048 & 0.053 & 0.054 \\
\hline & n-6 PUFA & 0.091 & 0.098 & 0.089 & 0.111 \\
\hline & $18: 2 n 6$ & 0.033 & 0.034 & 0.031 & 0.040 \\
\hline & $20: 4 n 6$ & 0.039 & 0.041 & 0.038 & 0.044 \\
\hline & $22: 5 n 6$ & 0.011 & 0.015 & 0.012 & 0.018 \\
\hline
\end{tabular}

HFD, high fat diet; LFD, low fat diet; MUFA, mono-unsaturated fatty acids; PUFA, poly-uunsaturated fatty acids; SFA, saturated fatty acids; UI, unsaturation index 


\section{Mitochondrial phospholipid composition in individual muscle types}

In addition to the full characterization of mixed muscle mitochondria we also assessed the FA composition of mitochondrial phospholipids of both the gastrocnemius and quadriceps muscles, in a separate experiment. To this purpose, mice (week 8: $n=15$ and week 20: $n=17$ ) were fasted for 6 hours and anaesthetized with a mixture of isofluorane (1.5\%), nitrous oxide (70\%) and oxygen (30\%). Mice were killed by cervical dislocation.Gastrocnemius and quadriceps muscles from the left hind leg were dissected and placed into ice-cold buffer containing $20 \mathrm{mM}$ MOPS, $100 \mathrm{mM} \mathrm{KCl}$ and $1 \mathrm{mM}$ EGTA (MKE). Mitochondria were isolated as described in the online appendix. Per diet group, mitochondria from individual animals were pooled for each muscle group. The gastrocnemius and quadriceps muscles from the right hind leg were dissected, snap-frozen in liquid nitrogen en stored at $-80^{\circ} \mathrm{C}$ for subsequent analysis.

Mitochondria from the gastrocnemius and quadriceps muscle were isolated as follows. Muscle tissue was freed of adipose tissue, finely minced with a tissue chopper (Campden Instruments, Loughborough, England), suspended in $1 \mathrm{ml} /$ muscle MKE with phosphate inhibitors (Sigma, Zwijndrecht, the Netherlands, MKEP) and centrifuged at $1000 \times \mathrm{g}$ for $30 \mathrm{~s}$ at $4{ }^{\circ} \mathrm{C}$. Pellets were suspended in $\sim 1 \mathrm{ml} /$ muscle MKEP with trypsin $(0.5 \mathrm{mg} / \mathrm{ml}$; Sigma-Aldrich), incubated for $3 \mathrm{~min}$ on ice and centrifuged at $1000 \mathrm{x}$ g for $30 \mathrm{~s}$ at $4{ }^{\circ} \mathrm{C}$. This step was repeated once with $30 \mathrm{~min}$ incubation. Per ml MKEP $250 \mu$ l quencher solution was added $(50 \mathrm{mg} / \mathrm{ml}$ FA-free BSA, phosphate inhibitors, proteinase inhibitors and $200 \mathrm{mM}$ phenylmethanesulfonyl (PMSF, Sigma)) and centrifuged at $1000 \times \mathrm{g}$ for $30 \mathrm{~s}$ at $4{ }^{\circ} \mathrm{C}$. Next, pellets were suspended in MKEP containing proteinase inhibitors and $200 \mathrm{mM}$ PMSF (MKE3P) and centrifuged at $1000 \times \mathrm{g}$ for $30 \mathrm{~s}$ at $4{ }^{\circ} \mathrm{C}$. Then, muscle pellets were suspended in MKE3P ( $1.5 \mathrm{ml} /$ muscle), pooled per muscle type per diet, mechanically homogenized and centrifuged at $800 \times \mathrm{g}$ for $5 \mathrm{~min}$ at $4{ }^{\circ} \mathrm{C}$. Supernatant was collected and muscle pellets were dissolved in $~ 1.5 \mathrm{ml} /$ muscle MKE3P after which this step was repeated twice. The collected supernatants were centrifuged at $15000 \times \mathrm{g}$ for 10 min at $4{ }^{\circ} \mathrm{C}$, the mitochondrial pellet was dissolved in 1-2 $\mathrm{ml}$ MKE3P, loaded on a 2step percoll (Sigma) gradient $(4 \mathrm{ml} \mathrm{70 \%} \mathrm{(v/v)} \mathrm{percoll} \mathrm{in} \mathrm{MKE;} 4 \mathrm{ml} \mathrm{30 \%} \mathrm{(v/v)} \mathrm{percoll}$ in MKE) and centrifuged at $20000 \mathrm{x} \mathrm{rpm}$ for $45 \mathrm{~min}$ at $4^{\circ} \mathrm{C}$ using a Beckham XL-80 ultracentrifuge. The brown mitochondrial band was collected by direct syringe aspiration, diluted 10 -fold with MKE3P and centrifuged at $15000 \times \mathrm{g}$ for $10 \mathrm{~min}$ at $4{ }^{\circ} \mathrm{C}$. The mitochondrial pellet was dissolved in $250 \mu \mathrm{l}$ MKE. An aliquot of $50 \mu \mathrm{l}$ was used to measure the protein concentration with the BCA protein assay kit (Pierce, EttenLeur, the Netherlands). Mitochondria were stored at $-80^{\circ} \mathrm{C}$ for further analysis. 
Supplementale Table 4.2

Relative amounts of SFA, MUFA, PUFA, $n-3$ PUFA, $n-6$ PUFA, the ratio $n-3$ vs. $n-6$ and the unsaturation index in mitochondrial phospholipids from gastrocenmius and quadriceps.

\begin{tabular}{|c|c|c|c|c|c|c|c|c|}
\hline & \multicolumn{4}{|c|}{ Gastrocnemius } & \multicolumn{4}{|c|}{ Quadriceps } \\
\hline & \multicolumn{2}{|c|}{ Week 8} & \multicolumn{2}{|c|}{ Week 20} & \multicolumn{2}{|c|}{ Week 8} & \multicolumn{2}{|c|}{ Week 20} \\
\hline & LFD & HFD & LFD & HFD & LFD & HFD & LFD & HFD \\
\hline SFA (\%) & 40,4 & 43,2 & 40,0 & 43,5 & 40,5 & 42,1 & 39,7 & 42,3 \\
\hline MUFA (\%) & 14,6 & 11,1 & 15,1 & 11,9 & 14,4 & 10,4 & 14,6 & 11,2 \\
\hline PUFA (\%) & 45,0 & 45,6 & 44,8 & 44,4 & 45,0 & 47,4 & 45,8 & 46,4 \\
\hline n-3 PUFA (\%) & 17,3 & 16,7 & 20,1 & 16,7 & 17,2 & 15,4 & 18,4 & 15,5 \\
\hline n-6 PUFA (\%) & 27,3 & 28,5 & 24,3 & 27,3 & 27,4 & 31,6 & 26,9 & 30,5 \\
\hline \multicolumn{9}{|l|}{$n-3$ vs. $n-6$} \\
\hline PUFA & 0,63 & 0,59 & 0,83 & 0,61 & 0,63 & 0,49 & 0,68 & 0,51 \\
\hline UI & 205,3 & 207,6 & 216,0 & 205,0 & 204,7 & 206,9 & 212,1 & 205,8 \\
\hline
\end{tabular}

HFD, high fat diet; LFD, low fat diet; MUFA, mono-unsaturated fatty acids; PUFA, poly-uunsaturated fatty acids; SFA, saturated fatty acids; UI, unsaturation index

Supplemental Table 4.3

Relative amounts of most abundant fatty acids in mitochondrial phospholipids from gastrocnemius and quadriceps

\begin{tabular}{lllllllll}
\hline & \multicolumn{3}{c}{ Gastrocnemius } & \multicolumn{4}{c}{ Quadriceps } \\
& \multicolumn{2}{c}{ Week 8 } & \multicolumn{2}{c}{ Week 20 } & \multicolumn{3}{c}{ Week 8 } & \multicolumn{2}{c}{ Week 20 } \\
& LFD & HFD & LFD & HFD & LFD & HFD & LFD & HFD \\
\hline $16: 0(\%)$ & 23,9 & 26,7 & 24,9 & 27,8 & 24,3 & 25,8 & 24,0 & 26,9 \\
$16: 1 \mathrm{n} 7(\%)$ & 3,2 & 1,4 & 3,5 & 1,3 & 3,2 & 1,4 & 3,2 & 1,3 \\
$18: 0(\%)$ & 15,3 & 15,4 & 13,8 & 14,6 & 15,1 & 15,4 & 14,5 & 14,5 \\
$18: 1 \mathrm{n} 7(\%)$ & 4,7 & 3,5 & 4,9 & 3,7 & 4,5 & 3,3 & 4,5 & 3,7 \\
$18: 1 n 9(\%)$ & 6,0 & 5,7 & 6,1 & 6,3 & 6 & 5,2 & 6,1 & 5,7 \\
$18: 2 n 6(\%)$ & 11,0 & 9,8 & 8,9 & 9,3 & 11,1 & 12,2 & 10,7 & 11,3 \\
$20: 4 n 6(\%)$ & 11,0 & 11,0 & 9,8 & 10,4 & 10,9 & 12,3 & 11,0 & 12,3 \\
$22: 5 n 6(\%)$ & 2,9 & 4,8 & 3,4 & 4,7 & 2,9 & 4,4 & 3,0 & 4,2 \\
$22: 6 n 3(\%)$ & 15,6 & 15,1 & 18,6 & 15,3 & 15,5 & 13,9 & 17,0 & 14,2 \\
\hline
\end{tabular}

HFD, high fat diet; LFD, low fat diet 
Supplemental Table 4.4

Parameters for mitochondrial density in the quadriceps and gastrocnemius muscle.

\begin{tabular}{|c|c|c|c|c|c|c|c|}
\hline & \multicolumn{7}{|c|}{ Quadriceps } \\
\hline & \multicolumn{2}{|c|}{8 weeks } & \multicolumn{2}{|c|}{20 weeks } & \multirow{2}{*}{$\begin{array}{l}P \text { value } \\
\text { diet }\end{array}$} & \multirow[b]{2}{*}{ time } & \multirow[b]{2}{*}{ diet $*$ time } \\
\hline & LFD & HFD & LFD & HFD & & & \\
\hline Mitochondrial DNA & $1.54 \pm$ & $1.63 \pm$ & $1.47 \pm$ & $1.70 \pm$ & 0.599 & 0.988 & 0.818 \\
\hline copy number (AU) & 0.32 & 0.34 & 0.27 & 0.28 & & & \\
\hline Sum of the 5 com- & $3.01 \pm$ & $2.42 \pm$ & $2.75 \pm$ & $1.97 \pm$ & 0.139 & 0.434 & 0.840 \\
\hline $\begin{array}{l}\text { plexes of respiratory } \\
\text { chain }(A U)\end{array}$ & 0.46 & 0.50 & 0.54 & 0.24 & & & \\
\hline $\mathrm{CS}(\mu \mathrm{mol} / \mathrm{min} / \mathrm{g}$ & $21.5 \pm$ & $24.1 \pm$ & $28.3 \pm$ & $29.3 \pm$ & 0.538 & 0.045 & 0.768 \\
\hline protein) & 3.0 & 3.5 & 2.0 & 1.9 & & & \\
\hline $\mathrm{HAD}(\mu \mathrm{mol} / \mathrm{min} / \mathrm{g}$ & $5.7 \pm$ & $5.4 \pm$ & $10.0 \pm$ & $13.2 \pm$ & 0.298 & $<0.001$ & 0.208 \\
\hline \multirow[t]{4}{*}{ protein) } & 1.0 & 0.9 & 1.4 & 1.9 & & & \\
\hline & \multicolumn{7}{|c|}{ Gastrocnemius } \\
\hline & \multicolumn{2}{|c|}{8 weeks } & \multicolumn{2}{|c|}{20 weeks } & \multirow{2}{*}{$\begin{array}{l}P \text { value } \\
\text { diet }\end{array}$} & \multirow[b]{2}{*}{ time } & \multirow[b]{2}{*}{ diet $*$ time } \\
\hline & LFD & HFD & LFD & HFD & & & \\
\hline Mitochdrial DNA & $1.01 \pm$ & $1.18 \pm$ & $1.52 \pm$ & $1.35 \pm$ & 1.000 & 0.163 & 0.495 \\
\hline copy number (AU) & 0.20 & 0.16 & 0.27 & 0.27 & & & \\
\hline $\begin{array}{l}\text { Sum of the } 5 \text { com- } \\
\text { plexes of respiratory } \\
\text { chain }(A U)\end{array}$ & $\begin{array}{l}1.42 \pm \\
0.09\end{array}$ & $\begin{array}{l}1.97 \pm \\
0.20\end{array}$ & $\begin{array}{l}1.93 \pm \\
0.28\end{array}$ & $\begin{array}{l}2.18 \pm \\
0.14\end{array}$ & 0.050 & 0.071 & 0.444 \\
\hline $\begin{array}{l}\mathrm{CS}(\mu \mathrm{mol} / \mathrm{min} / \mathrm{g} \\
\text { protein) }\end{array}$ & $\begin{array}{l}27.6 \pm \\
2.2\end{array}$ & $\begin{array}{l}23.7 \pm \\
3.5\end{array}$ & $\begin{array}{l}28.2 \pm \\
3.0\end{array}$ & $\begin{array}{l}33.4 \pm \\
1.6\end{array}$ & 0.821 & 0.073 & 0.114 \\
\hline $\begin{array}{l}\mathrm{HAD}(\mu \mathrm{mol} / \mathrm{min} / \mathrm{g} \\
\text { protein) }\end{array}$ & $\begin{array}{l}13.3 \pm \\
2.3\end{array}$ & $\begin{array}{l}6.9 \pm \\
1.2\end{array}$ & $\begin{array}{l}10.0 \pm \\
1.6\end{array}$ & $\begin{array}{l}15.3 \pm \\
2.3\end{array}$ & 0.787 & 0.213 & 0.007 \\
\hline $\begin{array}{l}\text { Parameters in the qua } \\
20 \text { weeks. Values are } \\
5 \text { complexes of the re } \\
\beta \text {-hydroxyacyl-CoA de }\end{array}$ & $\begin{array}{l}\text { iceps and } \\
\text { eans } \pm \mathrm{SE} \\
\text { iratory ch }\end{array}$ & $\begin{array}{l}\text { Jastrocne } \\
\text { in and } n=15-17\end{array}$ & $\begin{array}{l}\text { nius muscl } \\
\text { or mitocho } \\
6-7 \text { for CS }\end{array}$ & $\begin{array}{l}\text { in LFD mi } \\
\text { idrial DNA } \\
\text { nd HAD a } \\
\text { D, low fat }\end{array}$ & $\begin{array}{l}\text { e and HFD } \\
\text { copy numb } \\
\text { ivity). CS, }\end{array}$ & $\begin{array}{l}\text { mice at } 8 \\
\text { per; } n=6 \\
\text { citrate sy }\end{array}$ & $\begin{array}{l}\text { Neeks and } \\
\text { or sum of the } \\
\text { thase; HAD, } \\
\text { ior. }\end{array}$ \\
\hline
\end{tabular}




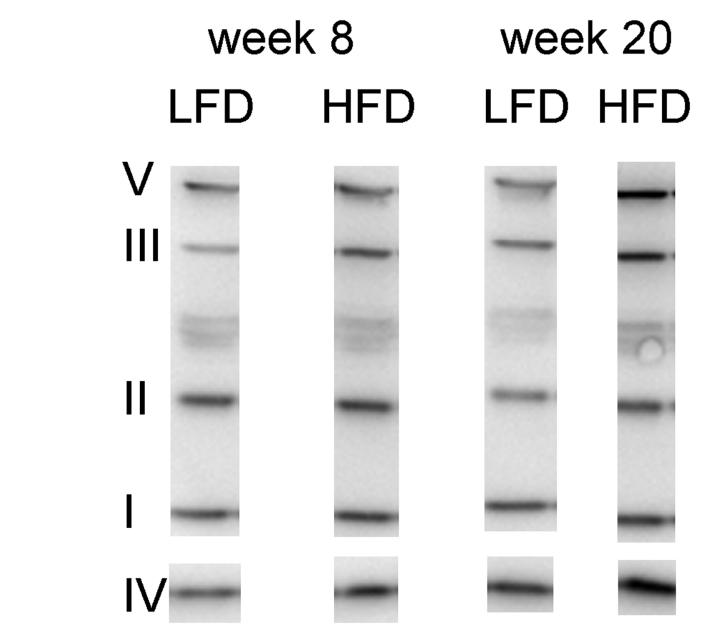

\section{Gapdh}

Supplemental Figure 4.1: Western blotting of subunits of the five complexes of the respiration chain in TA muscle of mice fed a LFD or HFD for 8 or 20 weeks, respectively. Shown are representative examples of equal amounts of total TA muscle protein $(n=6)$. The Gapdh signal was used for normalization. HFD, high fat diet; LFD, low fat diet; TA, tibialis anterior 
A

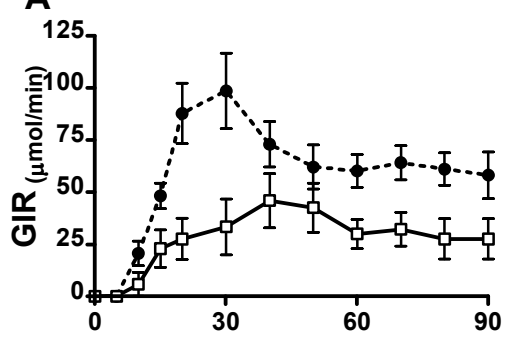

C

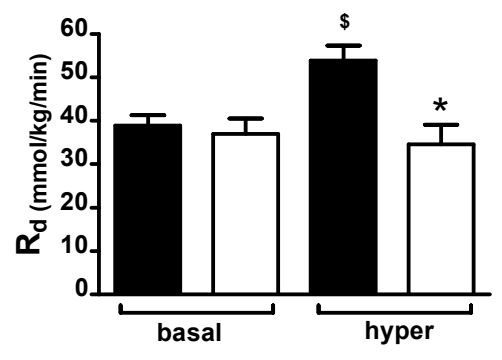

B

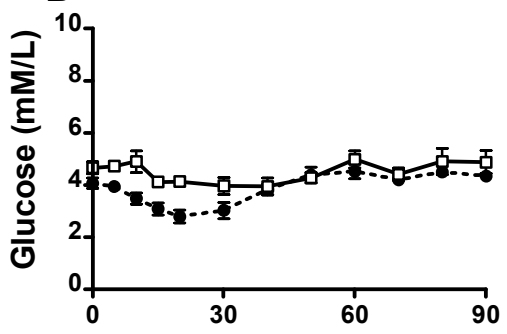

D

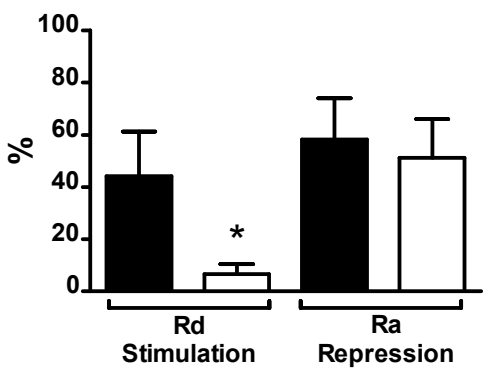

Supplemental Figure 4.2: A hyperinsulinemic euglycemic clamp was performed in mice fed the LFD and HFD for 5 weeks as described previously (1). The steady-state glucose infusion rate (GIR) was significantly lower in 5-week HFD mice than LFD mice (A). Plasma glucose levels did not differ between HFD mice and LFD mice during the clamp (B). Peripheral insulin sensitivity is expressed as the rate of disappearance (Rd) during the basal and hyperinsulinemic period. Insulin significantly increased the uptake of glucose by peripheral tissues in LFD mice, but not in HFD mice (C). Peripheral insulin sensitivity is expressed as the percentage of increase of glucose Rd during the hyperinsulinemic state compared to basal. The ability of insulin to stimulate the rate of disappearance of glucose was significantly lower in HFD mice than in LFD mice. Hepatic insulin sensitivity was expressed as the percentage of repression of hepatic glucose production (Ra) during the hyperinsulinemic state compared to basal. The ability of insulin to inhibit hepatic glucose production in HFD mice was similar to LFD mice suggesting that the liver was still insulin sensitive (D). LFD mice and HFD mice are indicated in black and white, respectively. Values are means $\pm \mathrm{SE}(\mathrm{N}=5-8) .{ }^{*} ; \mathrm{p}<0.05 \mathrm{HFD}$ compared to LFD, \$; $p<0.05$ hyper compared to basal. HFD, high fat diet; LFD, low fat diet.

\section{Supplemental data chapter 6}

Supplement 1, 2, 3 and 4 can be found at the website of BMC Genomics (http://www.biomedcentral.com/1471-2164/11/176). 

Dankwoord 


\section{Dankwoord}

Het dankwoord, het aller- allerlaatste onderdeel en dan is mijn proefschrift af! Nooit gedacht dat ik het zou schrijven op een zolderkamertje in Wageningen. Maar goed hier zit ik dan terugdenkende aan mijn promotietijd. Vier jaar hard werken waar ik met veel plezier aan terugdenk. Ik heb veel geleerd op wetenschappelijk en persoonlijk vlak en dat had ik niet willen missen. ledereen die hieraan een bijdrage heeft geleverd wil ik graag bedanken.

Om te beginnen mijn promotieteam bestaande uit Egbert Smit en Edwin Mariman. Egbert, ik ken weinig begeleiders die zo betrokken zijn als jij bent geweest. Met elke vraag kon ik bij je binnenlopen, mijn artikelen werden snel van het nodige commentaar voorzien en je vergezelde me regelmatig naar Wageningen om te helpen met experimenten in het CKP. Na 3 jaar besloot je de stap naar het bedrijfsleven te maken. Ik vond dit natuurlijk erg jammer, maar ook toen kon ik op je betrokkenheid rekenen. Edwin, als mijn promotor speelde je de eerste 3 jaar een belangrijke rol op de achtergrond. Het laatste jaar nam je de taak van Egbert als dagelijks begeleider met glans over. Op momenten dat ik het niet meer zag zetten, bleef jij rustig en sprak dan vaak de inmiddels legendarische woorden "het komt allemaal goed". Niet wat ik wilde horen op dat moment, maar ik moet je nu toch echt gelijk geven. Heren, bedankt voor alles!

De beoordelingscommissie bestaande uit Prof. Ronald Mensink, Dr. Chris Evelo, Prof. Jan Glatz, Prof. Jaap Keijer en Dr. Patrick Schrauwen wil ik bedanken voor de tijd die ze hebben besteed aan het beoordelen van mijn proefschrift.

Lieve paranimfen, wat fijn dat jullie vandaag achter me staan! Kaatje, van collega en kamergenootje werd je al snel een goede vriendin. Helaas, verliet je ons kamertje al na anderhalf jaar, maar natuurlijk bleven we elkaar zien. Ik heb genoten van ons geklets bij de DE koffiecorner, tijdens etentjes en drankjes in de stad. En onze NUGO week in Oxford zal ik niet snel vergeten! Freek, naast een leuke collega die voor iedereen klaar staat ben je gewoon een toffe vent. Bedankt dat ik als computerworst op je hulp kon rekenen als mijn computer weer eens iets deed wat ik niet wilde. Heel veel succes met je eigen promotie onderzoek! Paranimfen, bedankt voor alle steun!

Om je onderzoek af te ronden kan je als AIO niet zonder technische hulp en vakkundige kennis van anderen. In mijn geval betekende dat ik op steun kon rekenen uit Maastricht, Wageningen en Leiden. Ronny, ik leerde je kennen in de trein op weg naar een cursus in Breda. Het ijs was al snel gebroken toen we hetzelfde idee bleken te hebben over de invulling van die avond: voetbal kijken in 
de kroeg! Bedankt voor de leuke samenwerking, het draaien van de grote hoeveelheid Western blotjes en de gezelligheid op het lab. Martijn, je was net afgestudeerd toen je de taak kreeg om Ronny op te volgen. Door de vele studies en ik op standje over-de-kook was dit niet eenvoudig. Bedankt voor de bergen werk die je hebt verricht! Hasibe, Jos en Joan wil ik bedanken voor de hulp met de Cobas en de "last-minute" lipid bepalingen. Gert, bedankt voor de immunochemische kleuringen en HNE-blots die je hebt gedaan. Joris, hoewel onze studie niet liet zien wat we verwacht hadden hebben de resultaten geleid tot een mooi manuscript dat hopelijk snel wordt geaccepteerd. Bedankt voor de leuke samenwerking! Shohreh, thanks for learning me the ins-and-outs about isolating RNA! Mechteld en Jenny wil ik bedanken voor het draaien van de vele microarrays. Guido, Mark en Philip, bedankt voor jullie hulp en advies met het analyseren van de grote hoeveelheid microarray data. Nicole, bedankt dat ik op jouw naam dierproeven kon doen in Wageningen. En natuurlijk voor de gezelligheid als ik weer eens in Wageningen was. Ook aan onze trip naar München heb ik goede herinneringen. Die avond dat wij in onze spijkerbroek in een superchique restaurant gingen eten zal ik niet snel vergeten. Annelies, het was superleuk en gezellig om een week bij je op het lab te zijn. Bedankt dat je me het luminexen hebt geleerd. Ko, Peter, Silvia en Sjoerd wil ik bedanken voor de deskundige uitvoering van de clamp-experimenten.

Ook wil ik mijn studenten bedanken voor hun inzet en enthousiasme. Karin, inmiddels ben je zelf bezig met promoveren. Heel veel succes! Frank, ik ken niemand die zijn labjournaal nauwkeuriger bijhoudt dan jij dat doet. Veel succes verder bij pulmonologie. Ivar, ik vond het super om met je samen te werken. Veel succes met geneeskunde in Rotterdam. Violet, je was dan wel niet mijn studente, maar ik heb het erg gezellig met je gehad. Jammer, dat je we maar 1 keer hebben kunnen daten in Wageningen. Veel succes met de jacht naar een leuke baan!

De 4 jaar en 2 maanden die mijn AlO-tijd duurde heb ik met veel plezier bij Humane Biologie rondgelopen. Mijn kamergenootjes Antoine, Anke, Freek en Kaatje wil ik bedanken voor de gezellige tijd. Alle Fungenners, bedankt voor de leuke werksfeer! De dames van het secretariaat wil ik bedanken voor de hulp met faxen en printers, alle lekkere versnaperingen en zoveel meer. Alle andere collega's van HB, bedankt voor de leuke tijd op en buiten de uni. Ik had de kerstdiners, de vakgroepuitjes en de carnavalsavondjes in de Perroen niet willen missen!

Natuurlijk wil ik ook alle collega's van TIFN en het Nutrogenomics Consortium bedanken voor de leuke sfeer tijdens de vele meetings en uitstapjes.

Wat zijn dierproeven zonder de hulp van medewerkers van de proefdierfaciliteiten? ledereen van het CPV in Maastricht en het CKP in Wageningen bedankt! Bert W, 
jouw hulp was essentieel voor iemand als ik die eigenlijk toch een beetje bang was voor de muisjes. Ik heb genoten van alle mooie reisverhalen. Ze waren een prettige onderbreking van de soms lange dagen. Bedankt voor je betrokkenheid!

Mijn nieuwe collega's van Danone Research wil ik bedanken voor het warme welkom. Sander W, bedankt dat je aan me dacht toen deze functie vrijkwam in het Preventive Nutrition Team. Veel succes met jouw laatste loodjes! Kamergenootje Sander $\mathrm{H}$ wil ik bedanken voor alle handige tips en de gezellige werksfeer. Werken in Wageningen veroorzaakte de nodige veranderingen in mijn privé leven. Yvette, ik waardeer de belangstelling die je daarvoor hebt. Dit samen met de open werksfeer binnen het PN team heeft ervoor gezorgd dat ik me al snel thuis voelde. Collegaatjes, bedankt!

Lieve Leo(nie), na samen studeren en promoveren is het eigenlijk niet meer dan logisch dat we vandaag hier allebei staan. Wat begon als een wild idee in de kroeg hebben we toch maar mooi voor elkaar gekregen! Aan de 9 jaar dat ik je nu ken heb ik alleen maar mooie herinneringen. Onze stapavonturen als studentes, de vakanties in Poreč en Marmaris, samen shoppen, de saunabezoekjes, en de avondjes in de Fallstaff, het was allemaal geweldig. Ik ben superblij dat we deze dag samen beleven!

Lieve familie en vrienden, het was voor jullie af en toe verwarrend of ik nu nog studeerde of niet. En ook het moment dat ik het nu echt zou afronden was niet altijd even duidelijk. Maar vandaag is het dan eindelijk zo ver!

Carolien en Anna, lieve Zeeuwse vriendinnetjes, wat kennen we elkaar al lang! We zien elkaar niet meer zo vaak als toen op de middelbare school, maar het contact is er niet minder goed om geworden. Bedankt voor alle leuke bbq's, dinertjes en slaapfeestjes in de weekenden! Thijs, meer dan 9 jaar geleden kwam ik bij je in huis wonen. Door Nol en Rietje dacht ik dat je een rustige en vooral serieuze student was, maar niets was minder waar. We konden het al snel goed vinden en bleken veel overkomsten te hebben; zelfspot, een voorkeur voor foute tv-programma's en cocktails drinken bij andijviestamppot. Helaas zien we elkaar nu wat minder vaak, maar ik ben nog steeds superblij dat ik je Grace mag zijn! Jonathan, naast een leuke collega ben je inmiddels ook een goeie vriend. Ik (en natuurlijk ook Bram) hebben genoten van de avondjes en middagen met je vrouw en kids in Eijsden. Wanneer spelen we nog eens een potje halma? Mathijs met je mooie donkere krullen, wat moest ik aan je drukke karakter wennen zeg! :) Je oprechte interesse in mijn onderzoek heeft me geraakt. Thierry, natuurlijk wil ik je bedanken voor het ontwerpen van de kaft. Ik wist niet goed wat ik wilde, maar je hebt er iets heel moois van gemaakt! Jammer dat je er vandaag niet bij kan zijn, maar Curaçao is nu 
eenmaal niet om de hoek. Bennie en Rachelle, lieve buurtjes, wat hebben we om elkaar gelachen: jullie worstelend met een konijnenenhok en ik die het balkon schropte met een afwasborstel, de toon voor onze vriendschap was gezet. De bbq's, de mojito-avondjes, de wijntjes op het balkon en het weekendje EuroDisney, het was allemaal superleuk!

Lieve familie en schoonfamilie, ook jullie wil ik bedanken voor alle interesse in mijn onderzoek. Bas en Mireille, wat zal er eerder gebeuren? De verdediging van mijn proefschrift of de geboorte van jullie kindje?

Lieve paps en mams, we hebben het niet altijd even makkelijk gehad, maar ik heb altijd op jullie kunnen rekenen. Of het nou ging om klussen, verhuizen of gewoon een luisterend oor, jullie waren er voor me. Bedankt voor jullie steun, vertrouwen en zoveel meer! Mijn lieve zussen Maike en Vera, wat bof ik toch met jullie. Eigenlijk zien we elkaar veels te weinig, maar gelukkig bestaat er zoiets als skype! Maike, je bent een geweldige vrouw. Samen met je lieve man Mario en jullie lieve kindjes Isis en Tijm vormen jullie een mooi gezinnetje. Bedankt voor de alle leuke en knusse weekendjes in Aarle! Vera, ik ben ongelofelijk trots op de stappen die je de afgelopen jaren hebt genomen. Het opnieuw gaan studeren, je stage in Newcastle en binnen een maand na je afstuderen een baan. Je hebt allemaal toch maar even gedaan! Bedankt, als je me weer eens die spiegel voorhoudt die ik soms nodig heb.

Lieve Bram, als iemand weet hoe het is om samen te zijn met een promoverende vriendin dan ben jij het wel! Ik weet niet of ik het zonder jou had volgehouden. Je opbeurende woorden als ik het even niet zag zitten, je flauwe grapjes waar ik stiekem toch om moest lachen (;) of gewoon een arm om me heen, je was er altijd voor mij. Het leven beleven samen met jou is alles wat ik wil. Lieverdje, ik hou van je en ik kan niet wachten om samen met jou in een echt-grote-mensen-huis te gaan wonen. 

Publications 


\section{Publications}

De Wilde J, Hoeks J, Smit E, Van den Berg SAA, Schaart G, Willems van Dijk K, Hulshof MFM, Mariman ECM. High fat diet-induced changes in mouse muscle mitochondrial phospholipid composition and function are unrelated to insulin resistance. Submitted.

De Wilde J, Smit E, Boekschoten MV, De Groot P, Hulshof MFM, Mariman ECM. The embryonic genes Dkk3, Hoxd8, Hoxd9 and Tbx1 identify muscle types in a dietindependent and fiber-type unrelated. BMC genomics. 2010; 11: 176-187

De Wilde J, Smit E, Mohren R, Boekschoten MV, De Groot P, Van den Berg SAA, Bijland S, Voshol PJ, Willems Van Dijk K, De Wit NWJ, Bunschoten A, Schaart G, Hulshof MFM, Mariman ECM. An 8-week high fat diet induces obesity and insulin resistance with small changes in the muscle transcriptome. Journal of Nutrigenetics and Nutrigenomics. 2010; 2(6): 280-291

De Wilde J, Smit E, Snepvangers FJM, De Wit NWJ, Mohren R, Hulshof MFM, Mariman ECM. In vitro and in vivo regulation of adipophilin protein expression: a possible protective role against insulin resistance. FEBS journal. 2010; 277(3): 761-773.

De Wilde J, Mohren R, Van den Berg SAA, Boekschoten MV, Willems Van Dijk K, De Groot P, Müller M, Mariman ECM, Smit E. Short-term high fat-feeding results in morphological and metabolic adaptations in the skeletal muscle of $\mathrm{C} 57 \mathrm{BL} / 6 \mathrm{~J}$ mice. Physiological Genomics. 2008; 32(3): 360-369. 
Curriculum Vitae 


\section{Curriculum Vitae}

Janneke de Wilde was born on the $18^{\text {th }}$ of June 1983 in Oostburg. She completed secondary school at the Zwin College in Oostburg in 2001. In the same year she started her studies in Health Sciences, with specialization in Biological Health Sciences, at Maastricht University. She performed a 3-month internship at the department of Health Risk Analysis and Toxicology. For her thesis she performed a 7month internship at the department of Pathology at Maastricht University to explore the role of angiogenesis in Non-Hodgkin's lymphoma. She graduated in November 2005.

In November 2005 she started as a PhD student at the department of Human Biology at Maastricht University on a Nutrigenomics project of the Top Institute Food and Nutrition. Under supervision of Prof. dr. E.C.M. Mariman and dr. E. Smit she combined molecular research with more functional-based research to study the role of the skeletal muscle in the early onset of the metabolic syndrome.

In June 2010 she started working as a scientist at Danone Research within the Preventive Nutrition team. 

